\title{
NUMERICAL INVESTIGATION OF FAN PERFORMANCE IN A FORCED DRAFT AIR-COOLED STEAM CONDENSER
}

by

J.R. Bredell

Thesis presented in partial fulfilment of the requirements for the degree of

Master of Engineering (Mechanical) at the University of Stellenbosch

Supervisor: Prof. D.G. Kröger

Co-supervisor: Prof. G.D. Thiart

Department of Mechanical Engineering

University of Stellenbosch

South Africa

December 2005 


\section{Declaration}

I, Johann Richard Bredell, the undersigned, hereby declare that this thesis is my own original work. It is being submitted for the Degree of Master of Engineering (Mechanical) at the University of Stellenbosch. It has not been submitted, in its entirety or in part, for any degree or examination at any other University.

Signature of candidate

This day of 


\section{Abstract}

Forced draft air-cooled steam condensers (ACSCs) consisting of multiple fan units are used in direct cooled power plants to condense steam in a closed steam cycle. Axial flow fans located below an A-frame configuration of finned tube heat exchanger bundles, force ambient air through the system. In so doing, heat from the condensing steam is rejected to the environment via the finned tubes. The performance of an air-cooled system is proportional to the air mass flow rate and the temperature difference between the finned tubes and the ambient air. A variation in either will directly affect the efficiency of the steam turbines.

Air flow distortions at the fan inlet caused by structures, wind and other fans may result in a significant reduction in flow rate as well as fan blade vibration. This phenomenon has an adverse affect on the cooling capacity of an ACSC, and consequently turbine performance, due to a decrease in air mass flow rate. In this study the effect of inlet flow distortions on fan performance (i.e. flow rate and fan shaft power) in an ACSC is numerically investigated by modelling a section (or sector) of such a system using the commercial computational fluid dynamics (CFD) code, FLUENT. Fan performance at different platform heights, and corresponding different degrees of inlet flow distortions, is investigated.

The performance of two types of axial flow fans are also compared. The two fans have the same diameter, number of blades and rotational speed, but feature different blade designs, and hub-tip-ratios of respectively 0.153 and 0.4 . A fan model based on blade element theory, better known as an actuator disc model, is used to numerically model the fans.

Previous experimental studies have shown that a solid walkway installed along the edge or periphery of an ACSC platform can significantly increase the flow rate through the fans situated along the platform edge. The effects of such a walkway, and other windscreens on fan performance, are numerically investigated.

Numerical predictions correlate with earlier experimental results: the flow rate and fan shaft power are decreased by inlet flow distortions. It was found that the fan with a hub-tip-ratio of 0.4 was less affected by these flow distortions. The addition of a walkway increased the flow rate through the edge fan by up to $48 \%$. It is furthermore shown that wind effects can only be accurately modelled if the entire ACSC is considered. 


\section{Opsomming}

Geforseerde-trek lugverkoelde kondensators wat bestaan uit 'n aantal waaier-eenhede, word in direk-verkoelde kragstasies gebruik om stoom in 'n geslote stoomkringloop te kondenseer. Aksiaalvloei-waaiers wat onder 'n A-raam-konfigurasie van vinbuisbundels geïnstalleer is, forseer omgewingslug deur die stelsel. Sodoende word die hitte van die kondenserende stoom aan die omgewing oorgedra deur middel van die vinbuise. Die warmteoordragkapasiteit van 'n lugverkoelde kondensator is eweredig aan die massavloei-tempo van die lug, asook die temperatuurverskil tussen die vinbuise en die lug. 'n Verandering in enige van dié faktore sal die benuttingsgraad van die stoomturbines direk beïnvloed.

Lugvloeiversteurings by die waaier-inlate wat veroorsaak word deur geboue, wind en ander waaiers kan lei tot aansienlike verlagings in vloeitempo deur die waaiers. Sekondêre effekte soos waaierlemvibrasie kan ook veroorsaak word. In hierdie studie word die effek van inlaatvloeiversteurings op waaierwerkverrigting (dws vloeitempo en waaierdrywing) ondersoek deur 'n seksie (of sektor) van 'n lugverkoelde kondensator te modelleer deur gebruik te maak van die kommersiële numeriese vloeidinamika-pakket, FLUENT. Waaierwerkverrigting word by verkillende platformhoogtes, en gevolglik verskillende grade van inlaatvloeiversteurings, ondersoek.

Twee verskillende waaiers word ook vergelyk. Die waaiers het dieselfde diameter, aantal lemme en rotasiespoed, maar het verkillende lem ontwerpe, en naaf-lempunt-verhoudings van onderskeidelik 0.153 en 0.4 . 'n Waaiermodel wat gebaseer is op lem-element-teorie, beter bekend as 'n aksie-skyf-model, word gebruik om die waaiers numeries te modelleer.

Vorige eksperimentele studies het bewys dat 'n loopvlak om die rand van lugverkoelde kondensators die vloeitempo deur waaiers aansienlik kan verhoog. Die effek van so 'n loopvlak, en ander windskerms word numeries ondersoek.

Numeriese voorspellings stem ooreen met eksperimentele resultate: die vloeitempo en waaierdrywing word verlaag deur inlaat-vloeiversteurings. Dit is bevind dat die waaier met 'n naaf-lempunt-verhouding van 0.4 , minder beïnvloed word deur vloeiversteurings. 'n Loopvlak het die vloeitempo deur die randwaaier met tot $48 \%$ verhoog. Dit is ook bewys dat windeffekte alleenlik gemodelleer kan word deur die hele lugverkoelde kondensator in ag te neem. 


\section{Acknowledgements}

I would like to express my sincere gratitude towards the following people who made this study possible:

- $\quad$ To Prof. D.G. Kröger for motivation, inspiration and guidance

- $\quad$ To my family and friends for encouragement and support

- $\quad$ To Prof. G.D. Thiart, Dr. C.J. Meyer, Dr. J.H.M. Beyers, Dr. D.J. de Kock and Mr. René Heise for generously offering their help with matters regarding CFD

The financial support offered by the National Research Foundation (NRF) is also hereby thankfully acknowledged. 


\section{Table of contents}

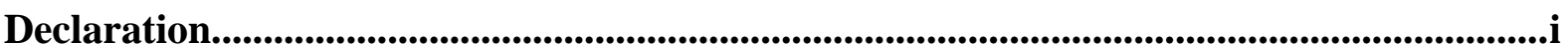

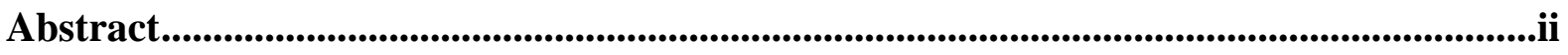



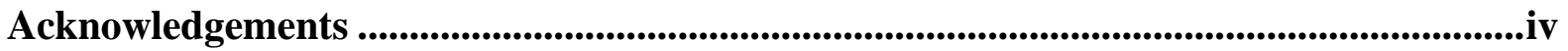

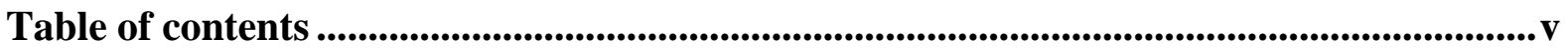

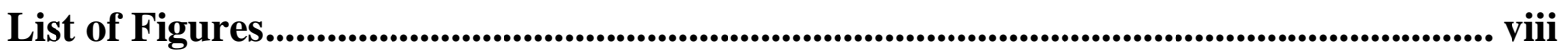

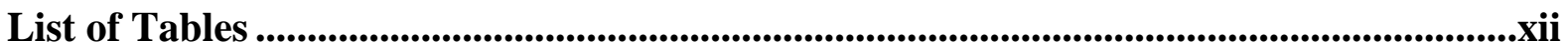

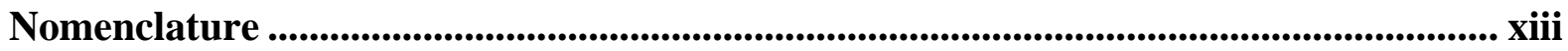

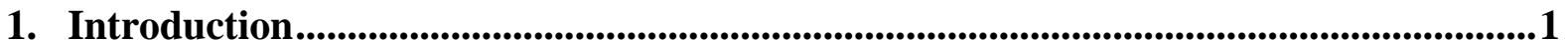

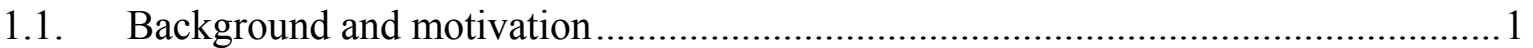

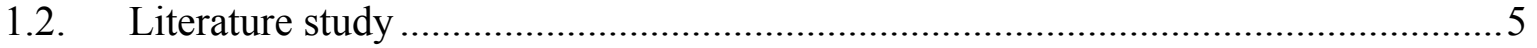

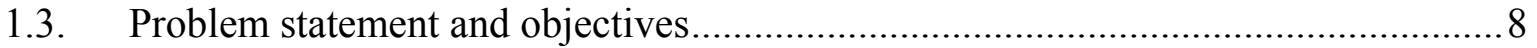

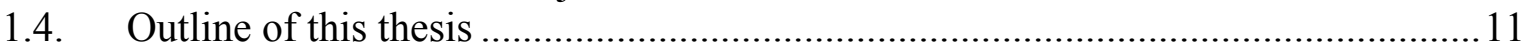

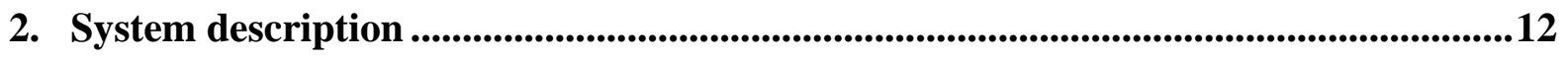

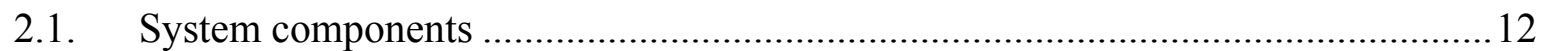

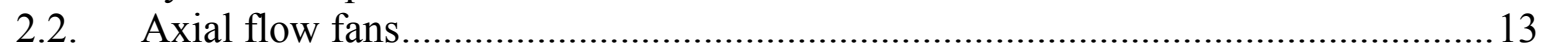

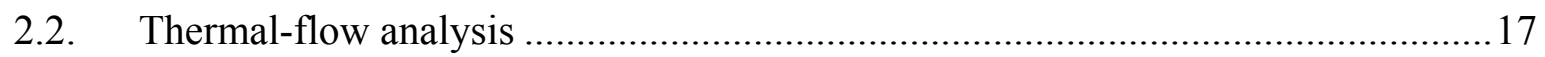

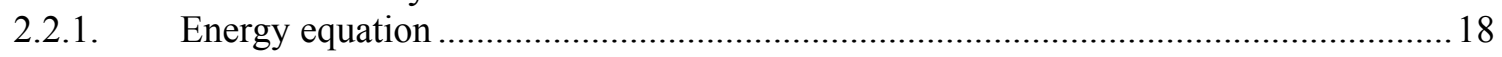

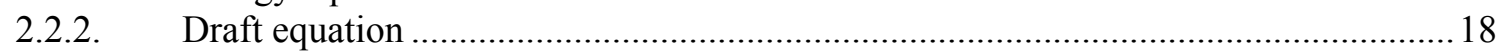

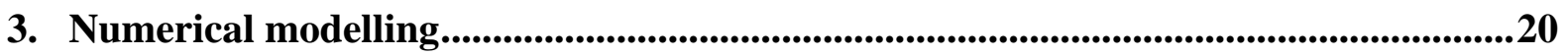

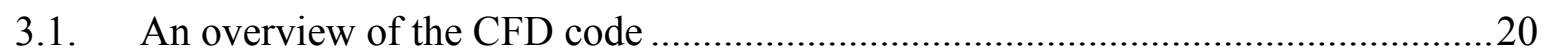

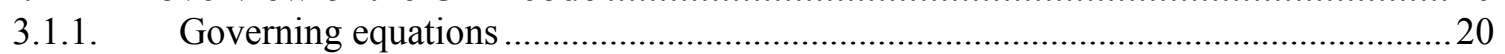

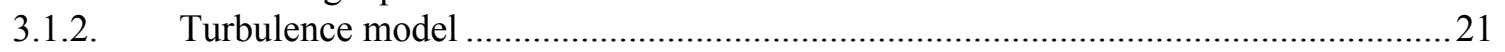

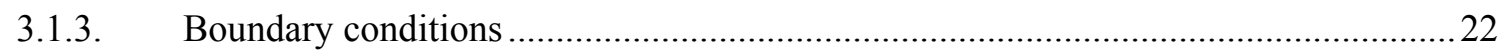

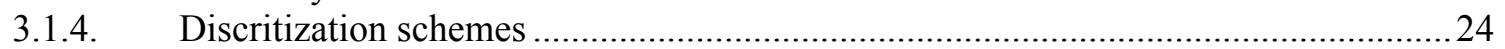

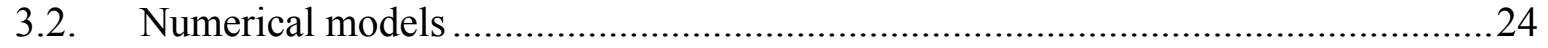

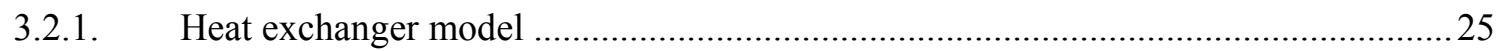

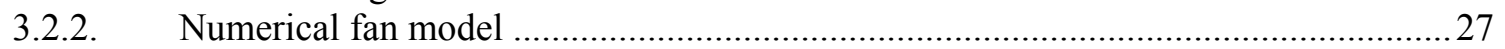

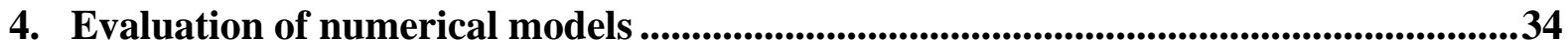

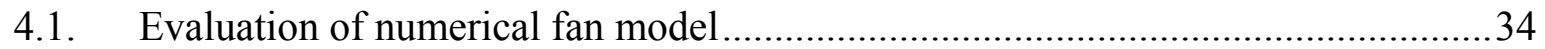

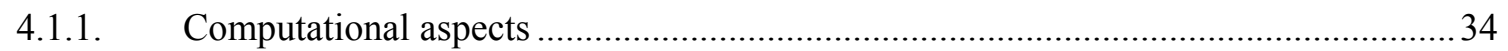

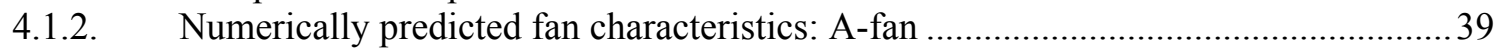



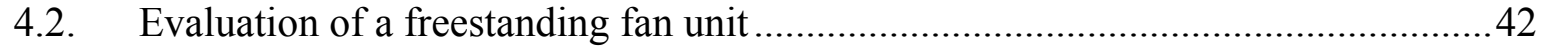

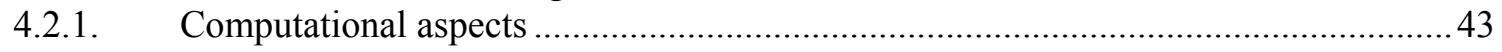



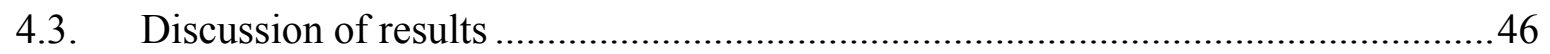




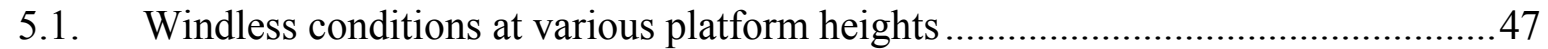



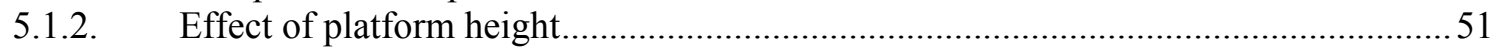

5.1.3. Comparison of the performance of the A-fan and B-fan ...........................................59



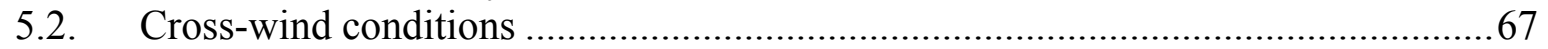

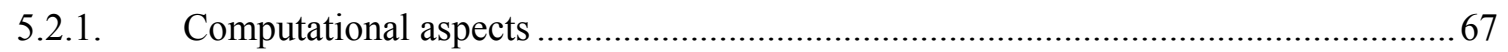

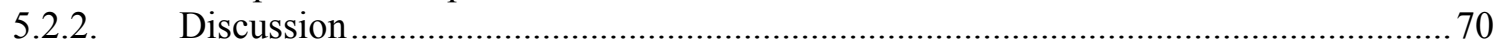

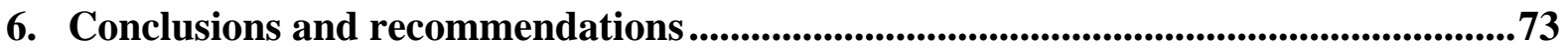

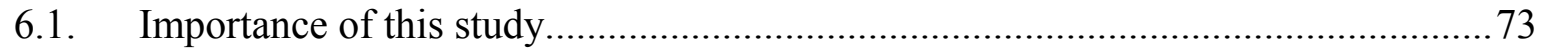

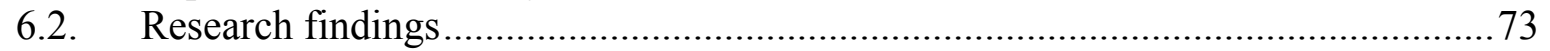

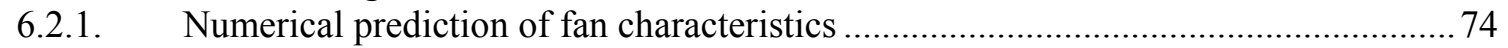

6.2.2. Effect of platform height on fan performance .......................................................... 74

6.2.3. Comparison of performance of the A-fan and B-fan ................................................. 75

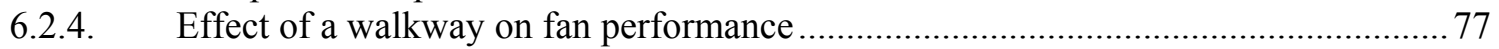

6.2.5. Modelling of cross-wind using an essentially two-dimensional approach ...................78

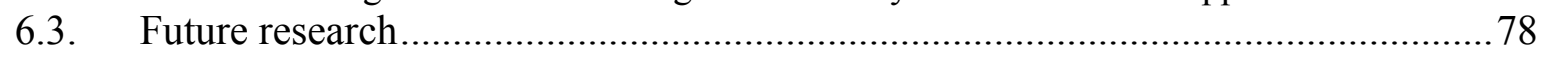

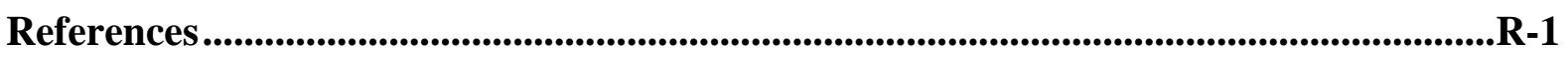

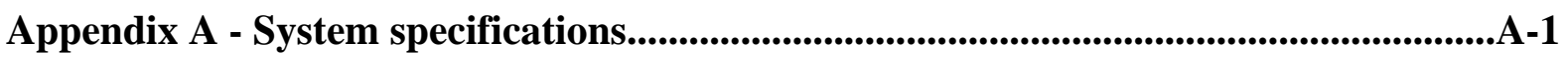

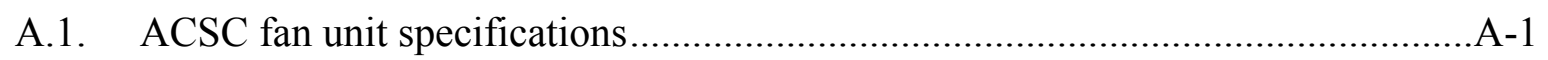

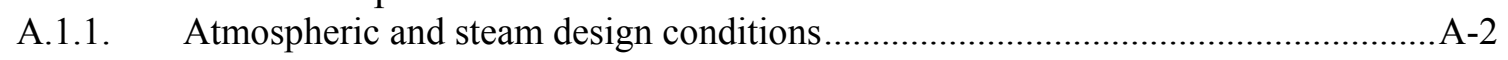

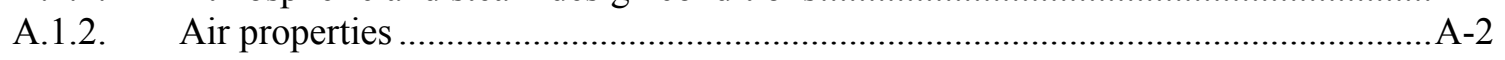

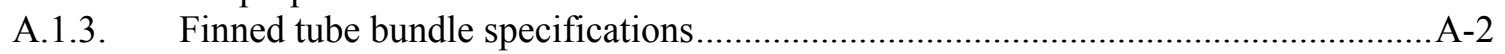

A.2. Upstream and downstream obstacles ...........................................................A-4

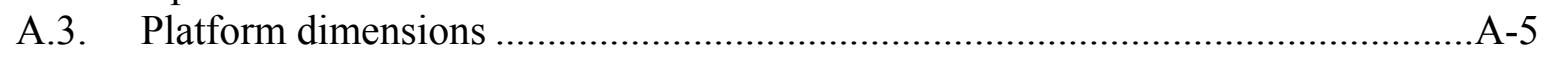

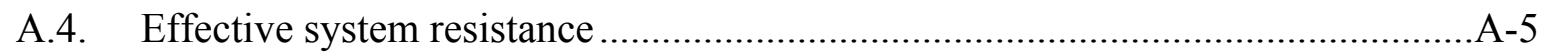

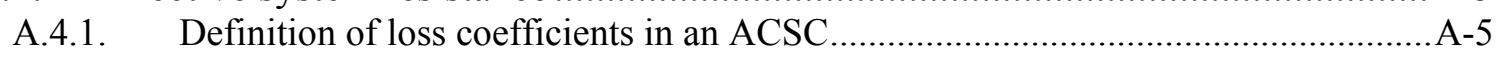

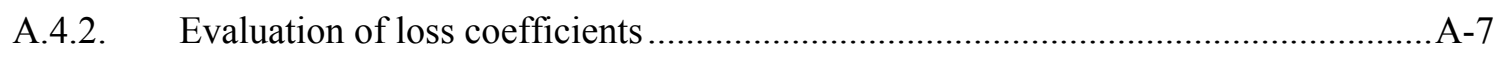

Appendix B - Fan installation specifications ................................................................................. B-1



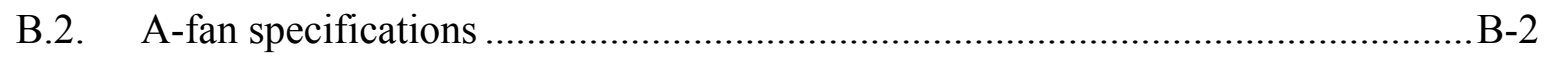



B.2.2. Performance characteristics of the A-fan......................................................... B-4

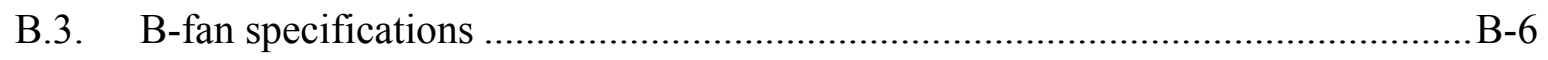

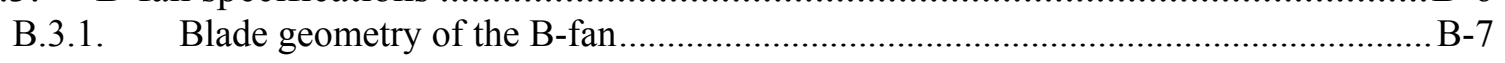

B.3.2. Performance characteristics of the B-fan model ................................................... B-8

Appendix C - Calculation of source terms in the numerical heat exchanger model .....C-1

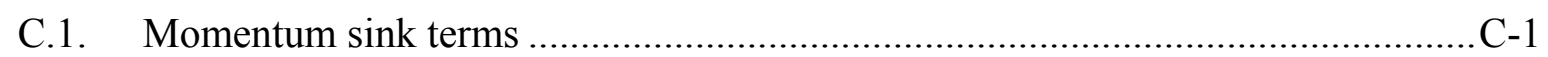

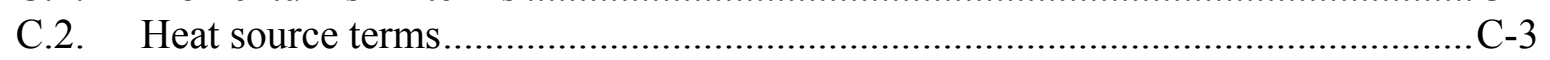

Appendix D - Fan blade profile lift and drag characteristics ..........................................D-1

D.1. Numerically determined lift and drag coefficients ..........................................

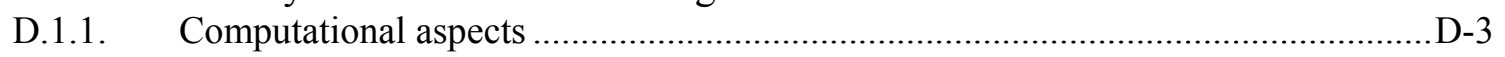

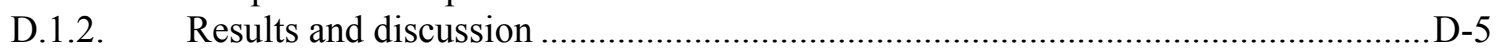

D.2. A-fan blade profile lift and drag characteristics .............................................. D-7

D.3. B-fan blade profile lift and drag characteristics............................................. 

windless conditions...........................................................................................................1

E.1. Fan performance of the A-fan at a platform height of $\mathrm{H}_{\mathrm{i}}=26 \mathrm{~m}$...........................

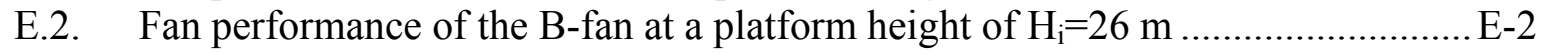

E.3. Fan performance of the A-fan at a platform height of $\mathrm{H}_{\mathrm{i}}=22 \mathrm{~m}$...........................

E.4. Fan performance of the B-fan at a platform height of $\mathrm{H}_{\mathrm{i}}=22 \mathrm{~m}$........................... E-4

E.4. Fan performance of the A-fan at a platform height of $\mathrm{H}_{\mathrm{i}}=18 \mathrm{~m}$......................... E-5

E.5. Fan performance of the $\mathrm{B}$-fan at a platform height of $\mathrm{H}_{\mathrm{i}}=18 \mathrm{~m}$.......................... E-6

E.7. Fan performance of the A-fan at a platform height of $\mathrm{H}_{\mathrm{i}}=14 \mathrm{~m}$...........................

E.8. Fan performance of the B-fan at a platform height of $\mathrm{H}_{\mathrm{i}}=14 \mathrm{~m}$........................ E-8 


\section{List of Figures}

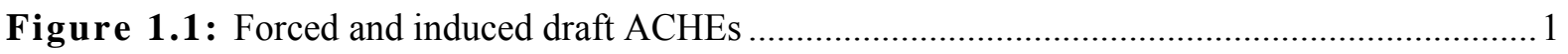

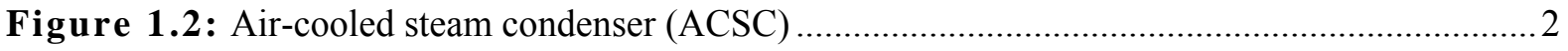

Figure 1.3: Schematic representation of a direct air-cooled power plant ........................................ 2

Figure 1.4: The Matimba direct air-cooled power plant ............................................................... 3



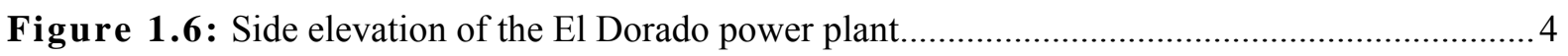

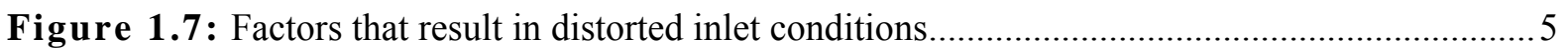

Figure 1.8: Computational grids used by Coetzee and du Toit [04CO1] in plan view ..................... 7

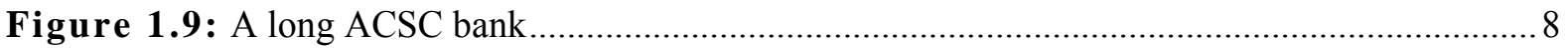

Figure 1.10: Two rotor-only axial flow fans in plan view........................................................

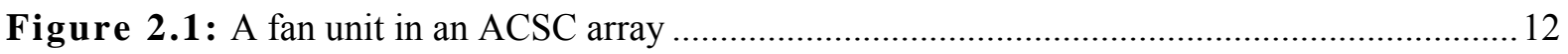

Figure 2.2: Industrial cooling fans (Courtesy Howden Cooling Fans and Cofimco) ...................... 13

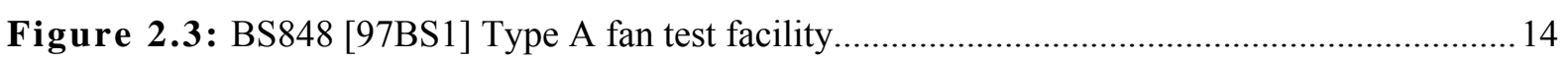

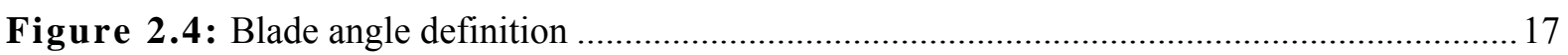

Figure 3.1: Simplified numerical model of an ACSC fan unit .....................................................24

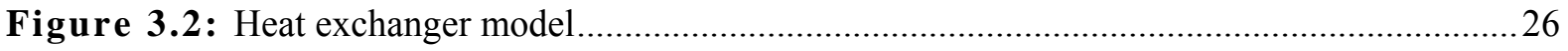

Figure 3.3: Vector plot for a three-dimensional rotating mesh fan model (Courtesy Fluent Inc.) .. 28

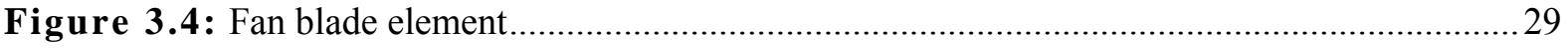

Figure 3.5: Schematic of the computational grid for actuator disc model .................................... 30

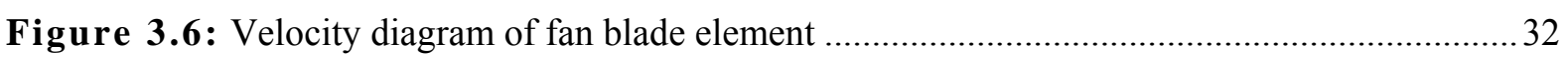

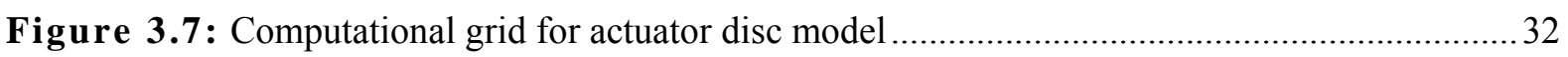

Figure 4.1: Geometrical layout of fan test model computational grid ........................................... 34

Figure 4.2: Section view of the computational grid for fan test model.......................................... 35

Figure 4.3: Isometric view of the computational grid for fan test model ....................................... 35

Figure 4.4: Detail view of the computational grid at the fan inlet ..................................................35

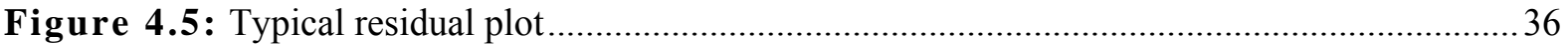

Figure 4.6: Static pressure $(\mathrm{Pa})$ plot for A-fan numerical model $\left(\mathrm{d}_{\mathrm{F}}=9.145 \mathrm{~m}, \gamma_{\mathrm{pt}}=16^{\circ}\right) \ldots \ldots \ldots \ldots \ldots . .37$

Figure 4.7: Static pressure $(\mathrm{Pa})$ plot for $\mathrm{B}$-fan numerical model $\left(\mathrm{d}_{\mathrm{F}}=1.542 \mathrm{~m}, \gamma_{\mathrm{cr}}=31^{\circ}\right) \ldots \ldots \ldots \ldots \ldots . . .37$

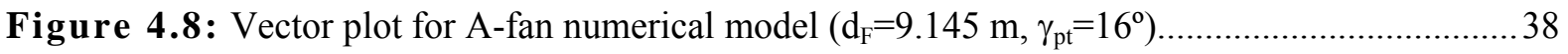

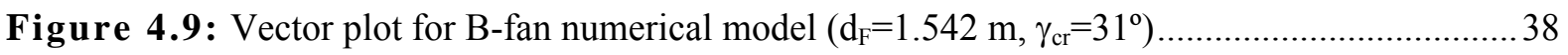


Figure 4.10: Fan static pressure for $A-f a n\left(d_{F}=9.145 \mathrm{~m}, \gamma_{\mathrm{pt}}=16^{\circ}\right)$

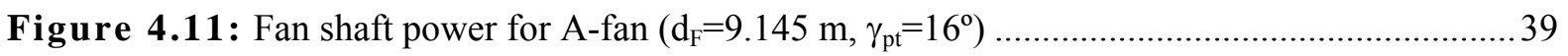

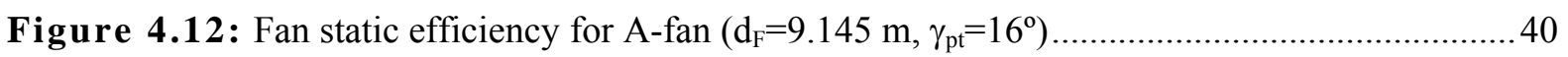

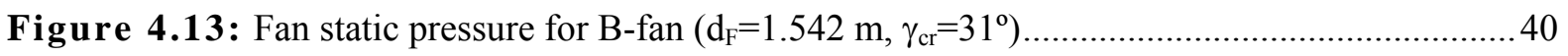

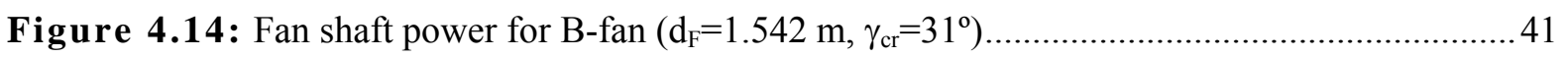

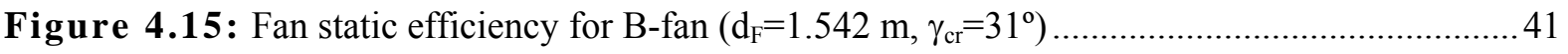

Figure 4.16: Operating point for the numerical ACSC fan unit model ..........................................42

Figure 4.17: Geometrical layout of the computational grid used to evaluate the ACSC fan unit model

Figure 4.18: Dimensions of the numerical ACSC fan unit model.................................................. 43

Figure 4.19: Section view of the computational grid for fan unit model.......................................... 44

Figure 4.20: Isometric view of the computational grid for fan unit model .................................... 44

Figure 4.21: Detail view of the computational grid for fan unit model.........................................4

Figure 4.22: Static pressure $(\mathrm{Pa})$ plot in the ACSC fan unit model with A-fan ............................. 45

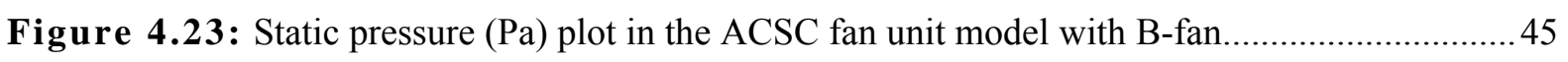

Figure 5.1: A section of a long ACSC bank located near its centre.

Figure 5.2: Layout of computational grid for modelling a section of the ACSC under windless conditions at various plat form heights

Figure 5.3: Computational grid for modelling a section of the ACSC under windless conditions.. 49

Figure 5.4: Enlarged sectional view of the computational grid near the fan units.......................... 49

Figure 5.5: Streamline plot indicating velocity magnitude for $\mathrm{H}_{\mathrm{i}}=26 \mathrm{~m}$ (plane $\left.\mathrm{Y}-\mathrm{Y}\right)$....................51

Figure 5.6: Streamline plot indicating velocity magnitude for $\mathrm{H}_{\mathrm{i}}=14 \mathrm{~m}$ (plane $\left.\mathrm{Y}-\mathrm{Y}\right)$....................51

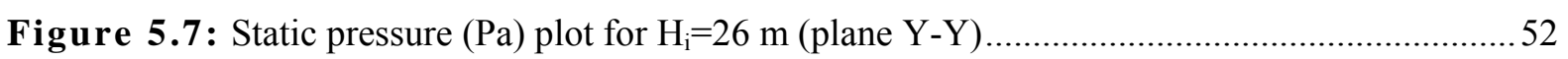

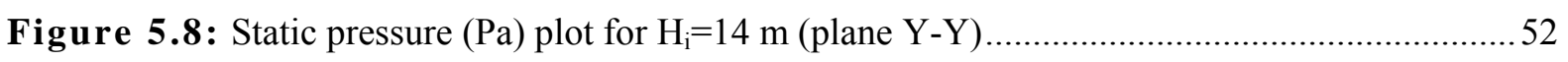



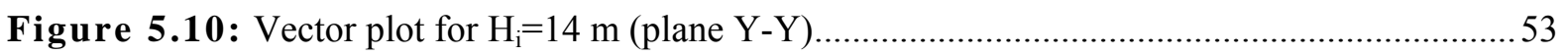

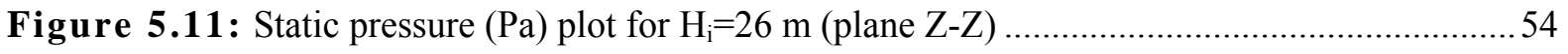

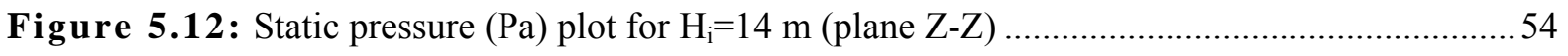

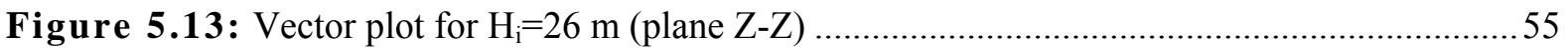

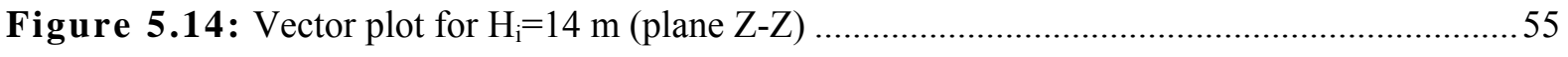

Figure 5.15: Angle of attack in the edge fan for the $\mathrm{A}-\mathrm{fan}$ at $\mathrm{H}_{\mathrm{i}}=26 \mathrm{~m}$.......................................56

Figure 5.16: Angle of attack in the edge fan for the A-fan at $\mathrm{H}_{\mathrm{i}}=14 \mathrm{~m}$........................................56

Figure 5.17: Volumetric effectiveness of the fans in a section of an ACSC at various platform heights ..... 
Figure 5.18: Fan shaft power ratio of the fans in a section of an ACSC at various platform heights

Figure 5.19: System volumetric effectiveness of an ACSC at various platform heights ...............58

Figure 5.20: Static pressure $(\mathrm{Pa})$ plot of edge fan employing the $\mathrm{B}$-fan with $\mathrm{H}_{\mathrm{i}}=14 \mathrm{~m}$................59

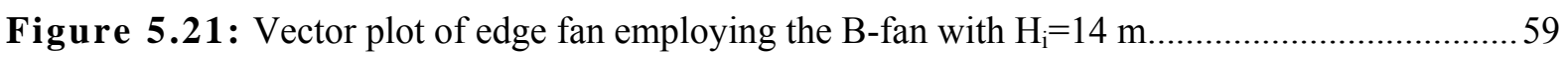

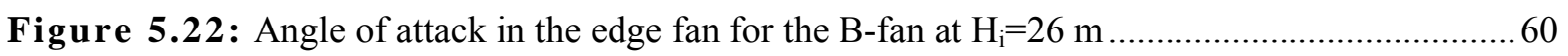

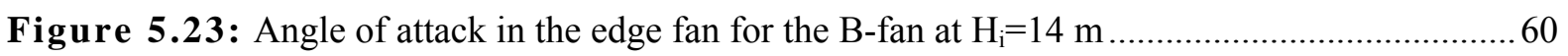

Figure 5.24: Volumetric effectiveness of the edge fan (for the A-fan and B-fan) in the section of the ACSC at various platform heights.

Figure 5.25: Fan shaft power ratio of the edge fan (for the A-fan and B-fan) in the section of the

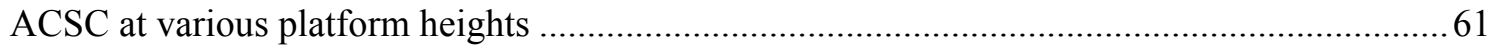

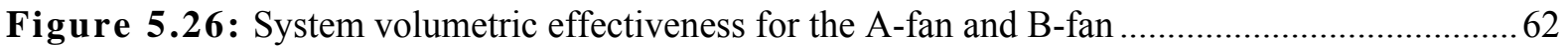

Figure 5.27: Four different walkway and windscreen configurations investigated........................6 62

Figure 5.28: Static pressure $(\mathrm{Pa})$ plot for case 1 employing the $\mathrm{A}$-fan with $\mathrm{H}_{\mathrm{i}}=14 \mathrm{~m} \ldots \ldots \ldots \ldots \ldots \ldots \ldots . . . . . . . .63$

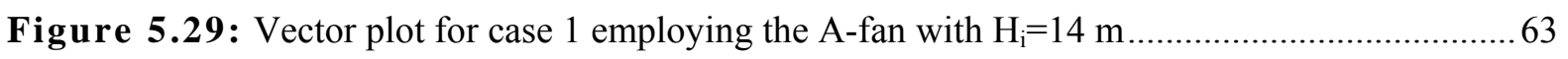

Figure 5.30: Volumetric effectiveness of the edge fan (A-fan) for cases 0 to 3 ..............................64

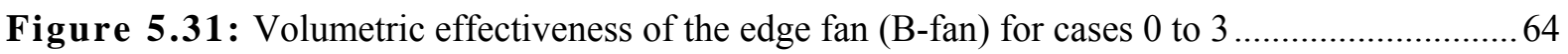

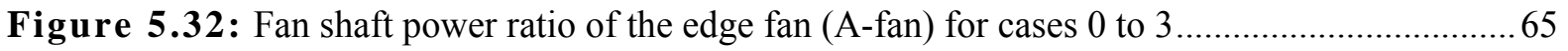

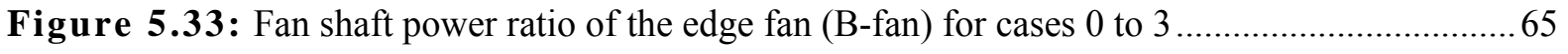

Figure 5.34: System volumetric effectiveness for cases 0 to 3 employing the A-fan .....................66

Figure 5.35: System volumetric effectiveness for cases 0 to 3 employing the B-fan......................66

Figure 5.36: Layout of computational grid for modelling the section of an ACSC under cross-wind conditions (essentially two-dimensional modelling approach)

Figure 5.37: Computational grid for modelling the section of an ACSC under cross-wind conditions

Figure 5.38: Enlarged section view of computational grid near the fan units ................................69

Figure 5.39: Streamline plot for a cross-wind of $3 \mathrm{~m} / \mathrm{s}$ after 70 iterations ..................................... 70

Figure 5.40: Temperature (K) plot for a cross-wind of $3 \mathrm{~m} / \mathrm{s}$ after 70 iterations ............................ 70

Figure 5.41: Static pressure $(\mathrm{Pa})$ plot for a cross-wind of $3 \mathrm{~m} / \mathrm{s}$ after 70 iterations ....................... 71

Figure 5.42: Velocity magnitude $(\mathrm{m} / \mathrm{s})$ plot for a cross-wind of $3 \mathrm{~m} / \mathrm{s}$ after 70 iterations .............71

Figure 5.43: Temperature (K) plot for a cross-wind of $3 \mathrm{~m} / \mathrm{s}$ after 300 iterations ......................... 72

Figure 6.1: Numerically determined performance characteristics for A-fan on B-fan .................... 75

Figure 6.2: Axial velocity profiles in actuator disc model for A-fan and B-fan .............................. 76

Figure 6.3: Effect of inlet flow distortion on volume flow rate .................................................... 77 
Figure A.1: ACSC fan unit dimensions .

Figure A.2: Finned tubes used in industrial air-cooling applications.....

Figure A.3: Finned tube configuration.

Figure B.1: Fan system dimensions

Figure B.2: Photographic image of a single fan blade of the A-fan .....

Figure B.3: A-fan blade dimensions

Figure B.4: A-fan blade profile

Figure B.5: Blade angle distribution at $\gamma_{\mathrm{pt}}=16^{\circ}$......

Figure B.6: Fan static pressure characteristic of the A-fan.

Figure B.7: Fan shaft power characteristic of the A-fan...

Figure B.8: Fan static efficiency of the A-fan

Figure B.9: Photographic image of the model B-fan

Figure B.10: B-fan blade profile, NASA GA(W)-2, McGhee et al [77MC1].

Figure B.11: Blade angle at $\gamma_{\mathrm{cr}}=30^{\circ}$ and chord length as a function of $\mathrm{r} / \mathrm{r}_{\text {tip }}$

Figure B.12: Fan static pressure characteristic of the B-fan.

Figure B.13: Fan shaft power characteristic of the B-fan.

Figure B.14: Fan static efficiency of the B-fan

Figure C.1: Numerical heat exchanger model.

Figure D.1: Lift and drag forces on an isolated blade profile

Figure D.2: Computational grid for the NASA GA(W)-2 airfoil

Figure D.3: Computational grid near the surface of the NASA GA(W)-2 airfoil

Figure D.4: Numerically determined lift coefficient of the NASA GA(W)-2 airfoil .

Figure D.5: Numerically determined drag coefficient of the NASA GA(W)-2 airfoil

Figure D.6: Streamline plot for the NASA GA(W)-2 airfoil at $\alpha=24^{\circ}$

Figure D.7: Numerically determined lift and drag coefficients for the NASA GA(W)-2 airfoil at $\alpha=24^{\circ}$

Figure D.8: Lift and drag coefficients of the A-fan blade profile for $-90^{\circ}<\alpha<90^{\circ}$

Figure D.9: Lift and drag coefficients of the B-fan blade profile for $-90^{\circ}<\alpha<90^{\circ}$.

Figure E.1: Volumetric effectiveness for the A-fan $\left(\mathrm{d}_{\mathrm{F}}=9.145 \mathrm{~m}, \gamma_{\mathrm{pt}}=16^{\circ}\right)$ at $\mathrm{H}_{\mathrm{i}}=26 \mathrm{~m}$.

Figure E.2: Fan shaft power ratio for the A-fan $\left(\mathrm{d}_{\mathrm{F}}=9.145 \mathrm{~m}, \gamma_{\mathrm{pt}}=16^{\circ}\right)$ at $\mathrm{H}_{\mathrm{i}}=26 \mathrm{~m}$.

Figure E.3: Volumetric effectiveness for the B-fan $\left(\mathrm{d}_{\mathrm{F}}=9.145 \mathrm{~m}, \gamma_{\mathrm{cr}}=34.5^{\circ}\right)$ at $\mathrm{H}_{\mathrm{i}}=26 \mathrm{~m}$.

Figure E.4: Fan shaft power ratio for the $B-f a n\left(d_{F}=9.145 \mathrm{~m}, \gamma_{\mathrm{cr}}=34.5^{\circ}\right)$ at $\mathrm{H}_{\mathrm{i}}=26 \mathrm{~m}$ 
Figure E.5: Volumetric effectiveness for the A-fan $\left(\mathrm{d}_{\mathrm{F}}=9.145 \mathrm{~m}, \gamma_{\mathrm{pt}}=16^{\circ}\right)$ at $\mathrm{H}_{\mathrm{i}}=22 \mathrm{~m}$ E-3

Figure E.6: Fan shaft power ratio for the A-fan $\left(d_{F}=9.145 \mathrm{~m}, \gamma_{\mathrm{pt}}=16^{\circ}\right)$ at $\mathrm{H}_{\mathrm{i}}=22 \mathrm{~m}$. E-3

Figure E.7: Volumetric effectiveness for the $\mathrm{B}-\mathrm{fan}\left(\mathrm{d}_{\mathrm{F}}=9.145 \mathrm{~m}, \gamma_{\mathrm{cr}}=34.5^{\circ}\right)$ at $\mathrm{H}_{\mathrm{i}}=22 \mathrm{~m}$ E-4

Figure E.8: Fan shaft power ratio for the $B-f a n\left(d_{F}=9.145 \mathrm{~m}, \gamma_{c r}=34.5^{\circ}\right)$ at $H_{i}=22 \mathrm{~m}$ E-4

Figure E.9: Fan shaft power ratio for the A-fan $\left(\mathrm{d}_{\mathrm{F}}=9.145 \mathrm{~m}, \gamma_{\mathrm{pt}}=16^{\circ}\right)$ at $\mathrm{H}_{\mathrm{i}}=18 \mathrm{~m}$ E-5

Figure E.10: Fan shaft power ratio for the A-fan $\left(\mathrm{d}_{\mathrm{F}}=9.145 \mathrm{~m}, \gamma_{\mathrm{pt}}=16^{\circ}\right)$ at $\mathrm{H}_{\mathrm{i}}=18 \mathrm{~m}$ E-5

Figure E.11: Volumetric effectiveness for the B-fan $\left(\mathrm{d}_{\mathrm{F}}=9.145 \mathrm{~m}, \gamma_{\mathrm{cr}}=34.5^{\circ}\right)$ at $\mathrm{H}_{\mathrm{i}}=18 \mathrm{~m}$ E-6

Figure E.12: Fan shaft power ratio for the $B-f a n\left(d_{F}=9.145 \mathrm{~m}, \gamma_{\mathrm{cr}}=34.5^{\circ}\right)$ at $\mathrm{H}_{\mathrm{i}}=18 \mathrm{~m}$ E-6

Figure E.13: Fan shaft power ratio for the A-fan $\left(\mathrm{d}_{\mathrm{F}}=9.145 \mathrm{~m}, \gamma_{\mathrm{pt}}=16^{\circ}\right)$ at $\mathrm{H}_{\mathrm{i}}=14 \mathrm{~m}$ E-7

Figure E.14: Fan shaft power ratio for the A-fan $\left(\mathrm{d}_{\mathrm{F}}=9.145 \mathrm{~m}, \gamma_{\mathrm{pt}}=16^{\circ}\right)$ at $\mathrm{H}_{\mathrm{i}}=14 \mathrm{~m}$ E-7

Figure E.15: Volumetric effectiveness for the B-fan $\left(\mathrm{d}_{\mathrm{F}}=9.145 \mathrm{~m}, \gamma_{\mathrm{cr}}=34.5^{\circ}\right)$ at $\mathrm{H}_{\mathrm{i}}=14 \mathrm{~m}$ E-8

Figure E.16: Fan shaft power ratio for the B-fan $\left(\mathrm{d}_{\mathrm{F}}=9.145 \mathrm{~m}, \gamma_{\mathrm{cr}}=34.5^{\circ}\right)$ at $\mathrm{H}_{\mathrm{i}}=14 \mathrm{~m}$. E-8 


\section{List of Tables}

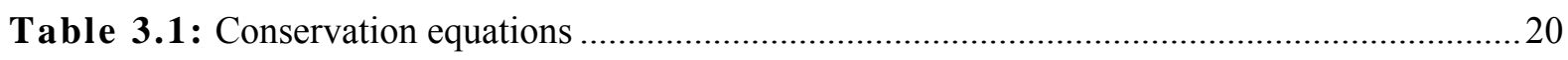



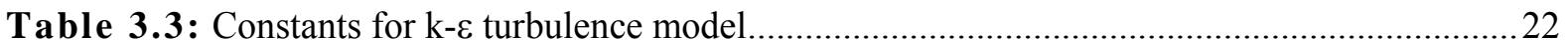

Table 3.4: Momentum sink terms for heat exchanger model ........................................................26

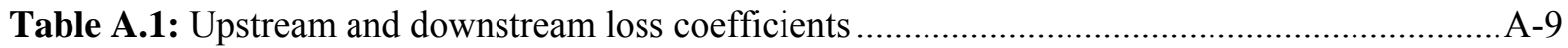




\section{Nomenclature}

\begin{tabular}{|c|c|}
\hline A & Area, $\mathrm{m}^{2}$ \\
\hline $\mathrm{C}$ & Constant \\
\hline $\mathrm{C}_{\mathrm{D}}$ & Drag coefficient \\
\hline $\mathrm{C}_{\mathrm{L}}$ & Lift coefficient \\
\hline c & Chord length, m \\
\hline $\mathrm{c}_{\mathrm{p}}$ & Specific heat at constant pressure, $\mathrm{J} / \mathrm{kgK}$ \\
\hline $\mathrm{D}$ & Drag force, $\mathrm{N}$ \\
\hline $\mathrm{d}$ & Diameter, $\mathrm{m}$ \\
\hline $\mathrm{e}$ & Effectiveness \\
\hline $\mathrm{F}$ & Momentum source term, $\mathrm{N} / \mathrm{m}^{3}$ \\
\hline $\mathrm{f}$ & Force, $\mathrm{N}$ \\
\hline G & Production term \\
\hline g & Gravitational acceleration, $\mathrm{m} / \mathrm{s}^{2}$ \\
\hline $\mathrm{H}$ & Height, m \\
\hline $\mathrm{h}$ & Vertical distance above the ground, $\mathrm{m}$ \\
\hline $\mathrm{K}$ & Loss coefficient \\
\hline $\mathrm{k}$ & Turbulent kinetic energy, $\mathrm{m}^{2} / \mathrm{s}^{2}$ \\
\hline $\mathrm{L}$ & Length, $\mathrm{m}$, or lift force, $\mathrm{N}$ \\
\hline M & Fan shaft torque, $\mathrm{Nm}$ \\
\hline $\mathrm{m}$ & Mass flow rate, $\mathrm{kg} / \mathrm{s}$ \\
\hline $\mathrm{N}$ & Rotational speed, rpm \\
\hline Ny & Characteristic heat transfer parameter, $1 / \mathrm{m}$ \\
\hline $\mathrm{n}$ & Number \\
\hline $\mathrm{P}$ & Power, W \\
\hline $\mathrm{p}$ & Pressure, $\mathrm{Pa}$ \\
\hline Q & Heat transfer rate, $\mathrm{W}$ \\
\hline $\mathrm{R}$ & Gas constant, $\mathrm{J} / \mathrm{kgK}$ \\
\hline Ry & Characteristic flow parameter, $1 / \mathrm{m}$ \\
\hline $\mathrm{r}$ & Radial co-ordinate, or radius, $\mathrm{m}$ \\
\hline $\mathrm{S}$ & Source term \\
\hline $\mathrm{T}$ & Temperature, ${ }^{\circ} \mathrm{C}$ or $\mathrm{K}$ \\
\hline
\end{tabular}


Axial thickness of the actuator disc model, $\mathrm{m}$ $\mathrm{x}$-velocity component, $\mathrm{m} / \mathrm{s}$

Friction velocity, $\mathrm{m} / \mathrm{s}$

Volume flow rate, $\mathrm{m}^{3} / \mathrm{s}$

$\mathrm{y}$-velocity component, or velocity, $\mathrm{m} / \mathrm{s}$

Velocity vector, $\mathrm{m} / \mathrm{s}$

Width, m

z-velocity component, $\mathrm{m} / \mathrm{s}$

Dimensionless platform height

Co-ordinate

Co-ordinate

Co-ordinate

Surface roughness length, $\mathrm{m}$

\section{Greek symbols}

$\alpha$

$\beta$

$\beta_{\mathrm{T}}$

$\Delta$

$\delta$

$\varepsilon$

$\phi$

$\Gamma$

$\gamma$

$\eta$

$\kappa$

$\mu$

$\theta$

$\rho$

$\sigma$

$\Omega$

Angle of attack, ${ }^{\circ}$

Relative flow angle, ${ }^{\circ}$

Thermal expansion coefficient, $1 / \mathrm{K}$

Differential

Incremental

Dissipation rate of turbulent kinetic energy, $\mathrm{m}^{2} / \mathrm{s}^{3}$

Field variable

Diffusion coefficient

Blade angle

Efficiency, \%

von Karman constant

Viscosity, $\mathrm{kg} / \mathrm{ms}$

Angle, or tangential co-ordinate, $\operatorname{rad}^{\circ}{ }^{\circ}$

Density, $\mathrm{kg} / \mathrm{m}^{3}$

Area ratio, or blade solidity, or constant in k- $\varepsilon$ turbulence model

Angular velocity, $\mathrm{rad} / \mathrm{s}$ 


\section{Dimensionless Groups}

$\operatorname{Pr}$

Prandtl number, $\mu \mathrm{c}_{\mathrm{p}} / \mathrm{k}$

Re

Reynolds number, $\rho v L / \mu$

\section{Subscripts}

\begin{tabular}{|c|c|}
\hline $\mathrm{a}$ & Air, or ambient \\
\hline $\mathrm{b}$ & Bellmouth, or bundle \\
\hline bl & Blade \\
\hline $\mathrm{c}$ & Casing, or chord, or contraction \\
\hline$d$ & Dynamic \\
\hline do & Downstream \\
\hline $\mathrm{E}$ & Energy \\
\hline $\mathrm{e}$ & Effective \\
\hline $\mathrm{F}$ & Fan \\
\hline fr & Frontal \\
\hline $\mathrm{h}$ & Hub \\
\hline he & Heat exchanger \\
\hline $\mathrm{i}$ & Inlet, or numerical index, $1,2,3 \ldots$ \\
\hline $\mathrm{j}$ & Jetting \\
\hline $\mathrm{m}$ & Mean \\
\hline $\mathrm{n}$ & Numerical index, $1,2,3 \ldots$ \\
\hline o & Outlet \\
\hline $\mathrm{p}$ & Practice \\
\hline $\mathrm{R}$ & Relative \\
\hline $\mathrm{r}$ & Reference, or root, or row \\
\hline S & Static, or steam \\
\hline $\mathrm{sc}$ & Settling chamber \\
\hline sys & System \\
\hline $\mathrm{T}$ & Test, or thermal \\
\hline $\mathrm{t}$ & Tip, or tube, or turbulent \\
\hline tot & Total \\
\hline up & Upstream \\
\hline
\end{tabular}




\section{Volumetric}

W

Walkway, or wind, or windwall 


\section{Introduction}

\subsection{Background and motivation}

Mechanical draft air-cooled heat exchangers (ACHEs) and air-cooled condensers (ACCs), use air as cooling medium to cool and condense process fluids. Based on economical and environmental considerations, these systems are often employed in the petro-chemical, airconditioning and power generating industries, instead of water-cooled systems. In an ACHE, heat from the circulating process fluid is transferred to the air via finned tubes. For construction and handling purposes, these finned tubes are grouped together in units called heat exchanger bundles. As illustrated in figure 1.1, a fan situated upstream or downstream of the heat exchanger forces air through the system to reject the heat to the environment. If the fan is located upstream of the heat exchanger, the ACHE is of the forced draft type, as opposed to an induced draft type ACHE, in which the fan is located downstream of the heat exchanger. Kröger [04KR1] elaborates on different types and configurations of ACHEs and ACCs, and on the advantages and disadvantages of each.

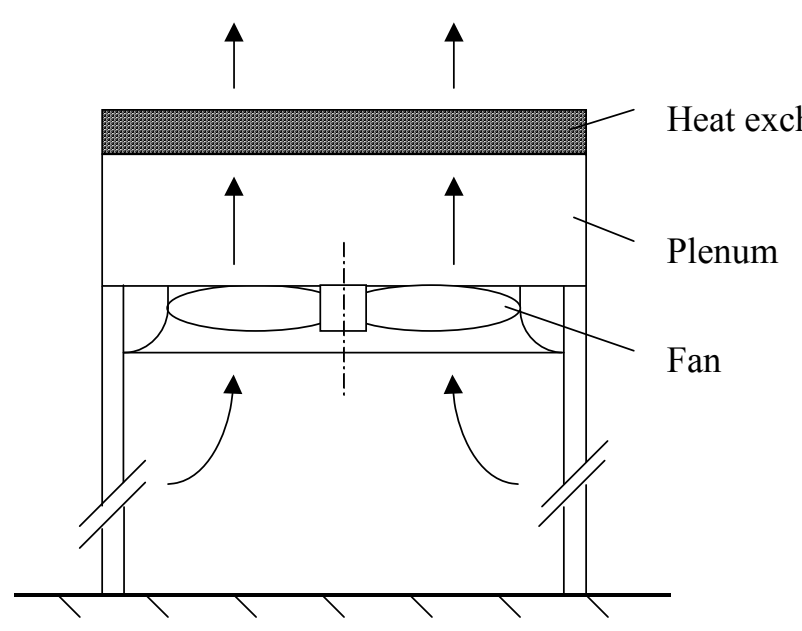

a) Forced draft ACHE

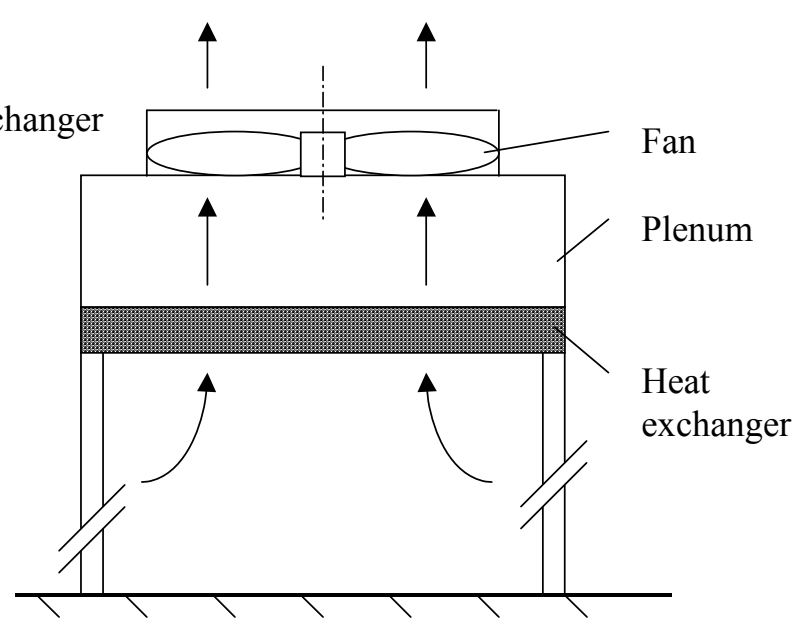

b) Induced draft ACHE

Figure 1.1: Forced and induced draft ACHEs

In an ACC the process fluid, initially in vapour form, is condensed inside the finned tubes. To remove the condensate effectively, and to reduce the plant footprint, the heat exchanger bundles are installed in a vertical or inclined configuration. Although there are various types of ACC configurations, only the A-frame type, frequently used in direct cooled power plants, 
shall be discussed in more detail. An A-frame air-cooled steam condenser (ACSC) unit, shown in figure 1.2, consists of a series of heat exchanger bundles arranged in an A-frame structure above an axial flow fan. Steam, supplied by a steam header, flows down through the finned tubes. As heat is rejected to the ambient air, the saturated or supersaturated steam condenses, and collects in the condensate duct.

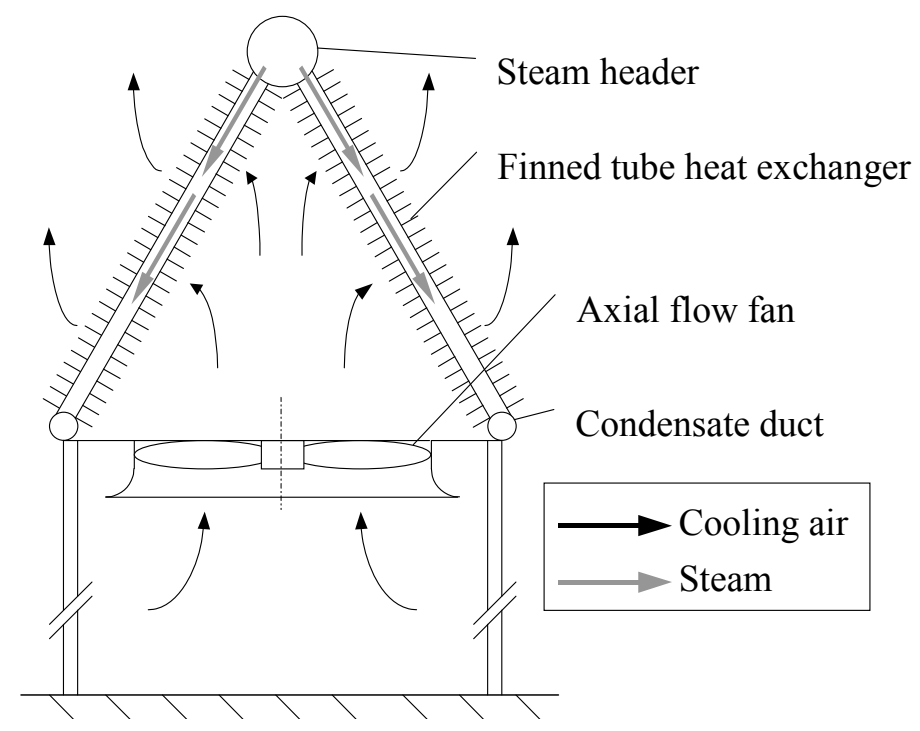

Figure 1.2: Air-cooled steam condenser (ACSC)

In a direct air-cooled power plant, the low-pressure steam from the turbine exhaust enters into the ACSC, as shown in figure 1.3. The condensate is then pumped back to the boiler via the condensate duct to form a closed steam cycle.

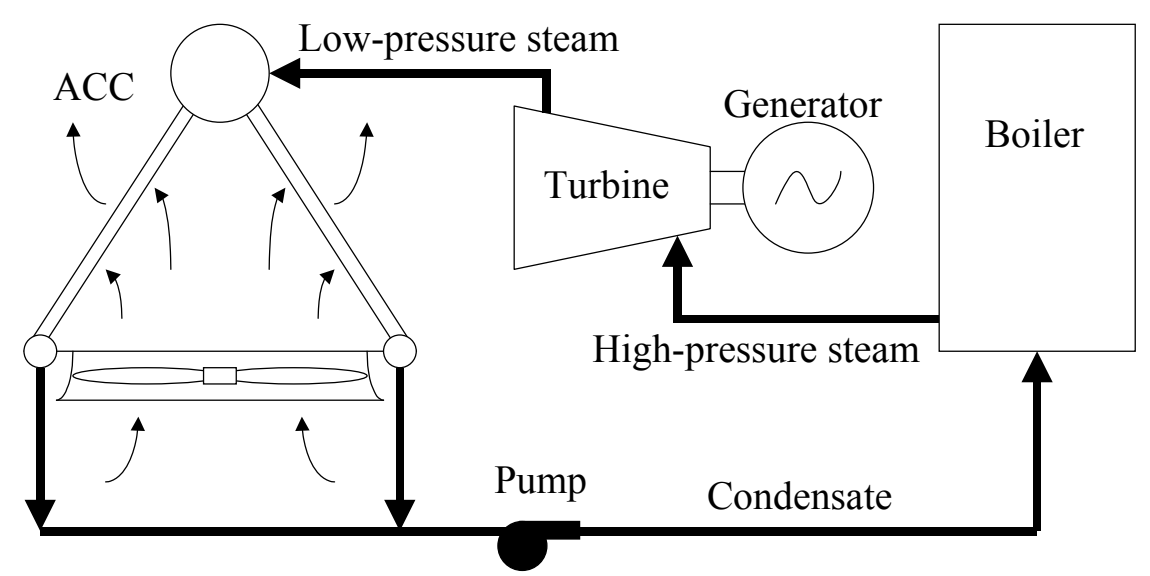

Figure 1.3: Schematic representation of a direct air-cooled power plant

Direct cooled power plants may differ considerably in layout, construction and capacity. As an illustration thereof, two direct cooled power plants are discussed in more detail. 
The world's largest forced draft direct air-cooled power plant, Matimba, shown schematically in figure 1.4, was commissioned in 1987 and is situated in the Limpopo province of the Republic of South Africa. It has a capacity of $6 \times 665 \mathrm{MW}(\mathrm{e})$ and employs an ACSC consisting of 288 axial flow fans $9.145 \mathrm{~m}$ in diameter each driven by a $270 \mathrm{~kW}$ electrical motor. The $6 \times 960 \mathrm{MW}$ ACSC platform is located $45 \mathrm{~m}$ above ground level and covers a plot area of $74.5 \mathrm{~m} \times 510 \mathrm{~m}$. The main dimensions of this plant are shown in figure 1.5

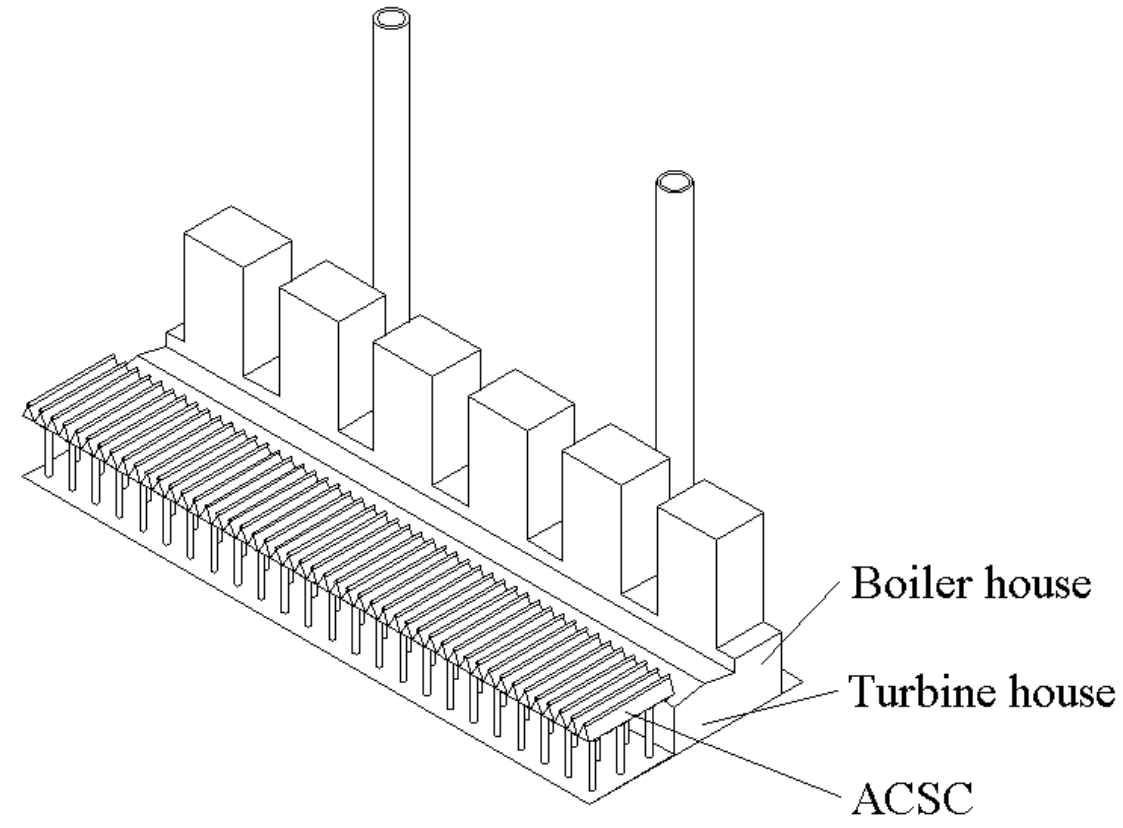

Figure 1.4: The Matimba direct air-cooled power plant

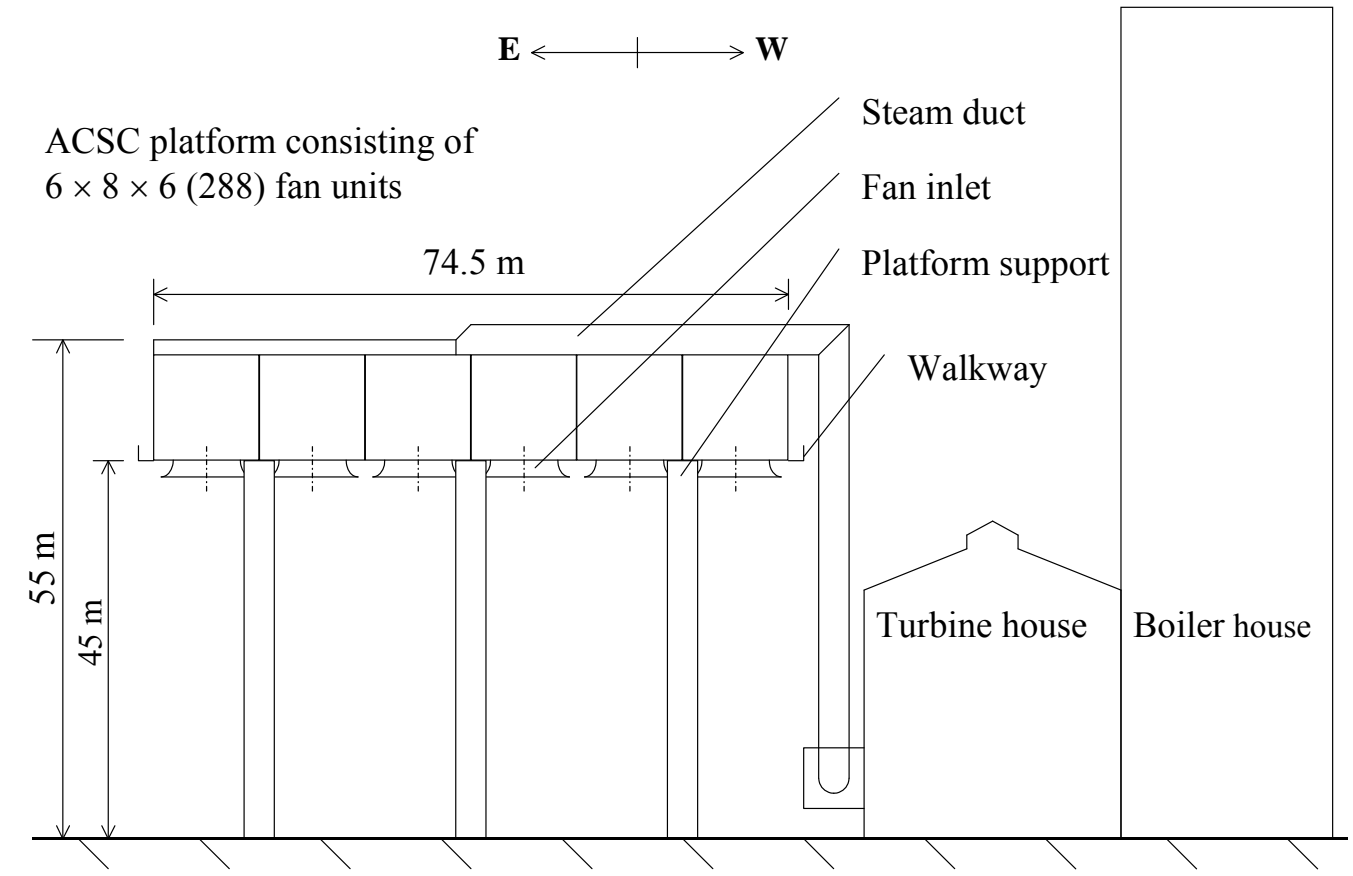

Figure 1.5: Side elevation of the Matimba power plant 
Another example of a direct air-cooled power plant is the $480 \mathrm{MW}(\mathrm{e})$ El Dorado plant, situated southeast of Las Vegas in the Nevada desert in the United States of America. This modern, high efficiency combined cycle plant has an ACSC employing 30 axial flow fans with a diameter of $10.363 \mathrm{~m}$. As shown in figure 1.6, the ACSC platform is located $19.2 \mathrm{~m}$ above ground level and covers a plot area of $83.2 \mathrm{~m} \times 70.5 \mathrm{~m}$.

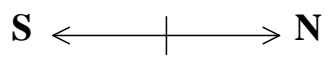

ACSC platform consisting of

$6 \times 5(30)$ fan units

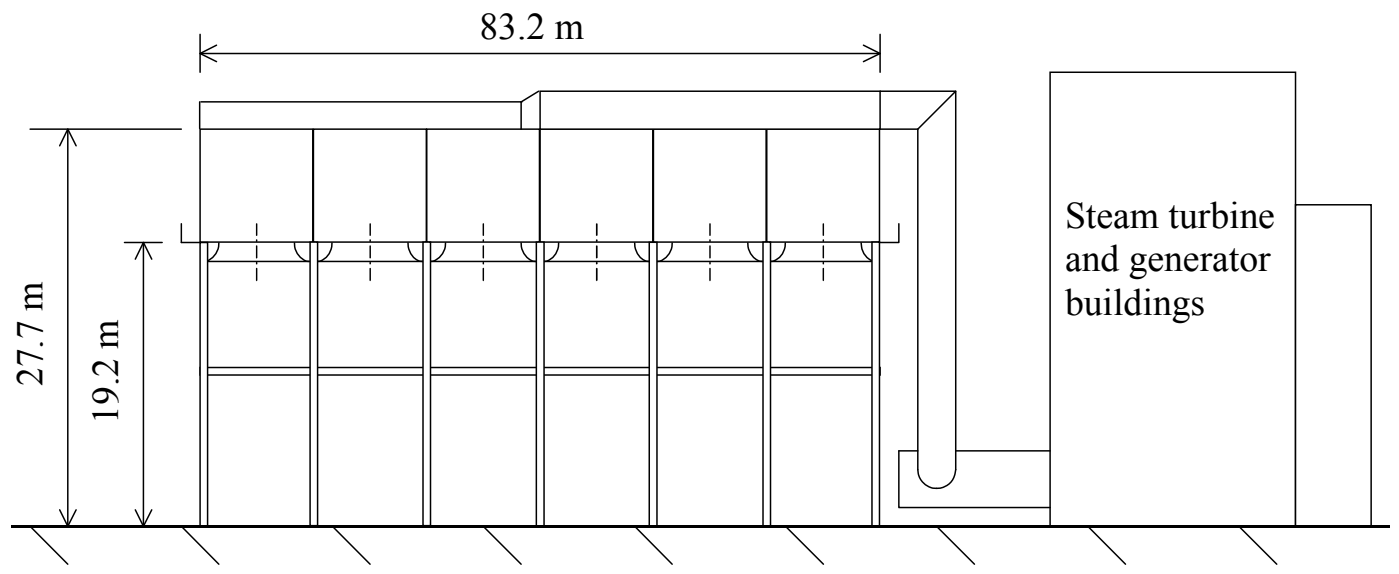

Figure 1.6: Side elevation of the El Dorado power plant

Because air is used as cooling medium, the heat rejection capacity is strongly influenced by ambient conditions such as dry bulb temperature, wind, atmospheric stability, and other meteorological phenomena. It is often found that under off-design conditions e.g. on hot and windy days, the reduced heat rejection capacity of the ACSC measurably reduces the output of power plants. Goldschagg [93GO1] reports on the reduction of turbine performance under windy conditions at the Matimba power plant. Due to the strong dynamic interaction between the steam turbine and the ACSC, turbine trips may occur under severe wind conditions.

Consideration of ambient conditions, particularly the prevailing winds, is therefore imperative in the design, location and orientation of large air-cooled systems. An example of such a case is that of Matimba (refer to figure 1.4 and figure 1.5). The plant is orientated so that the ACSC is upwind of the turbine and boiler buildings under prevailing easterly wind 
conditions. This limits the distortion of the inlet air flow by the buildings and reduces hot plume recirculation.

An understanding of the global flow field, as well as the detail flow field near the fan inlets, can be applied to optimise the cooling capacity of a forced draft air-cooled system. The current investigation involves the modelling of the flow field in a representative section of an ACSC using computational fluid dynamics (CFD), in order to obtain insight into the flow patterns and to qualitatively evaluate the effect of inlet flow distortions on the fans.

\subsection{Literature study}

According to Thiart and von Backström [93TH1] inlet air flow distortions in a forced draft ACHE (or ACC) can be caused by wind, nearby buildings, and cross-drafts induced by other fans, as shown in figure 1.7.

a)

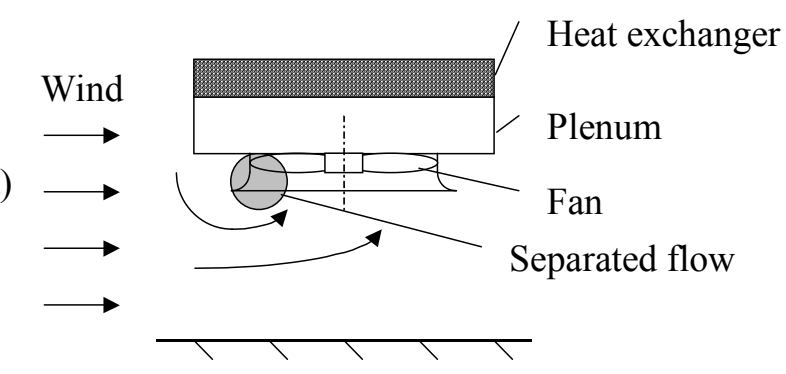

c)

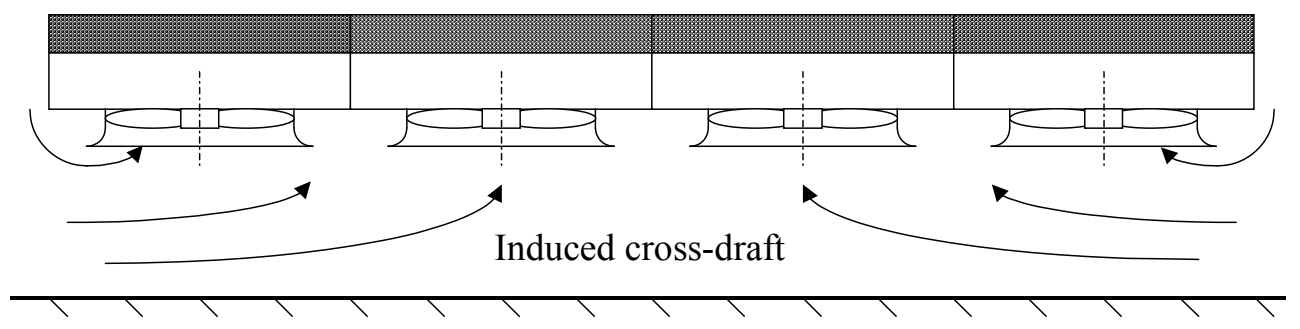

b)

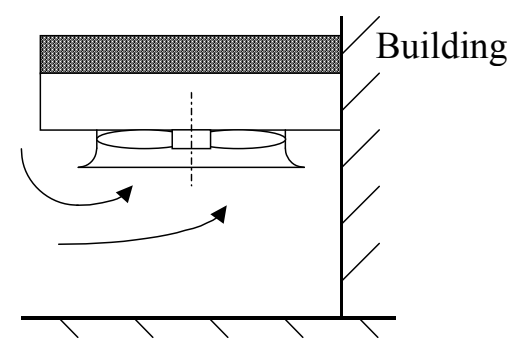

Figure 1.7: Factors that result in distorted inlet conditions

In an experimental study on a scale model of an ACHE, Salta and Kröger [95SA1] investigated the effect of inlet flow distortions on fan performance. With an experimental setup similar to figure $1.7 \mathrm{c}$ ), it was found that a reduction in the distance between the fan platform and the ground resulted in a significant decrease in flow rate through the fans. They also observed that the fans along the edge or periphery of an ACHE were most affected by flow distortions caused by the induced cross-draft. 
Bruneau [94BR1], who designed an axial flow fan for application in a cooling tower, explains this reduction in fan performance in more detail, and states that, "Depending on the severity of the distortions (i.e. non-uniform inlet profiles) the fan blade can stall, accompanied by losses in aerodynamic efficiency and peak pressure rise, as well as blade vibrations."

Duvenhage et al. [96DU2], numerically and experimentally investigated flow distortions at the inlet of forced-draft ACHEs under induced cross-draft conditions. The platform height, as well as three different inlet shrouds, namely cylindrical, conical and bell-mouth, were considered. Recommendations towards the optimal design of these inlet shrouds were made.

Although the main focus of the study is on the effect of flow distortions resulting from induced cross-drafts, a discussion of wind-effects is warranted seeing that the majority of the relevant literature on numerical modelling of forced draft ACHEs, involves the latter.

According to Duvenhage and Kröger [96DU1] the negative impact of wind on an ACHE (or ACC) can be divided into two categories. The first category, termed recirculation, results when a fraction of the buoyant plume is drawn back into the ACHE (or ACC) inlet, thereby increasing the temperature of the cooling medium and decreasing the heat rejection rate. The analytical, experimental and numerical investigation of the reduction in performance of mechanical draft ACHEs due to recirculation, are presented in numerous studies, [71GU1], [89KR1], [93DU1], [95DU1], [99RO1].

The second category is the reduction in fan performance due to distorted inlet flow conditions, as shown in figure $1.7 \mathrm{a}$ ). In this case the reduction in effectiveness of the ACHE is brought about by a decrease in air mass flow rate through the system. Although these two categories of wind-effects are often coupled, usually the one or the other is dominant, depending on the ACHE (or ACC) geometry, wind speed and direction.

During tests done on a full-scale ACHE under cross-wind conditions, Turner [75TU1] found that flow separation at the fan inlet caused maldistribution of air flow into the fan, which resulted in a reduction in fan performance. Van Aarde [90VA1] conducted experiments on a full-scale ACSC, and observed similar trends. A significant reduction in flow rate under windy conditions was reported. 
The influence of wind speed and direction on a long ACHE bank was numerically investigated by Duvenhage and Kröger [96DU1]. The reduction in fan performance, as well as plume recirculation, was successfully modelled. They report that cross-winds resulted in a significant reduction in flow rate through the upwind fans, while winds along the longitudinal axis lead to an increase in hot plume recirculation along the sides of the ACHE.

Coetzee [00CO1] conducted a numerical study on the influence of various atmospheric conditions on different ACHE configurations. He concludes that despite many simplifications and assumptions, CFD models can effectively be used to investigate ACHE operation in different conditions and environments. In a more recent study, Coetzee and du Toit [04CO1] compared two modelling approaches in order to determine the importance of end-effects in the numerical modelling of ACHEs subjected to wind. In the first approach, the full threedimensional model allows air to pass around the ACHE, thereby including end-effects, as shown in figure $1.8 \mathrm{a}$ ). In the second approach, illustrated in figure $1.8 \mathrm{~b}$ ), air is confined to a channel preventing any flow around the ACHE, and therefore excluding end-effects. These researchers point out that this essentially two-dimensional modelling approach can be used to represent a heat exchanger bay located near the centre of a large bank of ACHEs.

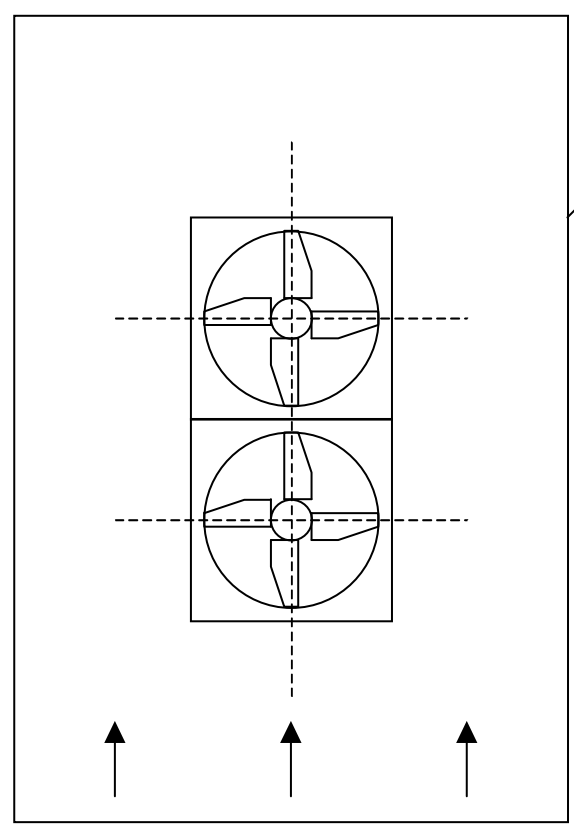

a) Full three-dimensional model



b) Essentially two-dimensional model

Figure 1.8: Computational grids used by Coetzee and du Toit [04CO1] in plan view 
Van Staden and Pretorius [96VA1] present an integrated numerical model to predict the global performance of a direct air-cooled power plant. The model employs CFD to simulate the effect of ambient conditions on the ACSC and takes into account the interaction between the steam turbine and ACSC. A case study was performed on the Matimba power plant. More recently this model was validated to some extent, by comparing steady state numerical results to measured on-site data. Van Staden [00VA1] reports agreement of temperature profiles, velocity distributions and air flow paths.

From the literature survey it can be concluded that modern numerical modelling techniques can effectively be used to analyse the flow field associated with an ACHE (or ACC) in order to predict its performance under various operating conditions. Although numerical methods such as CFD may provide valuable insight into such thermal flow problems, the importance of analytical and experimental investigations must not be overlooked.

\subsection{Problem statement and objectives}

This study involves the numerical modelling of the flow about and through a section (or sector) of an ACSC, as shown in figure 1.9.

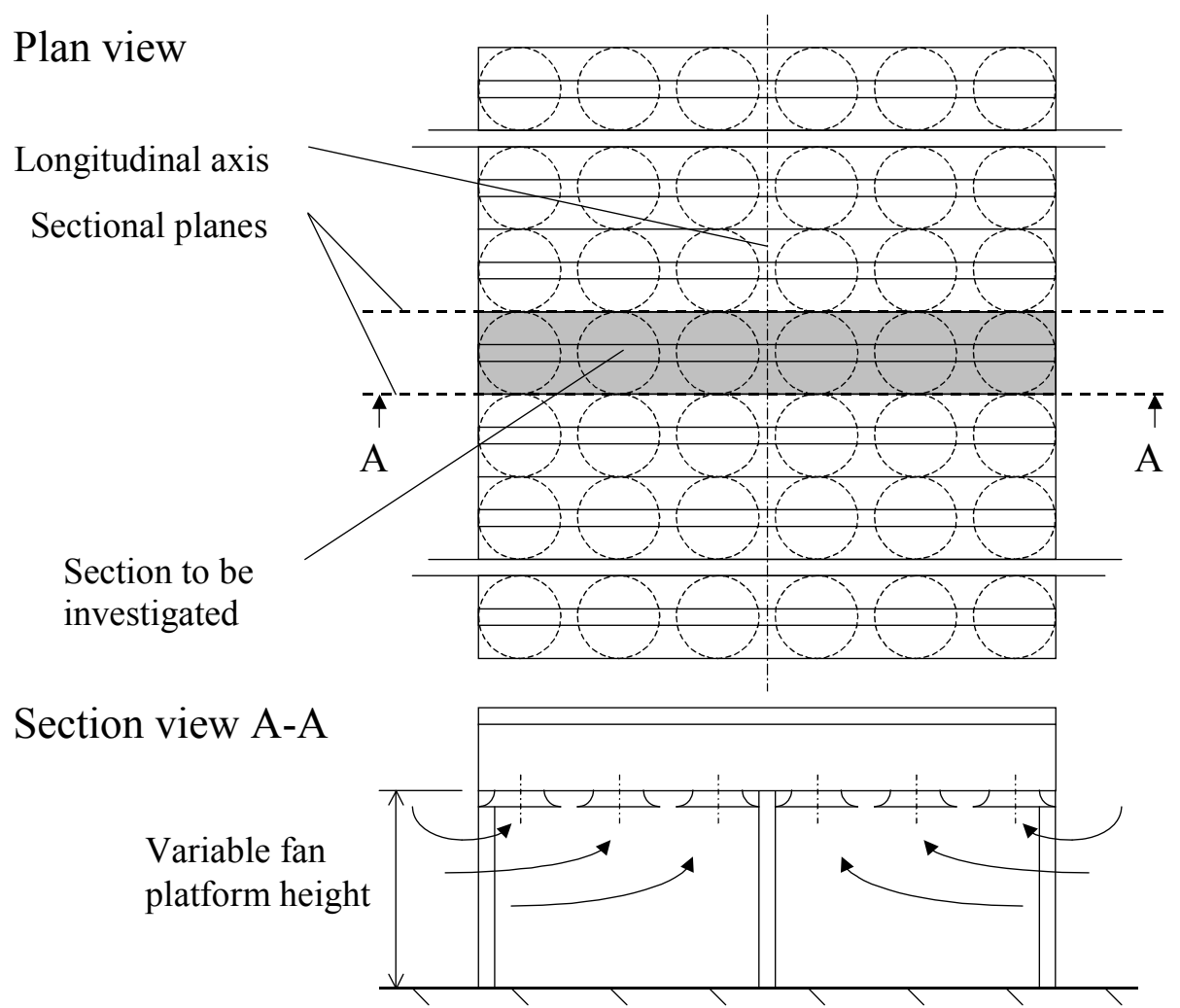

Figure 1.9: A long ACSC bank 
The section located near the centre of a long ACSC bank consists of six fan units, the specifications of which are given in Appendix A. Under windless conditions the assumption can be made that there is no flow across the sectional planes. The flow field at various platform heights, and corresponding levels of inlet flow distortion, is investigated.

The numerical investigation of the effect of inlet flow distortions and air maldistribution on the performance of multiple fans require a realistic, computationally inexpensive numerical fan model. An important part of this study is therefore the implementation and evaluation of a numerical fan model.

Two different rotor-only axial flow fans, schematically shown in figure 1.10, are investigated. The first fan, hereafter referred to as the A-fan, has the following main features: diameter $\mathrm{d}_{\mathrm{F}}=9.145 \mathrm{~m}$, number of fan blades $\mathrm{n}_{\mathrm{bl}}=8$, rotational speed $\mathrm{N}=125 \mathrm{rpm}$, hub-tip-ratio $\mathrm{d}_{\mathrm{h}} / \mathrm{d}_{\mathrm{F}}=0.153$ and a constant chord length of $\mathrm{c}=0.722 \mathrm{~m}$. Such fans are commonly used in general industrial cooling application.
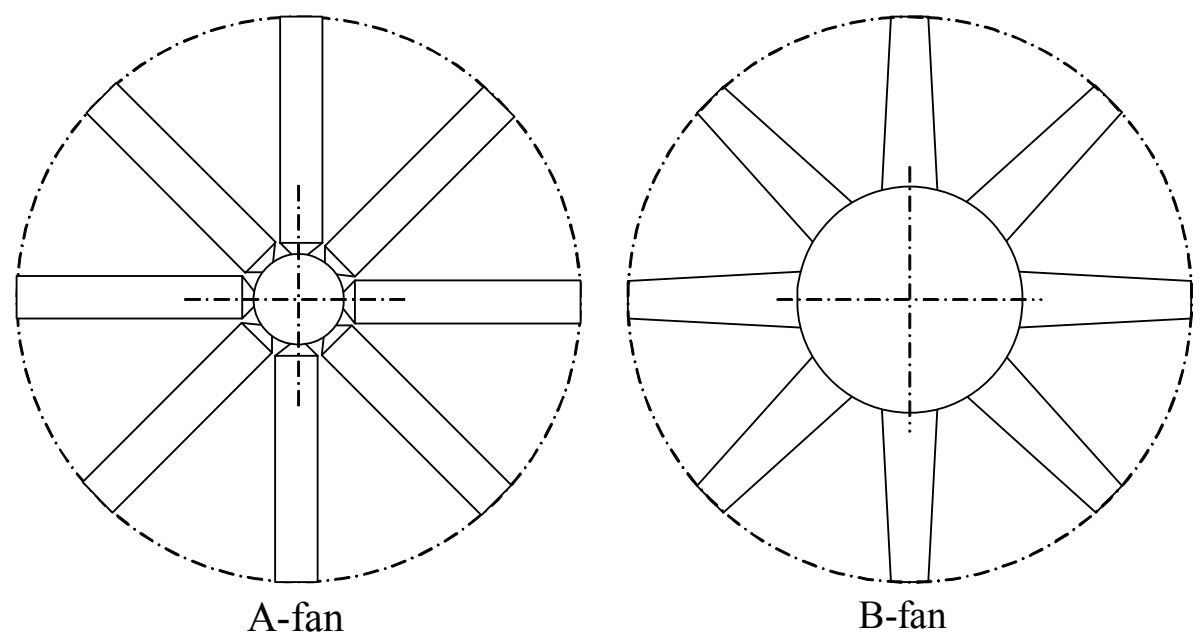

Figure 1.10: Two rotor-only axial flow fans in plan view

The second fan, hereafter referred to as the B-fan, has the same diameter, number of blades and rotational speed as the A-fan, but features an enlarged hub with a hub-tip-ratio of $\mathrm{d}_{\mathrm{h}} / \mathrm{d}_{\mathrm{F}}=0.4$ and a chord length decreasing linearly from $\mathrm{c}=1.072 \mathrm{~m}$ at the blade root to $\mathrm{c}=0.908 \mathrm{~m}$ at the blade tip. Bruneau [94BR1] designed the B-fan with the purpose of application in an existing ACSC. The original fan installation was of the low hub-tip-ratio type, similar to the A-fan. A characteristic of these low hub-tip-ratio type fans is the recirculation or reverse flow that occurs near the hub, as reported by van Aarde [90VA1] and 
Venter [90VE1]. In the design of the B-fan, the fan efficiency at the required volume flow rate and pressure rise, was improved by eliminating the reverse flow effect at the hub region by increasing the hub-tip-ratio and chord length. The consequences of different blade profiles were also considered. In order to prevent confusion, it must be stated that the B-fan in this study, refers to the B2-fan with the NASA GA(W)-2 blade profile in Bruneau [94BR1]. The fan blade geometry and performance characteristics for both fans are given in Appendix B.

Salta and Kröger [95SA1] report a measurable increase in the flow rate through the edge or peripheral fan with the addition of a walkway along the periphery of the ACHE bank. Similar modifications towards improving the fan inlet conditions are considered and evaluated.

In this study a simplified numerical model is used to qualitatively evaluate the fan performance (i.e. flow rate and fan shaft power) in a section of an ACSC subjected to various levels of inlet flow distortions. The main objectives of this study can be summarised as follows:

a) Numerically determining the performance characteristics of two different axial flow fans using a fan model.

b) Evaluation of the effect of cross-draft inlet flow distortions on the performance of fans in a section (or sector) of an ACSC.

c) Comparison of two different types of axial flow fans under distorted inlet flow conditions.

d) Evaluation of performance enhancing walkways and windscreens.

e) Determining whether or not an essentially two-dimensional modelling approach can be employed to realistically model a section (or sector) of an ACSC under cross-wind conditions. 


\subsection{Outline of this thesis}

Chapter 2 gives a detailed description of a typical fan unit in the ACSC being investigated. Emphasis is placed on the axial flow fans and the thermal-flow performance evaluation, i.e. energy and draft equation, applicable to the system.

Chapter 3 provides an in depth discussion of the numerical techniques employed. An overview of the finite volume CFD code is given, with reference to turbulence modelling and discritization schemes. The mathematical formulation of the numerical fan and heat exchanger models is provided.

Chapter 4 is the focus of the validation of the numerical models developed in the previous chapter. Results obtained from the numerical fan model in a free inlet, free outlet type configuration, are compared to experimental data. The combination of the fan and heat exchanger models are also tested in a single isolated fan unit model.

Chapter 5 presents the numerical modelling of a section of the ACSC consisting of six fan units at different platform heights under windless conditions. Various walkway and windscreen configurations, with the purpose of improving the performance of the fans, particularly the peripheral fan, are evaluated. Furthermore, a discussion regarding the validity of the essentially two-dimensional modelling approach to the system under consideration, is given.

Chapter 6 summarises the results of this study. Conclusions are drawn and recommendations are made for future research. 


\section{System description}

\subsection{System components}

The ACSC under consideration consists of an array of fan units as shown in figure 1.9. A schematic of a typical fan unit found along the edge of the ACSC platform, is shown in figure 2.1 .

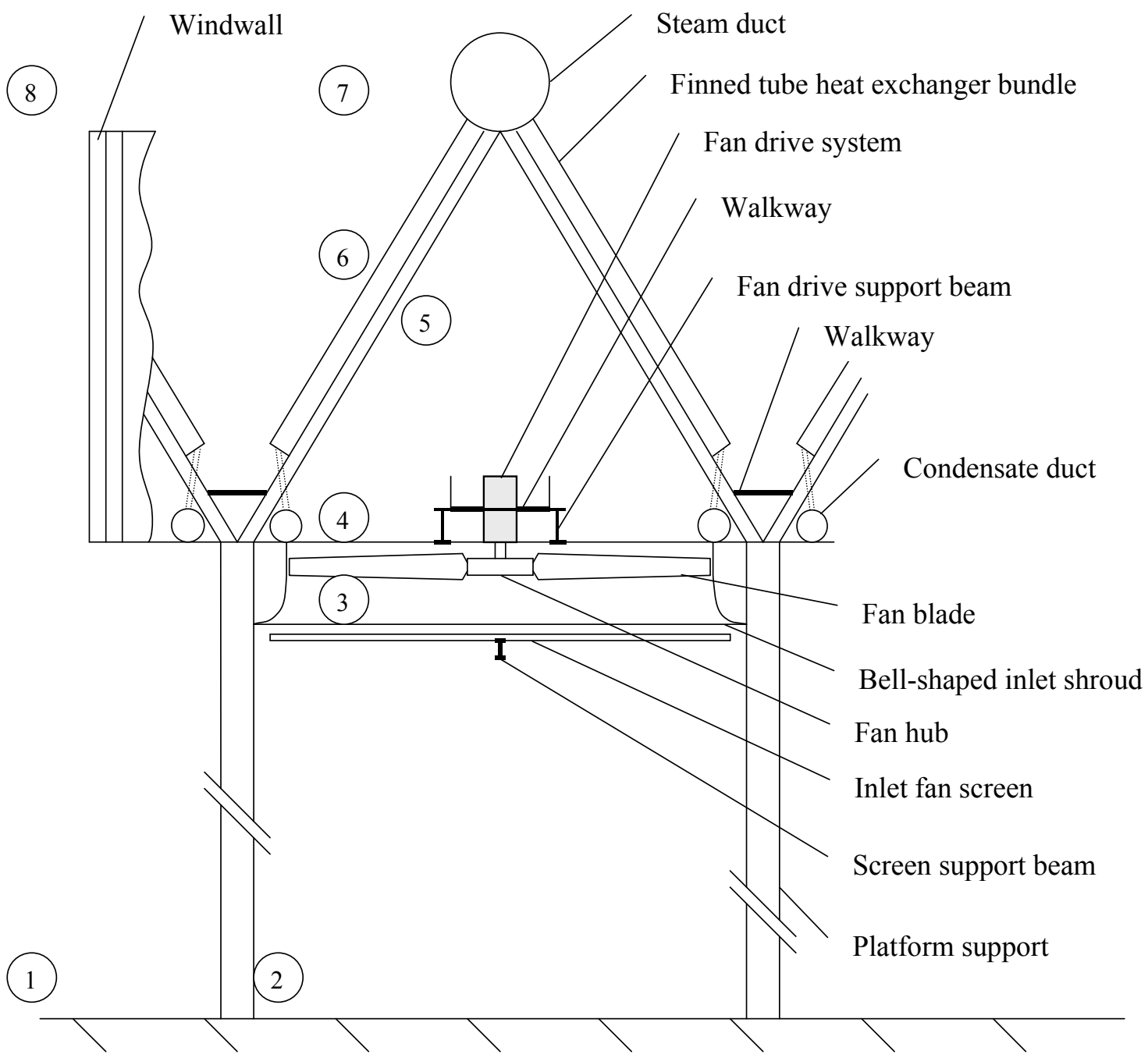

Figure 2.1: A fan unit in an ACSC array

Stagnant ambient air at (1) is accelerated towards the platform supports at (2). Air then flows up into the bell-shaped fan inlet at (3), through the fan, and enters the A-frame plenum at (4). 
The air is heated as it flows through the finned tube heat exchanger bundles between (5) and (6). The hot air then exits the system at (7). Windwalls along the edge or periphery of the ACSC reduce the amount of recirculation, thereby improving the performance of the system. Specifications of the system are given in Appendix A.

\subsection{Axial flow fans}

Axial flow fans are ideally suited for application in ACHEs and ACCs, where high volume flow rates at relatively low pressure rise are required. Figure 2.4 shows some of the fans used in industrial cooling applications. It can be seen that these fans differ significantly in size and construction. Cost, structural strength, material properties, and noise generation are some of the major considerations in fan selection.
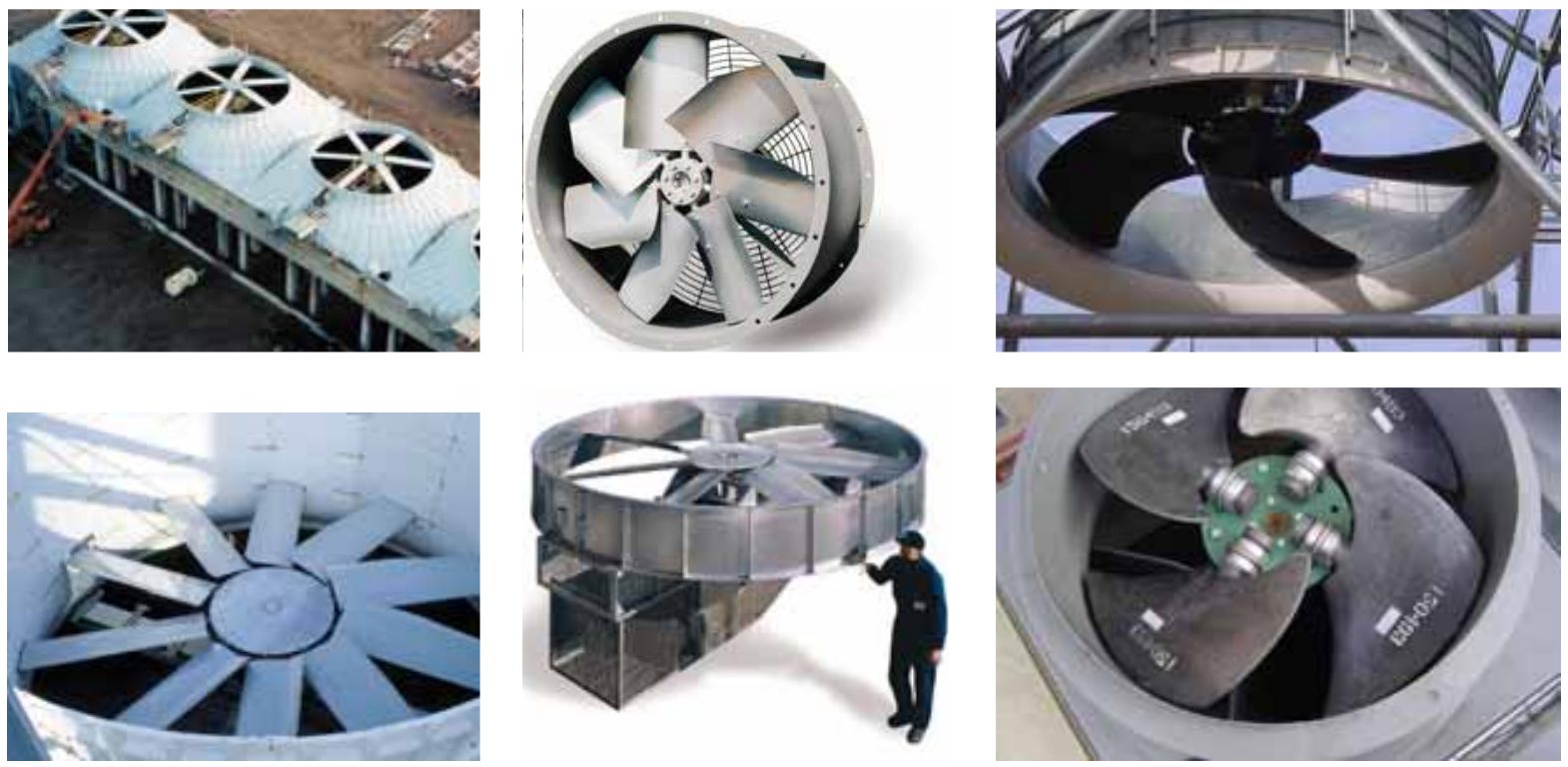

Figure 2.2: Industrial cooling fans (Courtesy Howden Cooling Fans and Cofimco)

Fan characteristics, i.e. pressure rise, fan shaft power and efficiency, are determined by one of many fan test codes or standards. Whether or not the fan test characteristics are an accurate representation of the fan performance in an actual installation, will depend on the ACC or ACHE geometry and operating conditions. 
Figure 2.5 shows a BS848 [97BS1] Type A fan test facility. Fans investigated in this study were tested according to this code. The test facility and calculation of the fan characteristics are therefore discussed in more detail.



Figure 2.3: BS848 [97BS1] Type A fan test facility

The mass flow rate, $\mathrm{m}_{\mathrm{T}}$, through the fan test facility is determined by measuring the relative static pressure just after the calibrated bell mouth inlet (1). The static pressure difference generated by the test fan, $\Delta \mathrm{p}_{\mathrm{sc}}$, is measured at the settling chamber inside wall (10), relative to atmospheric pressure. The air temperature, $\mathrm{T}_{\mathrm{a}}$, is also measured inside the settling chamber. According to the ideal gas equation, the fan test air density is

$\rho_{\mathrm{T}}=\frac{\left(\mathrm{p}_{\mathrm{a}}+\Delta \mathrm{p}_{\mathrm{sc}}\right)}{\mathrm{RT}_{\mathrm{a}}}$

The volume flow is therefore

$\mathrm{V}_{\mathrm{T}}=\frac{\mathrm{m}_{\mathrm{T}}}{\rho_{\mathrm{T}}}$ 
The dynamic pressure inside the settling chamber (8), is given by

$$
\mathrm{p}_{\mathrm{dT}}=\frac{1}{2 \rho_{\mathrm{T}}}\left(\frac{\mathrm{m}_{\mathrm{T}}}{\mathrm{A}_{\mathrm{sc}}}\right)^{2}
$$

Under these test conditions, the fan static pressure is defined as

$$
\Delta \mathrm{p}_{\mathrm{FsT}}=-\Delta \mathrm{p}_{\mathrm{sc}}-\Delta \mathrm{p}_{\mathrm{dT}}
$$

Furthermore the test fan rotational speed and shaft torque, denoted $\mathrm{N}_{\mathrm{T}}$ and $\mathrm{M}_{\mathrm{T}}$ respectively, are also measured. The fan shaft power is then given by

$$
\mathrm{P}_{\mathrm{FT}}=\frac{2 \pi \mathrm{N}_{\mathrm{T}} \mathrm{M}_{\mathrm{T}}}{60}
$$

where $\mathrm{N}_{\mathrm{T}}$ is in rpm. The fan static efficiency is then defined as

$$
\eta_{\mathrm{FsT}}=\frac{\mathrm{V}_{\mathrm{T}} \Delta \mathrm{p}_{\mathrm{FsT}}}{\mathrm{P}_{\mathrm{FT}}}
$$

It can be seen that the fan characteristics determined according to the aforementioned code, are determined for an isolated fan with ideal inlet conditions. Thus, it is important to take note of the following system effects in actual fan installations that may result in measurable deviation from the predicted fan performance:

a) In an actual fan installation, buildings, wind and other fans, may result in distorted inlet flow conditions, as shown in figure 1.7. As mentioned, these factors will usually cause a reduction in fan performance due to a combination of increased inlet flow losses and off-axis inlet flow conditions. Stinnes [98ST1] performed an experimental investigation on the performance of an axial fan subjected to a forced cross-flow component at the inlet. For a cross-flow ratio of 0.5 and 1 , he reports reductions in the pressure rise of $4 \%$ and $8 \%$, respectively. Stinnes and von Backström [02ST1] found 
that the decrease in fan static pressure was equal to the dynamic pressure corresponding to the cross-flow velocity component.

b) As seen in figure 2.5, air in the settling chamber moves through the test fan, and exits to the free atmosphere. In a forced draft ACHE or ACC, air is forced into a confined plenum chamber. In an experimental investigation on a range of ACHEs, Meyer and Kröger [98ME1] found that a fraction of the kinetic energy at fan outlet is recovered inside the plenum chamber. Neglecting this recovery effect, will result in a conservative prediction of the operating point. According to Kröger [04KR1] however, there is essentially no recovery in an A-frame plenum configuration.

c) Large fans ranging between $8 \mathrm{~m}$ and $11 \mathrm{~m}$ in diameter are often found in ACSC. For obvious reasons, it is impractical to test these fans in a standard test facility. The fan laws are therefore applied to data obtained from a geometrically similar model fan in order to predict the performance of the large fan. In a typical 1:6 scale model operating at the same tip speed as the full-scale fan, the Reynolds number based on the fan blade chord length may range between $6.8 \times 10^{4}$ and $4.5 \times 10^{5}$. In the fullscale model the corresponding Reynolds number will be six times higher, and range between $4.08 \times 10^{5}$ and $2.7 \times 10^{6}$. The lift and drag characteristics of the fan blade profiles are Reynolds number dependent. An increase in Reynolds number is generally associated with an increase in lift coefficient and a decrease in drag coefficient. The fan laws do not take into account the effect of Reynolds number variation. It can therefore be expected that the performance of a full-scale fan will differ from that predicted by the fan laws. In a numerical investigation Meyer and Kröger [04ME1] predict that the static pressure rise and fan power are respectively $3 \%$ and $4 \%$ higher than predicted by the fan laws.

The fan installation specifications, as well as the fan blade geometry and fan characteristics of the A-fan and B-fan, are given in Appendix B. For the effective interpretation of the fan characteristics and for further reference, a definition of the blade angle is required.

In order to provide a more uniform outlet velocity, the fan blades are designed with blade twist, i.e. the blade angle, $\gamma$, is a function of radius. In this study, if blade angle is measured between the plane of rotation and the chord line, it is denoted by $\gamma_{c}$. In practice however, the 
blade angle is sometimes referenced to the bottom surface of the fan blade profile in order to facilitate easier adjustment of the blade angle setting. In such a case the blade angle is denoted by $\gamma_{\mathrm{p}}$. These two angles are compared in figure 2.6. When $\gamma_{\mathrm{c}}$ or $\gamma_{\mathrm{p}}$ refers to a blade angle setting, a second subscript is added to indicate where the angle is measured, i.e. at the root or at the tip, respectively denoted by $r$ or t. E.g. $\gamma_{\mathrm{cr}}$, refers to a blade angle setting referenced to the chord line of a fan blade profile at the blade root.



Figure 2.4: Blade angle definition

\subsection{Thermal-flow analysis}

An ACSC is designed to condense a required amount of steam under prescribed design conditions. The first consideration in the thermal-flow design of such a system is the design of the heat exchangers so that it is capable of rejecting the required amount of heat to the environment. The second design consideration is the selection of an axial flow fan that will generate the required amount of air mass flow rate at, or near, maximum fan static efficiency. The rate of heat transfer to air is given by the energy equation, whereas the draft equation describes the pressure changes through the ACSC i.e. equates the pressure rise induced by the fan to the flow losses through the system. In the thermal-flow design or analysis of an ACSC these equations are inherently coupled and must be solved simultaneously. 


\subsubsection{Energy equation}

The heat transfer rate between the condensing steam and the cooling air flowing through a heat exchanger having $n_{r}$ finned tube rows, for a typical fan unit in a ACSC, is given by the following equation

$$
\mathrm{Q}=\sum_{\mathrm{i}=1}^{\mathrm{n}_{\mathrm{r}}} \mathrm{m}_{\mathrm{a}} \mathrm{c}_{\mathrm{pa}(\mathrm{i})}\left(\mathrm{T}_{\mathrm{ao}(\mathrm{i})}-\mathrm{T}_{\mathrm{a} i(\mathrm{i})}\right)=\sum_{\mathrm{i}=1}^{\mathrm{n}_{\mathrm{r}}} \mathrm{e}_{(\mathrm{i})} \mathrm{m}_{\mathrm{a}} \mathrm{c}_{\mathrm{pa}(\mathrm{i})}\left(\mathrm{T}_{\mathrm{s}}-\mathrm{T}_{\mathrm{a}(\mathrm{i})}\right)
$$

where $\mathrm{T}_{\mathrm{ai}(\mathrm{i})}, \mathrm{T}_{\mathrm{ao}(\mathrm{i})}$ and $\mathrm{T}_{\mathrm{s}}$ are the air inlet, air outlet and steam temperatures, respectively. The effectiveness, $\mathrm{e}_{(\mathrm{i})}$, of each row is given by

$$
\mathrm{e}_{(\mathrm{i})}=1-\exp \left(\frac{-\mathrm{UA}_{(\mathrm{i})}}{\mathrm{m}_{\mathrm{a}} \mathrm{c}_{\mathrm{pa}(\mathrm{i})}}\right)
$$

where $\mathrm{UA}_{(\mathrm{i})}$ is the overall heat transfer coefficient between the steam and the air. Due to the relatively low thermal resistance of the condensate film, $\mathrm{UA}_{(\mathrm{i})}$ is mainly dependent on the air side heat transfer characteristics of the finned tubes.

\subsubsection{Draft equation}

The air experiences mechanical energy losses as it moves through, or past, upstream and downstream obstacles and heat exchanger bundles. The pressure drop across these components are defined by means of a dimensionless loss coefficient given by equation (2.9)

$$
\mathrm{K}=\frac{\Delta \mathrm{p}}{\frac{1}{2} \rho \mathrm{v}^{2}}
$$

where $\Delta \mathrm{p}, \rho$ and $\mathrm{v}$ are the pressure drop, air density and characteristic velocity based on a prescribed cross-sectional area, respectively. 
If the vertical temperature and pressure gradients in the stagnant ambient air are neglected, the draft equation according to Kröger [04KR1] for an ACSC fan unit shown in figure 2.1, is given by

$$
\begin{aligned}
& \mathrm{p}_{\mathrm{a} 1}-\mathrm{p}_{\mathrm{a} 7} \approx 0=\mathrm{K}_{\mathrm{ts}} \frac{1}{2 \rho_{\mathrm{a} 1}}\left(\frac{\mathrm{m}_{\mathrm{a}}}{\mathrm{n}_{\mathrm{b}} \mathrm{A}_{\mathrm{fr}}}\right)^{2}+\mathrm{K}_{\mathrm{up}} \frac{1}{2 \rho_{\mathrm{a} 3}}\left(\frac{\mathrm{m}_{\mathrm{a}}}{\mathrm{A}_{\mathrm{e}}}\right)^{2}-\Delta \mathrm{p}_{\mathrm{Fs}}+\mathrm{K}_{\mathrm{do}} \frac{1}{2 \rho_{\mathrm{a} 3}}\left(\frac{\mathrm{m}_{\mathrm{a}}}{\mathrm{A}_{\mathrm{e}}}\right)^{2} \\
& +\mathrm{K}_{\theta \mathrm{t}} \frac{1}{2 \rho_{\mathrm{a} 56}}\left(\frac{\mathrm{m}_{\mathrm{a}}}{\mathrm{n}_{\mathrm{b}} \mathrm{A}_{\mathrm{fr}}}\right)^{2}
\end{aligned}
$$

where $\mathrm{K}_{\mathrm{ts}}, \mathrm{K}_{\text {up }}$ and $\mathrm{K}_{\mathrm{do}}$ are the loss coefficients for the platform supports, upstream obstacles and downstream obstacles, respectively. $\mathrm{K}_{\theta \mathrm{t}}$ is the total loss coefficient across the heat exchanger bundles and includes the kinetic energy losses at the outlet of the A-frame array. The total frontal area of the heat exchanger bundles is given by $n_{b} A_{f r}$, where $n_{b}$ and $A_{f r}$ are the number of bundles and frontal area of a single bundle, respectively. $A_{e}$ is the effective flow area through the fan, i.e. $\pi / 4\left(d_{c}^{2}-d_{h}{ }^{2}\right)$, where $d_{c}$ and $d_{h}$ is the fan casing and fan hub diameters, respectively. The $\Delta \mathrm{p}_{\mathrm{Fs}}$ term in equation (2.10) is the fan static pressure as determined by one of many fan test codes or standards. Fan characteristics determined for a free inlet, free outlet type of configuration (e.g. BS848 [97BS1] Type A), are used in the design of forced draft ACHEs and ACCs. 


\section{Numerical modelling}

\subsection{An overview of the CFD code}

In this study the commercially available CFD code, FLUENT, is used to investigate the flow field in a simplified model of an ACSC.

\subsubsection{Governing equations}

FLUENT numerically solves the finite volume based, steady-state differential equations for conservation of mass, momentum and energy, relevant to incompressible viscous fluids, as given in Versteeg and Malalasekera [95VE1]. The general transport equation for a field variable $\phi$ in a three-dimensional Cartesian coordinate system, is given by

$\frac{\partial}{\partial x}(\rho u \phi)+\frac{\partial}{\partial y}(\rho v \phi)+\frac{\partial}{\partial z}(\rho w \phi)=\frac{\partial}{\partial x}\left(\Gamma_{\phi} \frac{\partial \phi}{\partial x}\right)+\frac{\partial}{\partial y}\left(\Gamma_{\phi} \frac{\partial \phi}{\partial y}\right)+\frac{\partial}{\partial z}\left(\Gamma_{\phi} \frac{\partial \phi}{\partial z}\right)+S_{\phi}$

where $\mathrm{u}, \mathrm{v}$, and $\mathrm{w}$ are the velocities in the $\mathrm{x}, \mathrm{y}$ and $\mathrm{z}$ directions, respectively. Furthermore, the terms on the left hand side are the convection terms, and the first three terms on the right hand side, the diffusive terms.

Table 3.1: Conservation equations

\begin{tabular}{cccc}
\hline Equation & $\phi$ & $\Gamma_{\phi}$ & $\mathrm{S}_{\phi}$ \\
\hline Continuity & 1 & 0 & 0 \\
$\mathrm{x}$-momentum & $\mathrm{u}$ & $\mu_{\mathrm{e}}$ & $-\frac{\partial \mathrm{p}}{\partial \mathrm{x}}+\frac{\partial}{\partial \mathrm{x}}\left(\mu_{\mathrm{e}} \frac{\partial \mathrm{u}}{\partial \mathrm{x}}\right)+\frac{\partial}{\partial \mathrm{y}}\left(\mu_{\mathrm{e}} \frac{\partial \mathrm{v}}{\partial \mathrm{x}}\right)+\frac{\partial}{\partial \mathrm{z}}\left(\mu_{\mathrm{e}} \frac{\partial \mathrm{w}}{\partial \mathrm{x}}\right)+\mathrm{F}_{\mathrm{x}}$ \\
$\mathrm{y}$-momentum & $\mathrm{v}$ & $\mu_{\mathrm{e}}$ & $-\frac{\partial \mathrm{p}}{\partial \mathrm{y}}+\frac{\partial}{\partial \mathrm{x}}\left(\mu_{\mathrm{e}} \frac{\partial \mathrm{u}}{\partial \mathrm{y}}\right)+\frac{\partial}{\partial \mathrm{y}}\left(\mu_{\mathrm{e}} \frac{\partial \mathrm{v}}{\partial \mathrm{y}}\right)+\frac{\partial}{\partial \mathrm{z}}\left(\mu_{\mathrm{e}} \frac{\partial \mathrm{w}}{\partial \mathrm{y}}\right)+\mathrm{F}_{\mathrm{y}}$ \\
$\mathrm{z}-$-momentum & $\mathrm{w}$ & $\mu_{\mathrm{e}}$ & $-\frac{\partial \mathrm{p}}{\partial \mathrm{z}}+\frac{\partial}{\partial \mathrm{x}}\left(\mu_{\mathrm{e}} \frac{\partial \mathrm{u}}{\partial \mathrm{z}}\right)+\frac{\partial}{\partial \mathrm{y}}\left(\mu_{\mathrm{e}} \frac{\partial \mathrm{v}}{\partial \mathrm{z}}\right)+\frac{\partial}{\partial \mathrm{z}}\left(\mu_{\mathrm{e}} \frac{\partial \mathrm{w}}{\partial \mathrm{z}}\right)+\mathrm{F}_{\mathrm{z}}$ \\
Energy & $\mathrm{T}$ & $\mu_{\mathrm{e}} / \mathrm{Pr}$ & $\frac{1}{\mathrm{c}_{\mathrm{p}}}\left(\mathrm{u} \frac{\partial \mathrm{p}}{\partial \mathrm{x}}+\mathrm{v} \frac{\partial \mathrm{p}}{\partial \mathrm{y}} \mathrm{w} \frac{\partial \mathrm{p}}{\partial \mathrm{z}}+\mathrm{G}\right)+\mathrm{F}_{\mathrm{E}}$
\end{tabular}


The differential equations for continuity, x-momentum, y-momentum, z-momentum and energy can be obtained by substituting $\phi$ with $1, \mathrm{u}, \mathrm{v}, \mathrm{w}$ and $\mathrm{T}$ respectively, and assigning appropriate values to the diffusion coefficient, $\Gamma_{\phi}$, and source term $\mathrm{S}_{\phi}$, as shown in table 3.1.

In table $3.1 \mathrm{p}, \mathrm{T}, \mu_{\mathrm{e}}$ and $\mathrm{Pr}$ are the static pressure, temperature, effective viscosity and Prandtl number, respectively. $F_{x}, F_{y}$ and $F_{z}$ are external momentum source terms or body forces, such as gravity; e.g. for gravity in the $z$ direction $F_{x}=0, F_{y}=0$ and $F_{z}=\rho g$. These terms may also contain momentum sink or source terms, with the purpose of modelling devices such as flow resistances and fans. The production term $\mathrm{G}$ in the equation for energy is defined as follows:

$$
\mathrm{G}=\mu_{\mathrm{e}}\left\{2\left[\left(\frac{\partial \mathrm{u}}{\partial \mathrm{x}}\right)^{2}+\left(\frac{\partial \mathrm{v}}{\partial \mathrm{y}}\right)^{2}+\left(\frac{\partial \mathrm{w}}{\partial \mathrm{z}}\right)^{2}\right]+\left(\frac{\partial \mathrm{v}}{\partial \mathrm{x}}+\frac{\partial \mathrm{u}}{\partial \mathrm{y}}\right)^{2}+\left(\frac{\partial \mathrm{v}}{\partial \mathrm{z}}+\frac{\partial \mathrm{w}}{\partial \mathrm{y}}\right)^{2}+\left(\frac{\partial \mathrm{u}}{\partial \mathrm{z}}+\frac{\partial \mathrm{w}}{\partial \mathrm{x}}\right)^{2}\right\}
$$

These equations are integrated over each control volume or cell of a defined computational grid, and then discritized. The result is a set of implicit algebraic equations that can be solved numerically.

The SIMPLE algorithm discussed in Patankar [80PA1], for pressure correction and pressurevelocity coupling, augments the discritized governing equations.

\subsubsection{Turbulence model}

Turbulence is modelled using the $\mathrm{k}-\varepsilon$ model of Launder and Spalding [74LA1]. The semiempirical transport equations for the turbulent kinetic energy, $\mathrm{k}$, and its dissipation rate, $\varepsilon$, is obtained by adapting equation (3.1), as shown in table 3.2.

Table 3.2: Transport equations for $k-\varepsilon$ turbulence model

\begin{tabular}{cccc}
\hline Equation & $\phi$ & $\Gamma_{\phi}$ & $\mathrm{S}_{\phi}$ \\
\hline $\begin{array}{c}\text { Turbulent kinetic energy } \\
\text { Turbulent kinetic energy } \\
\text { dissipation rate }\end{array}$ & $\mathrm{k}$ & $\mu_{\mathrm{e}} / \sigma_{\mathrm{k}}$ & $\mathrm{G}-\rho \varepsilon$ \\
& $\varepsilon$ & $\mu_{\mathrm{e}} / \sigma_{\varepsilon}$ & $\frac{\varepsilon}{\mathrm{k}}\left(\mathrm{C}_{1} \mathrm{G}+\mathrm{C}_{2} \rho \varepsilon\right)$ \\
\hline
\end{tabular}


The effective viscosity, $\mu_{\mathrm{e}}$, is given by

$\mu_{\mathrm{e}}=\mu+\mu_{\mathrm{t}}$

where $\mu$ and $\mu_{\mathrm{t}}$ is the molecular viscosity and turbulent eddy viscosity, respectively,. The turbulent eddy viscosity is defined as

$\mu_{\mathrm{t}}=\mathrm{C}_{\mu} \rho \frac{\mathrm{k}^{2}}{\varepsilon}$

The constants in table 3.2 and equation 3.4 are given in table 3.3

Table 3.3: Constants for $\mathrm{k}-\varepsilon$ turbulence model

\begin{tabular}{ccccc}
\hline $\mathrm{C}_{\mu}$ & $\mathrm{C}_{1}$ & $\mathrm{C}_{2}$ & $\sigma_{\mathrm{k}}$ & $\sigma_{\varepsilon}$ \\
\hline 0.09 & 1.44 & 1.92 & 1 & 1.3 \\
\hline
\end{tabular}

\subsubsection{Boundary conditions}

The governing equations discussed in the previous two sections require boundary conditions in order to be solved numerically. Assigning appropriate boundary conditions and positioning domain boundaries are imperative in any CFD simulation. A discussion of the boundary conditions provided by FLUENT and used in this study are given below.

a) Velocity inlet boundary: This condition is used to specify the inlet velocity vector, as well as the temperature and turbulence parameters. The static pressure is not fixed, and is allowed to change to the appropriate value that will satisfy the specified inlet condition.

b) Pressure boundaries: This type of boundary condition allows for inflow and outflow across the boundary. For this boundary condition the static pressure, p, at the boundary plane, is specified. When outflow across the boundary occurs, field variables i.e. velocities, temperature and turbulence parameters, are extrapolated from interior cells. If however inflow occurs, the flow is assumed to be normal to the 
boundary. In this case the temperature and turbulence parameters need to be specified. This is referred to as a static pressure boundary.

FLUENT also allows the user to specify the relative (or gauge) total pressure at the boundary plane in cases where inflow occurs. This is referred to as a total pressure boundary. The relative static pressure, $\mathrm{p}$, in this case is then the difference between the specified total pressure, $p_{t o t}$, and dynamic pressure, as given in equation (3.5)

$\mathrm{p}=\mathrm{p}_{\text {tot }}-\mathrm{p}_{\mathrm{d}}=\mathrm{p}_{\mathrm{tot}}-\frac{1}{2} \rho \mathrm{v}_{\mathrm{i}}^{2}$

where $\mathrm{v}_{\mathrm{i}}$ is the inlet velocity at the boundary face.

c) Outlet boundary: Use of this boundary condition specifies a zero diffusion flux for all variables in a direction normal to the boundary face. This boundary condition is typically applied to developed flow where the cross-stream velocity profile is unchanging in the flow direction. Furthermore, an overall mass balance correction is applied.

d) Symmetry boundary: This boundary condition is used to model mirror planes, and assumes zero normal velocity and zero normal gradients for all other field variables. Flow across this boundary is therefore not allowed.

e) Wall boundaries: Solid surfaces are modelled using this boundary condition. The viscous shear stresses for turbulent flows in the near wall region are calculated by means of the law-of-the-wall, as proposed by Launder and Spalding [74LA1]. This is known as a zero-slip condition.

A slip-wall boundary condition can be obtained by specifying the surface shear stresses to be zero. Such a boundary is similar to a symmetry condition in the sense that is does not allow flow across the boundary, i.e. the normal velocity is zero. Zero gradients for other field variables will however not be enforced in the case of the slipwall condition. 


\subsubsection{Discritization schemes}

The convective terms in the governing equations are discritized using a specified differencing scheme [98FL1]. The first-order upwind differencing scheme is unconditionally bounded and will, according to Patankar [80PA1], always result in a physically realistic solution. Numerical diffusion is however a disadvantage which may affect the accuracy of the solution. Higher order accuracy can be obtained by using either the second-order upwind, or QUICK differencing schemes. The aforementioned schemes are however more unstable compared to the first-order scheme, and usually requires a finer computational grid for proper convergence.

\subsection{Numerical models}

In the numerical model of the ACSC fan unit, shown in figure 3.1, objects such as supports, inlet screens, beams, electrical fan drives and ducting were not modelled.

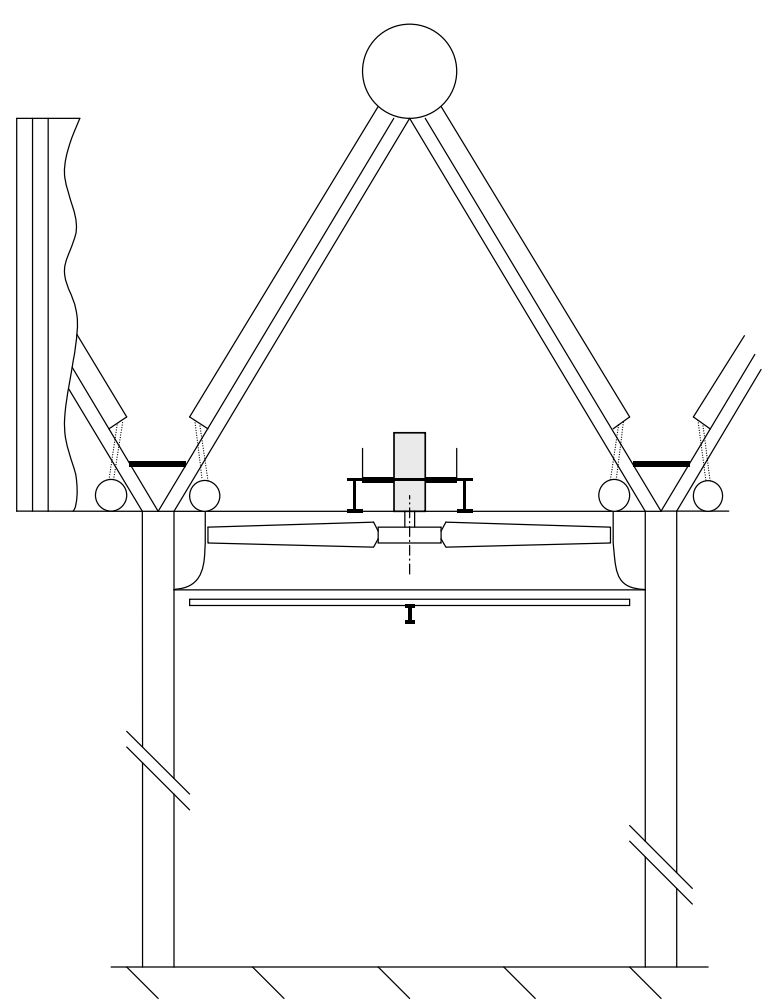

Actual ACSC fan unit

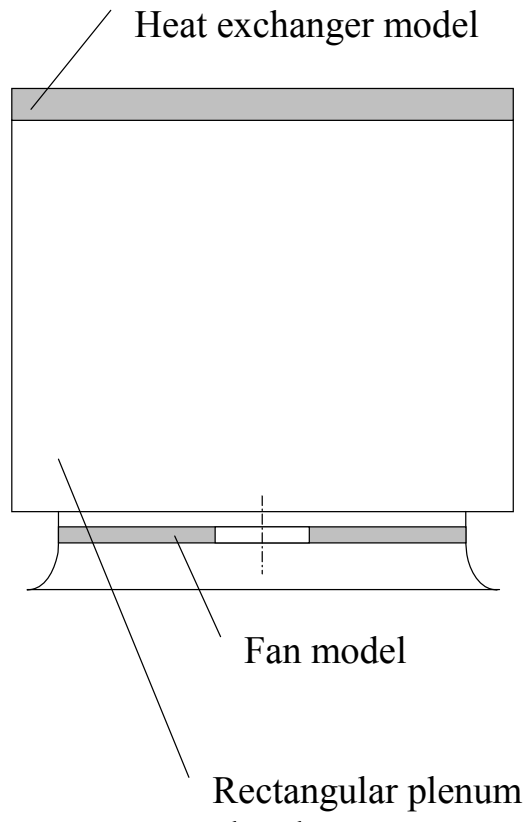

chamber

Figure 3.1: Simplified numerical model of an ACSC fan unit

The mechanical energy losses (or pressure drop) resulting from these obstacles were however taken into account in the heat exchanger model, which also includes heat exchanger and 
outlet losses. This simplification is justified, seeing that the purpose of this study is the investigation of fan performance, and not the detailed modelling of plenum chamber behaviour or outlet flow. Furthermore, the axial fan is simulated using a numerical fan model, which is discussed in more detail in section 3.2.2.

FLUENT allows the user to specify source terms, material properties and boundary conditions through what is known as user-defined-functions or UDFs. An UDF is computer code written in the $\mathrm{C}$ programming language that is capable of accessing data, such as field variables, material properties and cell centroid coordinates, from the solver. This information is then used to calculate function values, e.g. momentum source terms in a fan model, and return these values to the solver. UDFs were written for the two main components of the ACSC model, namely the heat exchanger and fan model. The mathematical modelling of these two models is discussed in more detail in subsequent sections.

\subsubsection{Heat exchanger model}

In the numerical heat exchanger model, losses in mechanical energy of the air due to the effective system resistance, as well as heat transfer to the air, are modelled. Based on the draft equation given in equation (2.10) the effective system resistance or pressure drop, $\Delta \mathrm{p}_{\mathrm{e}}$, for a single fan unit, is given by

$$
\begin{aligned}
\Delta \mathrm{p}_{\mathrm{e}}=- & -\left[\mathrm{K}_{\mathrm{ts}} \frac{1}{2 \rho_{\mathrm{a} 1}}\left(\frac{\mathrm{m}_{\mathrm{a}}}{\mathrm{n}_{\mathrm{b}} \mathrm{A}_{\mathrm{fr}}}\right)^{2}+\mathrm{K}_{\mathrm{up}} \frac{1}{2 \rho_{\mathrm{a} 3}}\left(\frac{\mathrm{m}_{\mathrm{a}}}{\mathrm{A}_{\mathrm{e}}}\right)^{2}+\mathrm{K}_{\mathrm{do}} \frac{1}{2 \rho_{\mathrm{a} 3}}\left(\frac{\mathrm{m}_{\mathrm{a}}}{\mathrm{A}_{\mathrm{e}}}\right)^{2}\right. \\
& \left.+\mathrm{K}_{\theta \mathrm{t}} \frac{1}{2 \rho_{\mathrm{a} 56}}\left(\frac{\mathrm{m}_{\mathrm{a}}}{\mathrm{n}_{\mathrm{b}} \mathrm{A}_{\mathrm{fr}}}\right)^{2}\right]
\end{aligned}
$$

It should be noted that the loss coefficients appearing in equation (3.6), and evaluated in Appendix A, are generally used in the one-dimensional thermal-flow performance evaluation of ACSCs [04KR1]. In the current investigation however, these coefficients are used to approximate the accumulative, or effective, system resistance in order to predict a realistic operating point for the numerical ACSC model. Concerning the critical evaluation of the loss coefficients, reference is made to Meyer [00ME1], who investigated plenum chamber aerodynamic behaviour. 
Numerically a flow resistance, or pressure drop, is modelled as momentum sink terms in the momentum conservation equations corresponding to the flow direction. FLUENT provides a porous media condition where these momentum sink terms are a function of velocity. For the numerical model shown in figure 3.2, these terms are given in table 3.4.



Figure 3.2: Heat exchanger model

Table 3.4: Momentum sink terms for heat exchanger model

\begin{tabular}{|c|c|c|}
\hline Direction & Body force & Momentum sink in $\mathrm{N} / \mathrm{m}$ \\
\hline $\mathrm{x}$ & $\mathrm{F}_{\mathrm{x}}$ & $-\left(\mathrm{C}_{\mathrm{x}} \frac{1}{2} \rho|\mathbf{v}| \mathrm{u}+\frac{\mu}{\alpha_{\mathrm{x}}} \mathrm{u}\right)$ \\
\hline $\mathrm{y}$ & $\mathrm{F}_{\mathrm{y}}$ & $-\left(\mathrm{C}_{\mathrm{y}} \frac{1}{2} \rho|\mathbf{v}| \mathrm{v}+\frac{\mu}{\alpha_{\mathrm{y}}} \mathrm{v}\right)$ \\
\hline $\mathrm{Z}$ & $\mathrm{F}_{\mathrm{z}}$ & $\left(\mathrm{C}_{\mathrm{z}} \frac{1}{2} \rho|\mathbf{v}| \mathrm{w}+\frac{\mu}{\alpha_{\mathrm{z}}} \mathrm{w}\right)$ \\
\hline
\end{tabular}

The momentum sink terms consist of two parts, namely the viscous resistance term and the inertial resistance term. Therefore, $1 / \alpha_{i}$ and $C_{i}$, are respectively the viscous and inertial loss coefficients. For the system under consideration $1 / \alpha_{z}$ and $C_{z}$, were determined in Appendix $C$ and found to be $1.897 \times 10^{6}$ and 59.136 , respectively. In order to restrict the discharge flow to the primary flow direction, the inertial loss coefficients in the $\mathrm{x}$ and $\mathrm{y}$ directions are specified to be a thousand times higher than $\mathrm{C}_{\mathrm{z}}$. 
Heat transfer to the air is modelled by calculating an energy source term, $F_{E}$ in $\mathrm{W} / \mathrm{m}^{3}$, based on equation (2.7). Details regarding the calculation of $\mathrm{F}_{\mathrm{E}}$ are given in Appendix $\mathrm{C}$.

\subsubsection{Numerical fan model}

The modelling of ACHEs and ACCs require a fan model in order to generate flow through the system. Various methods for the numerical modelling of axial fans are available. A discussion of these models with reference to the advantages and disadvantages of each model, as well as their practical implementation in a commercial CFD code, is given below:

a) Constant velocity fan model: Bender et al. [96BE1] conducted a numerical investigation on the wind-effects on the intake flow rate of an induced draft counter flow air-cooled heat exchanger. In the two-dimensional numerical model the axial fan was modelled by employing the active structure interior boundary method developed by Schreüder and du Plessis [90SC1]. In this model the fan is modelled by specifying the fan exit velocity corresponding to the desired volume flow rate through the fan. By decoupling the velocity pressure relationship, the velocity remains constant as the pressure correction is implemented. The model does not take into account any threedimensional flow, or turbulence effects.

b) Constant static pressure fan model: In this model a constant static pressure rise is induced by adding source terms to the axial direction momentum equation in the cells defining the axial flow fan. Under ideal inlet conditions this model will result in a constant outlet velocity profile. Furthermore, only an axial velocity component is induced by the pressure jump, therefore no swirl will be generated.

c) Varying static pressure fan model: Van Staden [00VA1] developed an axial fan model intended for the use in modelling the global flow field around a large ACSC. In this model the momentum source terms are calculated from the applicable fan static pressure characteristic curve. This results in an abrupt static pressure rise across the fan corresponding to the volumetric flow rate through the fan. The model is suitable for relatively coarse meshes and is therefore ideal for modelling a large number of axial fans. Once more, only an axial velocity component is produced by this model. 
d) Actuator disc model: Thiart and von Backström [93TH1] developed a numerical fan model for predicting the effect of distorted fan inlet conditions. This model solves the incompressible Navier-Stokes equations, together with the $\mathrm{k}-\varepsilon$ model for turbulence, and is based on the modelling approach followed by Pericleous and Patel [86PE1], who modelled the flow field inside a stirred reactor. In this model the effect of the axial flow fan is modelled by momentum source terms, which are calculated using blade element theory. This results in a realistic three-dimensional simulation of the air flow generated by an axial flow fan. Comparison of numerical and experimental results revealed that numerical predictions of distorted inflow effects on the performance of axial flow fans was good, considering the complexity of the problem. This model was also successfully employed and validated in numerous other numerical investigations: [90TH1], [96DU1], [96DU2], [00CO1], [00ME1], [04CO1], [04HO1], and [04ME1].

e) Full three-dimensional rotating mesh model: Modern CFD codes are capable of directly modelling axial fans and impellers. In this approach, the fan or impeller blades are modelled as solid rotating surfaces in the flow domain. A vector plot of such a model is shown in figure 3.3. It can be appreciated that a very fine mesh would be required to accurately capture flow effects around the blades. In some CFD codes blade deformation is also taken into account. Because this model is computationally extremely expensive, this approach is only suggested if detail of the flow between the blades is required.

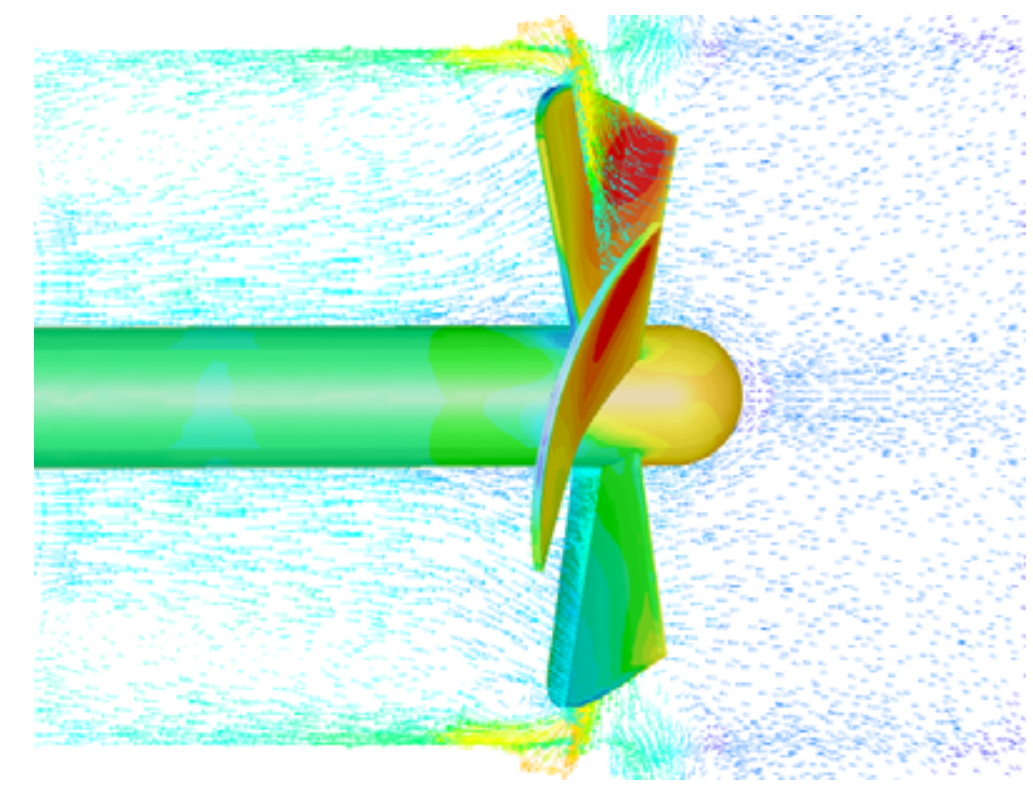

Figure 3.3: Vector plot for a three-dimensional rotating mesh fan model (Courtesy Fluent Inc.) 
Due to its relative computationally inexpensive nature and proven use, the actuator disc model was employed in the current investigation.

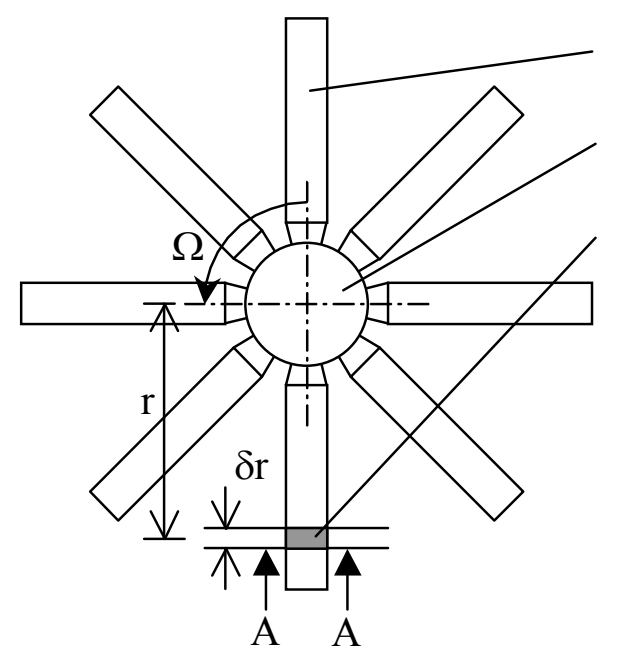

Plan view of axial fan

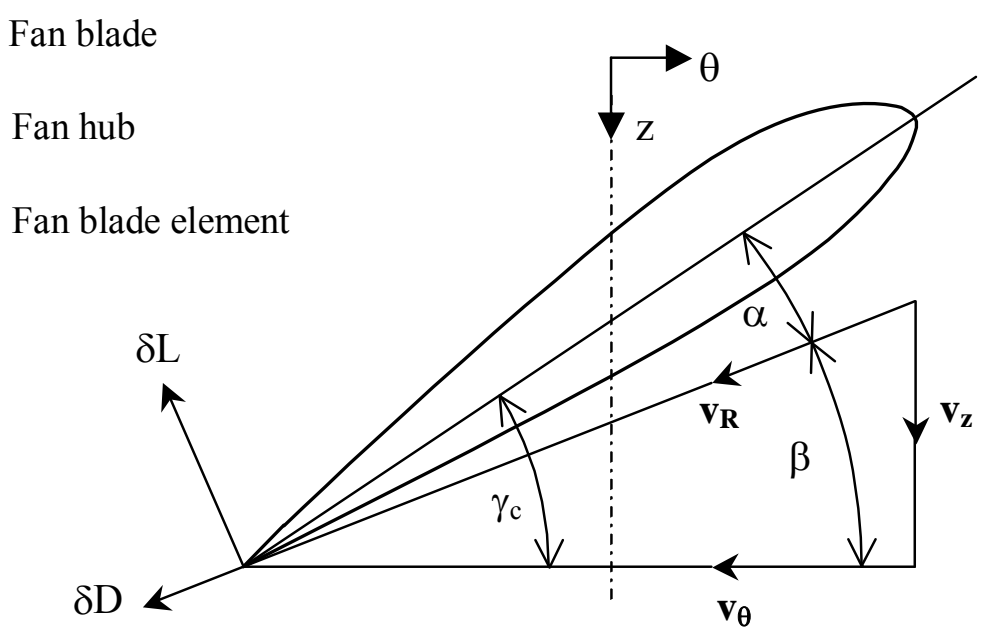

Enlarged sectional view A-A of fan blade element

Figure 3.4: Fan blade element

According to Wallis [80WA1] a radial fan blade element, as shown in figure 3.4, can be considered to be a two-dimensional airfoil section. Therefore, the lift and drag forces imparted on the fluid by the fan blade over a small span, $\delta$, are given by equation (3.7) and equation (3.8), respectively

$\delta \mathrm{L}=\frac{1}{2} \rho\left|\mathbf{v}_{\mathbf{R}}^{2}\right| \mathrm{C}_{\mathrm{L}} \mathrm{c} \delta \mathrm{r}$

and

$\delta \mathrm{D}=\frac{1}{2} \rho\left|\mathbf{v}_{\mathbf{R}}^{2}\right| \mathrm{C}_{\mathrm{D}} \mathrm{c} \delta \mathrm{r}$

where $\mathbf{v}_{\mathbf{R}}, \mathrm{C}_{\mathrm{L}}, \mathrm{C}_{\mathrm{D}}$, and $\mathrm{c}$ are the resultant relative air velocity, lift coefficient, drag coefficient and chord length respectively $\left(\mathrm{C}_{\mathrm{L}}, \mathrm{C}_{\mathrm{D}}\right.$, and $\mathrm{c}$ are defined in Appendix $\left.\mathrm{C}\right)$. 
The fan blade element exerts an equal but opposite force on the air. The axial and tangential components of this force can be written in terms of $\delta \mathrm{L}$ and $\delta \mathrm{D}$

$\delta f_{z}=\delta L \cos \beta-\delta \mathrm{D} \sin \beta$

and

$\delta f_{\theta}=\delta \operatorname{Lin} \beta+\delta D \cos \beta$

The numerical implementation of this model requires a computational grid in the form of a disc with radial and tangential increments, as shown in figure 3.5.
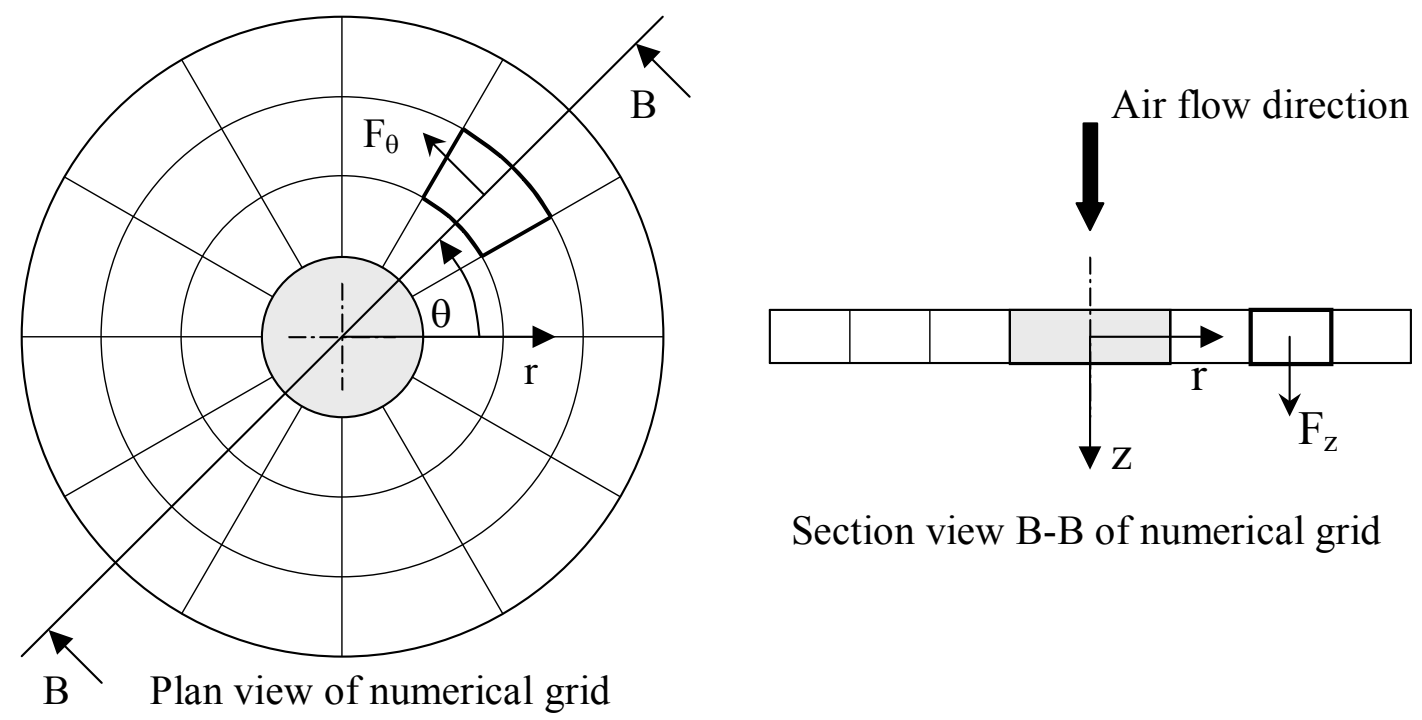

Section view B-B of numerical grid

Figure 3.5: Schematic of the computational grid for actuator disc model

The time averaged momentum source terms in the axial and tangential directions are given by

$\mathrm{F}_{\mathrm{z}}=\frac{\delta \mathrm{S}_{\mathrm{z}}}{\delta \mathrm{V}}=\frac{\sigma \delta \mathrm{S}_{\mathrm{z}}}{\mathrm{c} \delta \mathrm{rt}}$

and

$\mathrm{F}_{\theta}=\frac{\delta \mathrm{S}_{\theta}}{\delta \mathrm{V}}=\frac{\sigma \delta \mathrm{S}_{\theta}}{\mathrm{c} \delta \mathrm{rt}}$ 
where $\sigma$ and $\mathrm{t}$ denote the blade solidity and axial thickness of the fan rotor model, respectively. The blade solidity, serves as a time averaging factor, and is given by

$$
\sigma=\frac{\mathrm{n}_{\mathrm{b}} \mathrm{c}}{2 \pi \mathrm{r}}
$$

where $\mathrm{n}_{\mathrm{b}}$ is the number of blades.

By substituting equations (3.7) to (3.10) into equations (3.11) and (3.12), the final expressions for the momentum source terms are obtained

$$
\mathrm{F}_{\mathrm{z}}=\frac{1}{2} \rho\left|\mathbf{v}_{\mathbf{R}}^{2}\right| \frac{\sigma}{\mathrm{t}}\left(\mathrm{C}_{\mathrm{L}} \cos \beta-\mathrm{C}_{\mathrm{D}} \sin \beta\right)
$$

and

$$
\mathrm{F}_{\theta}=\frac{1}{2} \rho\left|\mathbf{v}_{\mathbf{R}}^{2}\right| \frac{\sigma}{\mathrm{t}}\left(\mathrm{C}_{\mathrm{L}} \cos \beta+\mathrm{C}_{\mathrm{D}} \sin \beta\right)
$$

The fan shaft torque and power are respectively given by equation (3.16) and equation (3.17),

$$
\mathrm{M}=\int_{\mathrm{V}} \mathrm{F}_{\theta} \mathrm{rdV}=\sum_{\mathrm{i}=1}^{\mathrm{n}} \mathrm{F}_{\theta(\mathrm{i})} \mathrm{r}_{(\mathrm{i})} \mathrm{dV}_{(\mathrm{i})}
$$

and

$$
\mathrm{P}_{\mathrm{F}}=\mathrm{M} \Omega
$$


In turbo machinery the convention is that the drag force on a blade element acts in a direction parallel to the mean relative velocity vector, as shown in the velocity diagram in figure 3.6.

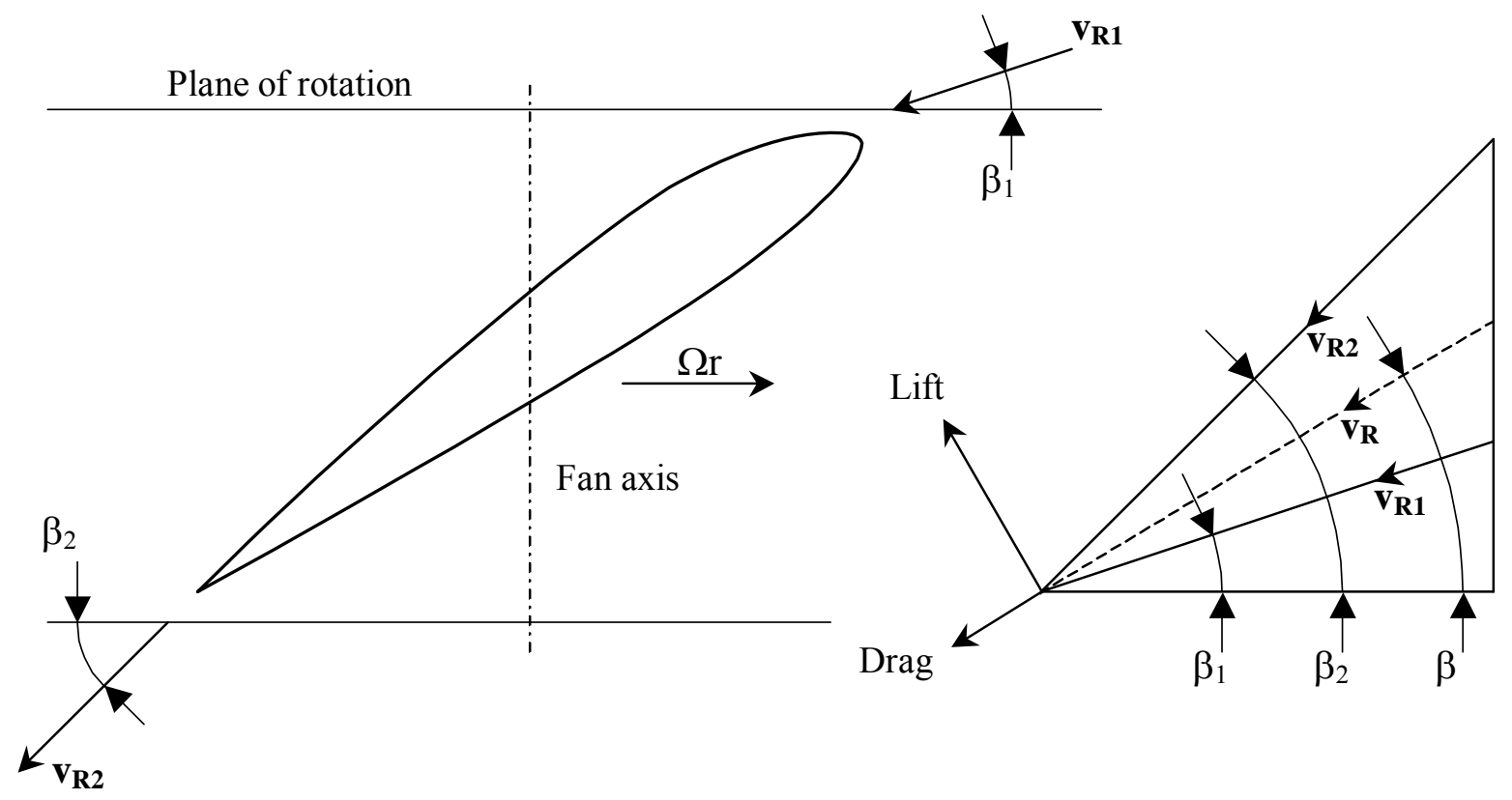

Figure 3.6: Velocity diagram of fan blade element

The relative velocity vector, $\mathbf{v}_{\mathbf{R}}$, in equations (3.14) and (3.15), is therefore the average between the upstream and downstream relative velocity vectors. In the actuator disc model, $\mathbf{v}_{\mathbf{R}}$ in each cell, is calculated by taking the average of the velocities in the corresponding upstream and downstream cells, as shown in figure 3.6.



Figure 3.7: Computational grid for actuator disc model 
With the method for the calculation of $\mathbf{v}_{\mathbf{R}}$ determined, it only remains to specify the lift and drag coefficients. The proposed blade element theory [80WA1] neglects the interference between fan blades, so that a fan blade element can be assumed to act alone in a free stream. Therefore, for the modelling of the low solidity fans investigated in this study, isolated blade profile or airfoil data is used.

With regards to the placement of the upstream and downstream discs in the flow domain, it was found that a distance of approximately half a chord length, respectively upstream and downstream of the actuator disc model, yielded best results with the use of isolated airfoil data.

In this study, both the A-fan and the B-fan was modelled using the actuator disc theory discussed above. The corresponding fan blade geometry (i.e. chord length and blade angle variation) and the fan blade profile characteristics (i.e. lift and drag coefficient data), required in the modelling, are respectively given in Appendix B and Appendix D. 


\section{Evaluation of numerical models}

\subsection{Evaluation of numerical fan model}

This section is concerned with the numerical testing and validation of the actuator disc model that was used to simulate the effect of an axial flow fan. The actuator disc model was implemented in a free inlet, free outlet type configuration in order to numerically predict fan performance, i.e. fan static pressure $\left(\Delta \mathrm{p}_{\mathrm{Fs}}\right)$, fan shaft power $\left(\mathrm{P}_{\mathrm{F}}\right)$, and fan static efficiency $\left(\eta_{\mathrm{Fs}}\right)$, for a range of flow rates. The numerically predicted fan characteristics are compared to data provider by the manufacturer in the case of the A-fan, and to experimental data measured by Stinnes [93ST1] in the case of the B-fan.

\subsubsection{Computational aspects}

The layout and dimensions of the computational grid used in determining the free inlet, free outlet fan characteristics are shown in figure 4.1. The flow was assumed to be isothermal, incompressible and time independent.

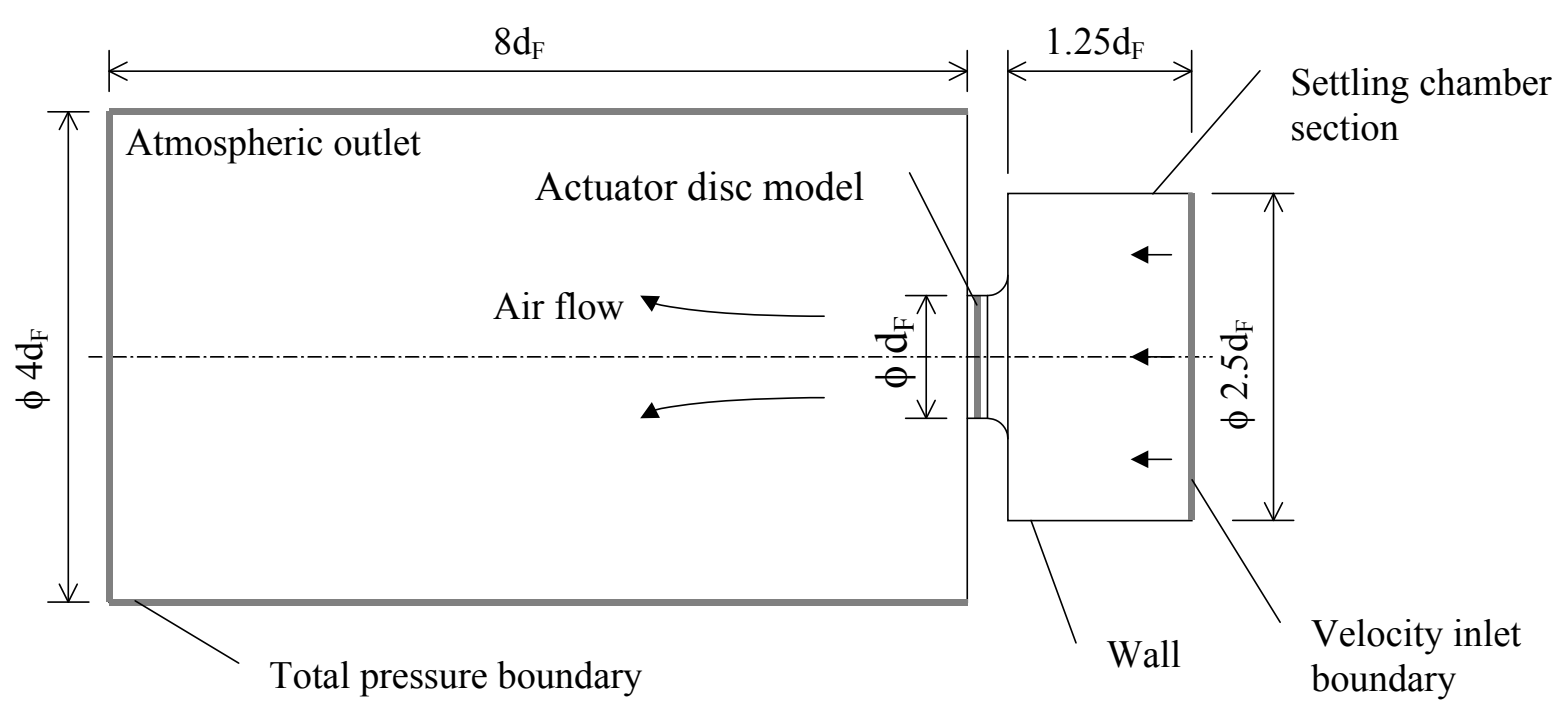

Figure 4.1: Geometrical layout of fan test model computational grid

The dimensions of the settling chamber section correspond to dimensions set out in BS848 [97BS1]. The computational grid consisting of 134000 cells is shown in figures 4.2 to 4.4 . 


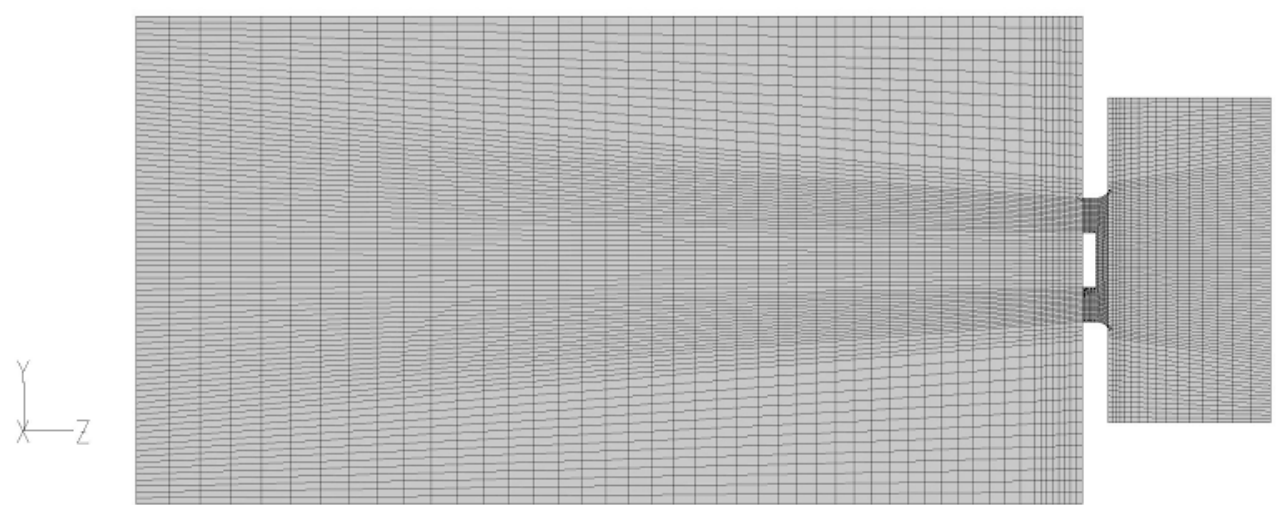

Figure 4.2: Section view of the computational grid for fan test model

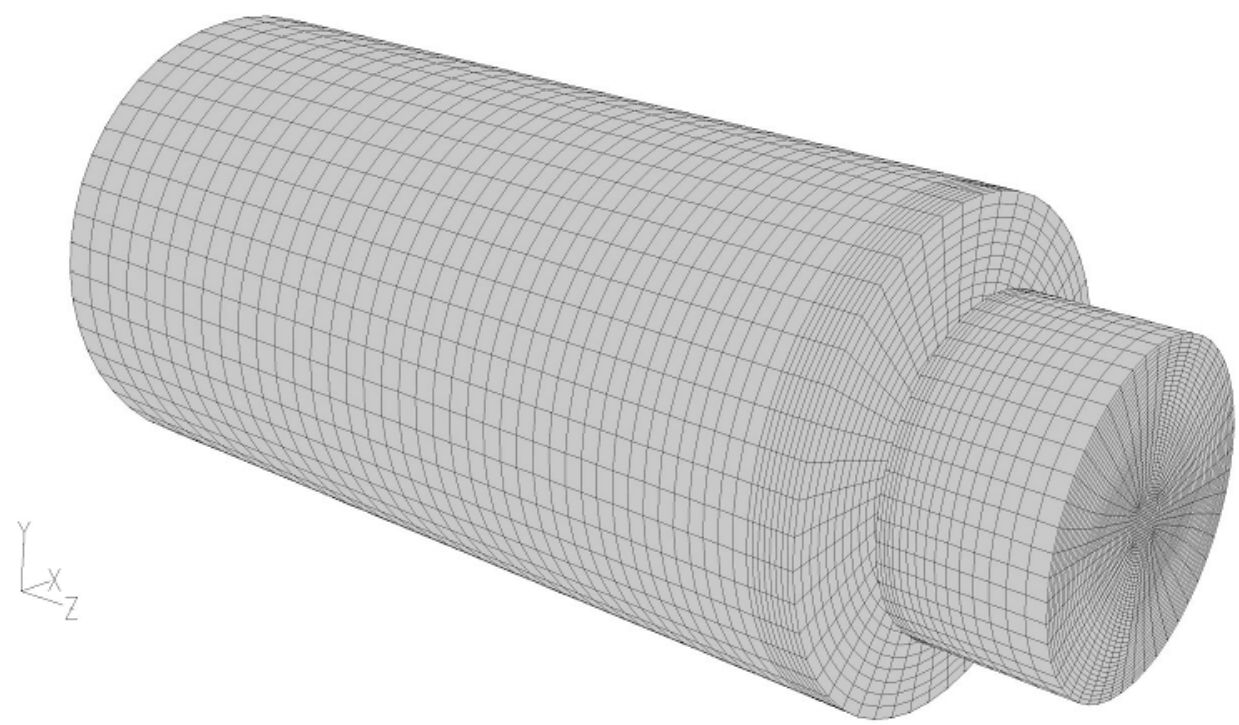

Figure 4.3: Isometric view of the computational grid for fan test model

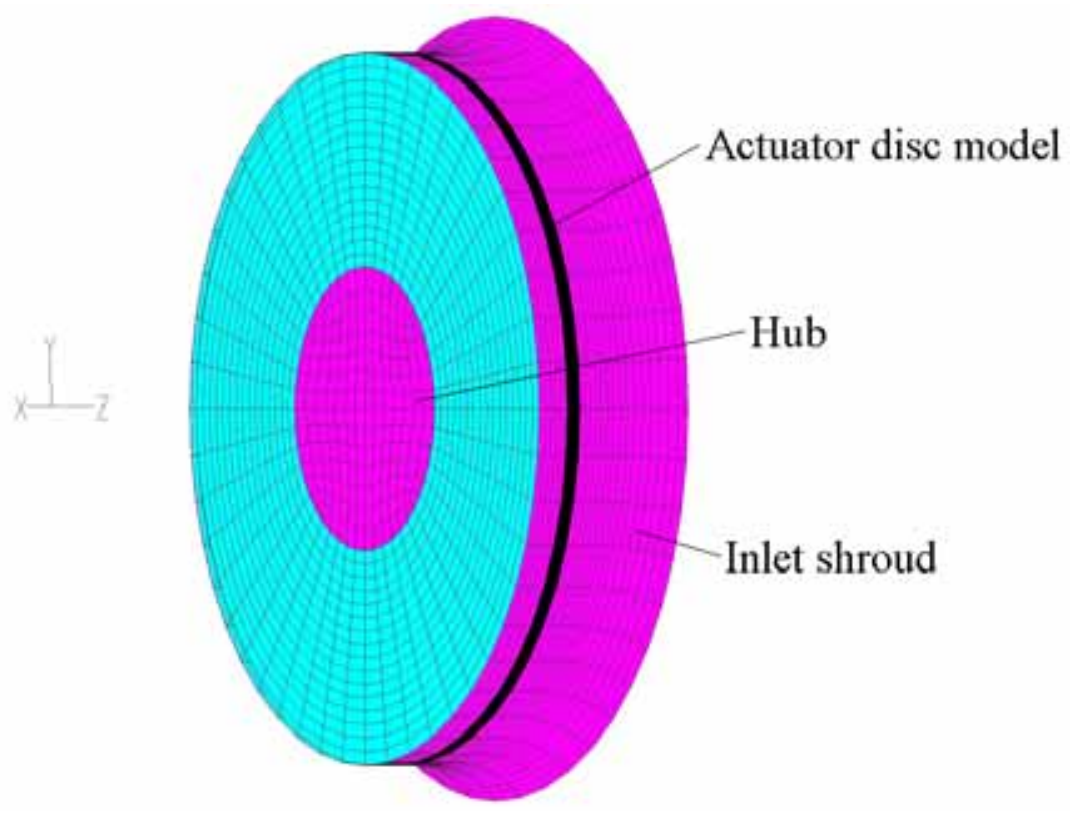

Figure 4.4: Detail view of the computational grid at the fan inlet 
The atmospheric outlet boundary, shown in figure 4.1, was modelled by specifying a total pressure boundary condition $\left(\mathrm{p}_{\mathrm{tot}}=0\right)$. The flow rate through the system was determined by specifying a uniform inlet velocity boundary condition at the inlet of the settling chamber section. By varying the inlet velocity the numerically predicted fan characteristics could be determined for a range of flow rates. The fan inlet shroud and hub was modelled as a zeroslip wall condition. The numerically predicted fan static pressure $\left(\Delta \mathrm{p}_{\mathrm{Fs}}\right)$ and fan shaft power $\left(\mathrm{P}_{\mathrm{F}}\right)$ for the A-fan $\left(\mathrm{d}_{\mathrm{F}}=9.145 \mathrm{~m}, \gamma_{\mathrm{pt}}=16^{\circ}\right)$ operating near maximum fan static efficiency, using the QUICK differencing scheme, varied by respectively $0.45 \%$ and $1.41 \%$ from the predictions of the corresponding simulation employing first order upwind differencing. For the purpose of this investigation the longer iteration times required by higher order differencing, was not justified, and the first-order upwind differencing scheme was used. The question of grid independence was addressed by comparing numerical results obtained using respectively a coarse (134000 cells, shown in figures 4.2 to 4.4$)$ and a fine (209000 cells, not shown) computational grid. It was found that the predicted fan static pressure $\left(\Delta \mathrm{p}_{\mathrm{Fs}}\right)$ and fan shaft power $\left(\mathrm{P}_{\mathrm{F}}\right)$ for the case stated above, differed by respectively $0.7 \%$ and $0.01 \%$. It was ascertained that the resolution of the computational grid containing 134000 cells was sufficient to resolve the flow field. Convergence of the mass flow rate to the sixth significant digit was established after approximately 800 iterations. A typical residual plot is shown in figure 4.5.

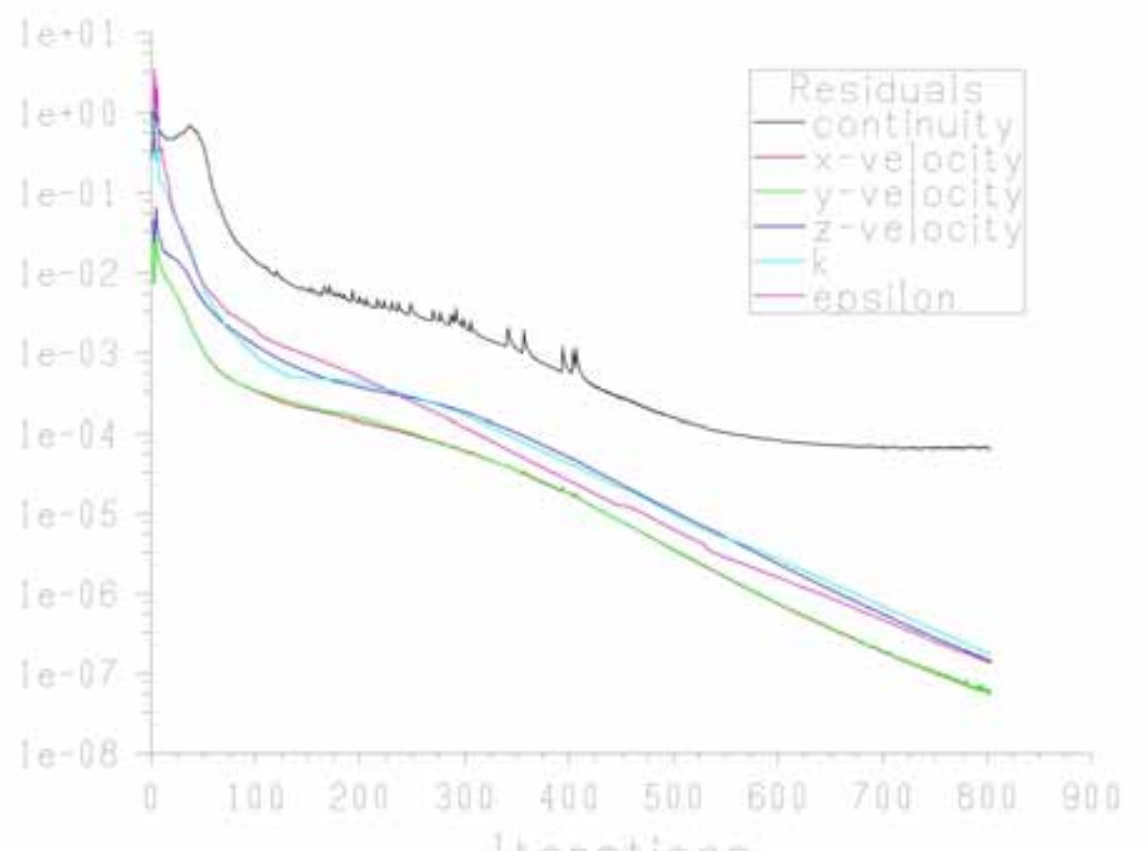

Figure 4.5: Typical residual plot 
Typical static pressure contour plots for the A-fan and B-fan models, operating at near maximum fan static efficiency, are shown in figure 4.6 and figure 4.7, respectively.

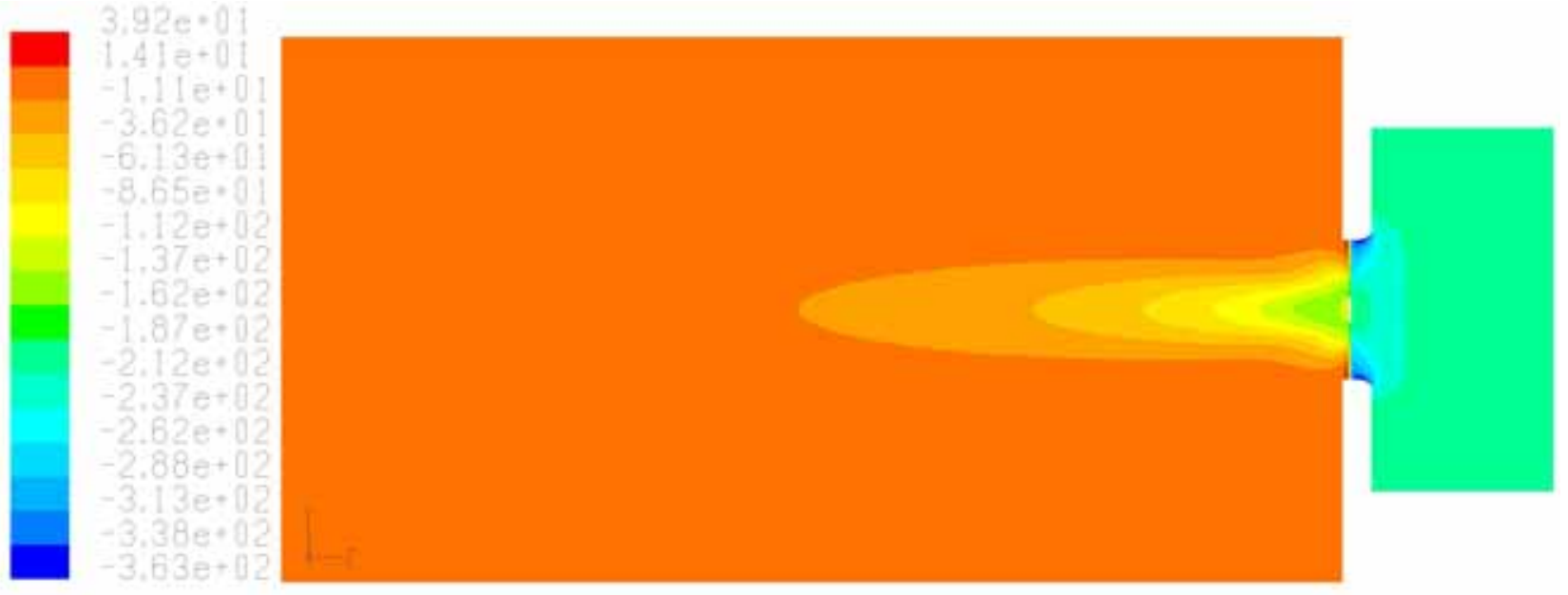

Figure 4.6: Static pressure (Pa) plot for A-fan numerical model $\left(\mathrm{d}_{\mathrm{F}}=9.145 \mathrm{~m}, \gamma_{\mathrm{pt}}=16^{\circ}\right)$
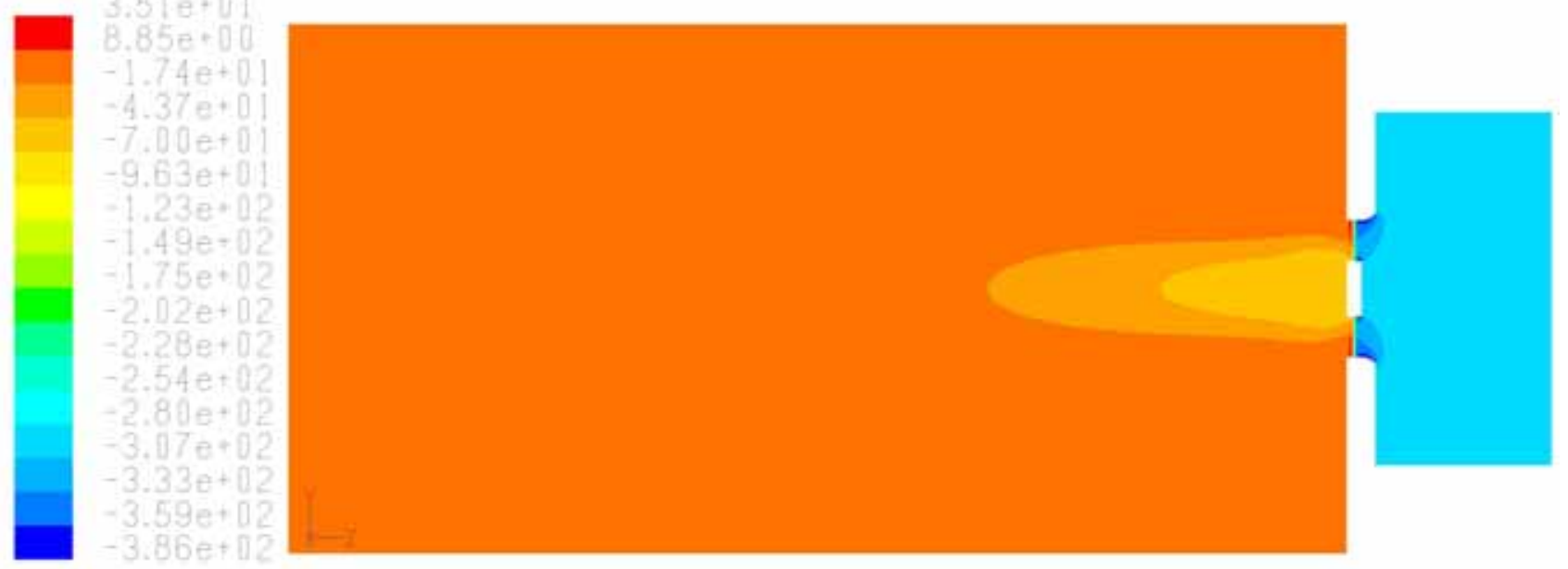

Figure 4.7: Static pressure $(\mathrm{Pa})$ plot for B-fan numerical model $\left(\mathrm{d}_{\mathrm{F}}=1.542 \mathrm{~m}, \gamma_{\mathrm{cr}}=31^{\circ}\right)$ 
The corresponding vector plots of the flow field through the fan models are shown in figure 4.8 and figure 4.9.



Figure 4.8: Vector plot for A-fan numerical model $\left(\mathrm{d}_{\mathrm{F}}=9.145 \mathrm{~m}, \gamma_{\mathrm{pt}}=16^{\circ}\right)$

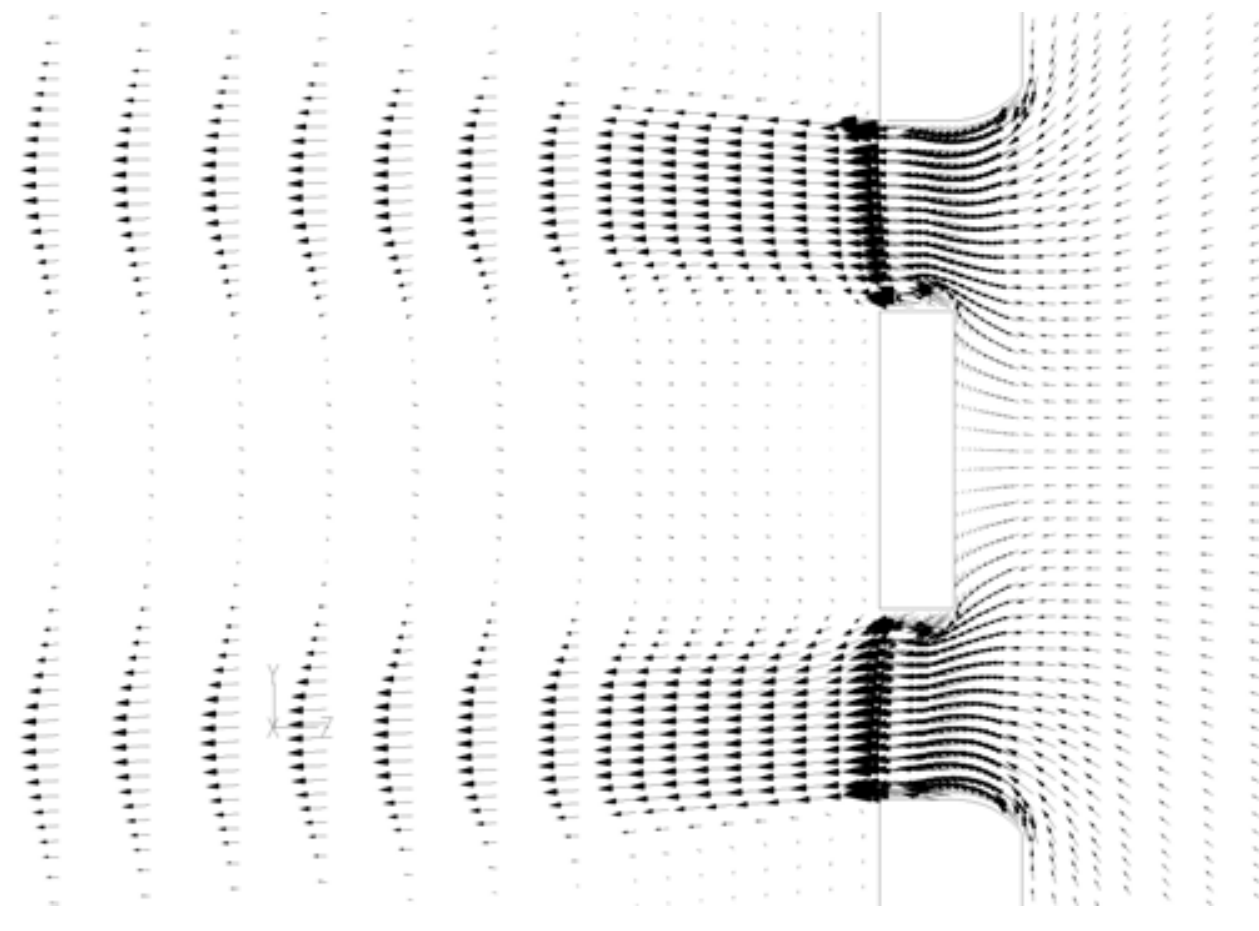

Figure 4.9: Vector plot for B-fan numerical model $\left(\mathrm{d}_{\mathrm{F}}=1.542 \mathrm{~m}, \gamma_{\mathrm{cr}}=31^{\circ}\right)$ 


\subsubsection{Numerically predicted fan characteristics: A-fan}

Numerically determined fan static pressure, fan shaft power and fan static efficiency for the A-fan, are compared to data provided by the manufacturer (given in Appendix B), in figures 4.10 to 4.12 , respectively.

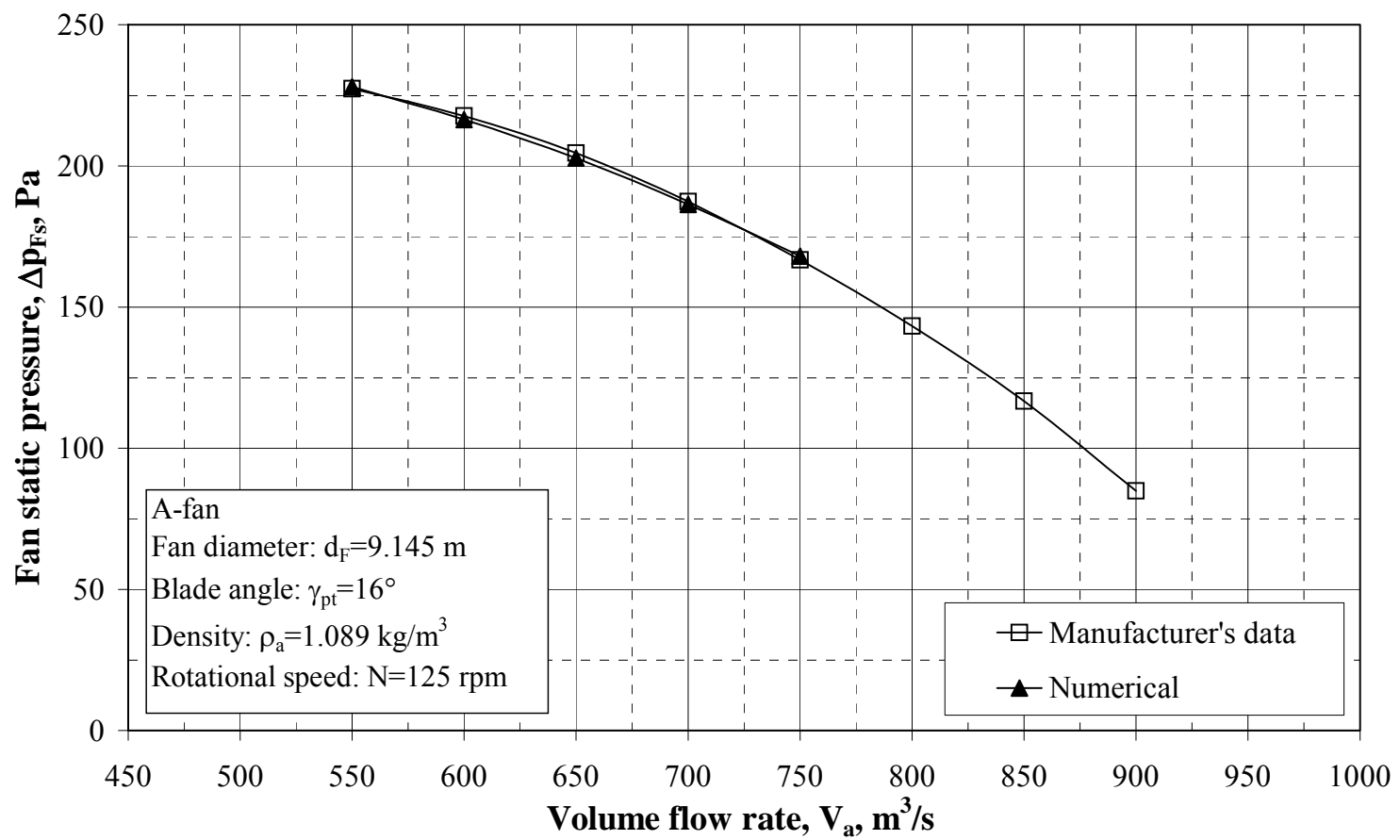

Figure 4.10: Fan static pressure for $A-f a n\left(d_{F}=9.145 \mathrm{~m}, \gamma_{\mathrm{pt}}=16^{\circ}\right)$



Figure 4.11: Fan shaft power for A-fan $\left(d_{\mathrm{F}}=9.145 \mathrm{~m}, \gamma_{\mathrm{pt}}=16^{\circ}\right)$ 




Figure 4.12: Fan static efficiency for $A-f a n\left(d_{F}=9.145 \mathrm{~m}, \gamma_{\mathrm{pt}}=16^{\circ}\right)$

\subsubsection{Numerically predicted fan characteristics: B-fan}

Numerically determined fan static pressure, fan shaft power and fan static efficiency for the B-fan, are compared to the experimental data measured by Stinnes [98ST1] (given in Appendix B), in figures 4.13 to 4.15 .

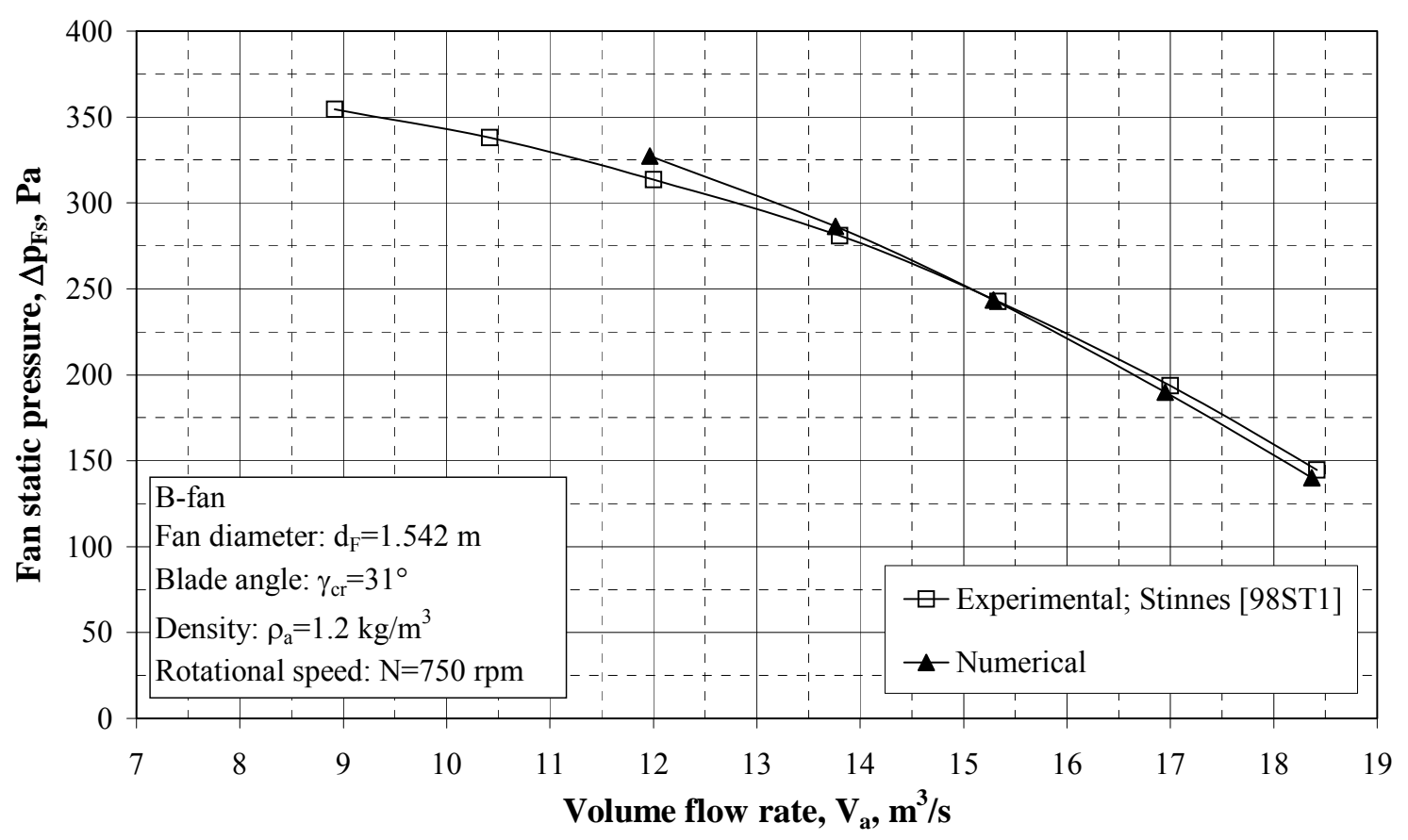

Figure 4.13: Fan static pressure for $B-f a n\left(d_{F}=1.542 \mathrm{~m}, \gamma_{c r}=31^{\circ}\right)$ 


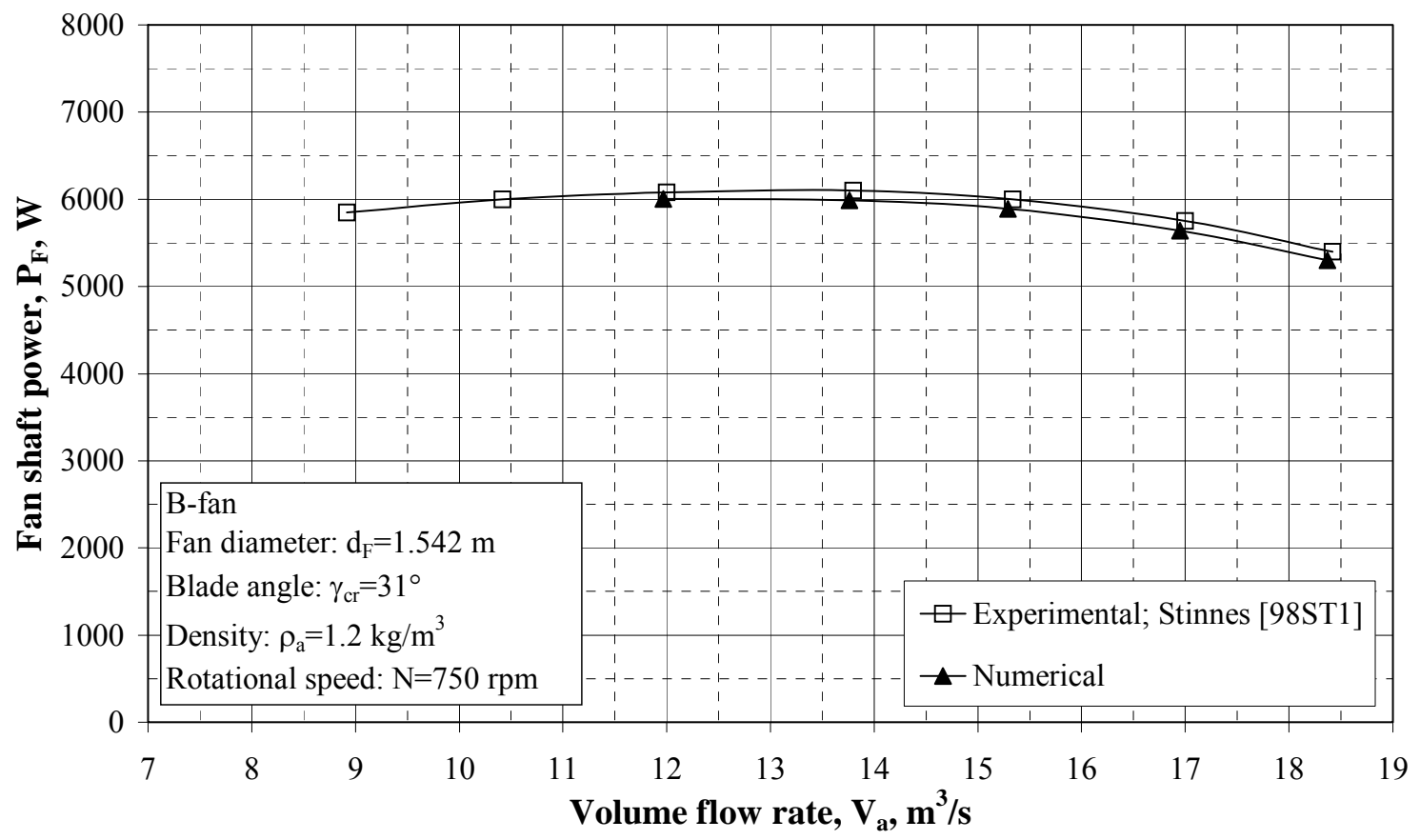

Figure 4.14: Fan shaft power for $B-f a n\left(d_{F}=1.542 \mathrm{~m}, \gamma_{c r}=31^{\circ}\right)$

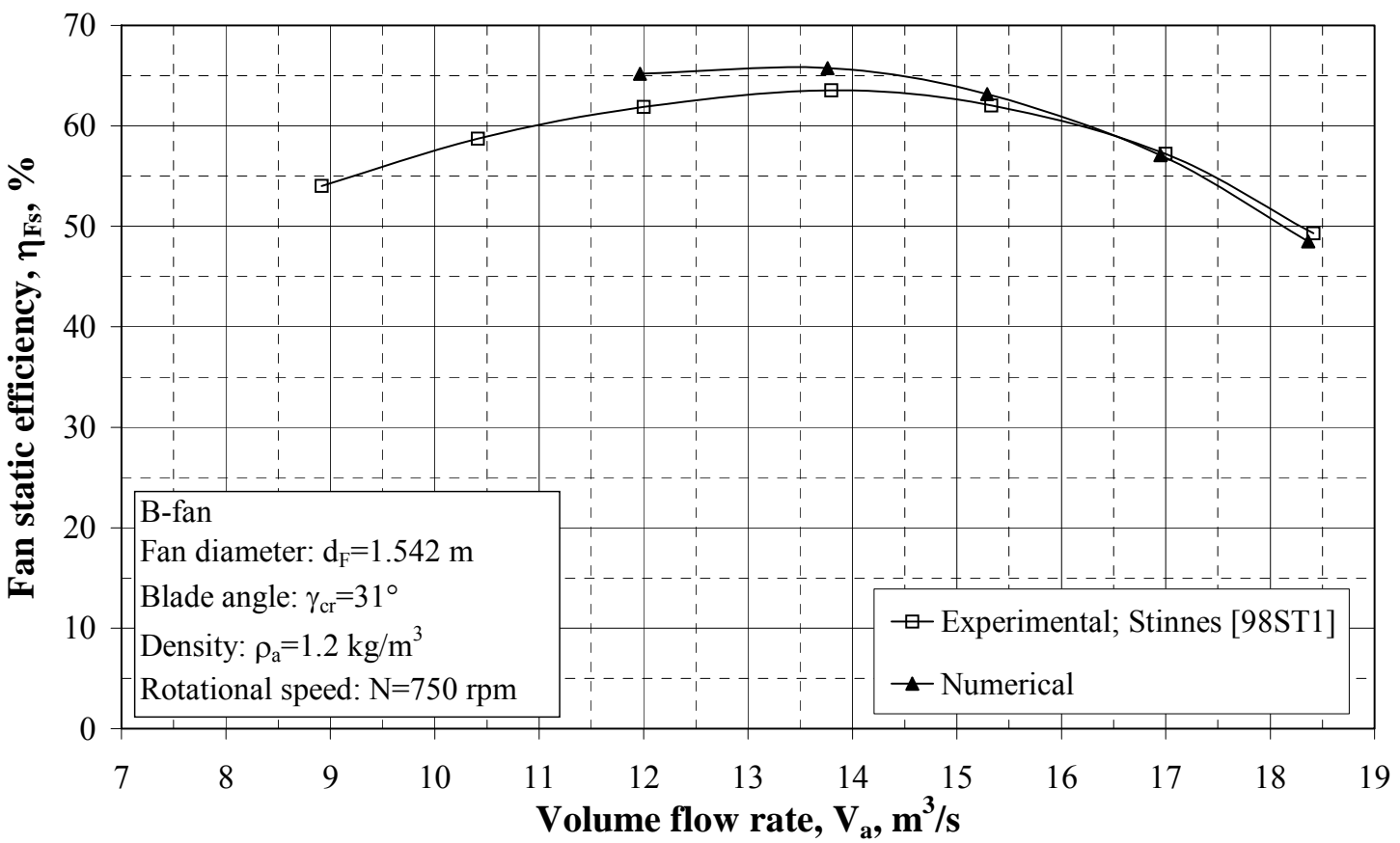

Figure 4.15: Fan static efficiency for $B-f a n\left(d_{F}=1.542 \mathrm{~m}, \gamma_{\mathrm{cr}}=31^{\circ}\right)$ 


\subsection{Evaluation of a freestanding fan unit}

In this section the combination of the numerical fan and heat exchanger models is evaluated in a single freestanding fan unit model. For the ACSC under consideration, a typical blade angle setting for the commercially available A-fan, is $\gamma_{\mathrm{pt}}=16^{\circ}$. In further numerical modelling of the A-fan, this particular blade angle setting is used. The expected operating point of the fan unit model can be found where the effective system resistance curve, defined by equation (3.6), intersects the appropriate fan static pressure curve, as shown in figure 4.16. In order to compare the performance of the prototype B-fan to the A-fan, both fans are required to have the same diameter and operating point. By numerically modelling the B-fan with a diameter of $\mathrm{d}_{\mathrm{F}}=9.145 \mathrm{~m}$, it was found that a blade angle setting of $\gamma_{\mathrm{cr}}=34.5^{\circ}$ resulted in approximately the same operating point being obtained as in the case of the A-fan with $\gamma_{\mathrm{pt}}=16^{\circ}$, as shown in figure 4.16.

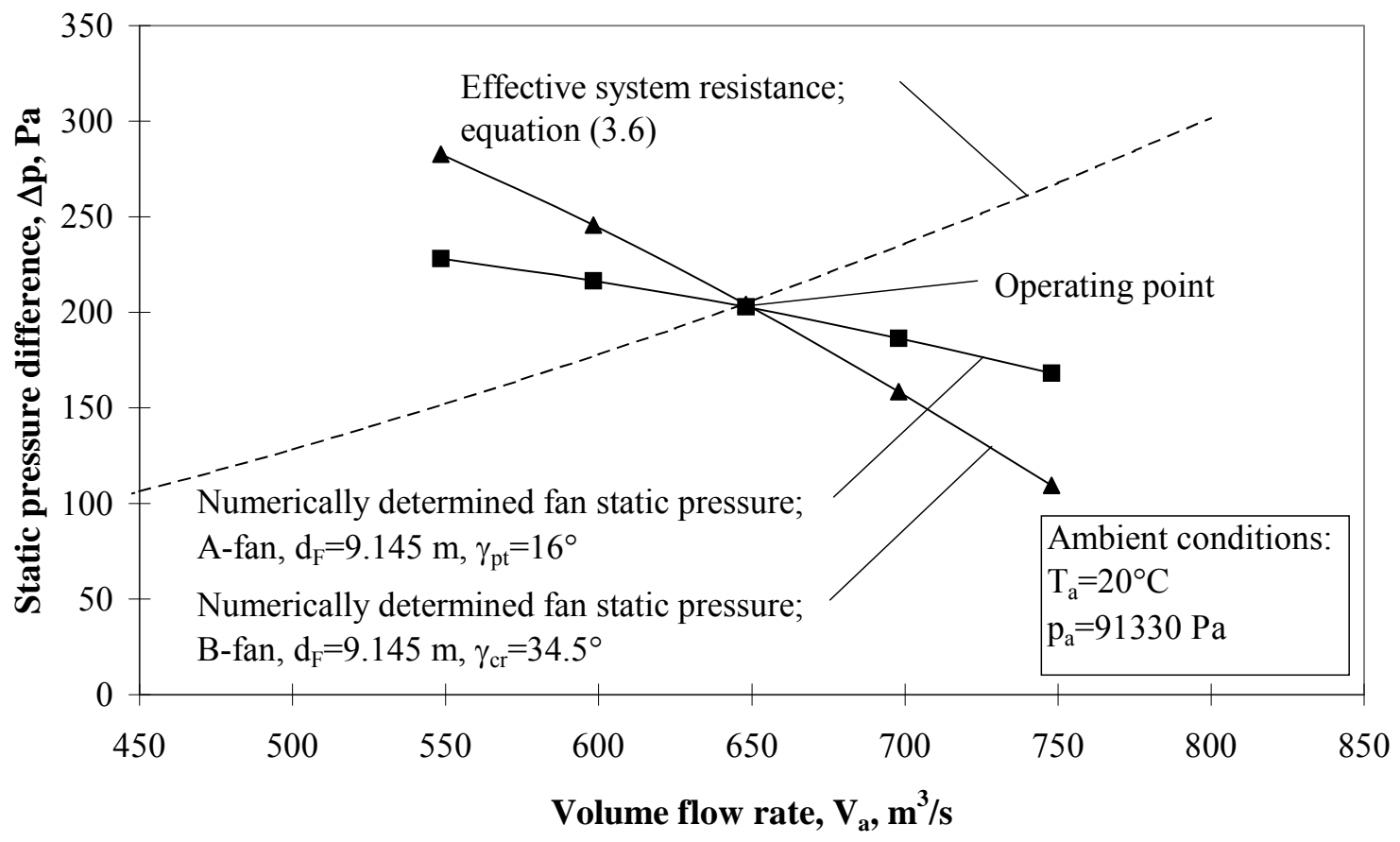

Figure 4.16: Operating point for the numerical ACSC fan unit model 


\subsubsection{Computational aspects}

The geometric layout of the computational grid used to model a freestanding fan unit is shown in figure 4.17.

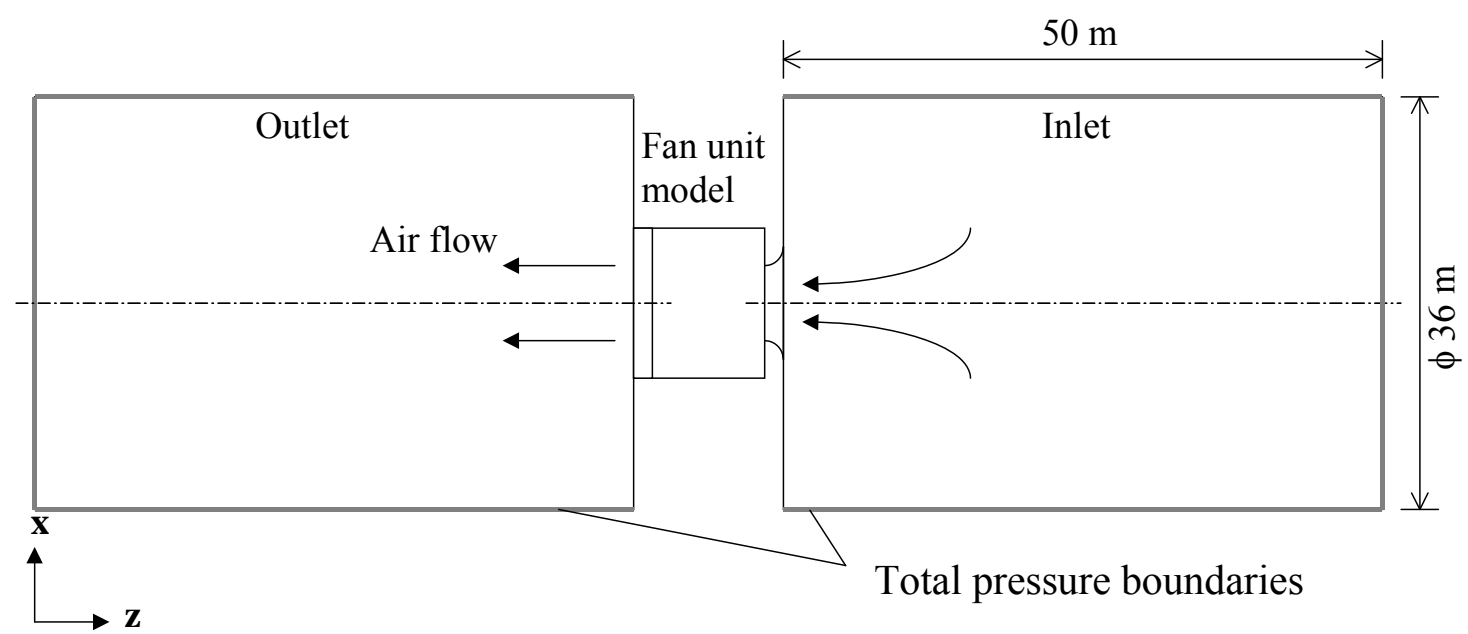

Figure 4.17: Geometrical layout of the computational grid used to evaluate the ACSC fan unit model

The geometry of the fan unit model, shown in figure 4.18, is based on the dimensions of the actual ACSC given in Appendix A. Dimensions of the inlet shroud are given in Appendix B.
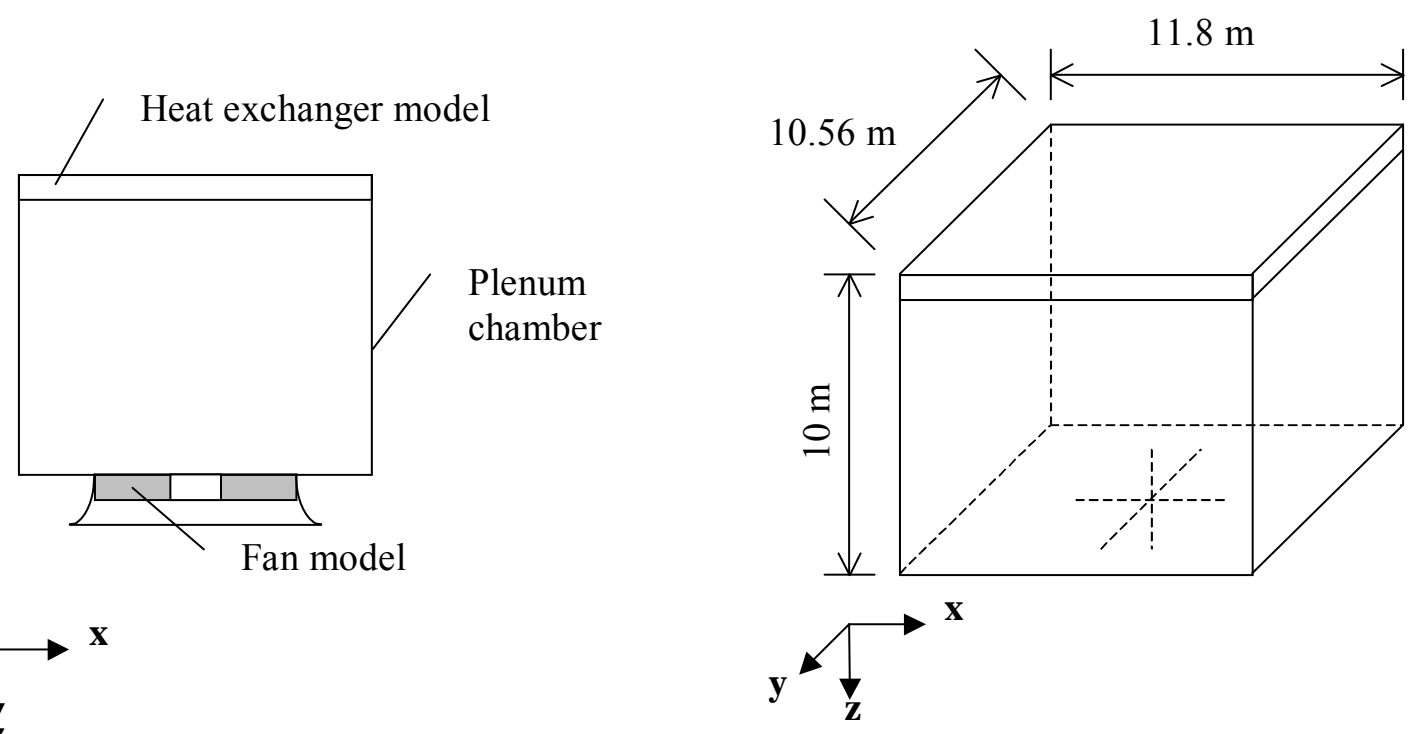

Figure 4.18: Dimensions of the numerical ACSC fan unit model

Detail of the computational grid consisting of 152000 cells is shown in figures 4.19 to 4.21 . 


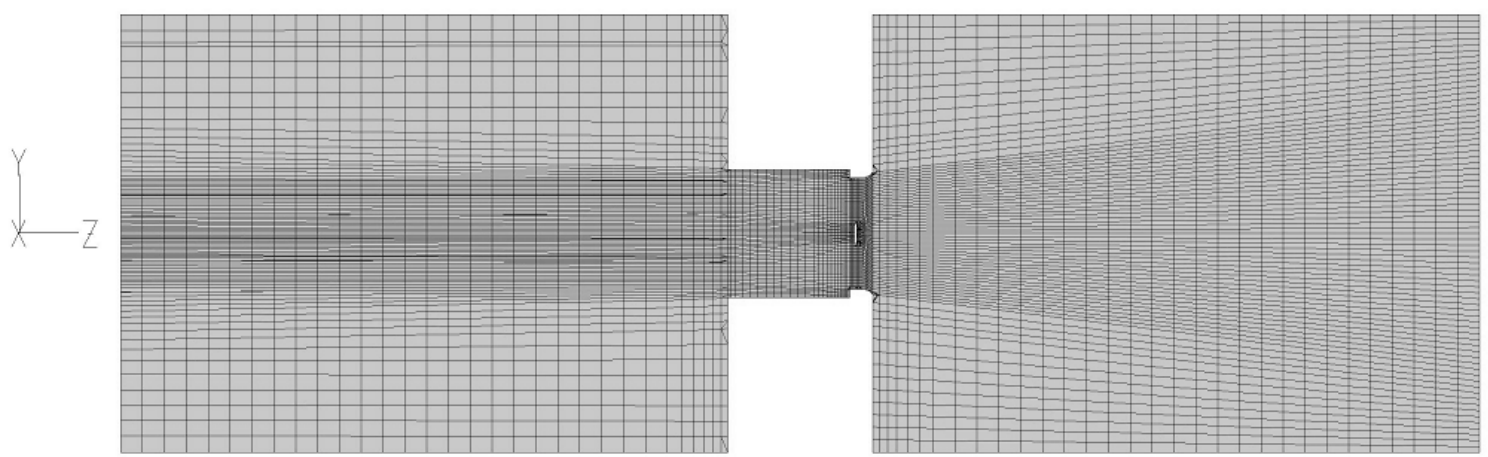

Figure 4.19: Section view of the computational grid for fan unit model

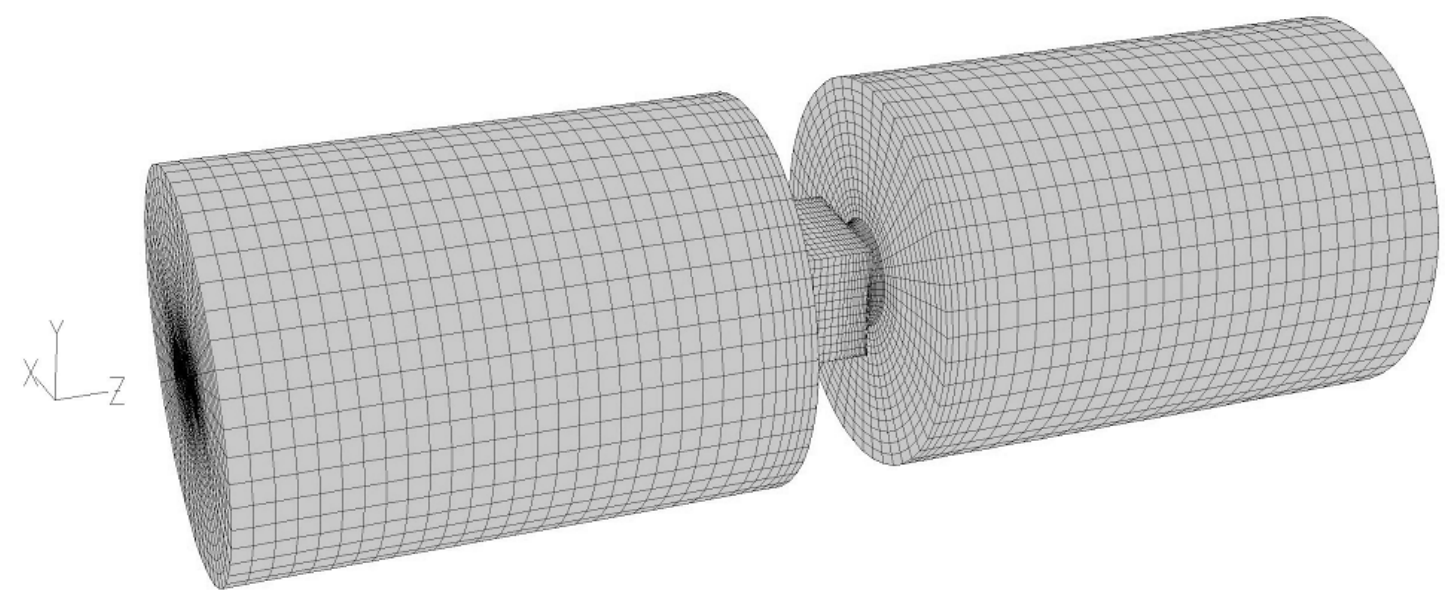

Figure 4.20: Isometric view of the computational grid for fan unit model



Figure 4.21: Detail view of the computational grid for fan unit model 
The inlet and outlet boundaries, shown in figure 4.17 , were modelled by specifying a total pressure boundary condition, with $\mathrm{p}_{\text {tot }}=0$. The flow of air through the fan unit model was therefore generated by the actuator disc model, and not the specified boundary conditions. The fan inlet and plenum chamber walls were specified as zero-slip walls. Convergence of the mass flow rate to the sixth significant digit was established after approximately 700 iterations. The resulting static pressure contour plots inside the plenum, for the A-fan and the B-fan, are shown in figure 4.22 and figure 4.23 , respectively.
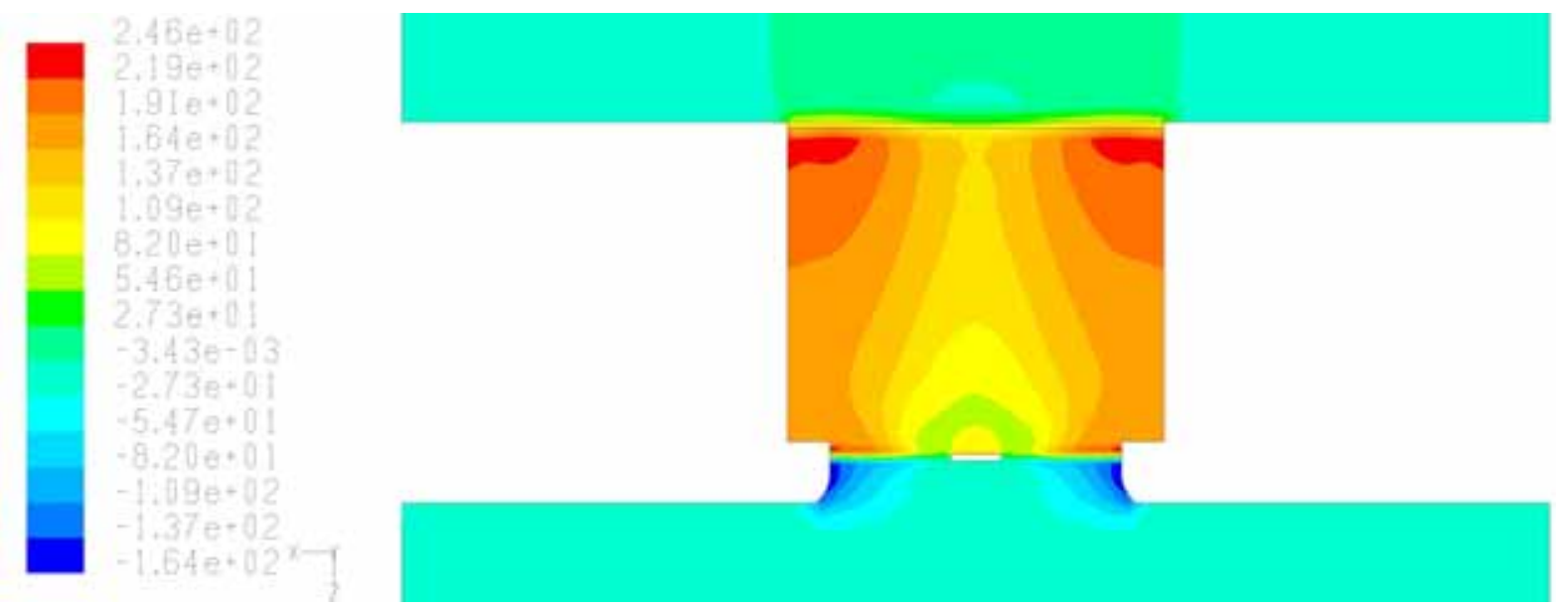

Figure 4.22: Static pressure $(\mathrm{Pa})$ plot in the ACSC fan unit model with A-fan
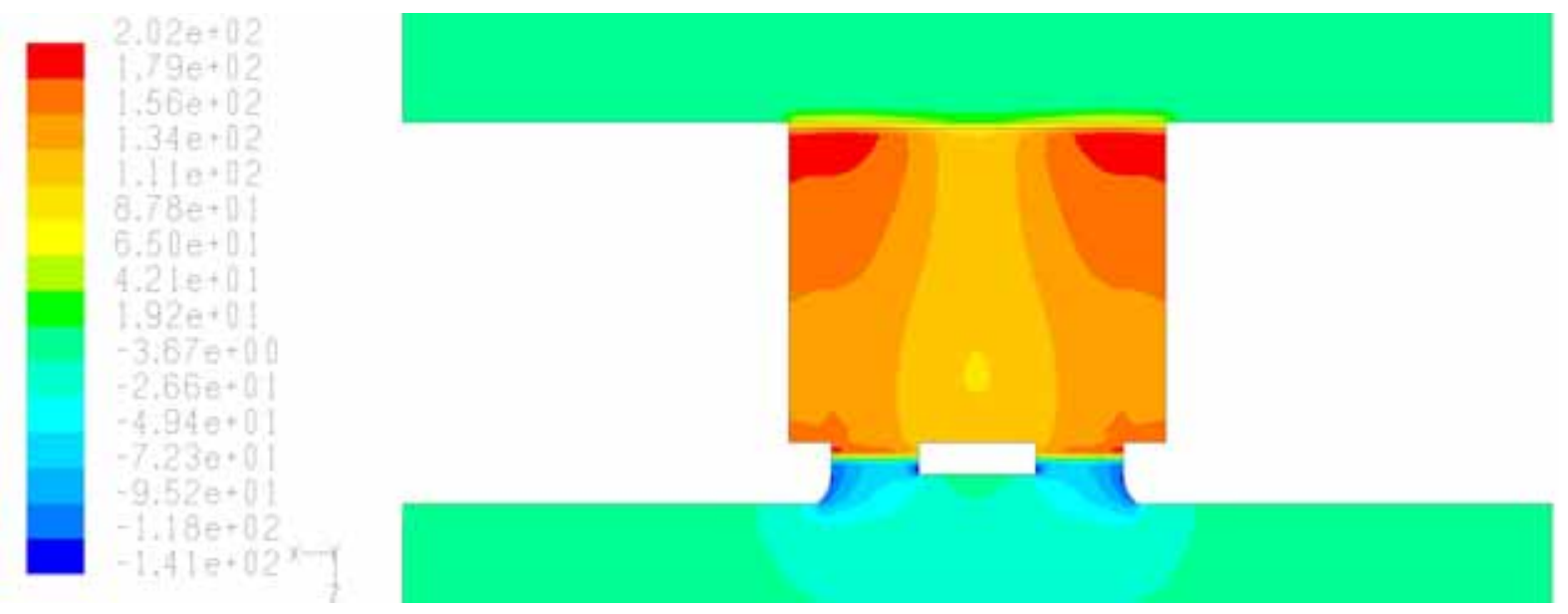

Figure 4.23: Static pressure $(\mathrm{Pa})$ plot in the ACSC fan unit model with B-fan 


\subsubsection{Numerical results}

A fan unit of the ACSC under consideration, employing both the A-fan and the B-fan, were modelled. For the given ambient conditions, and with the effective system resistance defined by equation (3.6), the volume flow rates for the A-fan and B-fan were respectively, $653.88 \mathrm{~m}^{3} / \mathrm{s}$ and $659.49 \mathrm{~m}^{3} / \mathrm{s}$. The corresponding fan shaft power was found to be $240.37 \mathrm{~kW}$ and $232.73 \mathrm{~kW}$, respectively. If heat transfer to the air is modelled, the corresponding heat rejection rates are, 22.32 MW and 22.52 MW. This simplified model of a fan unit can now be used to simulate the flow field in a section of ACSC array, consisting of multiple fan units.

\subsection{Discussion of results}

The numerically predicted fan static pressure $\left(\Delta \mathrm{p}_{\mathrm{Fs}}\right)$ and fan shaft power $\left(\mathrm{P}_{\mathrm{F}}\right)$ for the A-fan, differed by $0.7 \%$ and $10.6 \%$, respectively, from to data provided by the manufacturer. For the B-fan the numerically predicted $\Delta \mathrm{p}_{\mathrm{Fs}}$ and $\mathrm{P}_{\mathrm{F}}$ deviated by respectively $2.5 \%$ and $1.8 \%$ from the experimental data of Stinnes [98ST1]. The fan static efficiency $\left(\eta_{\mathrm{Fs}}\right)$ of both fan models, showed similar trends as the corresponding experimentally determined efficiency.

Except for $\mathrm{P}_{\mathrm{F}}$ of the A-fan model, the numerically predicted fan characteristics compare well to experimental data. In part, the aforementioned discrepancy in fan power may be attributed to the fact that, to date fan manufacturers have used fan similarity laws to scale up the performance characteristics obtained from a scale model fan. Information regarding the scale model fan test, on which the provided data is based, was unfortunately not available. Numerical results could therefore not be directly compared, due to the possible scaling error involved (refer to section 2.1.2). It was furthermore found that if the fan blade drag force is neglected in the actuator disc model (i.e. $\mathrm{C}_{\mathrm{D}}=0$ in equations (3.11) and (3.12)), the fan shaft power was still over predicted. Given the accuracy with which the performance characteristics of the B-fan were predicted, uncertainty regarding the exactness of the data provided by the manufacturer is vindicated. For the purpose of this investigation however, the numerical model for the A-fan shall be accepted as sufficiently accurate.

The recirculation or reverse flow that occurs near the hub of the commercially available A-fan, as reported by van Aarde [90VA1] and Venter [90VE1], can clearly be seen in figure 4.7. This phenomenon is however absent in the B-fan as expected. 


\section{Fan performance in a section of the ACSC}

\subsection{Windless conditions at various platform heights}

In this part of the study, the numerical modelling of the flow about and through a section of an ACSC under windless conditions, is considered. The ACSC consists of six long adjacent fan rows. The section under investigation, shown in figure 5.1, is representative of the fan units located near the centre of the ACSC.

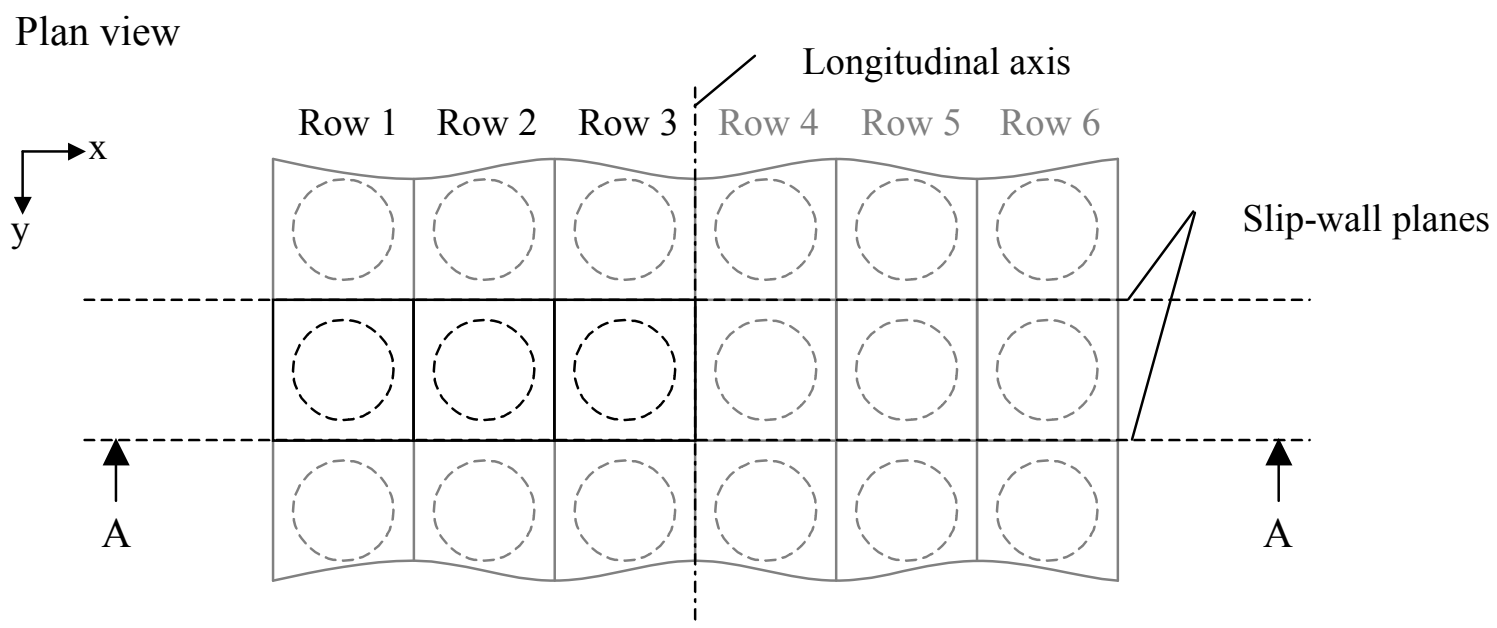

Section view A-A



Figure 5.1: A section of a long ACSC bank located near its centre

Due to the proximity of the ground, an unfavourable cross-flow velocity component is induced underneath the fan platform. Depending on the height of the fan platform, $\mathrm{H}_{\mathrm{i}}$, the induced cross-draft may result in flow separation and distortion at the fan inlets. 
In this section these system effects are investigated my modelling the section of the ACSC at various platform heights.

\subsubsection{Computational aspects}

Assuming the flow to be essentially two-dimensional, i.e. no flow occurring across the sectional planes, these planes were accordingly modelled as slip-walls. Owing to the symmetry plane through the longitudinal axis, it was only required to model one half of the section under consideration, as shown in figure 5.2.

According to Kröger [04KR1] the reduction of effectiveness due to recirculation (i.e. ratio of the heat transfer rate with recirculation, to the heat transfer rate without recirculation) under windless conditions for this type of ACSC, is less that $1 \%$. For the purpose of this investigation, the modelling of heat transfer to the air and the buoyant plume, were therefore not essential. By not modelling the discharge flow, the computational grid could consequently be simplified and reduced in size, resulting in shorter computing times.

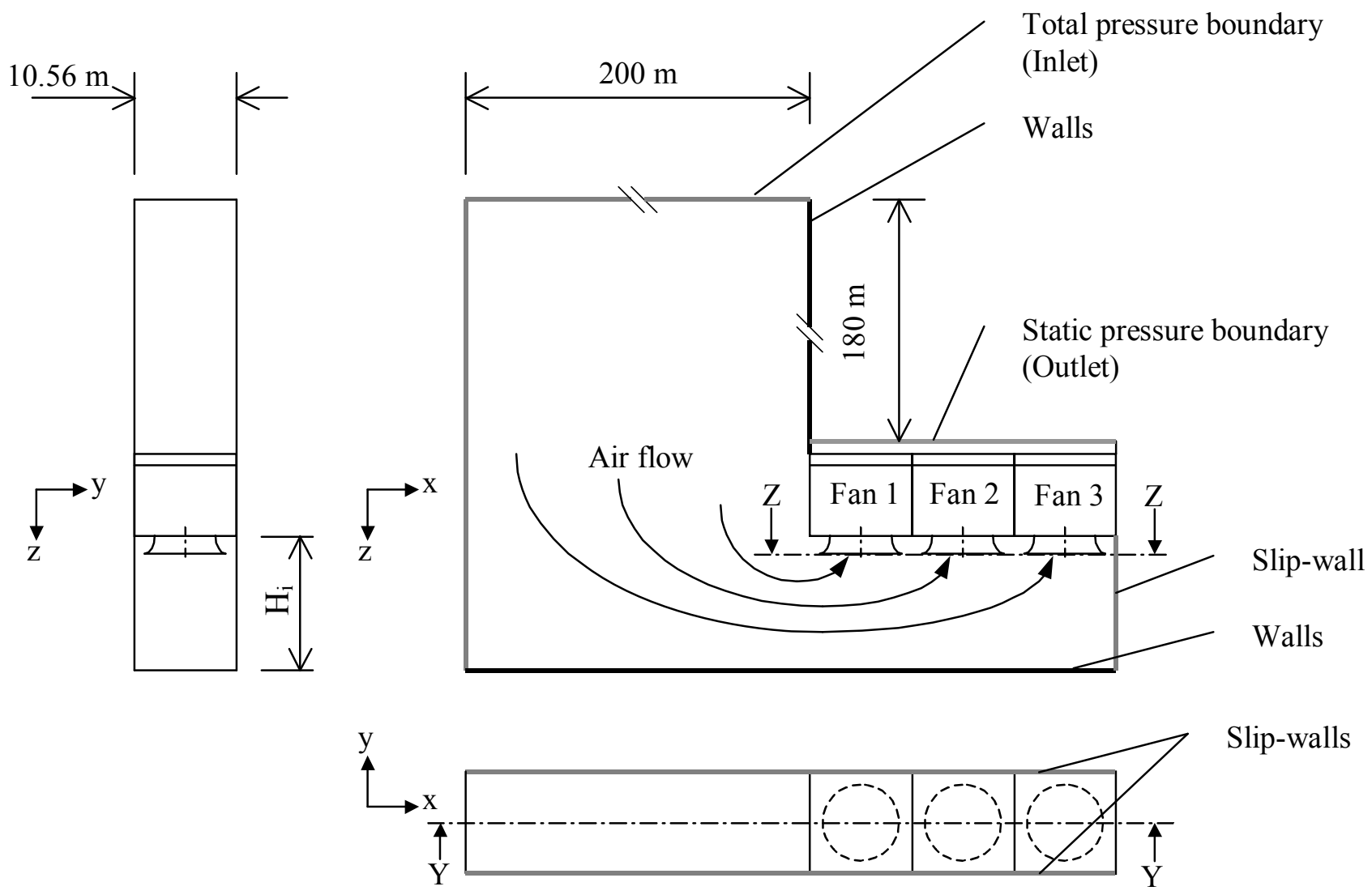

Figure 5.2: Layout of computational grid for modelling a section of the ACSC under windless conditions at various plat form heights 
A typical computational grid (consisting of between 450000 and 500000 cells depending on the platform height) is shown in figure 5.3 and figure 5.4.

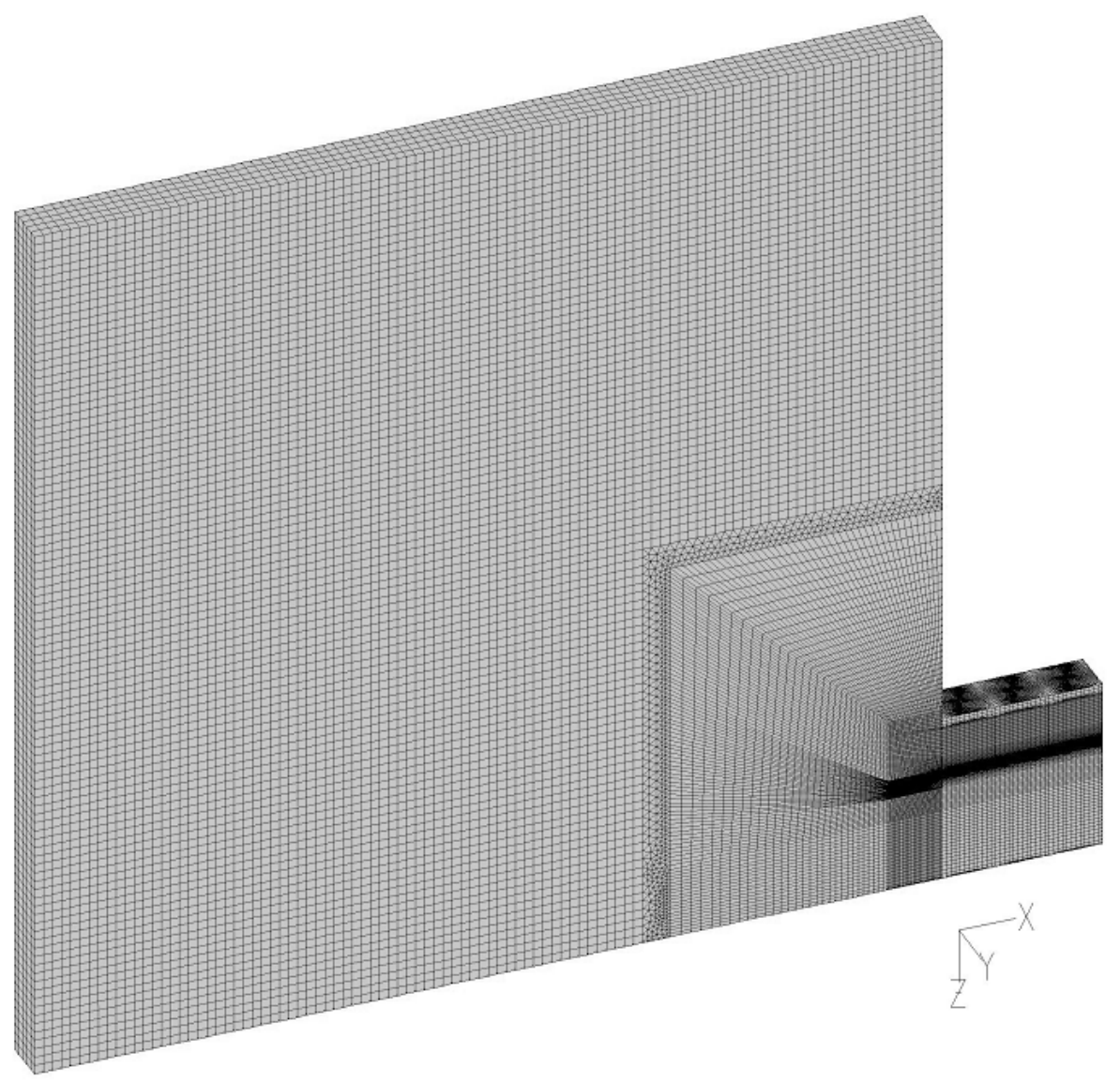

Figure 5.3: Computational grid for modelling a section of the ACSC under windless conditions

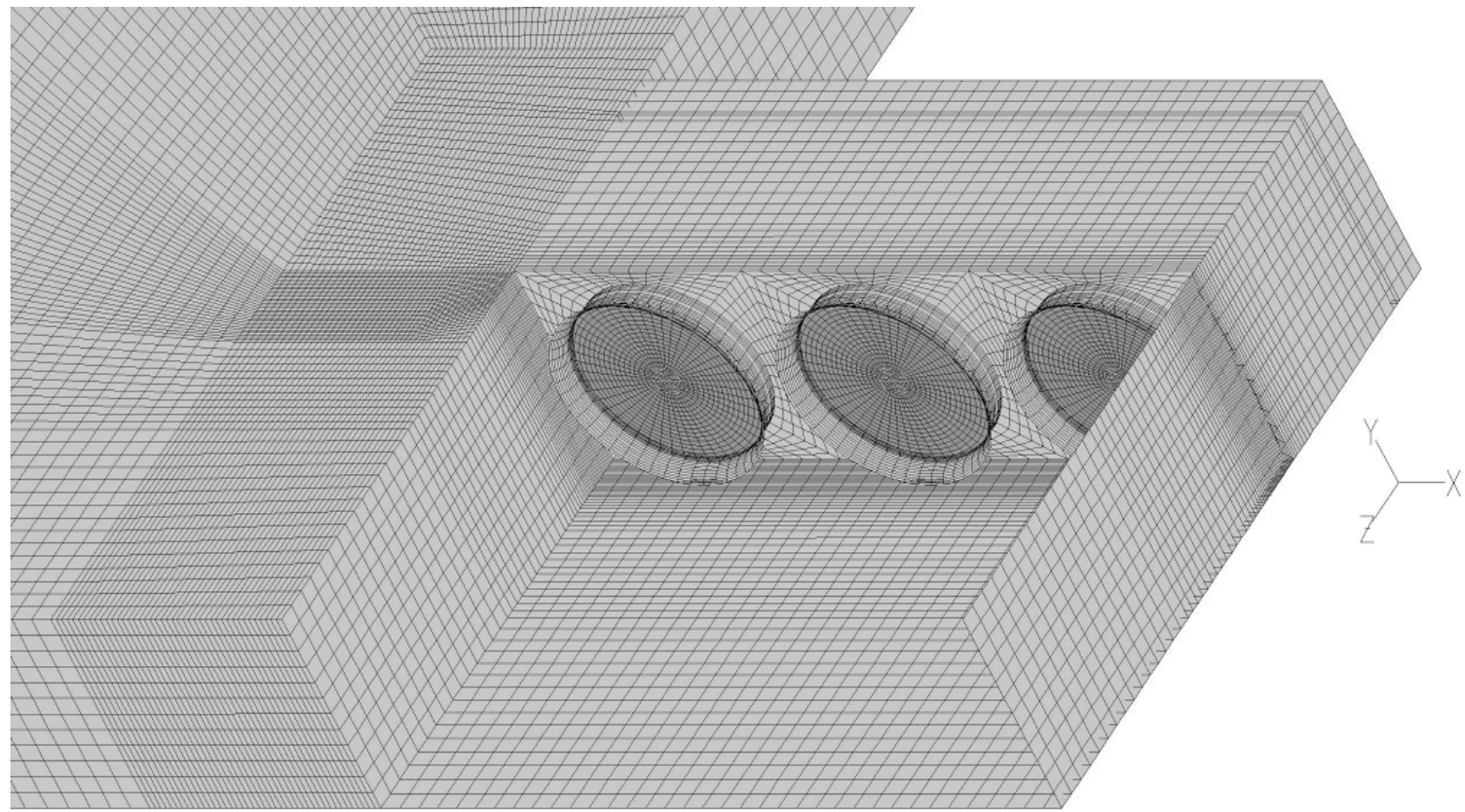

Figure 5.4: Enlarged sectional view of the computational grid near the fan units 
The atmospheric inlet boundary was modelled with a total pressure boundary condition, with $\mathrm{p}_{\text {tot }}=0$. With no recirculation or outflow occurring, the boundary condition presented no significant problem with regards to numerical stability. The outlet boundary, located $2 \mathrm{~m}$ above the fan units, was modelled as a static pressure boundary condition, with $p=0$. The ground, plenum walls, fan inlet and fan hub were modelled as zero-slip walls. Four different platform heights $\mathrm{H}_{\mathrm{i}}=26 \mathrm{~m}, 22 \mathrm{~m}, 18 \mathrm{~m}$ and $14 \mathrm{~m}$, were considered. The dimensions of a fan unit are given in figure 4.17. The thermo-physical properties of the air at the prescribed ambient conditions are given in Appendix A.

Due to the complexity of the flow (i.e. flow separation at fan inlets, the addition of body forces in the actuator disc model, etc.) first order upwind discritization was employed in the momentum and turbulence equations in order to maintain numerical stability. Overall convergence of a simulation was established when the mass flow rate through all three fan units converged to the fifth significant digit (typically obtained after 800 iterations).

In order to compare the performance of fans operating under distorted inlet conditions, to the ideal case with no inlet flow distortions, the following parameters were defined: the volumetric effectiveness of a fan, $e_{V(n)}$, defined by equation (5.1), is the ratio of the numerically determined flow rate through a particular fan unit in a multi-fan system simulation, $\mathrm{V}_{\mathrm{a}}$, to the reference flow rate of the same freestanding fan unit, $\mathrm{V}_{\mathrm{ar}}$,

$$
\mathrm{e}_{\mathrm{V}(\mathrm{n})}=\frac{\mathrm{V}_{\mathrm{a}(\mathrm{n})}}{\mathrm{V}_{\mathrm{ar}}}
$$

where $\mathrm{n}$ is an index corresponding to the appropriate fan number $(\mathrm{n}=1,2$ or 3$)$. The system volumetric effectiveness, $\mathrm{e}_{\mathrm{V}(\mathrm{sys})}$, of a multi-fan system is similarly defined by equation (5.2).

$$
\mathrm{e}_{\mathrm{V}(\mathrm{sys})}=\frac{\sum_{\mathrm{n}=1}^{\mathrm{n}_{\mathrm{F}}} \mathrm{V}_{\mathrm{a}(\mathrm{n})}}{\mathrm{n}_{\mathrm{F}} \mathrm{V}_{\mathrm{ar}}}
$$

where $n_{F}$ is the number of fan rows. The effect of flow distortion on fan shaft power of the $n^{\text {th }}$ fan is presented as the ratio of the predicted fan shaft power under distorted flow conditions, $\mathrm{P}_{\mathrm{F}(\mathrm{n})}$, to fan shaft power for the ideal case with no inlet flow distortion, $\mathrm{P}_{\mathrm{Fr}}$. 
The reference flow rates corresponding to the A-fan $\left(\mathrm{d}_{\mathrm{F}}=9.145 \mathrm{~m}, \gamma_{\mathrm{pt}}=16^{\circ}\right)$ and the B-fan $\left(\mathrm{d}_{\mathrm{F}}=9.145 \mathrm{~m}, \gamma_{\mathrm{cr}}=34.5^{\circ}\right)$, are determined in section 4.1 .2 as $653.88 \mathrm{~m}^{3} / \mathrm{s}$ and $659.49 \mathrm{~m}^{3} / \mathrm{s}$, respectively. The corresponding fan shaft power is $240.37 \mathrm{~kW}$ and $232.73 \mathrm{~kW}$, respectively. Numerical fan performance results of subsequent sections are given in Appendix E.

\subsubsection{Effect of platform height}

The effect of platform height on the performance of the A-fan $\left(d_{F}=9.145 \mathrm{~m}, \gamma_{\mathrm{pt}}=16^{\circ}\right)$ is investigated by modelling a section of the ACSC at various platform heights, $\mathrm{H}_{\mathrm{i}}=26 \mathrm{~m}, 22 \mathrm{~m}$, $18 \mathrm{~m}$ and $14 \mathrm{~m}$. The streamline plots on plane Y-Y (refer to figure 5.2), for the extreme cases of $\mathrm{H}_{\mathrm{i}}=26 \mathrm{~m}$ and $\mathrm{H}_{\mathrm{i}}=14 \mathrm{~m}$ are shown in figure 5.5 and figure 5.6.

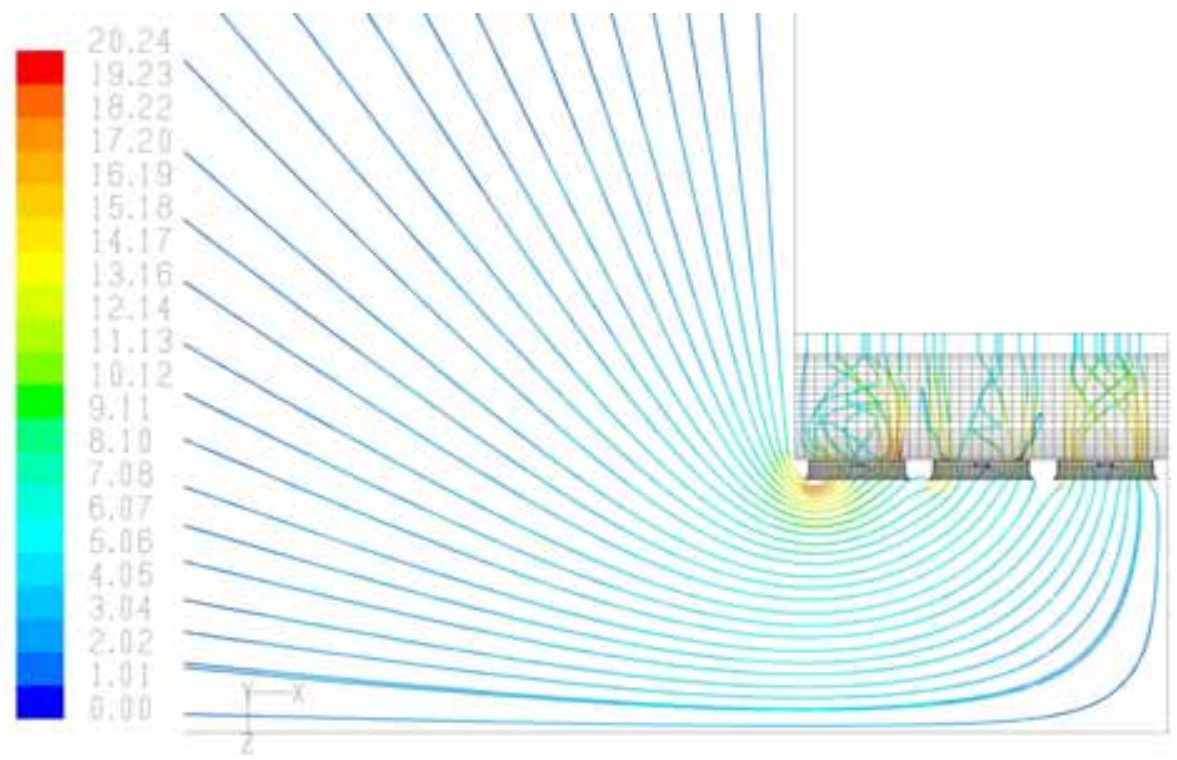

Figure 5.5: Streamline plot indicating velocity magnitude for $\mathrm{H}_{\mathrm{i}}=26 \mathrm{~m}$ (plane $\mathrm{Y}-\mathrm{Y}$ )

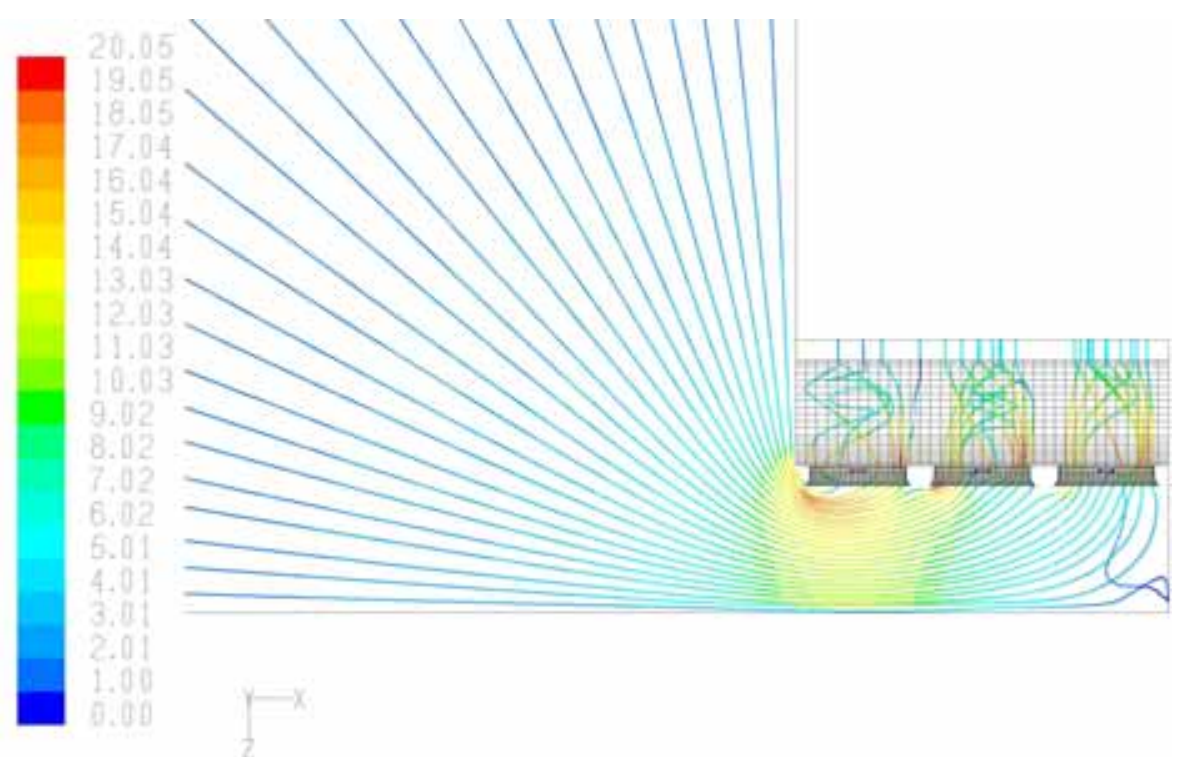

Figure 5.6: Streamline plot indicating velocity magnitude for $\mathrm{H}_{\mathrm{i}}=14 \mathrm{~m}$ (plane $\mathrm{Y}-\mathrm{Y}$ ) 
Static pressure contours on plane $\mathrm{Y}-\mathrm{Y}$ for $\mathrm{H}_{\mathrm{i}}=26 \mathrm{~m}$ and $\mathrm{H}_{\mathrm{i}}=14 \mathrm{~m}$ are shown in figure 5.7 and figure 5.8, respectively.

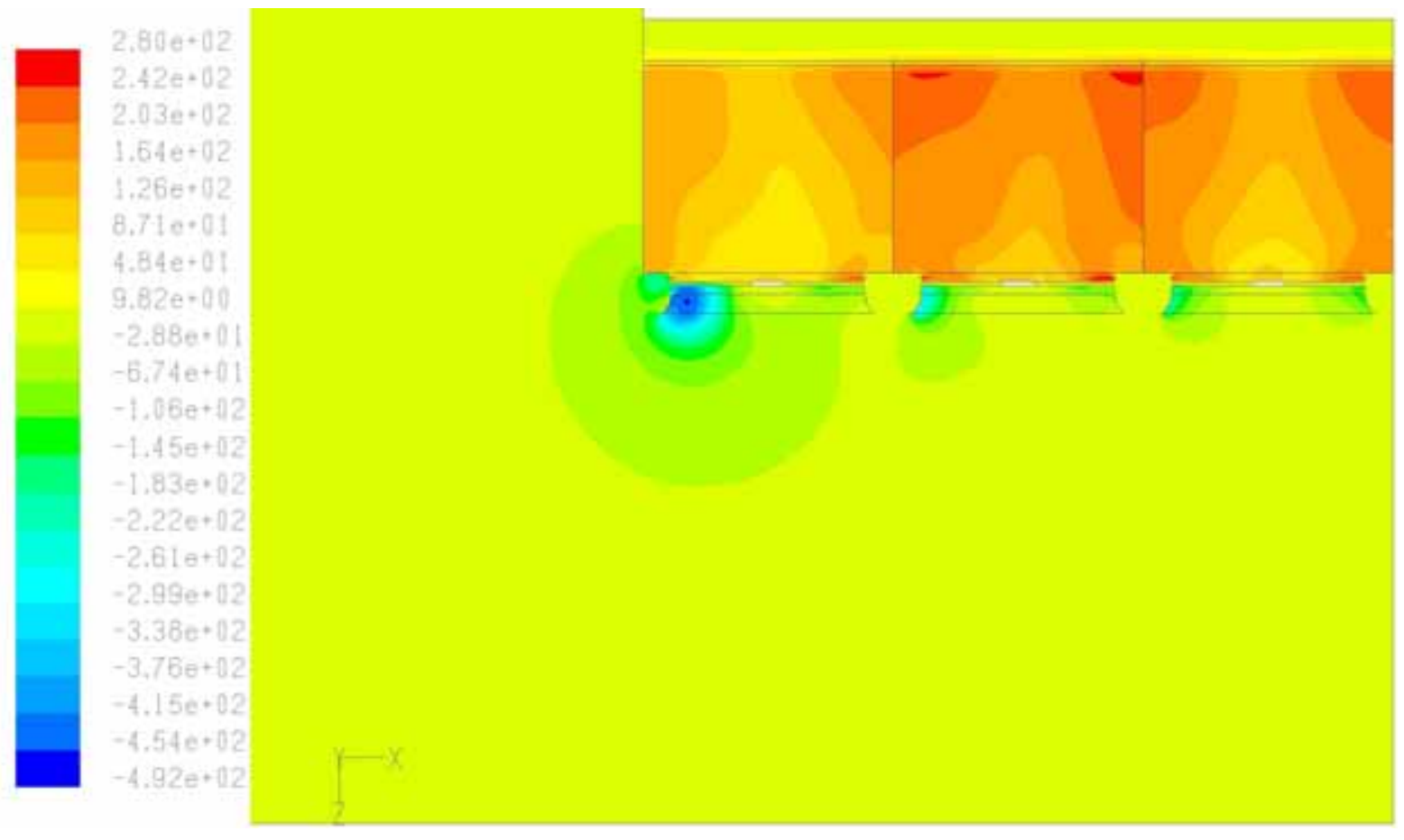

Figure 5.7: Static pressure (Pa) plot for $\mathrm{H}_{\mathrm{i}}=26 \mathrm{~m}$ (plane $\mathrm{Y}-\mathrm{Y}$ )

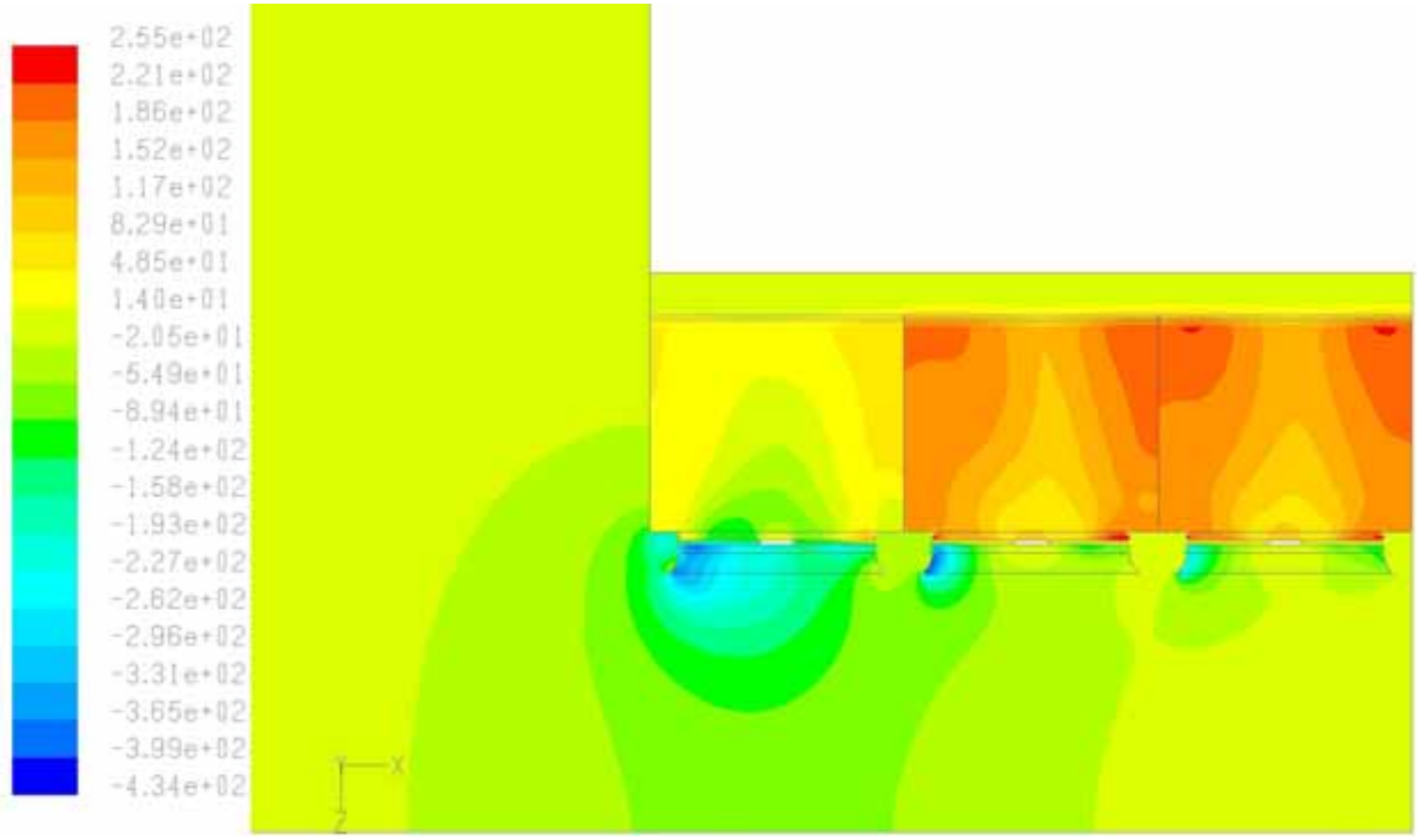

Figure 5.8: Static pressure $(\mathrm{Pa})$ plot for $\mathrm{H}_{\mathrm{i}}=14 \mathrm{~m}$ (plane $\mathrm{Y}-\mathrm{Y}$ ) 
The corresponding vector plots of the flow through the edge fan are respectively shown in figure 5.9 and figure 5.10.

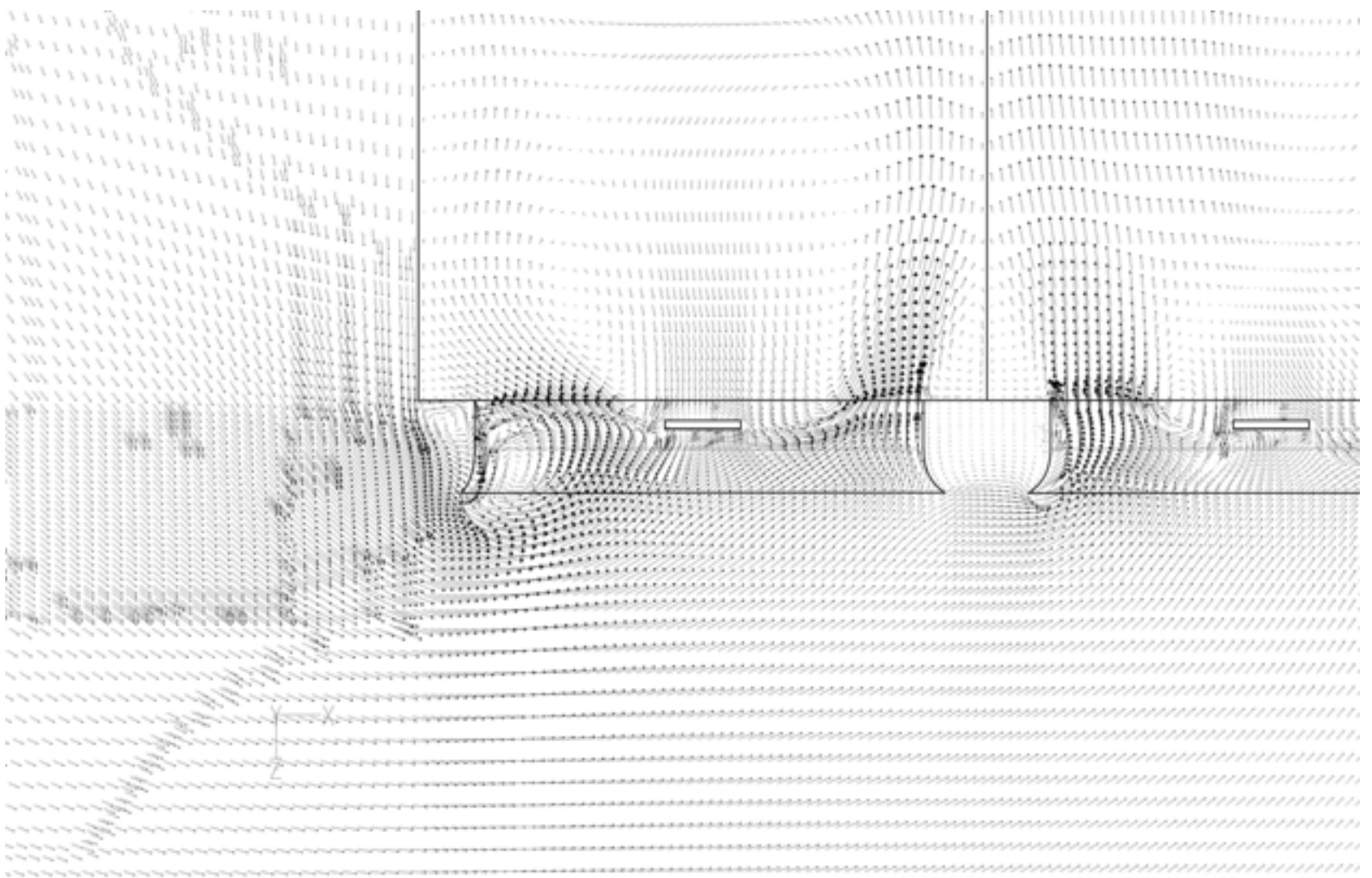

Figure 5.9: Vector plot for $\mathrm{H}_{\mathrm{i}}=26 \mathrm{~m}$ (plane $\mathrm{Y}-\mathrm{Y}$ )

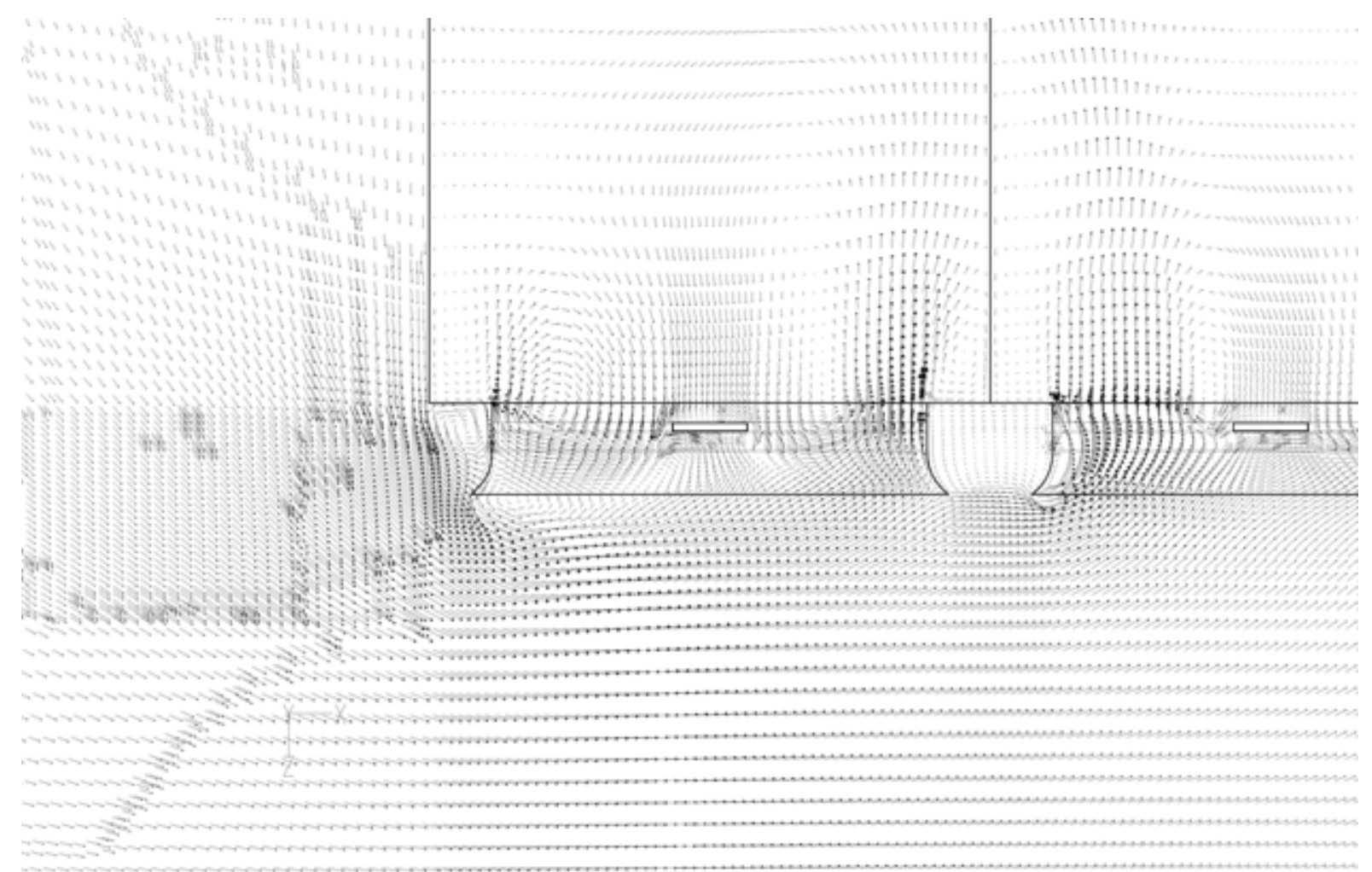

Figure 5.10: Vector plot for $\mathrm{H}_{\mathrm{i}}=14 \mathrm{~m}$ (plane $\mathrm{Y}-\mathrm{Y}$ ) 
Static pressure contours on plane Z-Z (refer to figure 5.2) at the inlet of the edge fan, for $\mathrm{H}_{\mathrm{i}}=26 \mathrm{~m}$ and $\mathrm{H}_{\mathrm{i}}=14 \mathrm{~m}$ are shown in figure 5.11 and figure 5.12, respectively.

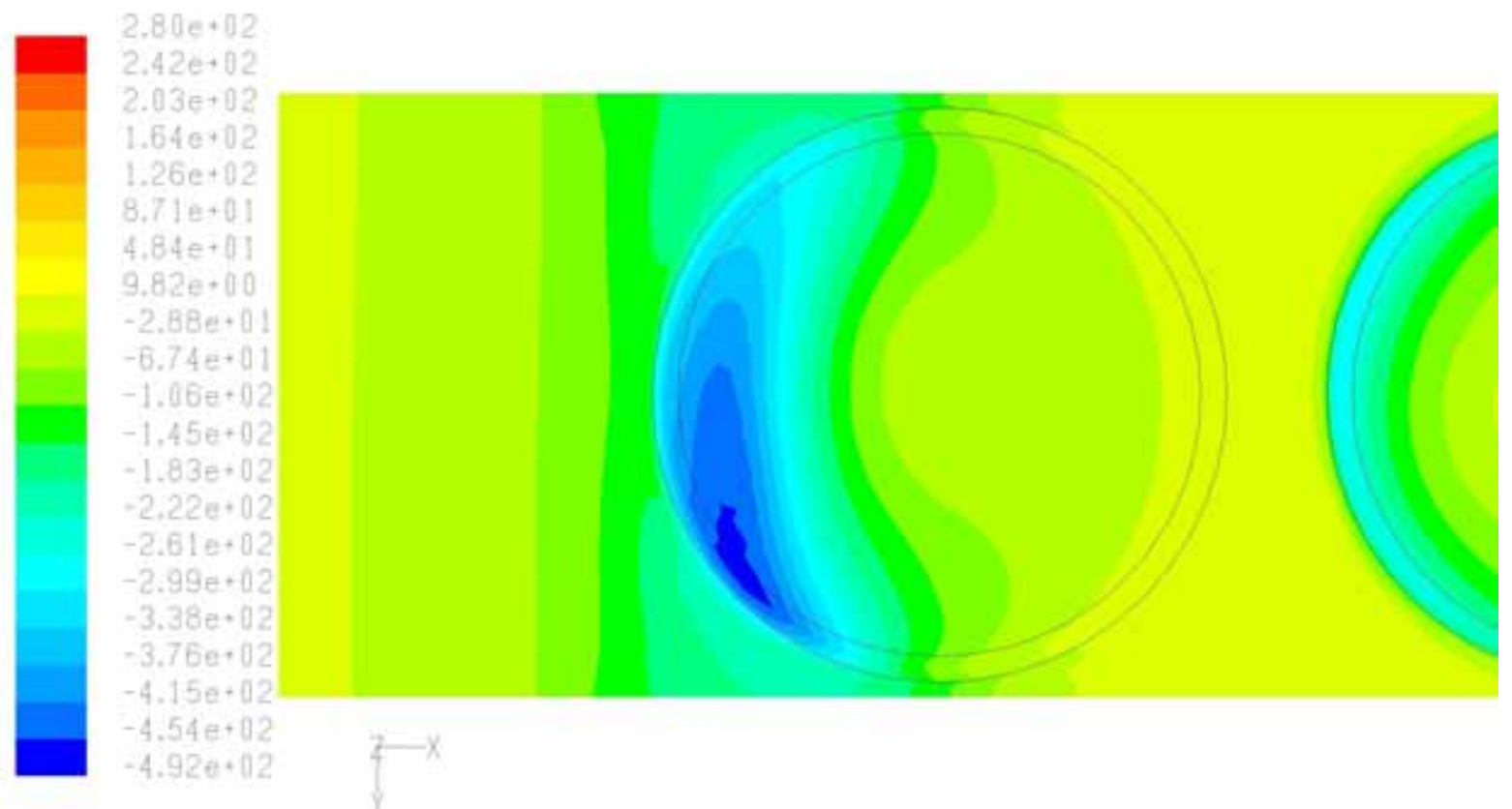

Figure 5.11: Static pressure $(\mathrm{Pa})$ plot for $\mathrm{H}_{\mathrm{i}}=26 \mathrm{~m}$ (plane $\mathrm{Z}-\mathrm{Z}$ )

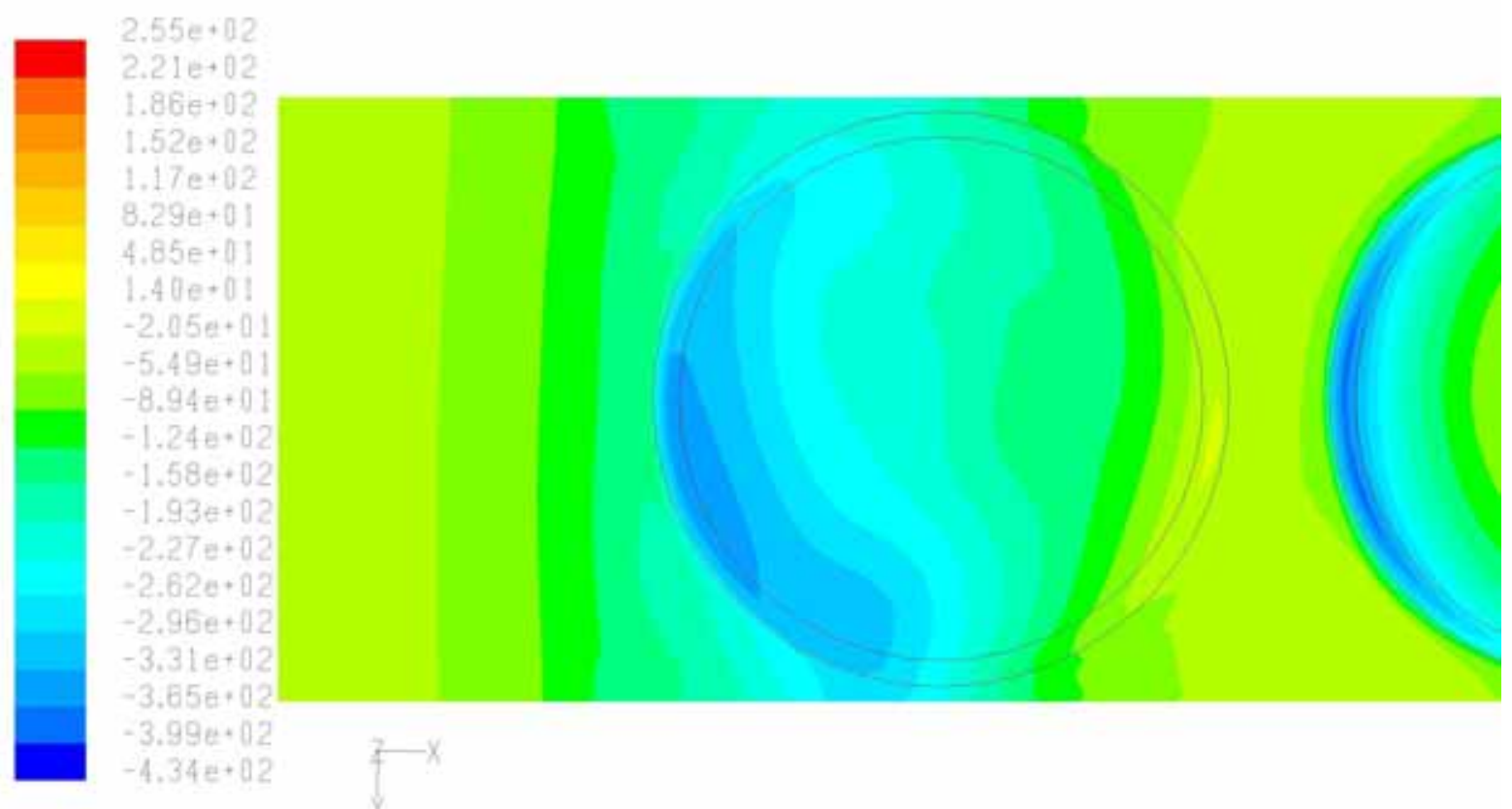

Figure 5.12: Static pressure $(\mathrm{Pa})$ plot for $\mathrm{H}_{\mathrm{i}}=14 \mathrm{~m}$ (plane $\mathrm{Z}-\mathrm{Z}$ ) 
The corresponding vector plots on plane Z-Z are respectively shown in figure 5.13 and figure 5.14.

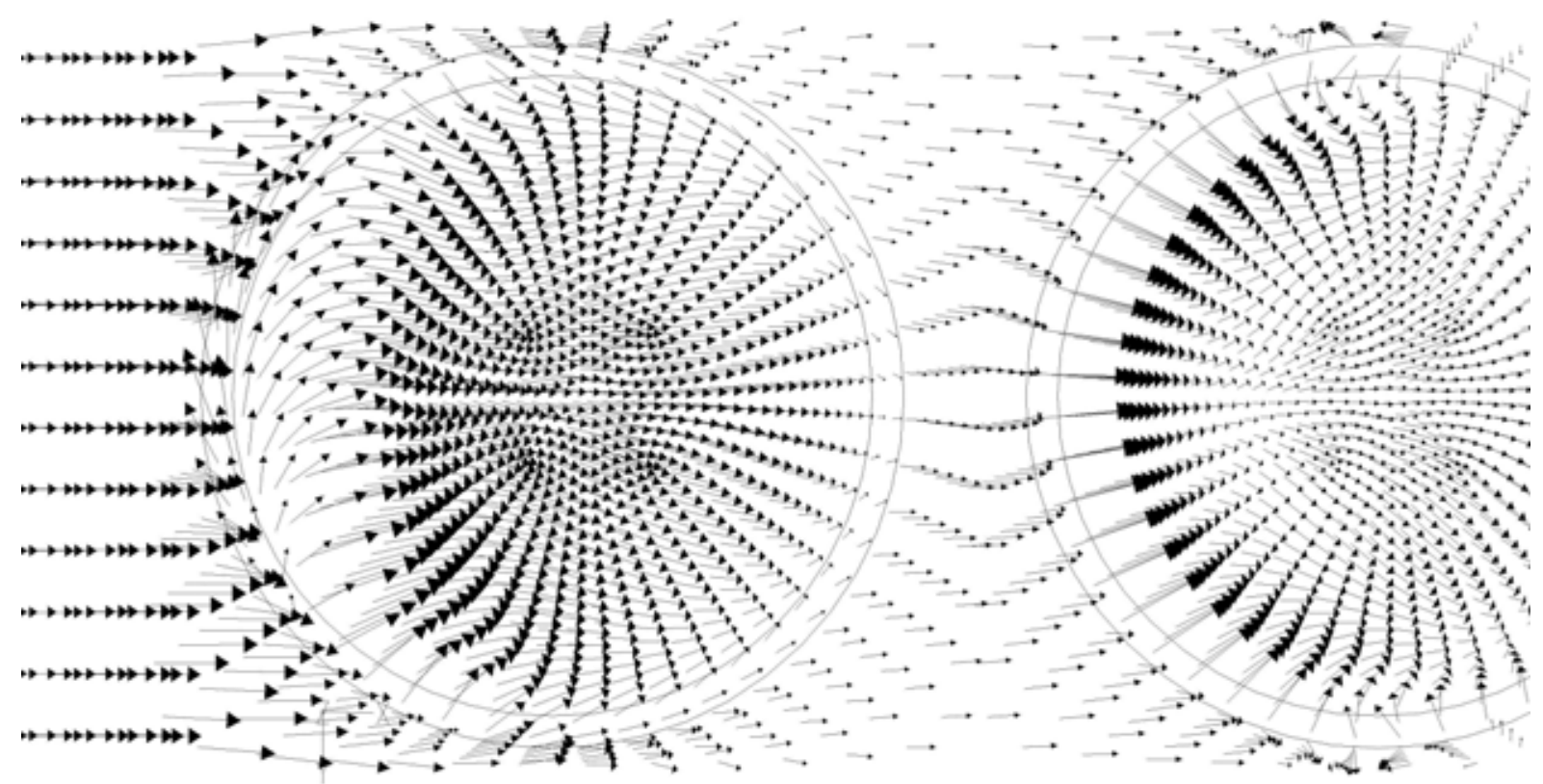

Figure 5.13: Vector plot for $\mathrm{H}_{\mathrm{i}}=26 \mathrm{~m}$ (plane $\mathrm{Z}-\mathrm{Z}$ )

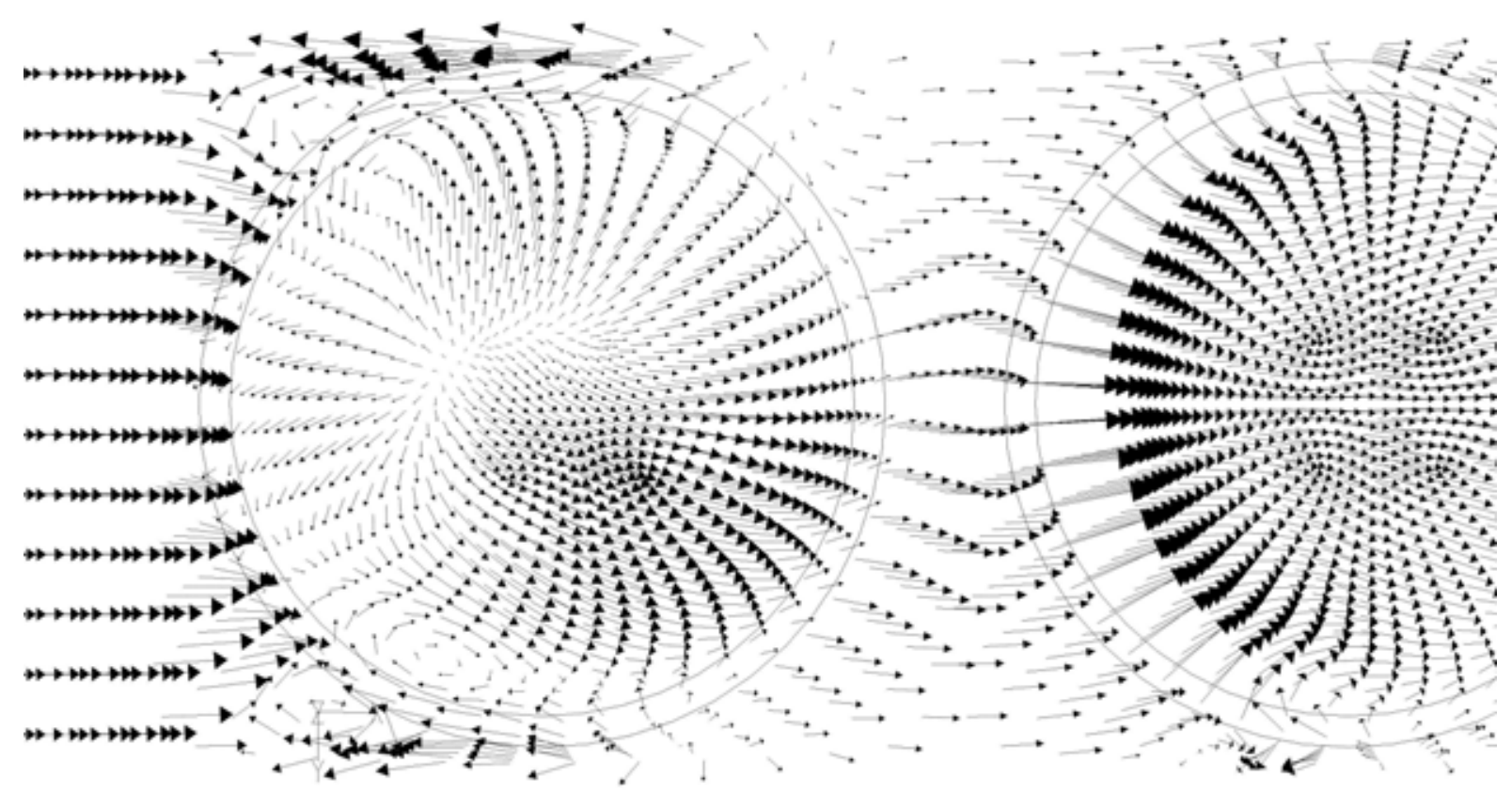

Figure 5.14: Vector plot for $\mathrm{H}_{\mathrm{i}}=14 \mathrm{~m}$ (plane $\mathrm{Z}-\mathrm{Z}$ ) 
The corresponding local angle of attack at various radii of the edge fan, is shown in figure 5.15 and figure 5.16 as a function of blade angular position. From these figures the highly distorted nature of the flow is evident.

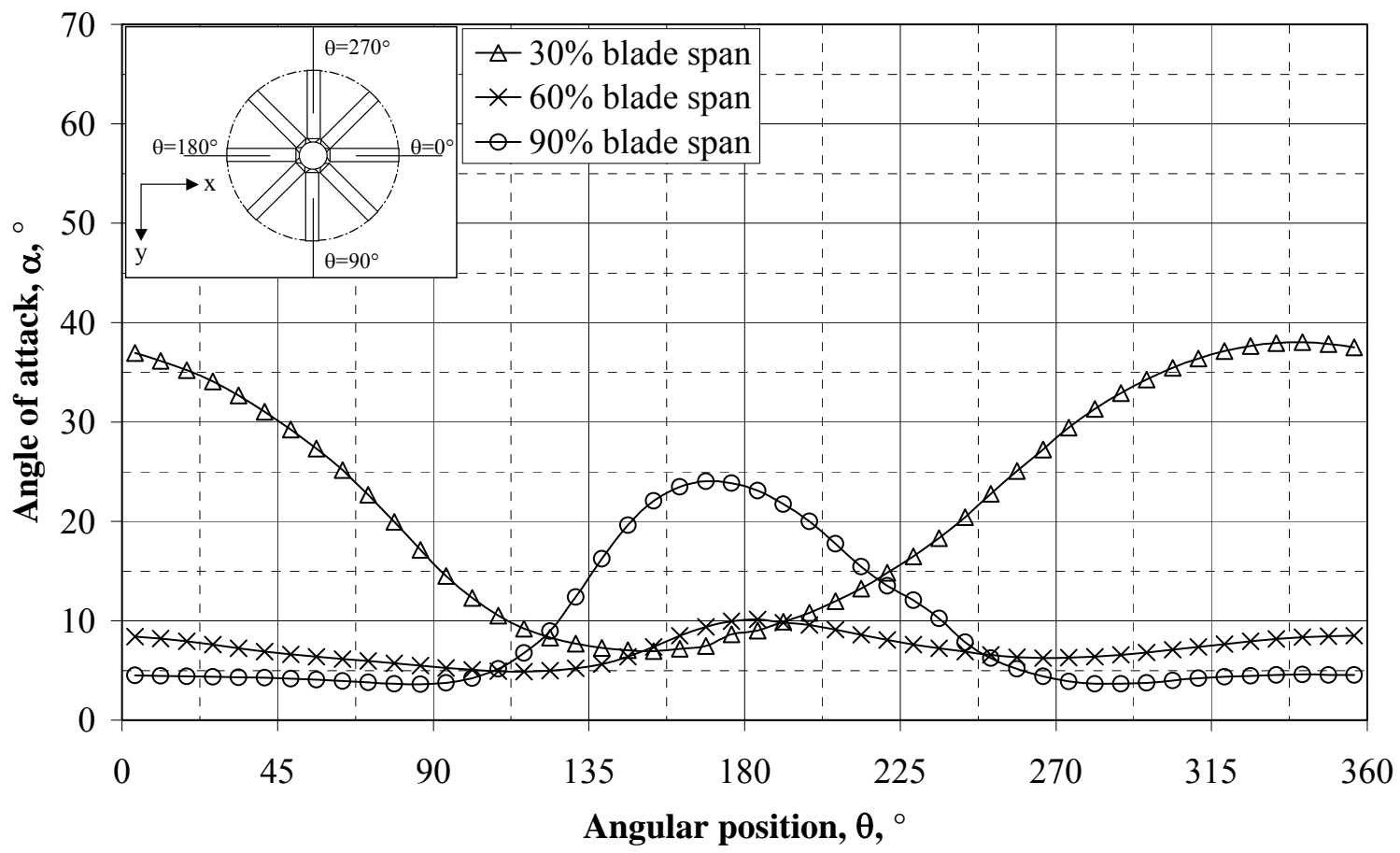

Figure 5.15: Angle of attack in the edge fan for the $\mathrm{A}$-fan at $\mathrm{H}_{\mathrm{i}}=26 \mathrm{~m}$

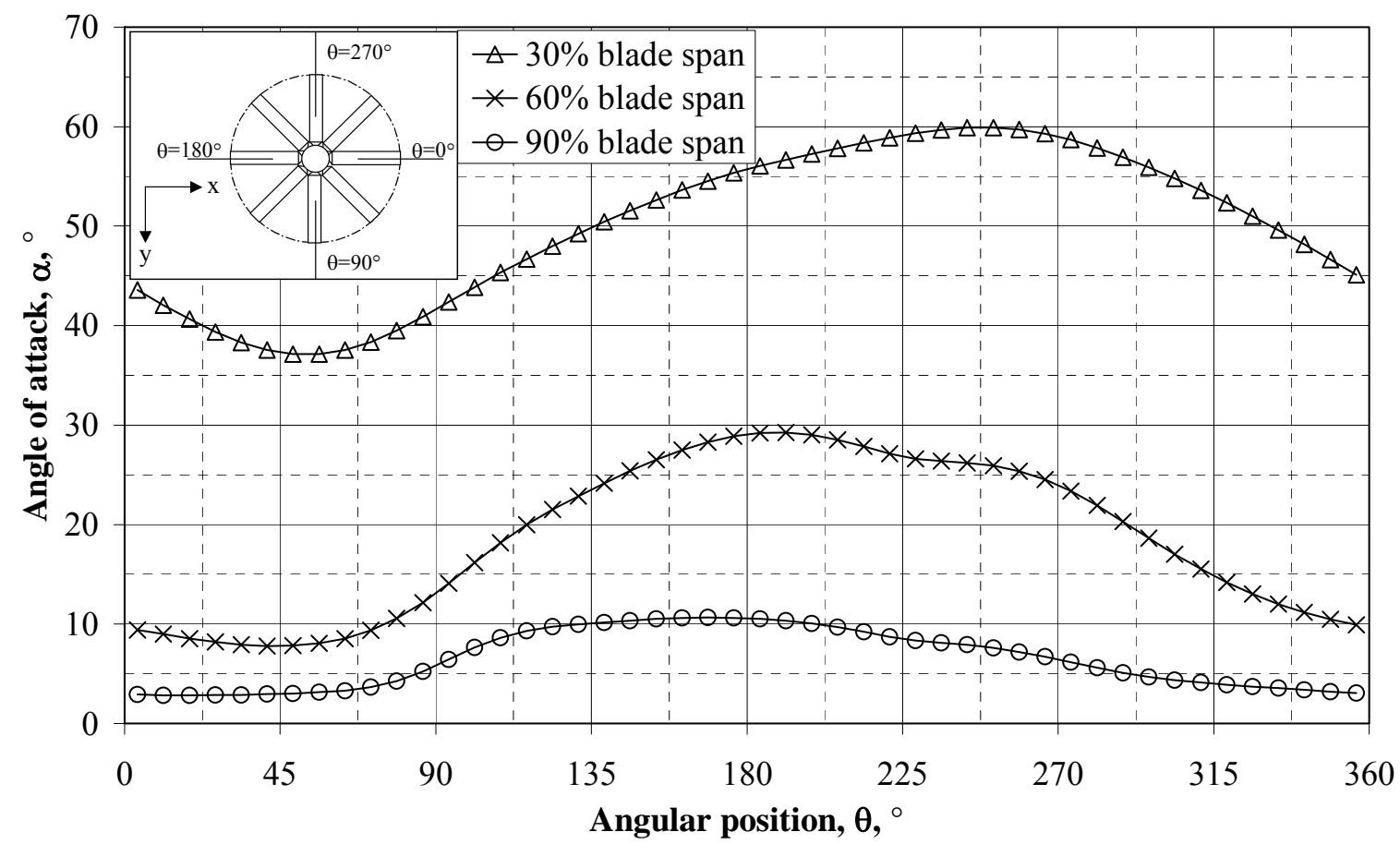

Figure 5.16: Angle of attack in the edge fan for the $A-$ fan at $\mathrm{H}_{\mathrm{i}}=14 \mathrm{~m}$ 
In figures 5.5 to 5.16 , the flow separation or distortion occurring at the inlet of the edge fan, is evident. The resulting reductions in flow rate through the fans are shown in figure 5.17.

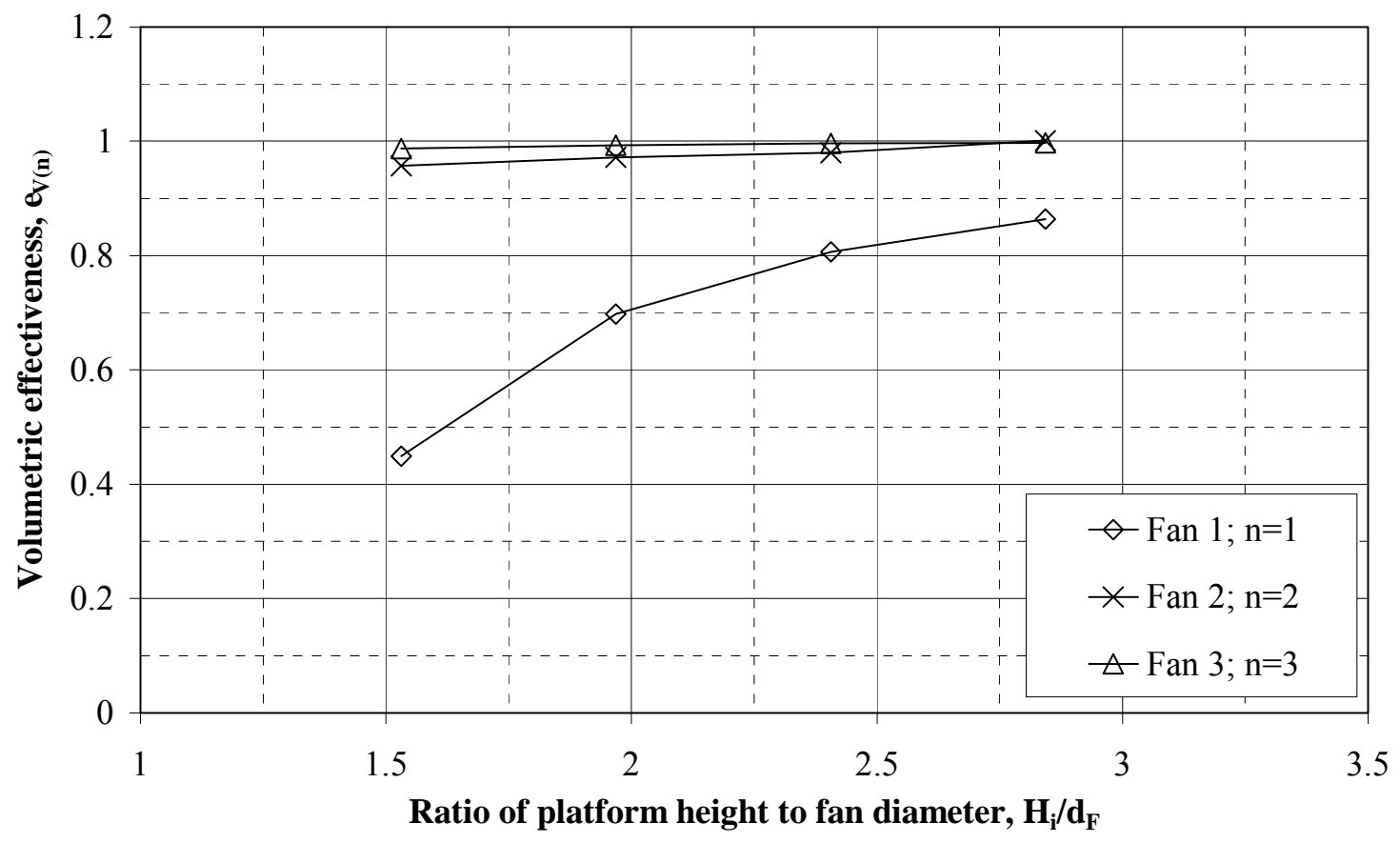

Figure 5.17: Volumetric effectiveness of the fans in a section of an ACSC at various platform heights

Figure 5.18 shows the corresponding effect on fan shaft power.

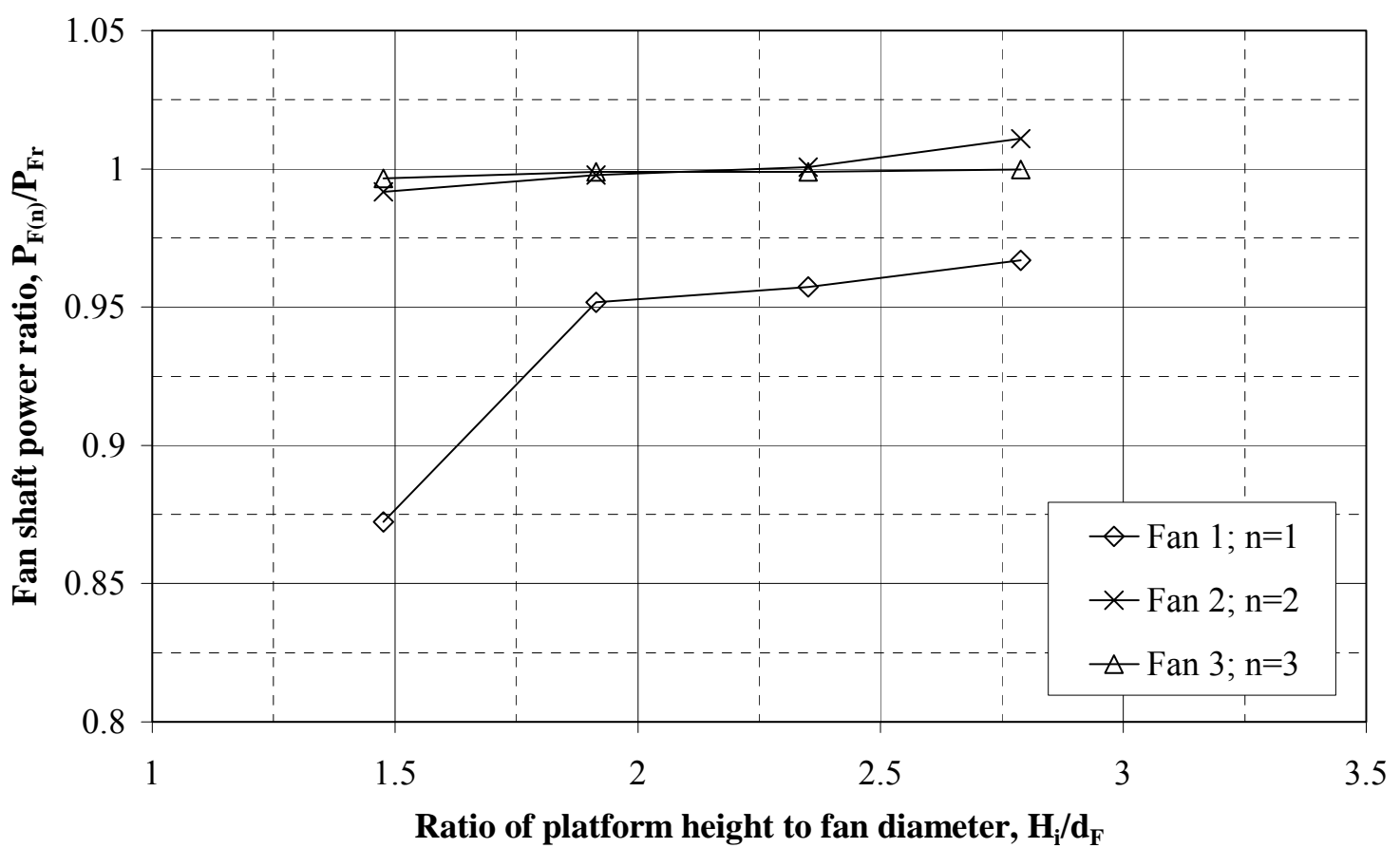

Figure 5.18: Fan shaft power ratio of the fans in a section of an ACSC at various platform heights 
Salta and Kröger [95SA1] present the following empirical relation to describe the reduction

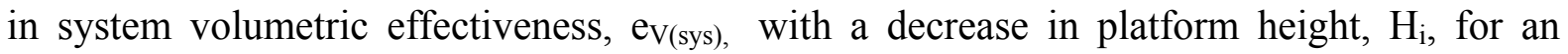
ACHE or ACC with $n_{F}$ fan rows

$\mathrm{e}_{\mathrm{V}((\mathrm{sys})}=0.985-\exp ^{(-\mathrm{x})}$

where

$X=\frac{\left(1+45 / \mathrm{n}_{\mathrm{F}}\right) \mathrm{H}_{\mathrm{i}}}{\left(6.35 \mathrm{~d}_{\mathrm{F}}\right)}$

This correlation is applicable for $\mathrm{n}_{\mathrm{F}}>1, \mathrm{H}_{\mathrm{b}} / \mathrm{d}_{\mathrm{F}}=0.19, \mathrm{~L}_{\mathrm{F}} / \mathrm{d}_{\mathrm{F}}=1.27$ and $\mathrm{d}_{\mathrm{h}} / \mathrm{d}_{\mathrm{F}}=0.26$. For the ACSC under consideration, $\mathrm{n}_{\mathrm{F}}=6, \mathrm{H}_{\mathrm{b}} / \mathrm{d}_{\mathrm{F}}=0.21, \mathrm{~L}_{\mathrm{F}} / \mathrm{d}_{\mathrm{F}}=1.29$ and $\mathrm{d}_{\mathrm{h}} / \mathrm{d}_{\mathrm{F}}=0.153$. Although the geometry and fans of the numerical model differs from the experimental apparatus used by Salta and Kröger [95SA1], the numerically determined system volumetric effectiveness shows a similar trend to that predicted by equation (5.3), as shown in figure 5.19.

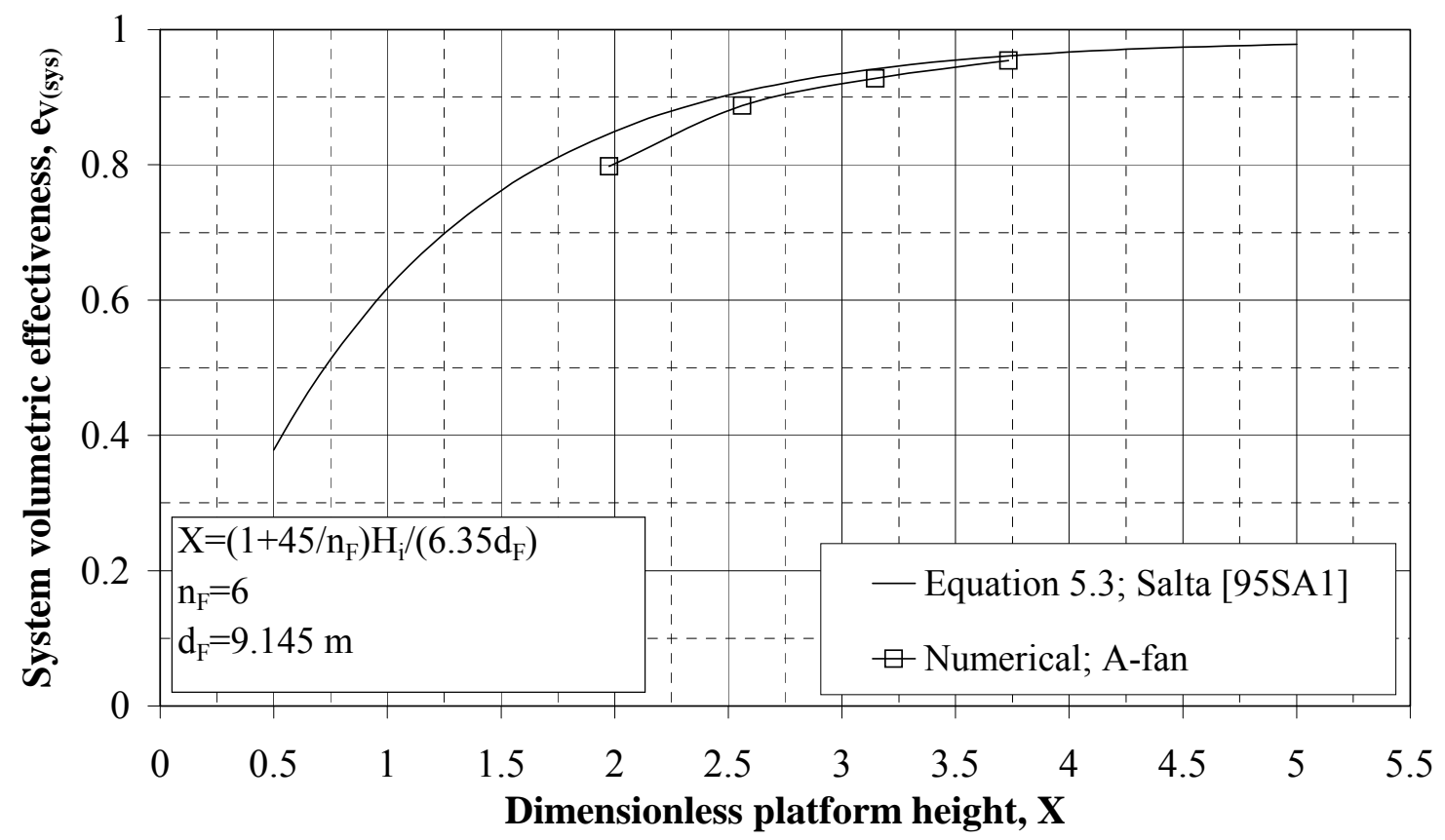

Figure 5.19: System volumetric effectiveness of an ACSC at various platform heights 


\subsubsection{Comparison of the performance of the A-fan and B-fan}

The numerically predicted performance of the B-fan $\left(d_{F}=9.145 \mathrm{~m}, \gamma_{\mathrm{cr}}=34.5^{\circ}\right)$ in the section of the ACSC at different platform heights is considered. The pressure and vector plots of the edge fan for the worst case of $\mathrm{H}_{\mathrm{i}}=14 \mathrm{~m}$ are shown in figure 5.20 and figure 5.21, respectively.

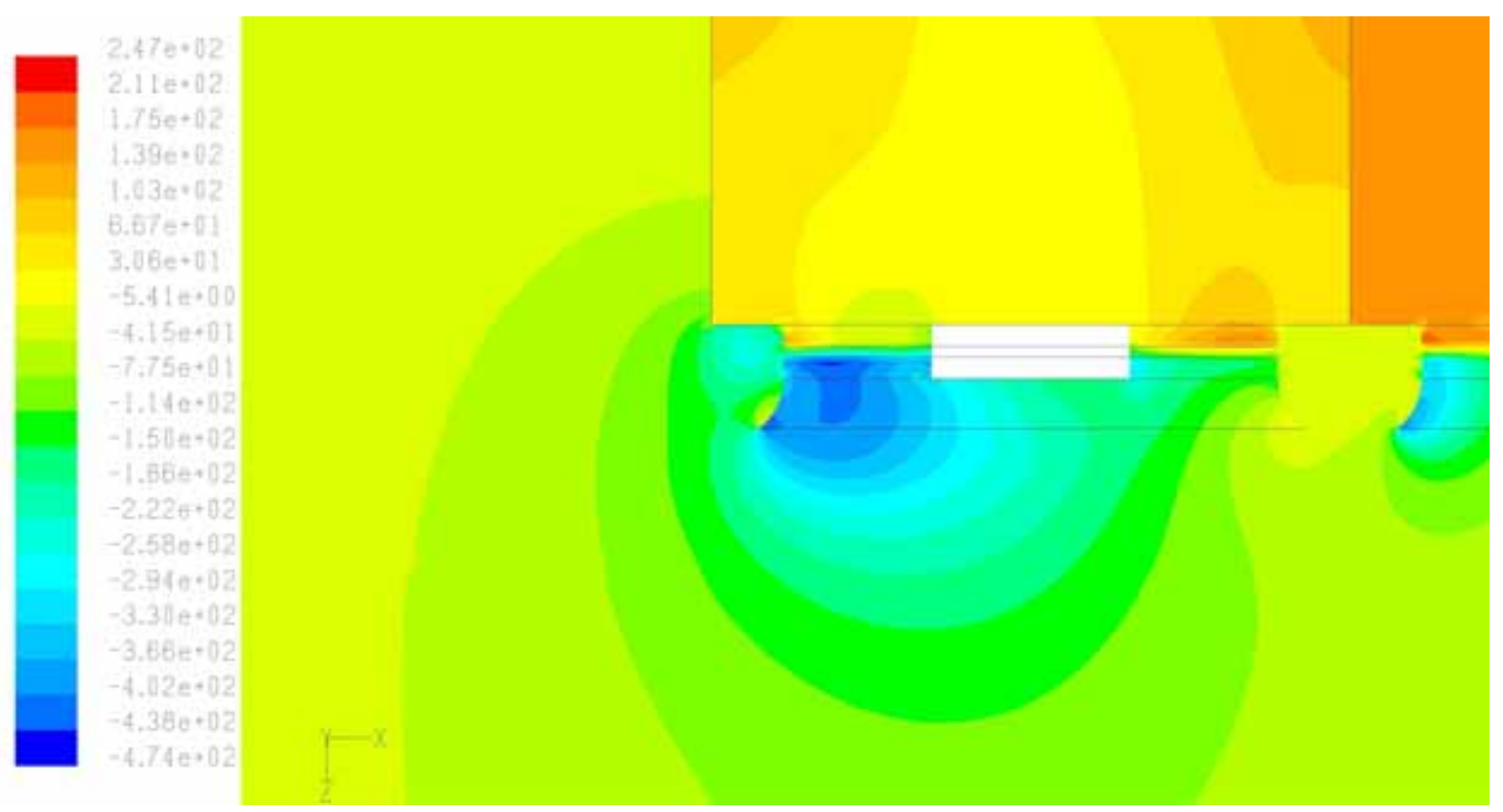

Figure 5.20: Static pressure (Pa) plot of edge fan employing the $\mathrm{B}$-fan with $\mathrm{H}_{\mathrm{i}}=14 \mathrm{~m}$

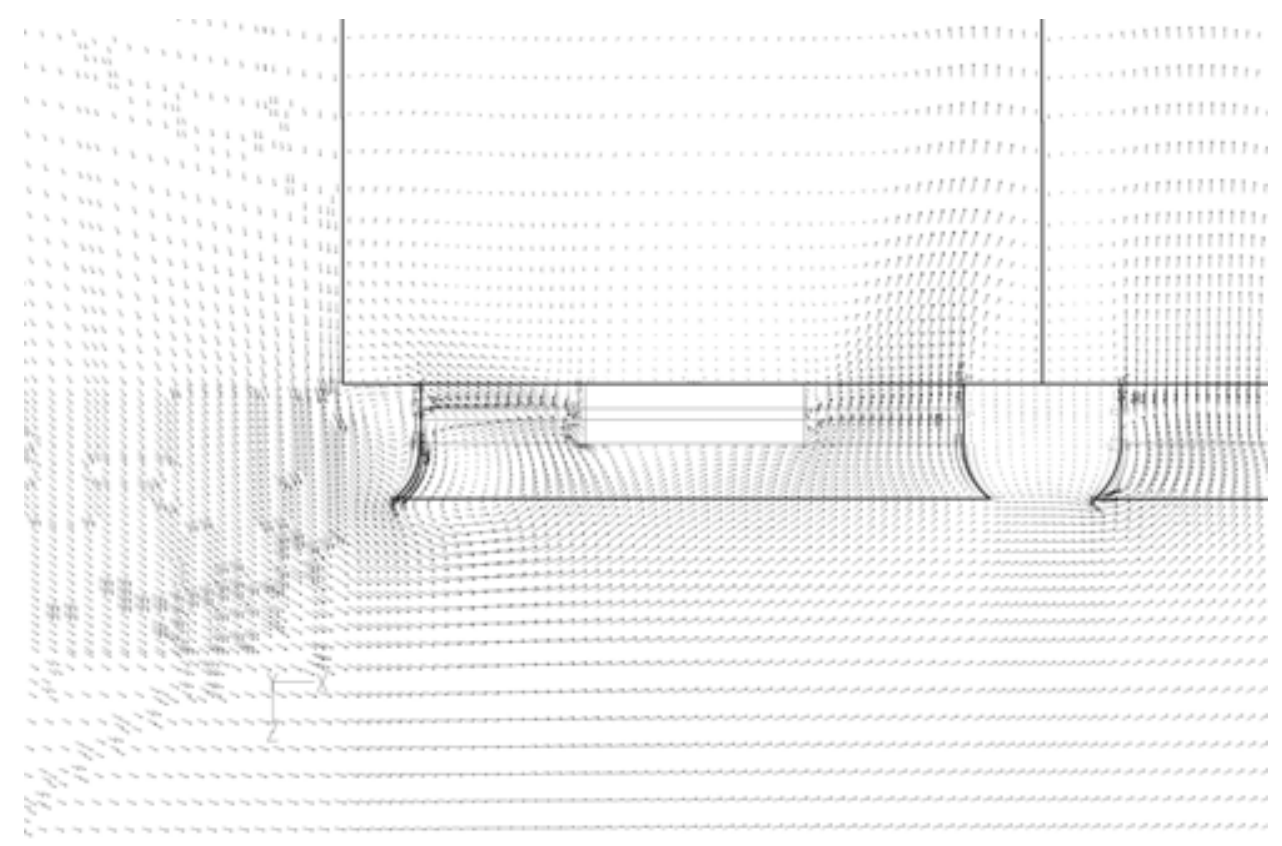

Figure 5.21: Vector plot of edge fan employing the B-fan with $\mathrm{H}_{\mathrm{i}}=14 \mathrm{~m}$ 
The local angle of attack at various radii of the edge fan, corresponding to the B-fan at platform heights of $\mathrm{H}_{\mathrm{i}}=26 \mathrm{~m}$ and $\mathrm{H}_{\mathrm{i}}=14 \mathrm{~m}$, is shown respectively in figure 5.22 and figure 5.23 as a function of blade angular position. It can be seen that the fraction of the fan blade area experiencing stall conditions $\left(\alpha>16^{\circ}\right)$, increases as the platform height is reduced.

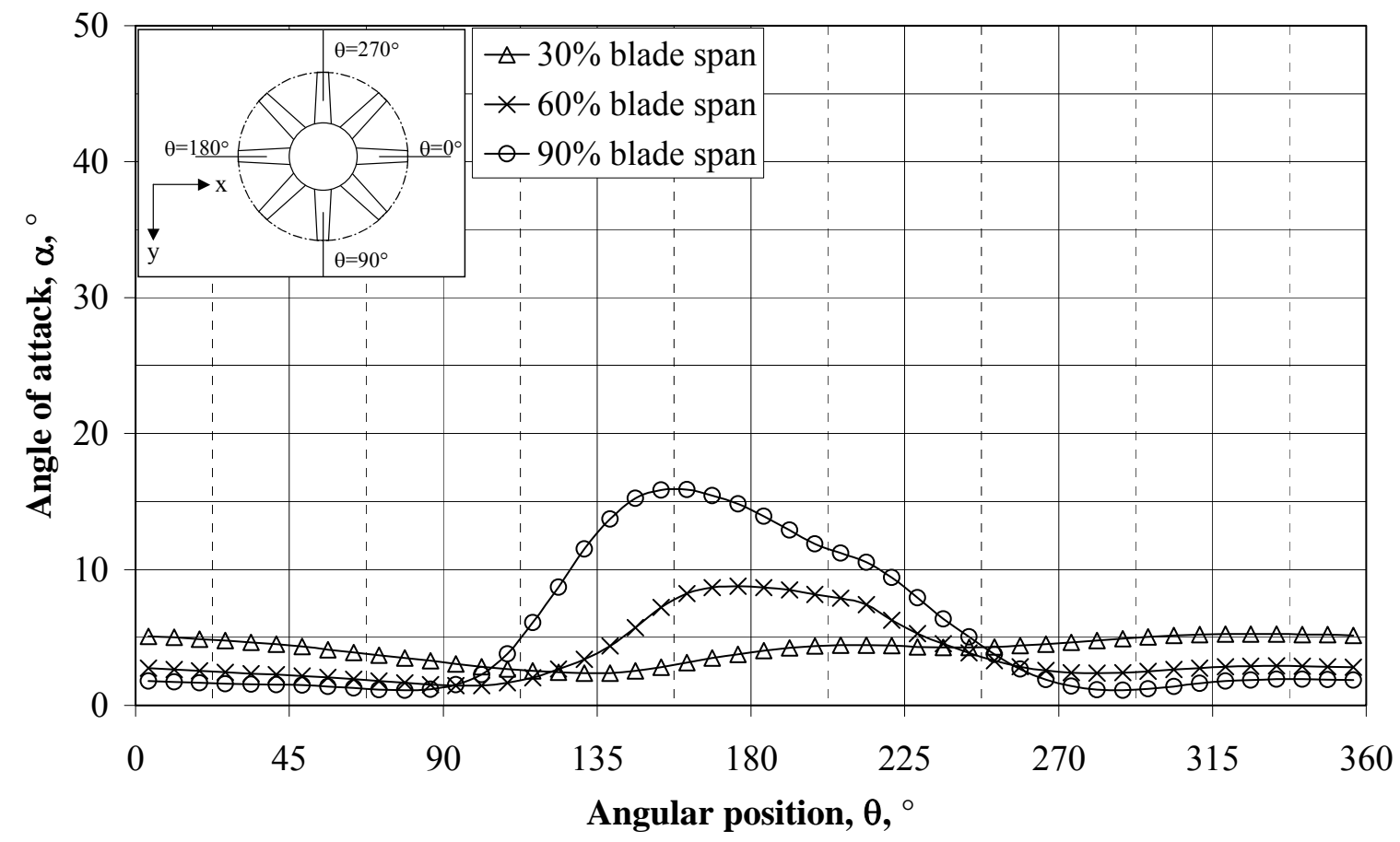

Figure 5.22: Angle of attack in the edge fan for the $\mathrm{B}$-fan at $\mathrm{H}_{\mathrm{i}}=26 \mathrm{~m}$

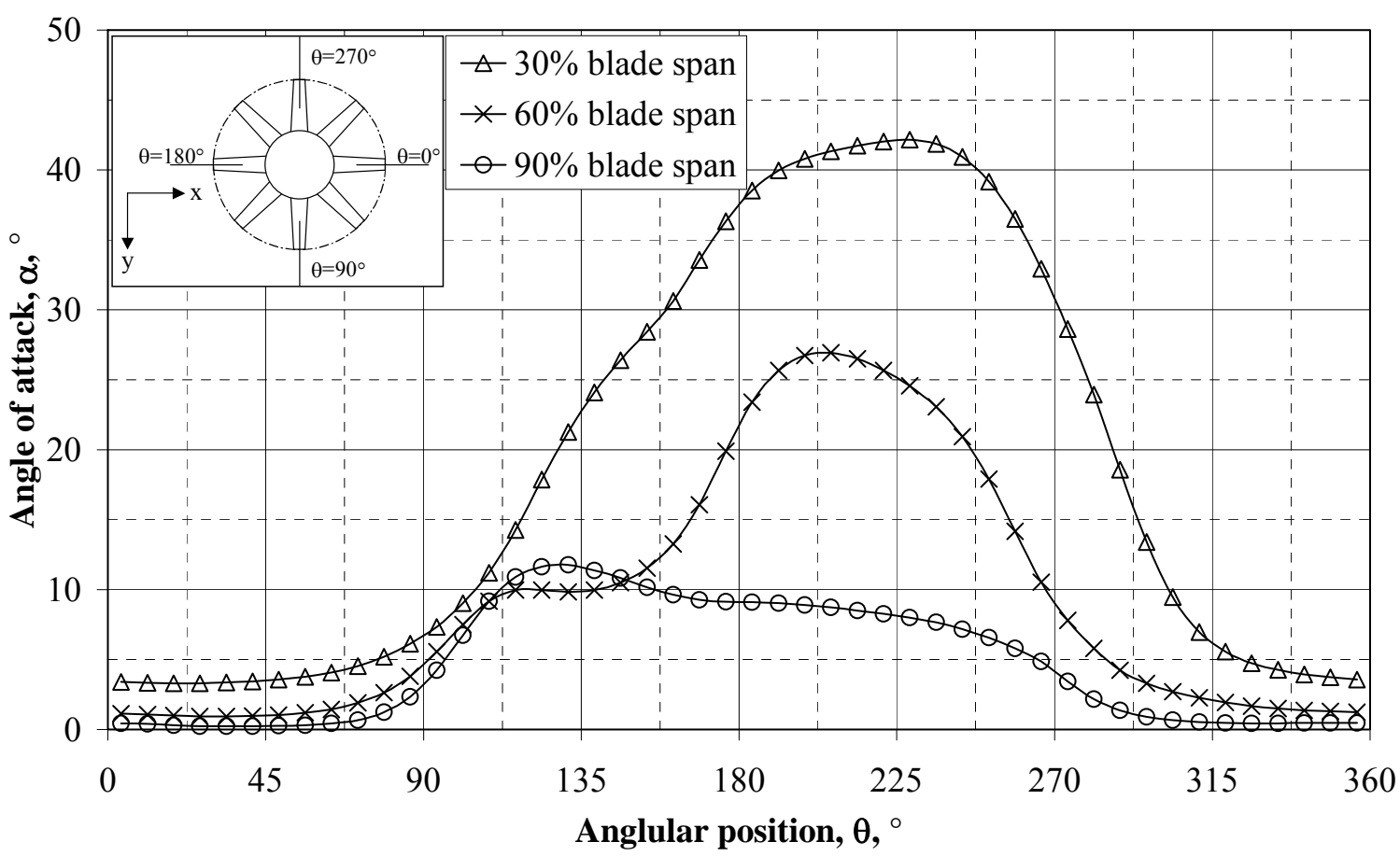

Figure 5.23: Angle of attack in the edge fan for the $\mathrm{B}$-fan at $\mathrm{H}_{\mathrm{i}}=14 \mathrm{~m}$ 
Figure 5.24 depicts the variation of volumetric effectiveness of the edge fan with platform height for both the A-fan and B-fan.

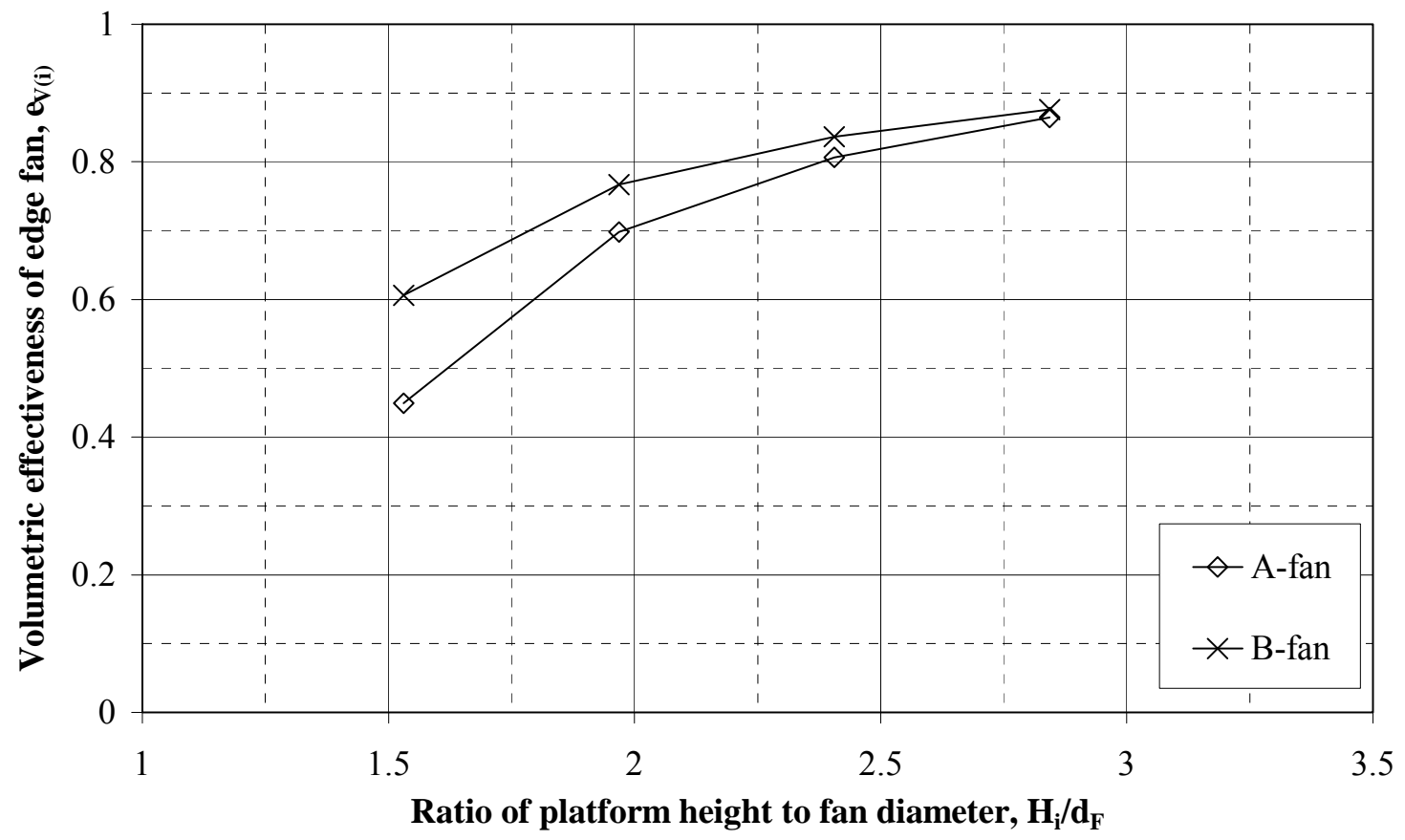

Figure 5.24: Volumetric effectiveness of the edge fan (for the A-fan and B-fan) in the section of the ACSC at various platform heights

The corresponding effect on fan shaft power is shown in figure 5.25.

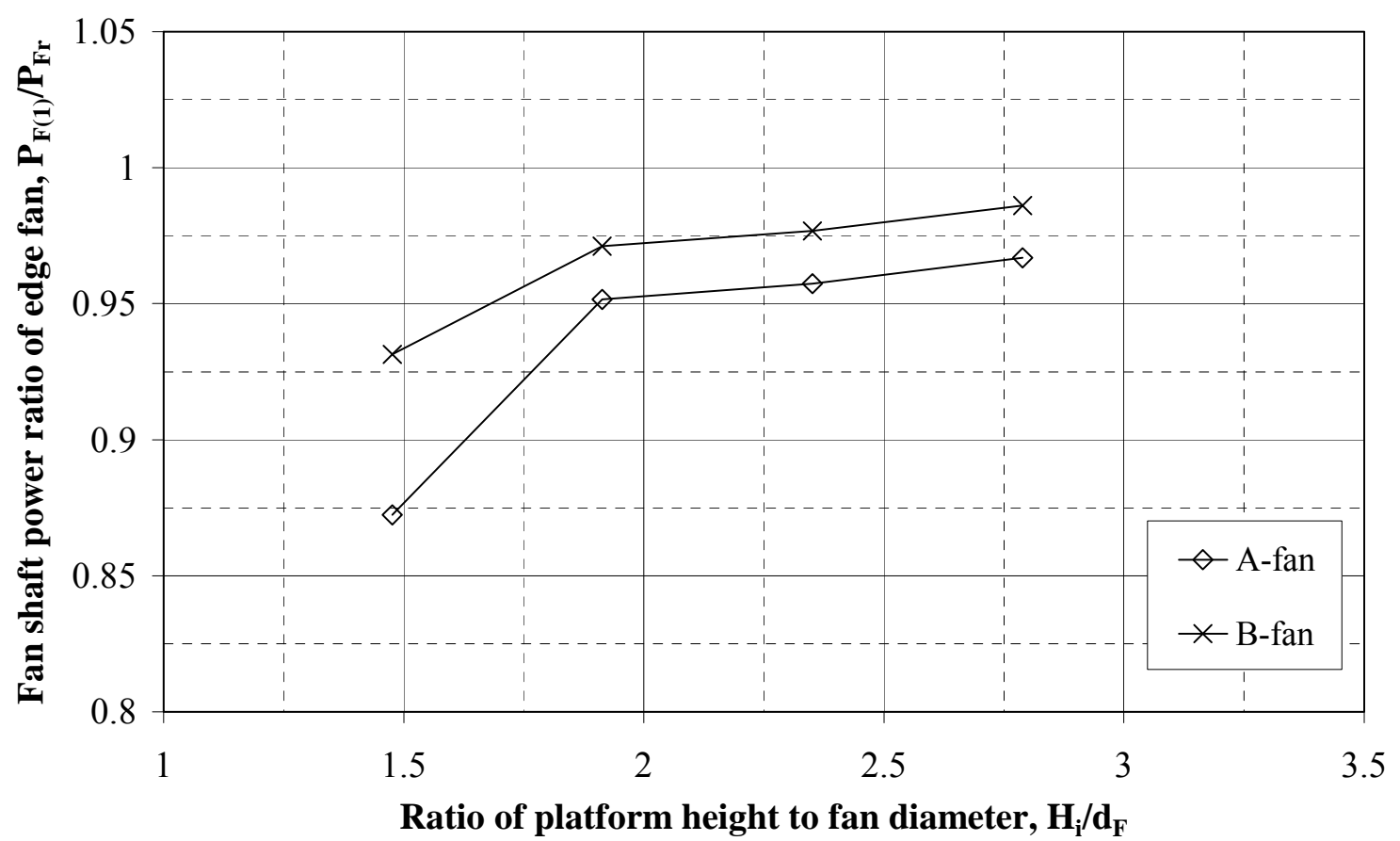

Figure 5.25: Fan shaft power ratio of the edge fan (for the A-fan and B-fan) in the section of the $\mathrm{ACSC}$ at various platform heights 
The corresponding system volumetric effectiveness for the A-fan and B-fan is shown in figure 5.26 .



Figure 5.26: System volumetric effectiveness for the A-fan and B-fan

\subsubsection{Effect of walkways and windscreens}

Based on experimental tests, Salta and Kröger [95SA1] have shown that the volumetric effectiveness of an ACHE (or ACC) can be improved by adding a solid walkway around the fan platform. In this section the effect of such a walkway on fan performance is numerically investigated. The effect of additional shade net windscreens, are also modelled. Four different configurations, or test cases, schematically shown in figure 5.27, are considered.

Edge fan

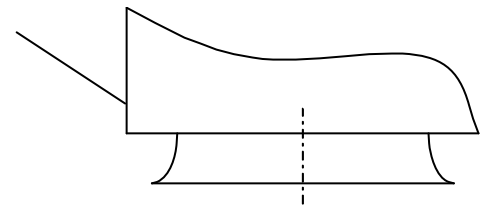

Case 0

Solid walkway $40 \%$ shade net

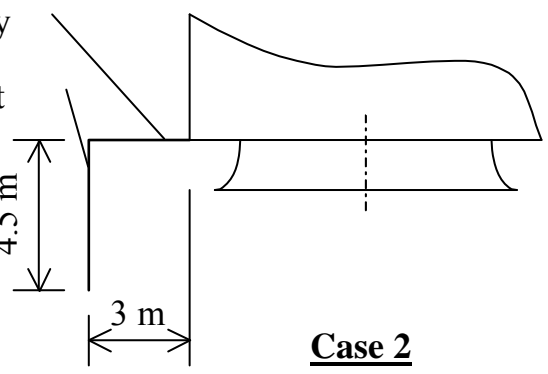

Solid walkway

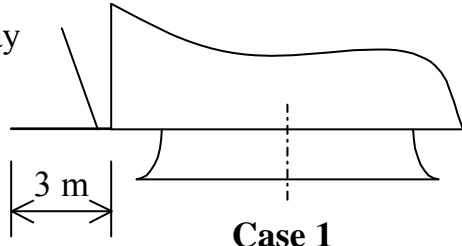

Case 1

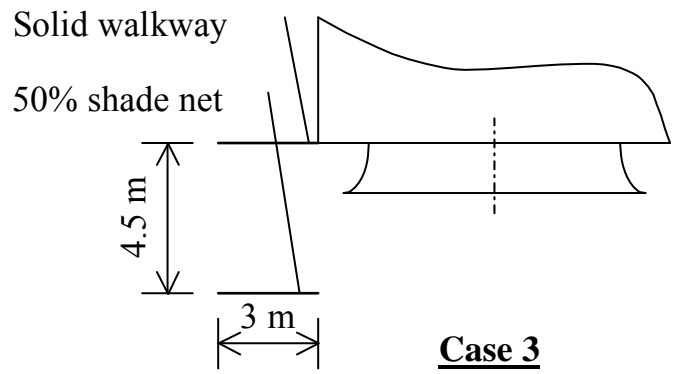

Figure 5.27: Four different walkway and windscreen configurations investigated 
The shade net screens were numerically modelled in FLUENT using the porous jump boundary condition. This condition calculates a pressure drop across a face in the flow domain, based on the normal velocity and a prescribed loss coefficient, i.e. $\Delta p=K 0.5 \rho v^{2}$. The loss coefficients for normal flow through the $40 \%$ and $50 \%$ shade net were experimentally determined by von Gossler [04VO1] and found to have values of 0.5737 and 1.13, respectively. Furthermore the solid walkway was modelled as a zero-slip wall.

It was found that the solid walkway resulted in a significant increase in volumetric effectiveness, mainly due to improved inlet conditions of the edge fan. This is illustrated in the static pressure and vector plots, shown in figure 5.28 and figure 5.29 respectively, for case 1 employing the A-fan at a platform height of $\mathrm{H}_{\mathrm{i}}=14 \mathrm{~m}$.

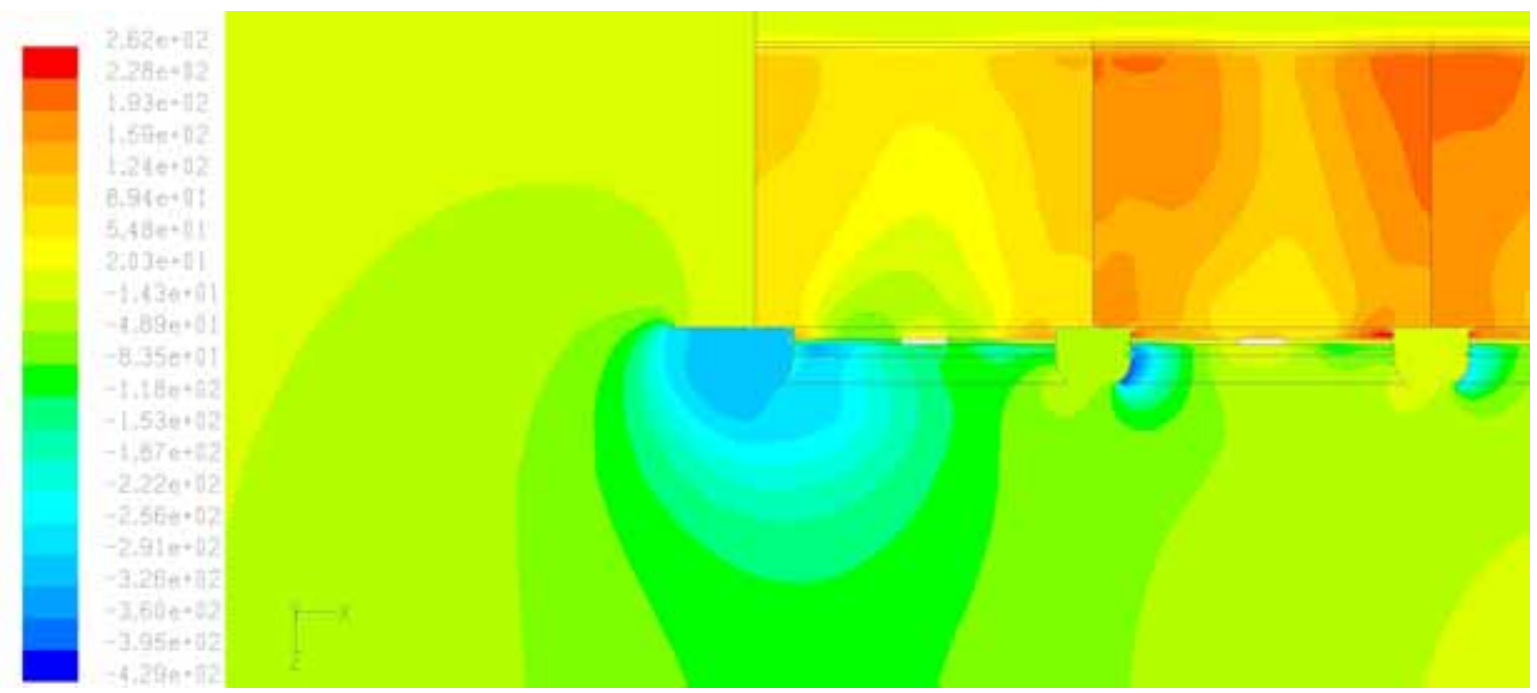

Figure 5.28: Static pressure (Pa) plot for case 1 employing the A-fan with $\mathrm{H}_{\mathrm{i}}=14 \mathrm{~m}$

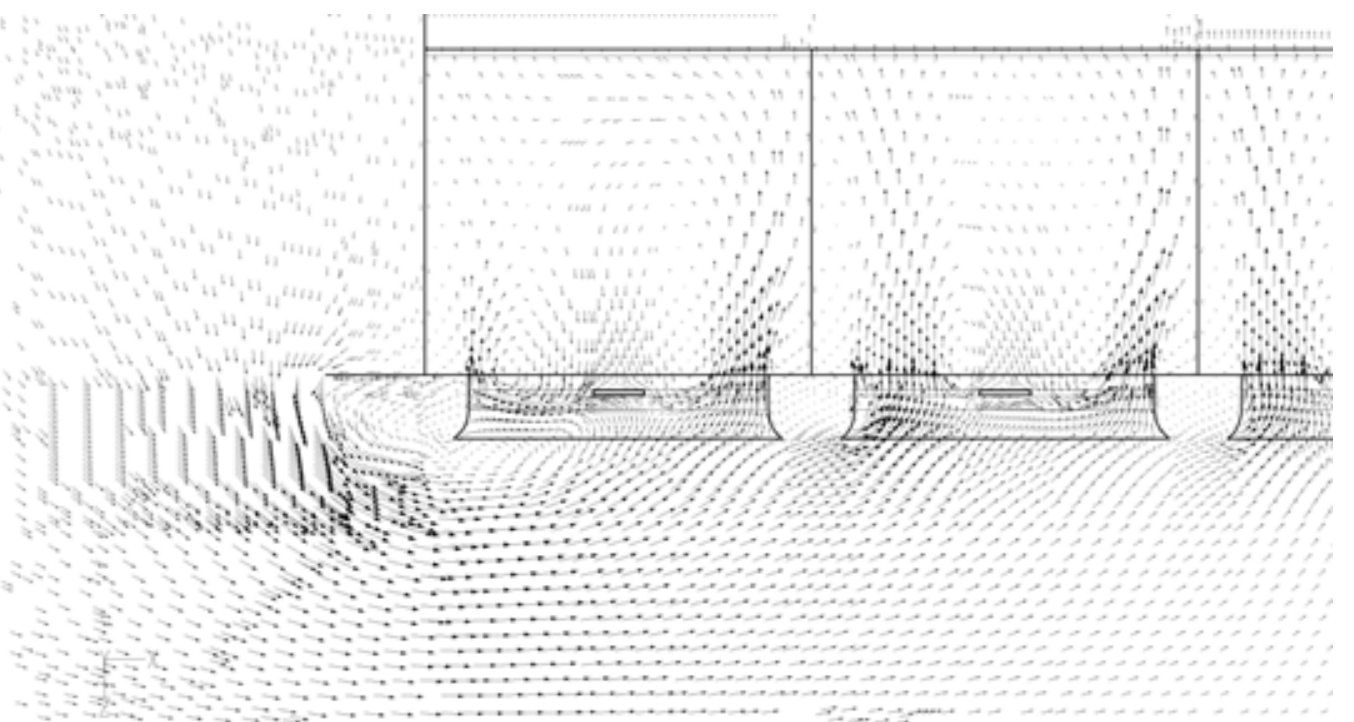

Figure 5.29: Vector plot for case 1 employing the A-fan with $\mathrm{H}_{\mathrm{i}}=14 \mathrm{~m}$ 
The volumetric effectiveness of the edge fan for cases 0 to 4 at various platform heights, employing the A-fan and B-fan, are respectively shown in figure 5.30 and figure 5.31.

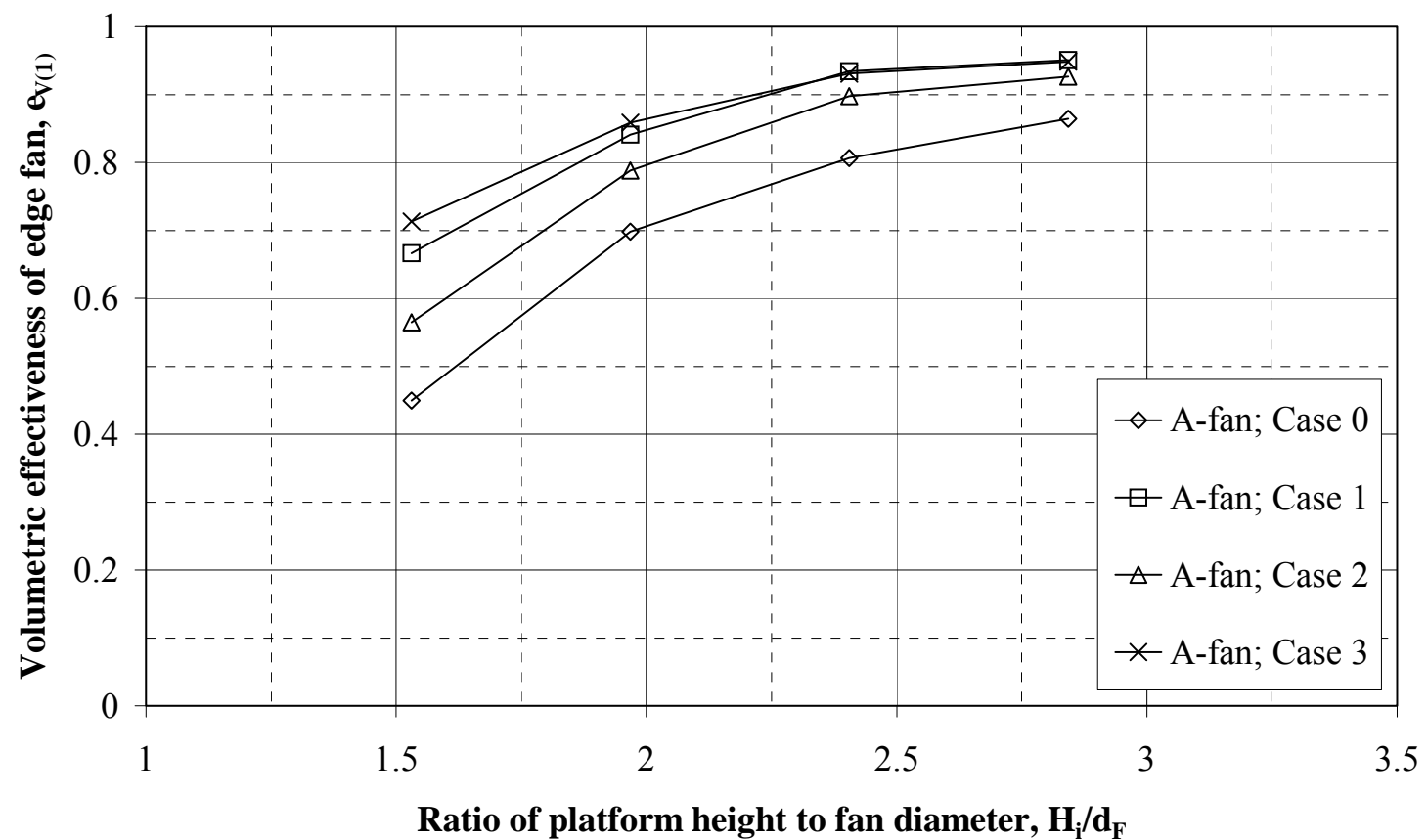

Figure 5.30: Volumetric effectiveness of the edge fan (A-fan) for cases 0 to 3

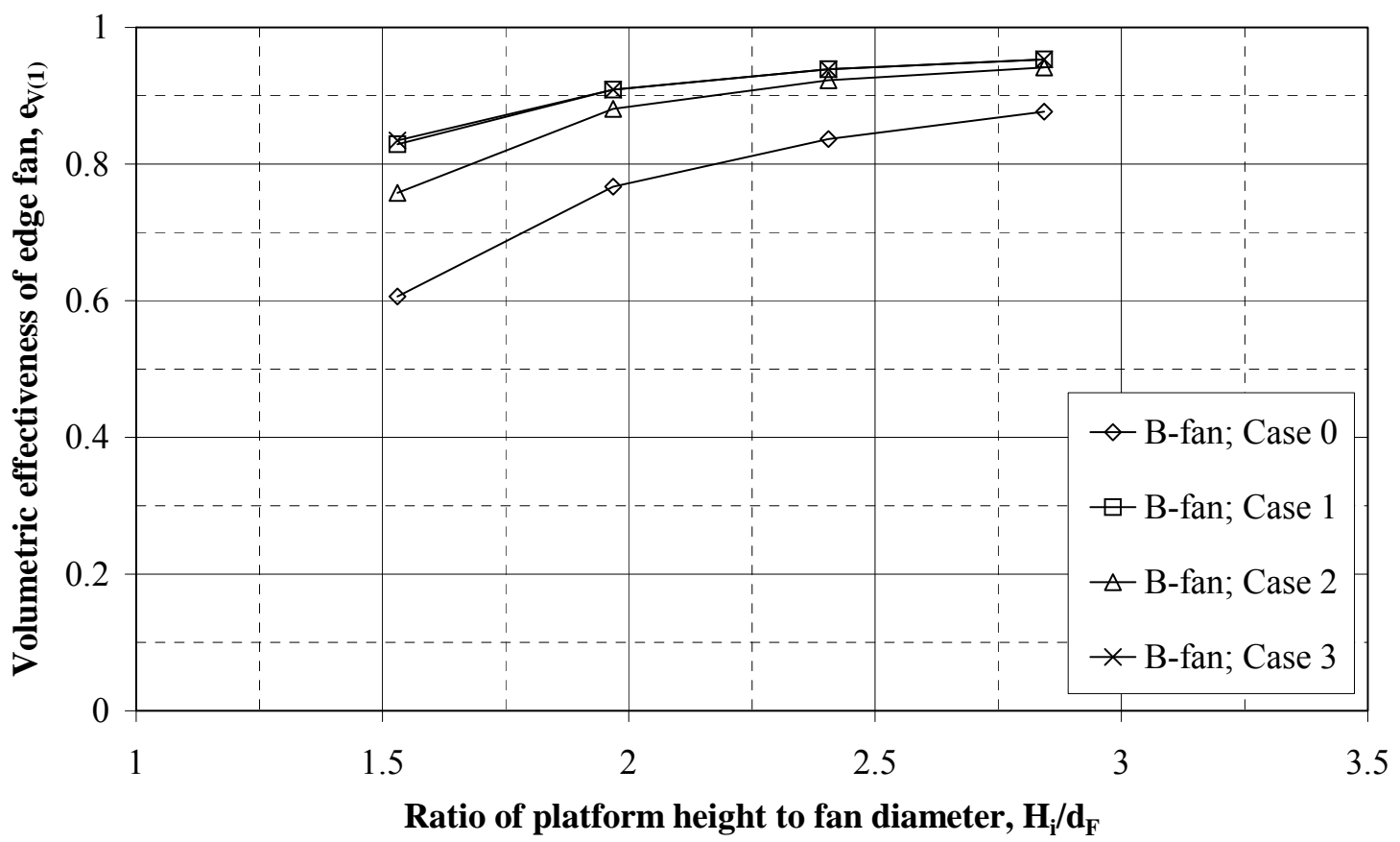

Figure 5.31: Volumetric effectiveness of the edge fan (B-fan) for cases 0 to 3 
The corresponding fan shaft power ratios for the A-fan and B-fan are respectively shown in figure 5.32 and figure 5.33.



Figure 5.32: Fan shaft power ratio of the edge fan (A-fan) for cases 0 to 3

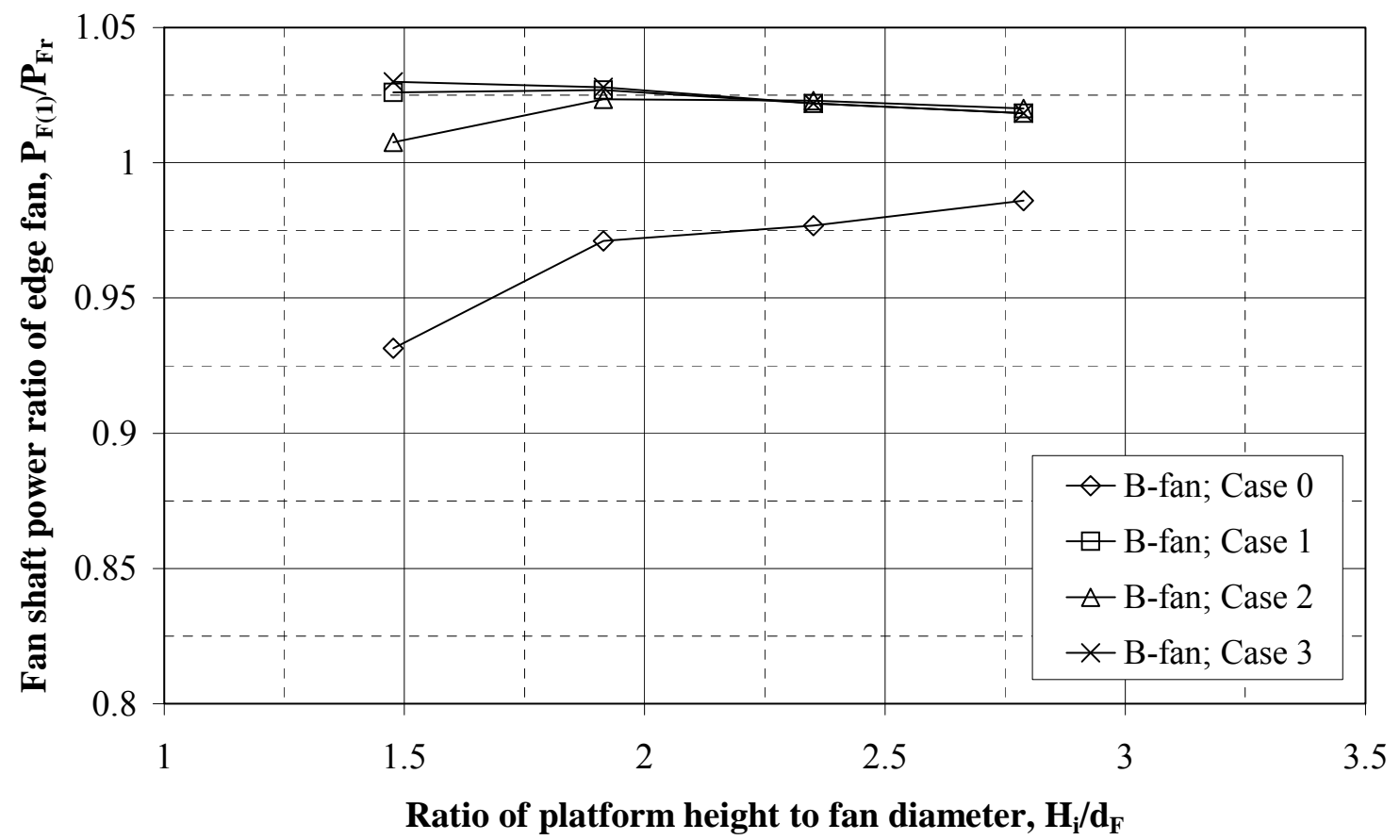

Figure 5.33: Fan shaft power ratio of the edge fan (B-fan) for cases 0 to 3 
The system volumetric effectiveness for cases 0 to 4 at various platform heights, employing the A-fan and B-fan, are respectively shown in figure 5.34 and figure 5.35.

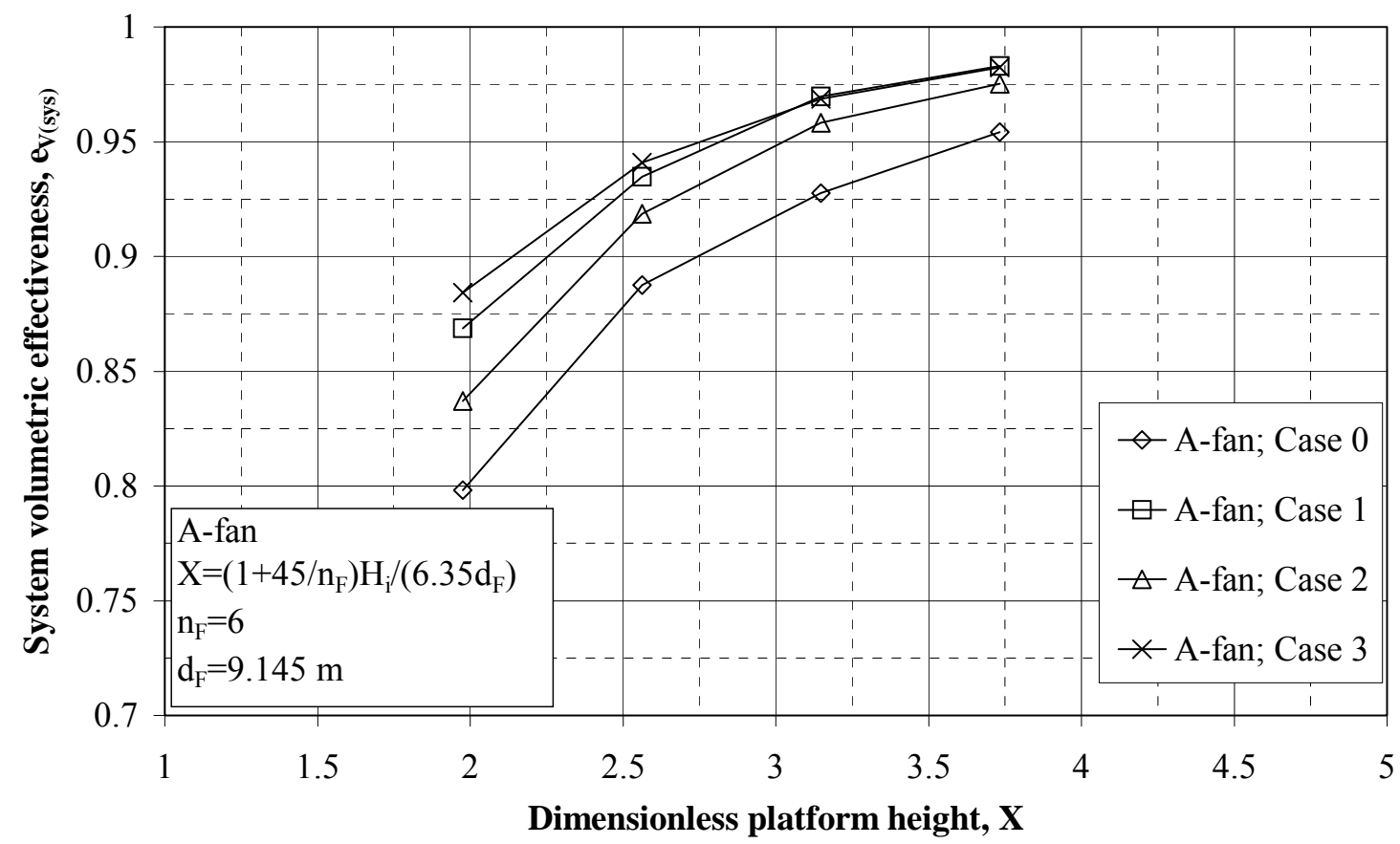

Figure 5.34: System volumetric effectiveness for cases 0 to 3 employing the A-fan

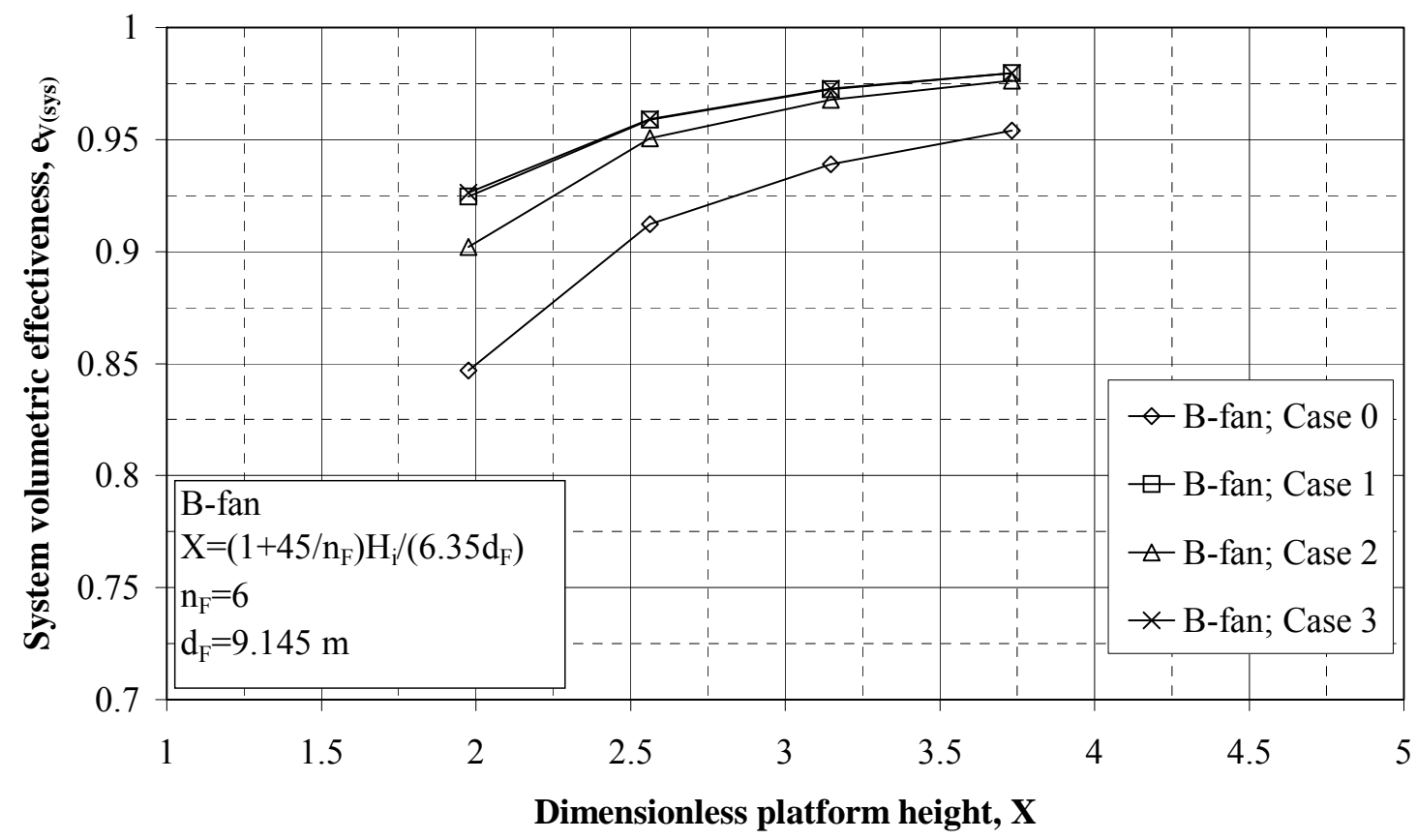

Figure 5.35: System volumetric effectiveness for cases 0 to 3 employing the B-fan

Numerical results showed that the vertical $40 \%$ shade net screen in case 2 had a choking effect on the flow. The horizontal $50 \%$ shade net in case 3 marginally improved the performance of the A-fan, whilst having no effect on the B-fan. 


\subsection{Cross-wind conditions}

The modelling of the effect of cross-wind, i.e. wind normal to the longitudinal axis of the fan platform, on the section of the ACSC using an essentially two-dimensional modelling approach, is considered. The objective of this part of the study is to assess whether or not this modelling approach results in a realistic representation of the air flow though the section of the ACSC located near the centre.

\subsubsection{Computational aspects}

The applied boundary conditions and the layout of the computational grid, are shown in figure 5.36 .

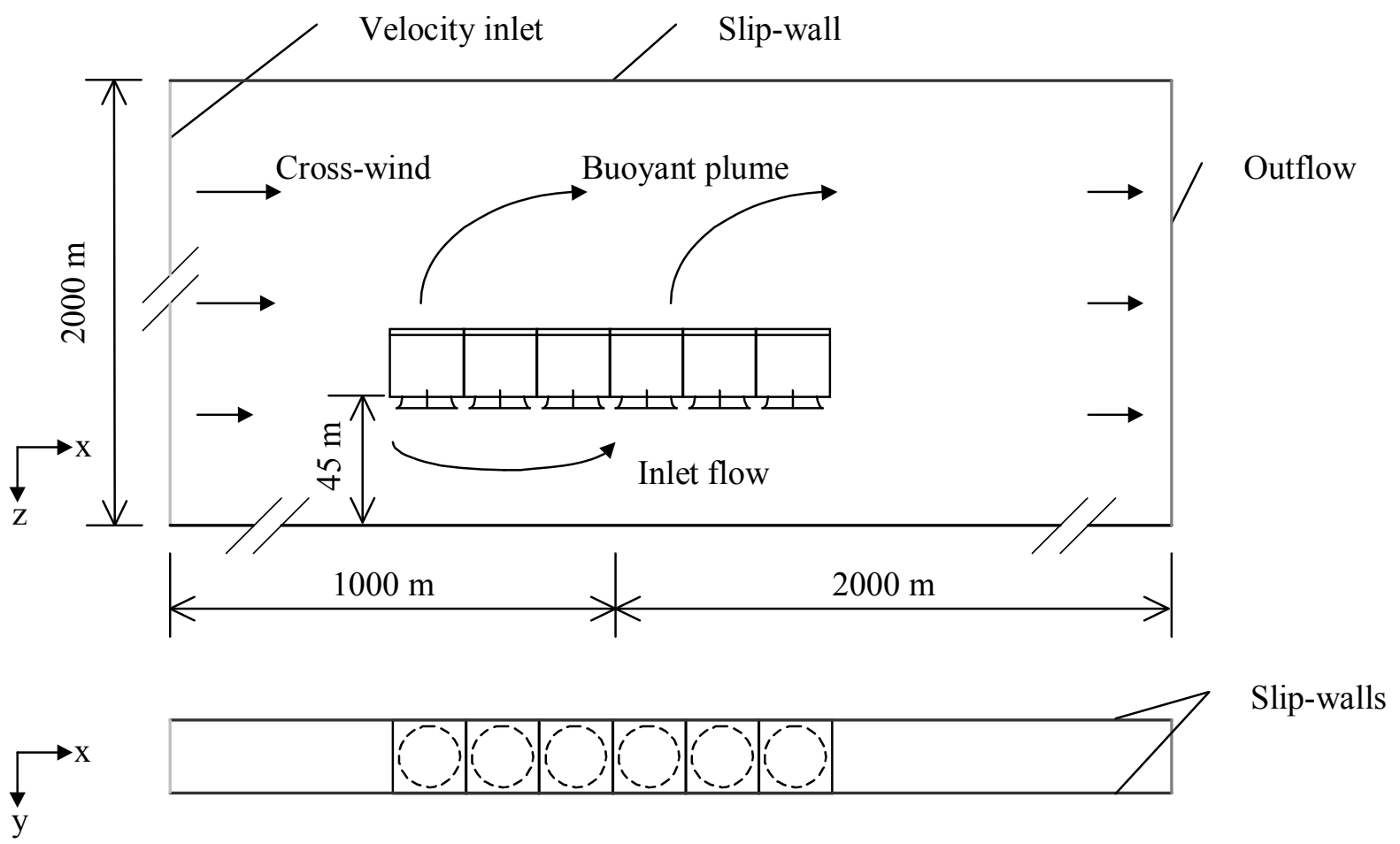

Figure 5.36: Layout of computational grid for modelling the section of an ACSC under cross-wind conditions (essentially two-dimensional modelling approach)

Air entering the flow domain through the velocity inlet boundary, is confined to a channeltype flow by the top, side and bottom slip-wall boundaries. The flow exits the domain through the outflow boundary, which is placed far enough downstream so as to avoid inflow across it. 
The inlet profiles for the wind velocity, $\mathrm{v}_{\mathrm{w}}$, turbulent kinetic energy, $\mathrm{k}$, and rate of dissipation, $\varepsilon$, as a function of vertical distance above the ground, h, as per Richards and Hoxey [93RI1], are respectively given by equation (5.3), (5.4) and (5.5)

$$
\begin{aligned}
& \mathrm{v}_{\mathrm{w}}=\frac{\mathrm{u}_{*}}{\kappa} \ln \left(\frac{\mathrm{h}+\mathrm{z}_{0}}{\mathrm{z}_{0}}\right) \\
& \mathrm{k}=\frac{\mathrm{u}_{*}^{2}}{\sqrt{\mathrm{C}_{\mu}}} \\
& \varepsilon=\frac{\mathrm{u}_{*}^{2}}{\kappa\left(\mathrm{h}+\mathrm{z}_{0}\right)}
\end{aligned}
$$

where the friction velocity $\mathrm{u} *$ is defined as

$$
\mathrm{u}_{*}=\frac{\kappa \mathrm{v}_{\mathrm{r}}}{\ln \left(\frac{\mathrm{h}_{\mathrm{r}}+\mathrm{z}_{0}}{\mathrm{z}_{0}}\right)}
$$

The constants appearing in equations (5.3) to (5.6) are defined in table 5.1.

Table 5.1: Constants in equations (5.3) to (5.6)

\begin{tabular}{ll}
\hline Von Karman constant & $\kappa=0.41$ \\
Surface roughness length ${ }^{*}$ & $\mathrm{z}_{0}=0.05 \mathrm{~m}$ \\
Constant in k- $\varepsilon$ turbulence model & $\mathrm{C}_{\mu}=0.09$ \\
Reference height & $\mathrm{h}_{\mathrm{r}}=45 \mathrm{~m}$ \\
Wind velocity at reference height & $\mathrm{V}_{\mathrm{r}}=3 \mathrm{~m} / \mathrm{s}$ \\
\hline *According to Eurocode 1 [91EU1] for terrain category II (i.e. farmlands with \\
occasional small farm structures, houses or trees)
\end{tabular}

Buoyancy effects on the plume were taken into account by means of the Boussinesq model, whereby the buoyancy body force in the momentum equation is approximated by

$$
\mathrm{F}_{\mathrm{z}}=\left(\rho-\rho_{\mathrm{a}}\right) \mathrm{g} \approx-\rho_{\mathrm{a}} \beta_{\mathrm{T}}\left(\mathrm{T}-\mathrm{T}_{\mathrm{a}}\right) \mathrm{g}
$$

where $\beta_{\mathrm{T}}$ is the thermal expansion coefficient, which is $1 / \mathrm{T}$ for an ideal gas, and $\mathrm{g}$ is the gravitational acceleration acting in the positive z-direction. 
The computational grid, consisting of 810000 cells, is shown in figure 5.37 and figure 5.38.

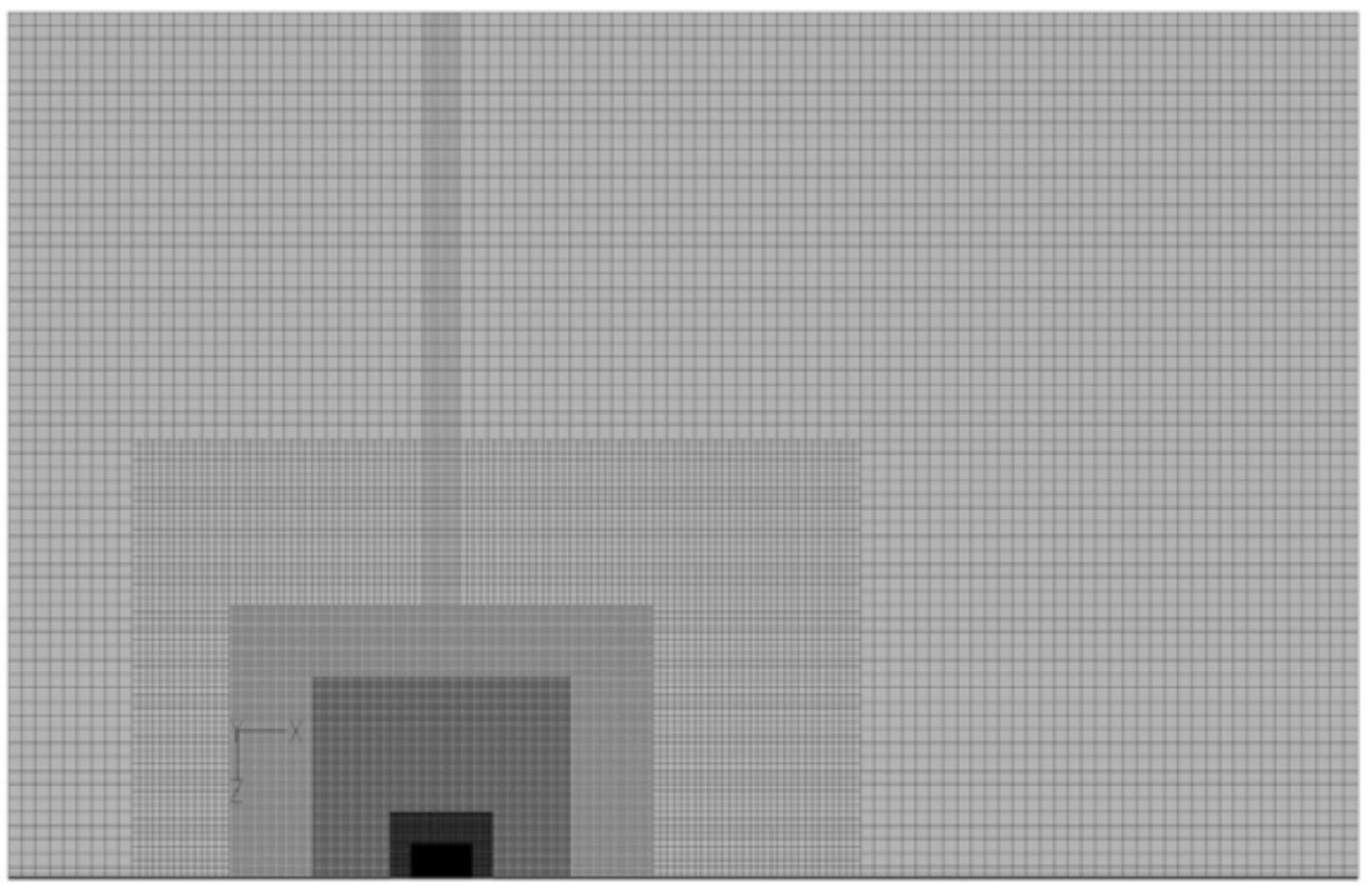

Figure 5.37: Computational grid for modelling the section of an ACSC under cross-wind conditions



Figure 5.38: Enlarged section view of computational grid near the fan units 


\subsubsection{Discussion}

Figure 5.39 and figure 5.40 respectively show the streamline and temperature plots after 70 iterations.

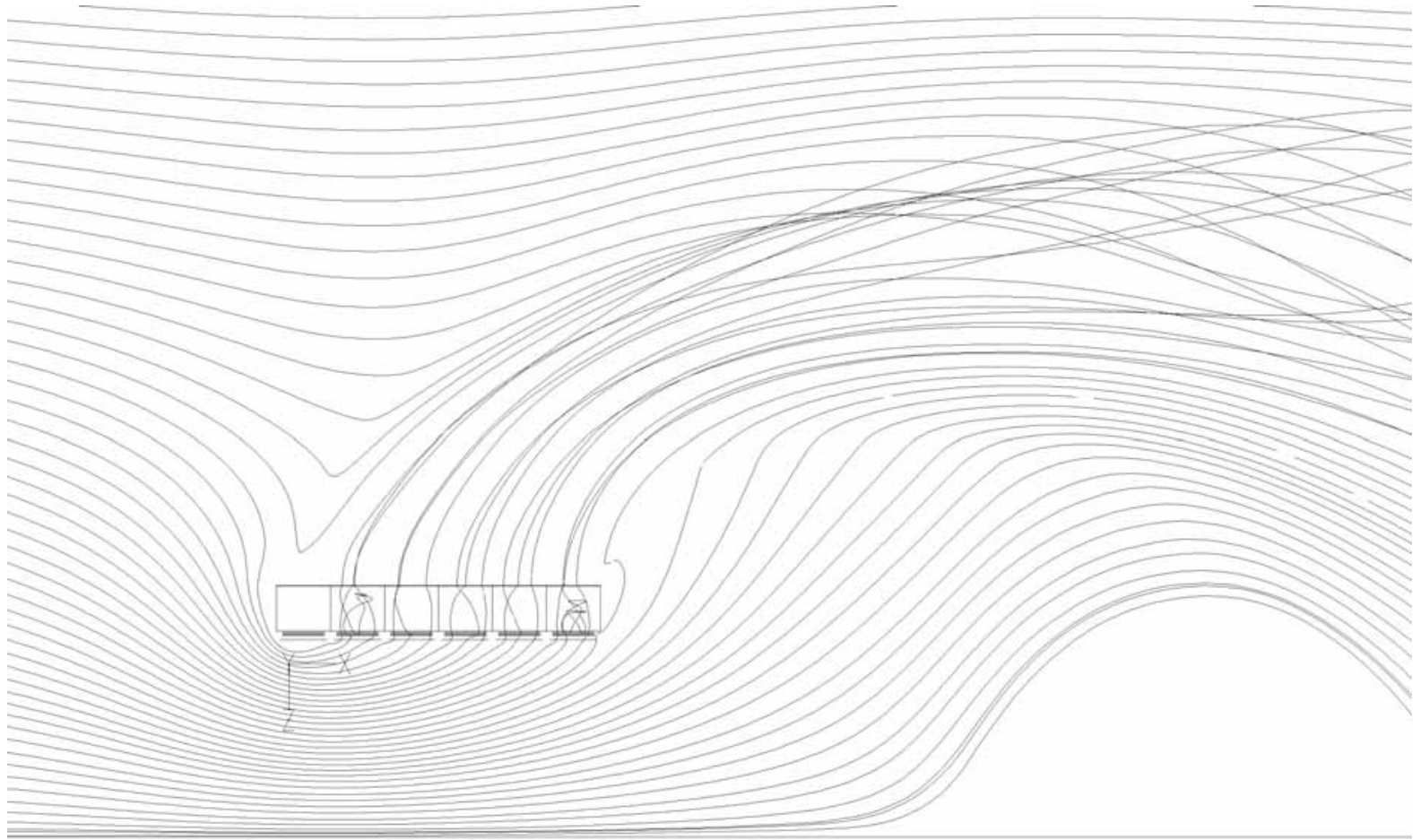

Figure 5.39: Streamline plot for a cross-wind of $3 \mathrm{~m} / \mathrm{s}$ after 70 iterations



Figure 5.40: Temperature $(\mathrm{K})$ plot for a cross-wind of $3 \mathrm{~m} / \mathrm{s}$ after 70 iterations 
For this channel-type flow, the air is prevented from moving around the buoyant plume, resulting in the plume being forced horizontally by the oncoming flow, or wind. Because the oncoming air or wind cannot penetrate or move around the plume, a low pressure pocket, or region, is formed underneath the plume, as shown in figure 5.41. Consequently, unrealistically high velocities are induced underneath the fan platform as the air is drawn to the low pressure region, as shown in figure 5.42 .

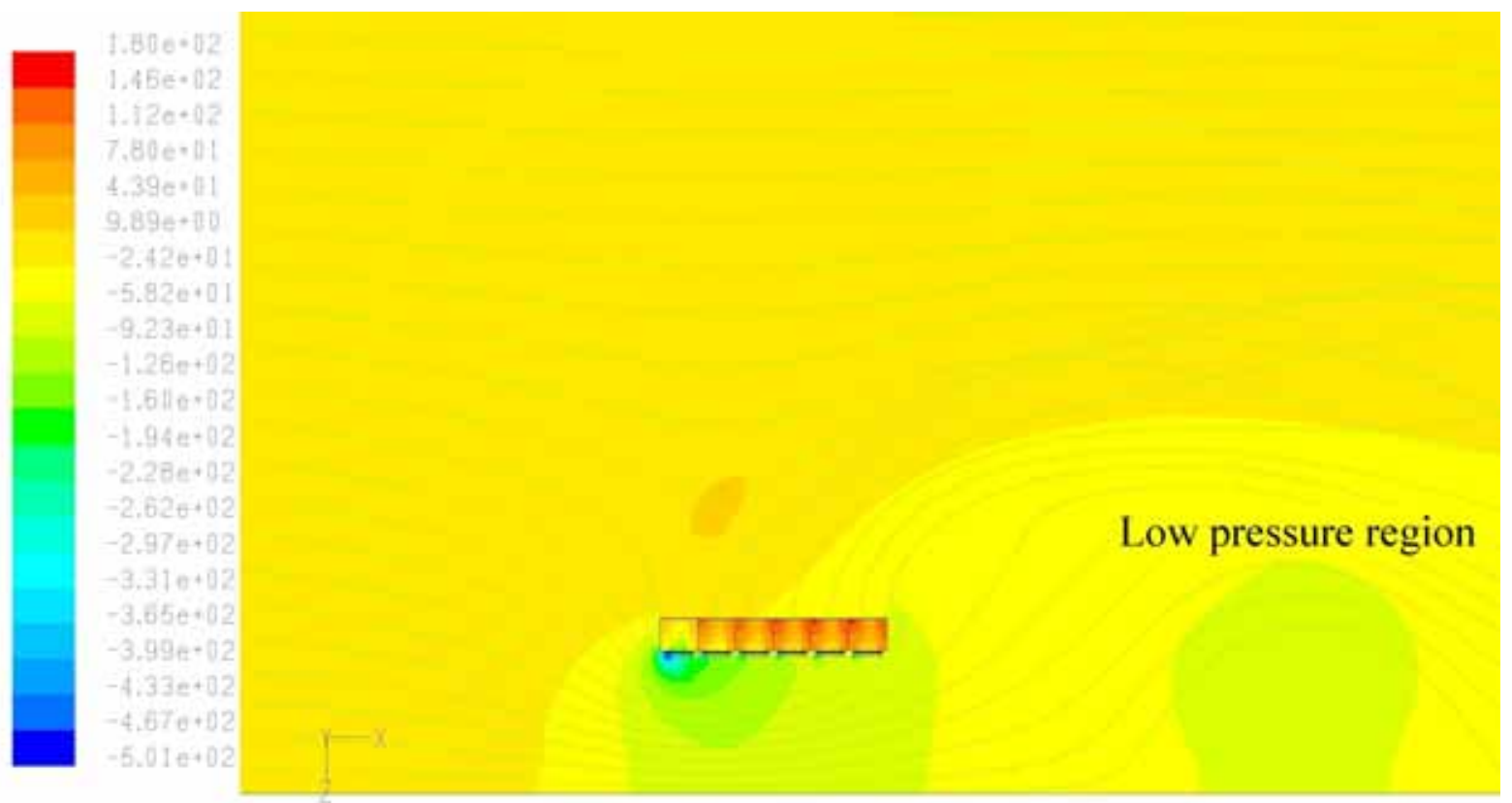

Figure 5.41: Static pressure $(\mathrm{Pa})$ plot for a cross-wind of $3 \mathrm{~m} / \mathrm{s}$ after 70 iterations

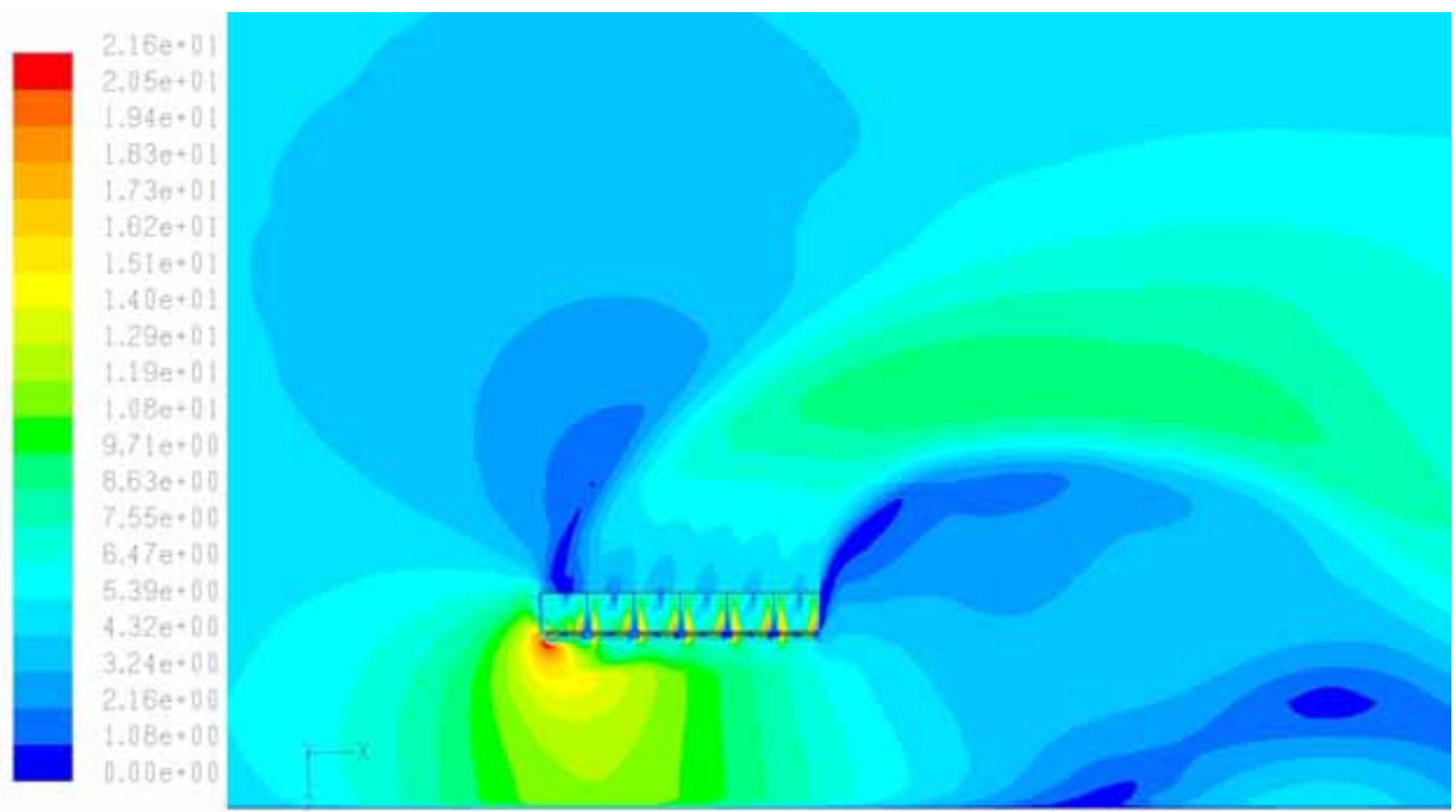

Figure 5.42: Velocity magnitude $(\mathrm{m} / \mathrm{s})$ plot for a cross-wind of $3 \mathrm{~m} / \mathrm{s}$ after 70 iterations 
With further iteration it was found that the average velocity underneath the fan platform increased to around $20 \mathrm{~m} / \mathrm{s}$, resulting in backflow through the first two fan units, as shown in the temperature plot in figure 5.43.

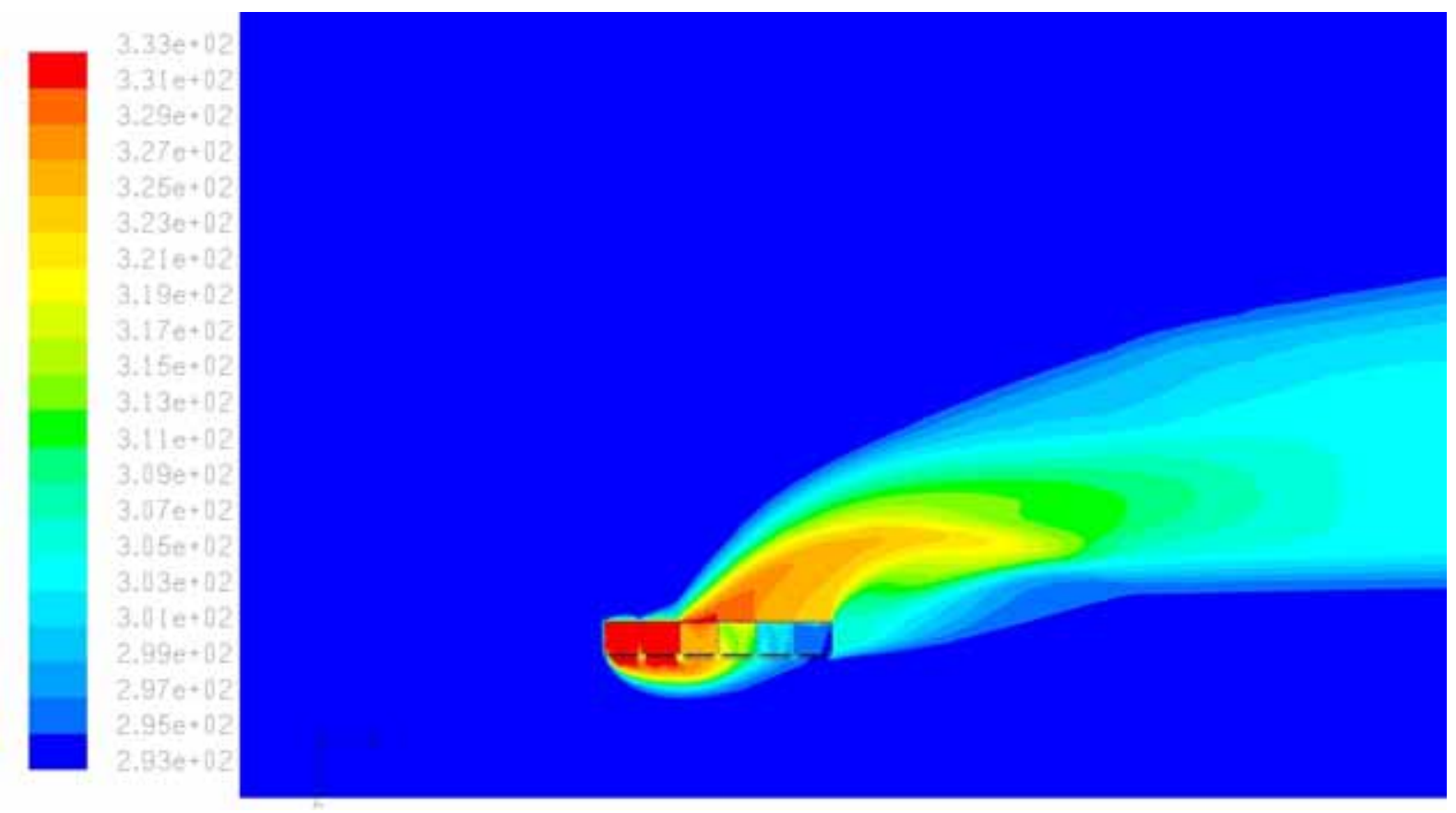

Figure 5.43: Temperature $(\mathrm{K})$ plot for a cross-wind of $3 \mathrm{~m} / \mathrm{s}$ after 300 iterations

Van Staden [00VA1] numerically modelled the air flow through the ACSC of the Matimba power plant (refer to figure 1.4 and figure 1.5), using a full three-dimensional modelling approach. For this relatively long ACSC with a platform height of $45 \mathrm{~m}$, van Staden [00VA1] reports a plume rise angle in the order of $40^{\circ}$ to $50^{\circ}$ for low cross-wind speeds $(\approx 3 \mathrm{~m} / \mathrm{s})$. Van Aarde [90VA1] who conducted extensive experimental testing at Matimba under various wind conditions, does not report any backflow occurring. The nearly horizontal, or $90^{\circ}$, plume dispersion and backflow predicted by the essentially two-dimensional numerical model in the current investigation, is therefore considered to be unrealistic.

It can be deduced that the effective and realistic numerical simulation of the effect of wind on fan performance and plume dispersion associated with an ACSC, requires a full threedimensional numerical model. 


\section{Conclusions and recommendations}

\subsection{Importance of this study}

A forced draft air-cooled steam condenser (ACSC) in a direct cooled power plant condenses steam, in a closed power cycle. Axial flow fans in the ACSC move ambient air through an A-frame configuration of finned tube heat exchanger bundles in order to reject the latent heat of the condensing steam to the environment. The heat rejection capacity of an ACSC is proportional to the air mass flow rate and the temperature difference between the ambient air and the finned tubes. Therefore, owing to the dynamic interaction between the steam turbines and the ACSC, ambient conditions (i.e. dry bulb temperature, wind, etc.) and the flow rate delivered by the axial fans have a direct influence on the efficiency of such a direct air-cooled power plant. Consequently, the design and optimisation of an ACSC, requires a fundamental understanding of the performance reducing effects on axial fans.

\subsection{Research findings}

The flow field in a representative section (or sector) of an ACSC is numerically investigated using the CFD code FLUENT. Based on interpretation of CFD results (i.e. vector, pressure and streamline plots) the conclusion was drawn that inlet flow distortions caused by induced cross-drafts have an adverse effect on fan flow rate due to a combination of the following factors:

a) Increased inlet flow losses (i.e. flow separation at the edge of the fan inlet) resulting in a decrease in flow rate.

b) Maldistribution of air into the fan (i.e. non-uniform inlet profiles) resulting in fan blade stall and reduction in aerodynamic efficiency.

c) Off-axis inflow conditions, which decreases the static pressure rise generated by the fan.

Because of the complex nature of the flow it is difficult to quantify the relative contribution of each of the abovementioned effects. Such an analysis is beyond the scope of the current 
investigation. With reference to the objectives stated in section 1.3, corresponding discussions of the research results are given.

\subsubsection{Numerical prediction of fan characteristics}

Two axial flow fans respectively referred to as the A-fan and the B-fan were considered. The A-fan is a commercially available fan commonly found in industrial cooling plants, whilst the B-fan is a prototype fan designed by Bruneau [94BR1] for application in an ACSC. The A-fan and the $B$-fan have the same diameter $d_{F}=9.145 \mathrm{~m}$, number of blades $n_{b l}=8$, and rotational speed $\mathrm{N}=125 \mathrm{rpm}$, but feature hub-tip-ratios of respectively $\mathrm{d}_{\mathrm{h}} / \mathrm{d}_{\mathrm{F}}=0.153$ and $\mathrm{d}_{\mathrm{h}} / \mathrm{d}_{\mathrm{F}}=0.4$.

An actuator disc model was used to numerically simulate and predict the performance of the axial fans. The aforementioned model entails the calculation of momentum source terms based on blade element theory, thereby modelling the effect of an axial flow fan without actually modelling the fan blades as rotating solid surfaces in the flow domain. In order to validate the numerical fan model, the numerically predicted free inlet, free outlet fan characteristics were compared to data provided by the manufacturer in the case of the A-fan, and to experimental data measured by Stinnes [93ST1] in the case of the B-fan. Good consistency of the numerical predictions was found, as discussed in section 4.3.

\subsubsection{Effect of platform height on fan performance}

An ACSC consisting of six long adjacent fan rows was considered. A section located near the centre of the platform was modelled under windless conditions assuming essentially two-dimensional flow.

At a platform height of $\mathrm{H}_{\mathrm{i}} / \mathrm{d}_{\mathrm{F}}=2.84$, the volumetric efficiency for the edge fan was found to be $86.4 \%$ in the case of the A-fan, due to the effect of inlet flow distortions. It was found that lowering the platform height caused the flow separation and distortion at the inlet to become more severe, consequently reducing the flow rate further. Volumetric effectiveness of the edge fan at the lowest platform height of $\mathrm{H}_{\mathrm{i}} / \mathrm{d}_{\mathrm{F}}=1.53$ for the case of the A-fan, was predicted to be $44.9 \%$ which corresponded to a system volumetric effectiveness of $79.8 \%$. Numerical predictions displayed similar trends as the experimental results of Salta and Kröger [95SA1]. In addition to the reduction in flow rate, the fan shaft power ratio decreased from $96.7 \%$ for 
$\mathrm{H}_{\mathrm{i}} / \mathrm{d}_{\mathrm{F}}=2.84$ to $87.2 \%$ for $\mathrm{H}_{\mathrm{i}} / \mathrm{d}_{\mathrm{F}}=1.53$. Salta and Kröger [95SA1] did however not measure power consumption, hence the aforementioned trends could not be experimentally confirmed.

Although a platform height of $\mathrm{H}_{\mathrm{i}} / \mathrm{d}_{\mathrm{F}}=1.53$ is perhaps unrealistically low for practical ACSCs of this size, Duvenhage and Kröger [96DU1] states that, "The influence of wind on fan performance appears to exhibit features similar to the influence of platform height on fan performance". The reduction in fan performance under windless conditions at low platform heights, i.e. induced cross-draft conditions, may to a certain extent represent the effect of cross-winds on the performance of fans located on the windward edge of the fan platform. The relevance of this part of the study is therefore not only limited to the case of windless conditions.

\subsubsection{Comparison of performance of the A-fan and B-fan}

Numerical simulation of the B-fan at different platform heights showed overall superior performance of this particular fan. Volumetric effectiveness of the edge fan ranged between $87.6 \%$ for $\mathrm{H}_{\mathrm{i}} / \mathrm{d}_{\mathrm{F}}=2.84$, and $60.6 \%$ for $\mathrm{H}_{\mathrm{i}} / \mathrm{d}_{\mathrm{F}}=1.53$. The corresponding fan shaft power ratios varied between $98.1 \%$ and $93.1 \%$. The fact that the B-fan is less affected by inlet flow disturbances can in part be explained by referring to the performance characteristics of the A-fan and the B-fan shown in figure 6.1.

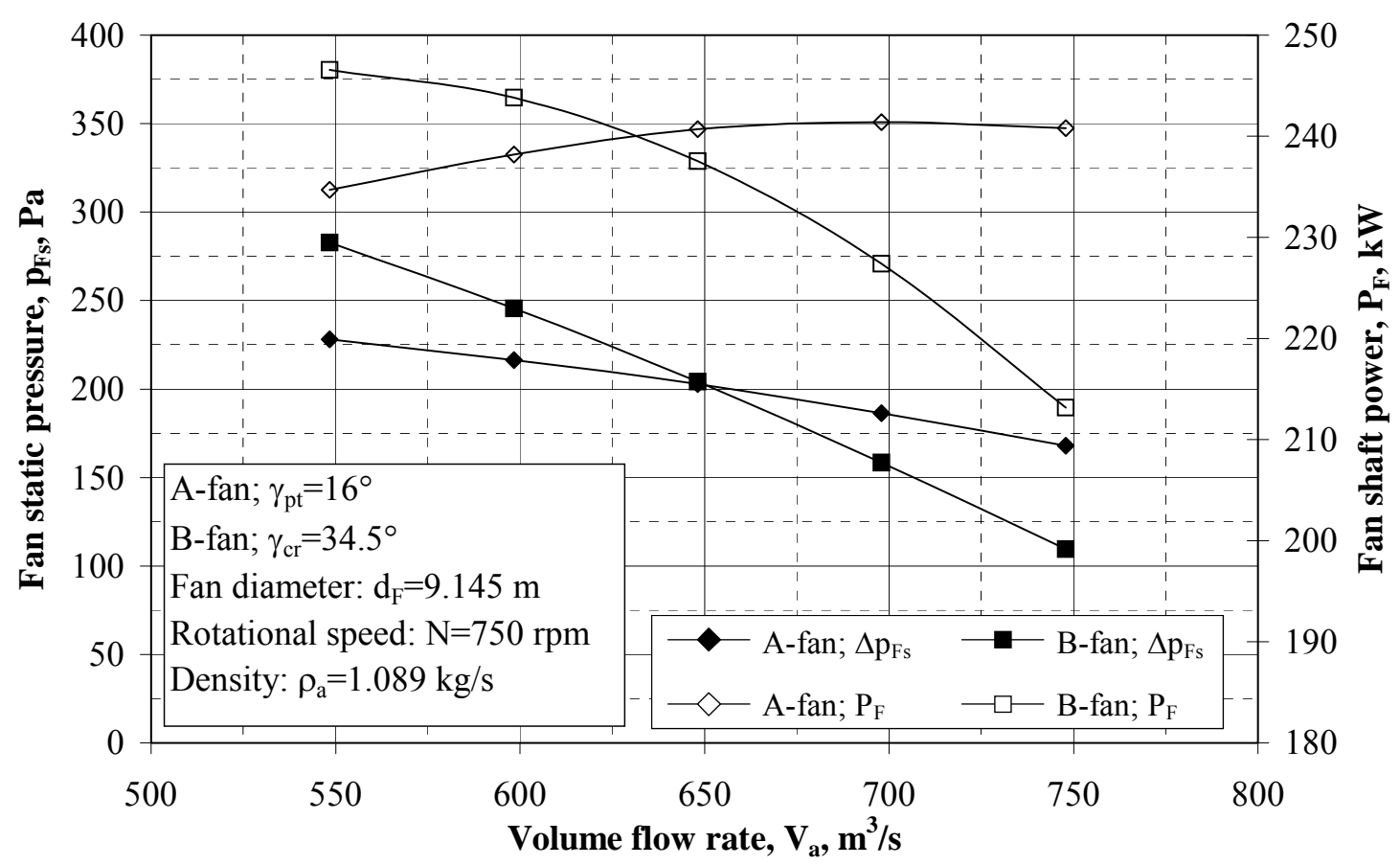

Figure 6.1: Numerically determined performance characteristics for A-fan on B-fan 
The B-fan exhibits a steeper fan static pressure gradient compared to that of the A-fan. Close scrutiny of the axial velocity profiles in the actuator disc model of the A-fan and B-fan, clarified the difference in the corresponding fan static pressure gradients. Figure 6.2 shows the axial velocity profiles for the A-fan and the B-fan at volume flow rates of $550 \mathrm{~m}^{3} / \mathrm{s}$ and $650 \mathrm{~m}^{3} / \mathrm{s}$.

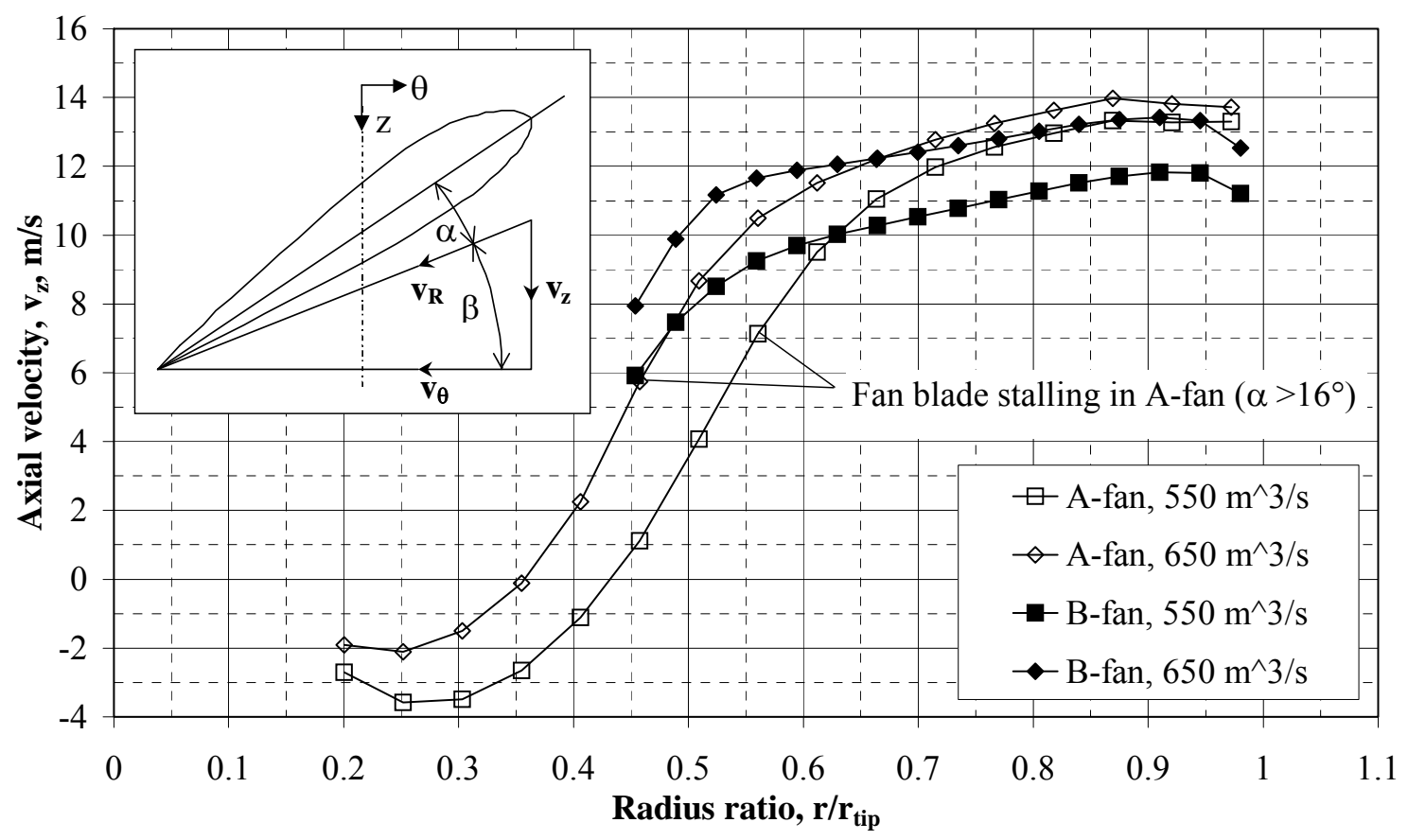

Figure 6.2: Axial velocity profiles in actuator disc model for A-fan and B-fan

The flow blockage effect caused by the recirculation or backflow near the hub of the A-fan (refer to figure 4.7) is clearly illustrated in the corresponding axial velocity profiles. It can be seen that for a flow rate of $550 \mathrm{~m}^{3} / \mathrm{s}$ only about $52 \%$ of the blade span is effectively utilised. Increasing the flow rate to $650 \mathrm{~m}^{3} / \mathrm{s}$, results in reduced flow blockage, so that approximately $64 \%$ of the blade span is utilised. Thus, the effective through-flow area increases with flow rate. The conclusion drawn is that the average axial velocity is not proportional to the flow rate. In contrast, the entire blade span of the B-fan operates below stall for the flow rates considered. With no flow blockage or recirculation occurring, the through-flow area remains constant and the average axial velocity is proportional to the flow rate.

It can be seen in figure 6.2 that for a given change in flow rate, the corresponding change in axial velocity, $\mathbf{v}_{\mathbf{z}}$, (referring especially to the velocities in the outer annulus near the blade tip, where most of the useful work is done) in the B-fan, is greater than in the case of the A-fan. Referring to the velocity diagram in figure 6.2 , it is evident that a positive change in flow 
rate, and consequently $\mathbf{v}_{\mathbf{z}}$, deceases the angle of attack. Because the axial momentum source term of the actuator disc model, given by equation (3.14), is strongly dependent on the lift coefficient, $C_{L}$, and $C_{L}$ is in turn strongly dependent on $\alpha\left(C_{L} \approx 0.12 \alpha+0.5\right.$ for $\left.-10^{\circ}<\alpha<10^{\circ}\right)$, the static pressure rise in the B-fan is therefore more sensitive to a change in flow rate, explaining the steeper negative fan static pressure gradient.

For an additional flow loss or pressure drop caused by inlet flow distortions, denoted $\delta \mathrm{p}_{\mathrm{i}}$, the resultant change in volume flow rate for the A-fan and B-fan is respectively $\delta \mathrm{V}_{\mathrm{A}}$ and $\delta \mathrm{V}_{\mathrm{B}}$, with $\delta \mathrm{V}_{\mathrm{A}}>\delta \mathrm{V}_{\mathrm{B}}$, as illustrated in figure 6.3.

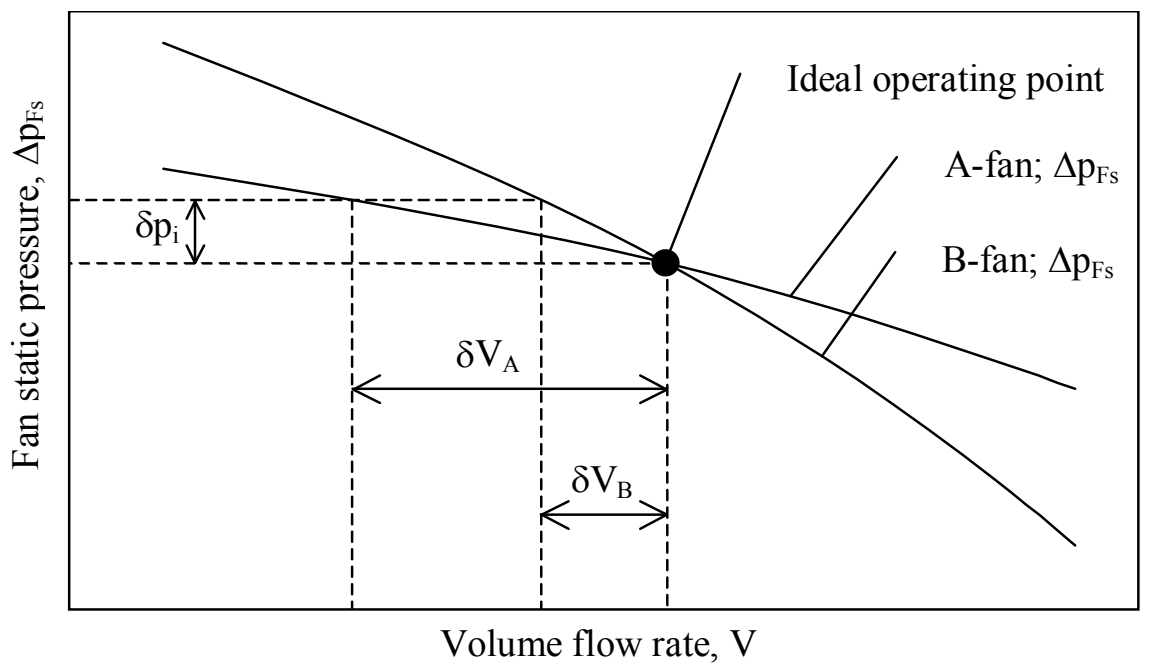

Figure 6.3: Effect of inlet flow distortion on volume flow rate

Although the fan characteristics are influenced by cross-flow and inlet flow distortion, as respectively reported by Stinnes [98ST1] and Thiart and von Backström [93TH1], the fan static pressure curve of the B-fan would however still display a steeper gradient than that of the A-fan under similar inlet conditions. Stinnes [98ST1] compared the experimentally determined performance characteristics of two fans, having hub-tip-ratios of respectively $\mathrm{d}_{\mathrm{h}} / \mathrm{d}_{\mathrm{F}}=0.26$ and $\mathrm{d}_{\mathrm{h}} / \mathrm{d}_{\mathrm{F}}=0.4$, over a range of off-axis inflow conditions. The present study presents similar results to that of Stinnes [98ST1], where it emerged that the fan with $\mathrm{d}_{\mathrm{h}} / \mathrm{d}_{\mathrm{F}}=0.4$ was less sensitive to cross-flow than the fan with $\mathrm{d}_{\mathrm{h}} / \mathrm{d}_{\mathrm{F}}=0.26$.

\subsubsection{Effect of a walkway on fan performance}

Previous experimental studies have shown that the volumetric effectiveness of the fans in an ACHE (or ACC) can significantly be improved by adding a walkway or by extending the fan 
platform. This was found to be especially applicable to the edge fans at low platform heights. In this part of the study the effect of a solid walkway with a width of $\mathrm{W}_{\mathrm{w}} / \mathrm{d}_{\mathrm{F}}=0.33$ was numerically investigated. At a platform height of $\mathrm{H}_{\mathrm{i}} / \mathrm{d}_{\mathrm{F}}=1.53$, i.e. severely distorted inlet conditions, the numerically predicted volumetric effectiveness of the edge fan in the case of the A-fan and the B-fan, were respectively $66.7 \%$ and $83.4 \%$, corresponding to fan power ratios of $93.0 \%$ and $102.7 \%$. From the vector and pressure plots it was concluded that the increase in flow rate was mainly as a result of reduced cross-flow velocity and abatement of separation or distortion occurring at the inlet of the edge fan. The effectiveness of an ACSC can therefore be improved through relatively simple and economical modifications. Numerical techniques can successfully be used to design and evaluate such performance enhancing walkways and windscreens.

\subsubsection{Modelling of cross-wind using an essentially two-dimensional approach}

The final part of the study involved the modelling of the effect of a $3 \mathrm{~m} / \mathrm{s}$ cross-wind on fan performance in a section of the ACSC at a platform height of $\mathrm{H}_{\mathrm{i}}=45 \mathrm{~m}$, using an essentially two-dimensional modelling approach. This modelling approach lead to average cross-flow velocities of up to $20 \mathrm{~m} / \mathrm{s}$ being induced underneath the fan platform, resulting in backflow through the first two fan units. Therefore, the assumption that no flow crosses the sectional planes, posed an unrealistic restriction on the numerical flow problem. The major difference between the essentially two-dimensional modelling approach under windless conditions and cross-wind conditions, is that under windless conditions, the flow through the domain is driven or generated entirely by the actuator disc model(s). In contrast, under cross-wind conditions, the flow is restricted to a confined channel-type flow by the velocity inlet and slip-wall boundary conditions, preventing the oncoming flow from moving around the plume and resulting in unrealistic plume dispersion. From these observations it can be concluded that the effective and realistic modelling of wind-effects require a full three-dimensional modelling approach.

\subsection{Future research}

As mentioned above, the modelling of wind-effects require a full three-dimensional modelling approach taking into account the entire ACSC. Firstly, such a model can be used to investigate performance reducing factors such as inlet flow distortions and recirculation. Secondly, it can be used to evaluate ways of improving performance through windscreens, walkways, alternative inlet sections, etc. 
The primary focus of this study was on the implementation and comparison of different numerical techniques and methods used in the modelling of ACHE and ACC. Experimental validation of numerical results of such complex thermal-flow problems is however imperative. Therefore, more attention should be paid to this aspect in future research.

Development and refinement of the actuator disc model into a useful fan design and analysis tool is another field of potential future research. Suggested improvements and modifications include:

a) The use of improved fan blade profile lift and drag characteristics.

b) The modelling of radial forces, in addition to axial and tangential forces.

c) Determining the effect of different turbulence models.

d) Under distorted inlet flow conditions, fan blades are subjected to severe cyclic loading. The actuator disc model can be used to analyse the aerodynamic forces on a fan blade.

The effective operation of an ACSC under excessive ambient temperatures may require additional wet cooling in order to maintain the backpressure on the steam turbines within specified limits. According to Kröger [04KR1] this may be achieved by deluging the heat exchanger bundles with water, or by precooling through humidification. Although deluging may increase the heat transfer rate by up to five times, disadvantages such as corrosion and fouling make it impractical and expensive, especially for large ACSC. Precooling by humidification or adiabatic cooling of the ambient air can be achieved by spraying water into the cooling air stream. To prevent corrosion the spray should preferably not wet the finned tube surfaces. It is therefore advisable to locate the sprayers upstream of the fans, so as to allow the spray droplets to evaporate before they move through the heat exchangers bundles. FLUENT offers extensive Lagrangian particle-modelling capabilities (i.e. trajectory calculation, heat and mass transfer models, etc.) that can be employed to simulate precooling. These techniques can be used to strategically position the sprayers for optimum precooling. 
Diminishing fossil fuel reserves, stringent environmental legislation and high capital cost require air-cooled power and petro-chemical plants to be highly efficient. This study has shown that CFD can effectively be used to predict trends in fan performance, and therefore ACSC (or ACHE) effectiveness. 


\section{References}

60SC1 Schlichting, H., Boundary Layer Theory, McGraw-Hill, New York, 1960.

65HO1 Hoerner, S.F., Fluid-dynamic Drag, Brick Town, New York, 1965.

71 GU1 Gunter, A.Y. and Shipes, K.V., Hot Air Recirculation by Air-coolers, Paper presented at the Twelfth National Heat Transfer Conference (AIChE -ASME), Tulsa, Oklahoma, USA, 1971.

74LA1 Launder, B.E. and Spalding, D.B., The Numerical Computation of Numerical Flows, Computer Methods in Applied Mechanics and Engineering, Vol. 3, pp. 269-289, 1974.

75HO1 Hoerner, S.F. and Borst, H.V., Fluid-dynamic Lift, Brick Town, New York, 1975.

75TU1 Turner, J.T., The Aerodynamics of Forced Draft Air-cooled Heat Exchangers, International Symposium on Cooling Systems, BHRA Fluid Engineering, Cranfield, England, pp. 81-99, 1975.

77MC1 McGhee, R.J., Beasley, W.D. and Somers, D.M., Low-speed Characteristics of a 13-persent-thick Airfoil Section Designed for General Aviation Applications, NASA Technical Memorandum, NASA TM X-72697, 1977.

80PA1 Patankar, S.V., Numerical Heat Transfer, McGraw-Hill, New York, 1980.

80WA1 Wallis, R.A., Axial Flow Fans and Ducts, Willey, New York, 1980.

82HO1 Houghton, E.L. and Carpenter, P.W., Aerodynamics for Engineering Students, Edward Arnold, London, 1982. 
86PE1 Pericleous, K.A. and Patel, M.K., The Modelling of Tangential and Axial Agitators in Chemical Reactors, Physicochemical Hydrodynamics, Vol. 8, pp.105-123, 1986.

89KR1 Kröger, D.G., Reduction in Performance Due to Recirculation in Mechanical Draft Cooling Towers, Heat Transfer Engineering, Vol. 10, No. 4, pp. 37-43, 1989.

90SC1 Schreüder, W.A. and du Plessis, J.P., Numerical Modelling of Interior Boundaries, Numerical Heat Transfer, Vol. 17, pp. 197-215, 1990.

90TH1 Thiart, G.D., A Numerical Procedure for Predicting the Effects of Distorted Inflow Conditions on the Performance of Axial Flow Fans, PhD Thesis, Department of Mechanical Engineering, University of Stellenbosch, 1990.

90VA1 van Aarde, D.J., Vloeiverliese deur 'n A-raam Vinbuisbundel in 'n Lugverkoelde Kondensator, MSc Thesis, Department of Mechanical Engineering, University of Stellenbosch, 1990.

90VE1 Venter, S.J., The Effectiveness of Axial Flow Fans in A-frame Plenums, MSc Thesis, Department of Mechanical Engineering, University of Stellenbosch, 1990.

91EU1 Eurocode 1: Actions on Structures, EN 1991-1-4 General actions- Wind actions, 1991.

91WH1 White, F.M., Viscous Fluid Flow, McGraw-Hill, New York, 1991.

93DU1 du Toit, C.G. and Kröger, D.G., Modelling of the Recirculation in Mechanical Draft Heat Exchangers, R\&D Journal of the South African Institution of Mechanical Engineering, Vol. 9, No. 1, pp. 2-8, 1993. 
93GO1 Goldschagg, H.B., Lessons Learned from the World's Largest Forced Draft Direct Air-cooled Condenser, Paper presented at the EPRI Int. Symp. On Improved Technology for Fossil Fuel Power Plants - New and Retrofit Applications, Washington, 1993.

93RI1 Richards, P.J. and Hoxey, R.P., Appropriate Boundary Conditions for Computational Wind Engineering Models using the k-E Turbulence Model, Journal of Wind Engineering and Industrial Aerodynamics, Vol. 46/47, pp. 145-153, 1993.

93TH1 Thiart, G.D. and von Backström, T.W., Numerical Simulation of the Flow Field near an Axial Flow Fan Operating under Distorted Inflow Conditions, Journal of Wind Engineering and Industrial Aerodynamics, Vol. 45. pp. 189214, 1993.

94BR1 Bruneau, P.R.P., The Design of a Single Rotor Axial Flow Fan for a Cooling Tower Application, MSc Thesis, Department of Mechanical Engineering, University of Stellenbosch, 1994.

94ME1 Menter, F.R., Two-Equation Eddy-Viscosity Turbulence Models for Engineering Applications, AIAA Journal, Vol. 32, No. 8, pp. 1598-1605, 1994.

95DU1 Duvenhage, K. and Kröger, D.G., Plume Recirculation in Mechanical Draft Air-cooled Heat Exchangers, Heat Transfer Engineering, Vol. 16, No. 4, 1995.

95SA1 Salta, C.A. and Kröger, D.G., Effect of Inlet Flow Distortions on Fan Performance in Forced Draft Air-cooled Heat Exchangers, Heat Recovery Systems \& CHP, Vol. 15, No. 6, pp. 555-561, 1995.

95VE1 Versteeg, H.K. and Malalasekera, W., An Introduction to Computational Fluid Dynamics, Prentice Hall, Harlow, 1995. 
96BE1

Bender, T. J., Bergstrom, D. J. and Rezkallah, K. S., A Study on the Effects of Wind Intake Flow Rate of a Cooling Tower. Part 3: Numerical Study, Journal of Wind Engineering and Industrial Aerodynamics, Vol. 64, pp. 81-100, 1996.

96DU1 Duvenhage, K. and Kröger, D.G., The Influence of Wind on the Performance of Forced Draft Air-Cooled Heat Exchangers, Journal of Wind Engineering and Industrial Aerodynamics, Vol. 62, pp. 259-277, 1996.

96DU2 Duvenhage, K., Vermeulen, J.A., Meyer, C.J. and Kröger, D.G., Flow Distortions at the Fan Inlet of Forced Draft Air-cooled Heat Exchangers, Applied Thermal Engineering, Vol. 16, No. 8/9, pp. 741-752, 1996.

96VA1 Van Staden, M.P. and Pretorius, L., Integrated Approach to CFD Modelling of Air-cooled Condensers, Paper presented at the $1^{\text {st }}$ South African Conference on Applied Mechanics (SACAM), Midrand, South Africa, 1996.

97BS1 British Standards Institution, Fans for General Purposes, Part 1, Methods for Testing Performance, BS 848, 1997.

98FL1 Fluent 6.1.22 User's Guide, Fluent Inc., 1998.

98ME1 Meyer, C.J. and Kröger, D.G., Plenum Chamber Flow Losses in Forced Draft Air-cooled Heat Exchangers, Applied Thermal Engineering, Vol. 18, pp. 875893, 1998.

98ST1 Stinnes, W.H., The Performance of Axial Fans Subjected to Forced Crossflow at Inlet, MSc Thesis, Department of Mechanical Engineering, University of Stellenbosch, 1998.

99RO1 Rogers, J.A., Won, K. and Stang, W., Validation of CFD Models for Evaluating Hot-air-recirculation in Air-cooled Heat Exchangers, Paper presented at the AIChE Spring Meeting, Houston, Texas, USA 1999. 
99VA1 Van Dam, C.P., Recent Experience with Different Methods of Drag Prediction, Progress in Aerospace Science, Vol. 35, pp. 751-798, 1999.

00CO1 Coetzee, R.V., Numerical simulation of an Air-cooled Heat Exchanger, MSc Thesis, Department of Mechanical Engineering, Potchefstroom University for Christian Higher Education, 2000.

00ME1 Meyer, C.J., A Numerical Investigation of the Plenum Chamber Aerodynamic Behavior of Mechanical Draught Air-cooled Heat Exchangers, PhD Thesis, Department of Mechanical Engineering, University of Stellenbosch, 1992.

00VA1 Van Staden, M.P., An Integrated Approach to Transient Simulation of Large Air-cooled Condensers using Computational Fluid Dynamics, PhD Thesis, Department of Mechanical Engineering, Rand Afrikaans University, 2000.

02ST1 Stinnes, W.H and von Backström, T.W., Effect of Cross-flow on the Performance of Air-cooled Heat Exchanger Fans, Applied Thermal Engineering, Vol. 22, pp. 1403-1415, 2002.

04CO1 Coetzee, R.V. and du Toit, C.G., Numerical Modelling of an Air-cooled Heat Exchanger, R\&D Journal of the South African Institution of Mechanical Engineering, Vol. 20, No. 1, 2004.

04HO1 Hotchkiss, P., Development of a Rotor Model for the Numerical Simulation of Helicopter Exterior Flow-fields, MSc Thesis, Department of Mechanical Engineering, University of Cape Town, 2004.

04KR1 Kröger, D.G., Air-cooled Heat Exchangers and Cooling Towers, PennWell Corp., Tulsa, 2004.

04ME1 Meyer, C.J. and Kröger, D.G., A Numerical Investigation of the Errors Associated with the Scaling of Axial Flow Fan Performance Characteristics, R\&D Journal of the South African Institution of Mechanical Engineering, Vol. 20, No. 4, 2004. 
04VA1 Von Gossler, J., Effects of Screens on the Performance of Fans in Forced Draft Air-Cooled Heat Exchangers, BEng Mechanical Project, Department of Mechanical Engineering, University of Stellenbosch, 2004. 


\section{Appendix A - System specifications}

\section{A.1. ACSC fan unit specifications}

The following specifications are applicable to a typical A-frame fan unit in an array of fan units in an ACSC. A schematic illustration of such a unit is shown in figure A.1.



Figure A.1: ACSC fan unit dimensions 


\section{A.1.1. Atmospheric and steam design conditions}

Air temperature at ground level

$$
\begin{aligned}
& \mathrm{T}_{\mathrm{a}}=20^{\circ} \mathrm{C} \\
& \mathrm{p}_{\mathrm{a}}=91330 \mathrm{~Pa} \\
& \mathrm{~T}_{\mathrm{v}}=60^{\circ} \mathrm{C}
\end{aligned}
$$

Barometric pressure at ground level

Saturated steam supply temperature

\section{A.1.2. Air properties}

The thermo-physical properties of air, evaluated at ambient temperature and pressure, are given below:

Density

Thermal conductivity

Specific heat

Molecular viscosity

Prandtl number

$$
\begin{aligned}
& \rho_{\mathrm{a}}=1.085 \mathrm{~kg} / \mathrm{s} \\
& \mathrm{k}_{\mathrm{a}}=0.02559 \mathrm{~W} / \mathrm{mK} \\
& \mathrm{c}_{\mathrm{p}}=1006.729 \mathrm{~W} / \mathrm{kgK} \\
& \mu_{\mathrm{a}}=1.849 \times 10^{-5} \mathrm{~kg} / \mathrm{ms} \\
& \operatorname{Pr}=0.71133
\end{aligned}
$$

\section{A.1.3. Finned tube bundle specifications}

Examples of finned heat exchanger tubes typically used in industrial air-cooling applications are shown in figure 2.2. These tubes are usually of aluminium, or galvanized steel construction in order to prevent corrosion.

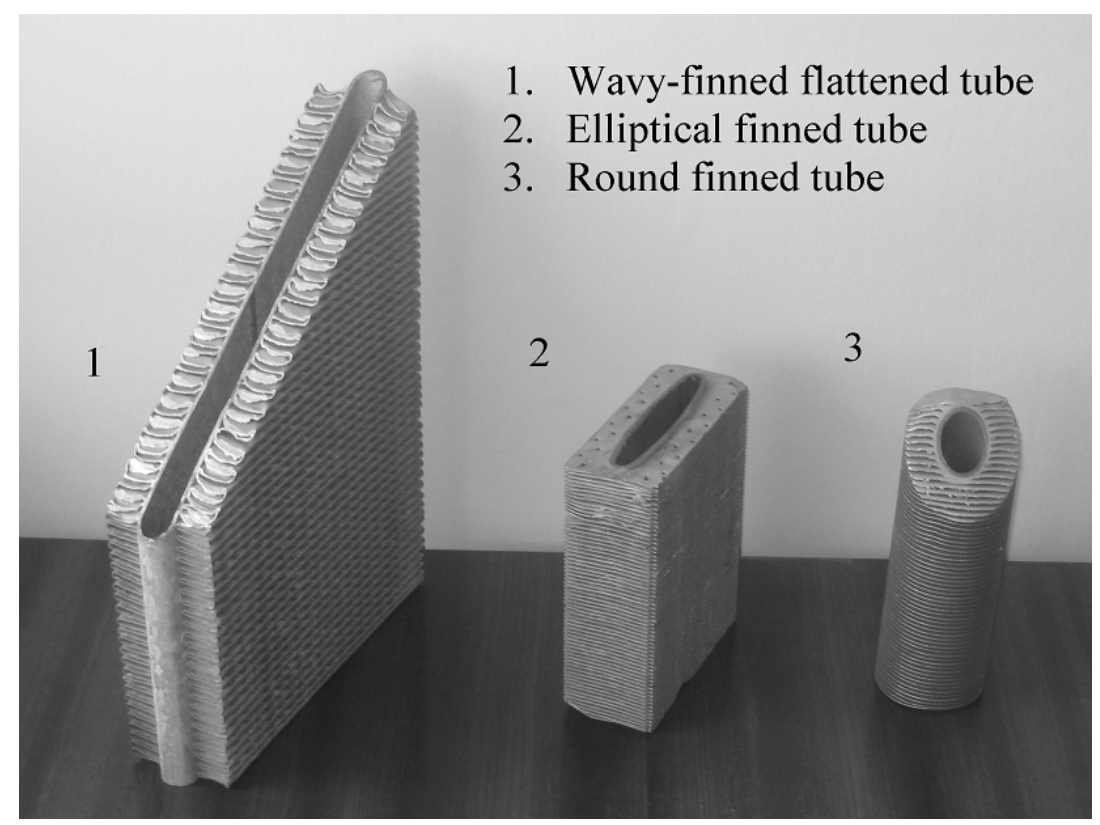

Figure A.2: Finned tubes used in industrial air-cooling applications 
The system under consideration employs two rows of elliptical finned tubes in staggered arrangement, as shown in figure 2.3. This tube features an elliptically shaped tube to reduce flow resistance and extended rectangular plate fins to increase the airside heat transfer area. The pressure drop and heat transfer characteristics of the finned tubes, obtained through experimental testing, are given in Appendix A. Each fan unit has 8 heat exchanger bundles consisting of 57 and 58 finned tubes in respectively the first and second tube rows.

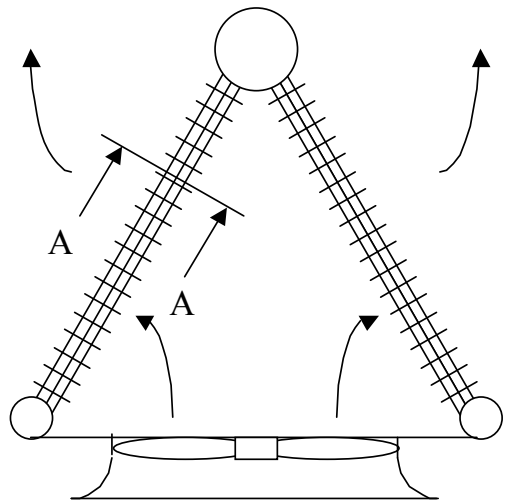

Side elevation

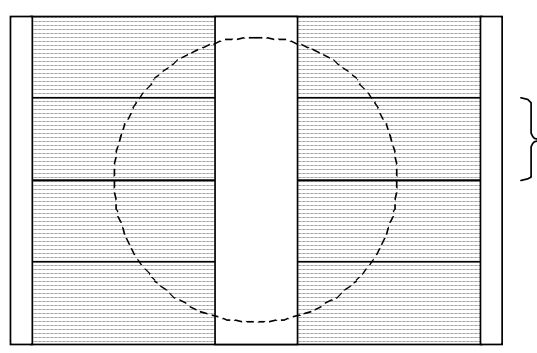

Plan view

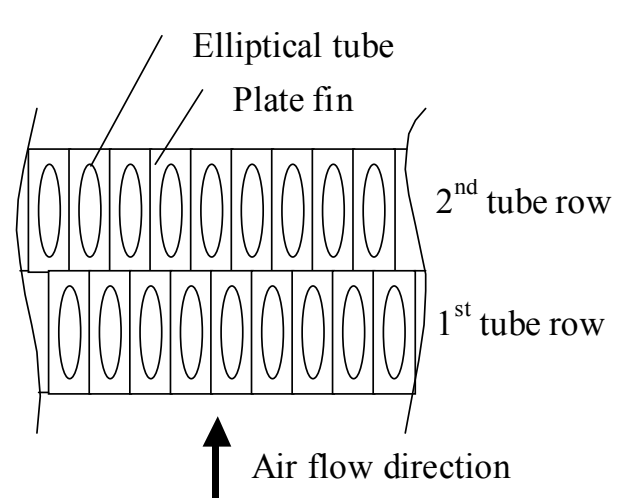

Enlarged sectional view A-A

Figure A.3: Finned tube configuration

Number of heat exchanger bundles above one fan

Frontal area of one bundle

Effective finned tube length

Heat exchanger apex angle

Number of finned tubes tube rows

Number of finned tubes per bundle in the first row

Number of finned tubes per bundle in the second row

Ratio of minimum to free stream flow

area through finned tube bundle

Ratio of minimum to free stream flow

area at inlet of finned tube bundle $\mathrm{n}_{\mathrm{b}}=8$

$\mathrm{A}_{\mathrm{fr}}=27.434 \mathrm{~m}^{2}$

$\mathrm{L}_{\mathrm{t}}=9.55 \mathrm{~m}$

$2 \theta=56^{\circ}$

$\mathrm{n}_{\mathrm{r}}=2$

$\mathrm{n}_{\mathrm{tb} 1}=57$

$\mathrm{n}_{\mathrm{tb} 2}=58$

$\sigma=0.41$

$\sigma_{21}=0.86$ 
The experimentally determined characteristic heat transfer parameter, $\mathrm{Ny}$, for normal flow through the first row of tubes is

$\mathrm{Ny}_{1}=583.8307 \mathrm{Ry}^{0.4031}$

and for the second row

$$
\mathrm{Ny}_{2}=1277.726 \mathrm{Ry}^{0.3806}
$$

The loss coefficient for both rows under normal flow conditions is

$$
\mathrm{K}_{\mathrm{he}}=4464.831 \mathrm{Ry}^{-0.43927}
$$

where Ny and Ry are respectively defined by equation (A.4) and equation (A.5).

$$
\mathrm{Ny}=\frac{\mathrm{hA}}{\mathrm{k}_{\mathrm{a}} \mathrm{A}_{\mathrm{fr}} \operatorname{Pr}^{0.333}}
$$

and

$$
\mathrm{Ry}=\frac{\mathrm{m}_{\mathrm{a}}}{\mu_{\mathrm{a}} \mathrm{A}_{\mathrm{fr}}}
$$

Note that in equation (A.4) and equation (A.5), $\mathrm{A}_{\mathrm{fr}}$ and $\mathrm{m}_{\mathrm{a}}$ refer to the total frontal area and the corresponding mass flow rate.

\section{A.2. Upstream and downstream obstacles}

The following dimensions refer to obstacles upstream and downstream of the fan, as shown in figure A.1.

Inlet screen distance from fan blade (upstream)

Support beam distance from fan blade (upstream)

Support beam distance from fan blade (downstream)

Walkway distance from fan blade (downstream)

$$
\begin{aligned}
& \mathrm{x}_{\mathrm{si}}=1.29 \mathrm{~m} \\
& \mathrm{x}_{\mathrm{bi}}=1.336 \mathrm{~m} \\
& \mathrm{x}_{\mathrm{bo}}=0.5345 \mathrm{~m} \\
& \mathrm{x}_{\mathrm{wo}}=0.995 \mathrm{~m}
\end{aligned}
$$


Ratio of inlet screen area to fan casing area

$\sigma_{\mathrm{si}}=0.109$

Ratio of support beam area to fan casing area (upstream)

$\sigma_{\mathrm{bi}}=0.154$

Ratio of support beam area to fan casing area (downstream)

$\sigma_{\mathrm{bo}}=0.0523$

Ratio of walkway area to fan casing area

$\sigma_{\mathrm{wo}}=0.0912$

\section{A.3. Platform dimensions}

With reference to figure A.1, the following dimensions are given

Average steam header diameter

$\mathrm{d}_{\mathrm{s}}=2.34 \mathrm{~m}$

Half-width of walkway between A-frames

$\mathrm{L}_{\mathrm{w}}=0.397 \mathrm{~m}$

Height of windwall

$\mathrm{H}_{\mathrm{w}}=10 \mathrm{~m}$

Dimension shown in figure A.1.

$\mathrm{L}_{\mathrm{x}}=10.56 \mathrm{~m}$

Dimension shown in figure A.1.

$\mathrm{L}_{\mathrm{y}}=11.8 \mathrm{~m}$

Dimension shown in figure A.1.

$\mathrm{L}_{\mathrm{r}}=10.6 \mathrm{~m}$

Dimension shown in figure A.1.

$\mathrm{L}_{\mathrm{b}}=4.924 \mathrm{~m}$

Dimension shown in figure A.1.

$\mathrm{L}_{\mathrm{s}}=4.102 \mathrm{~m}$

\section{A.4. Effective system resistance}

In this section the effective system resistance of the ACSC is calculated. Equations based on extensive experimental and theoretical research by Kröger [04KR1], are used to evaluate the loss coefficients. For the calculation of the loss coefficients the flow is assumed to be isothermal. Variation in thermo-physical properties is also neglected.

\section{A.4.1.Definition of loss coefficients in an ACSC}

For ease of reference, the effective system resistance, $\Delta \mathrm{p}_{\mathrm{e}}$, given by equation (3.6), is repeated here

$$
\begin{aligned}
\Delta \mathrm{p}_{\mathrm{e}}=- & -\mathrm{K}_{\mathrm{ts}} \frac{1}{2 \rho_{\mathrm{a} 1}}\left(\frac{\mathrm{m}_{\mathrm{a}}}{\mathrm{n}_{\mathrm{b}} \mathrm{A}_{\mathrm{fr}}}\right)^{2}+\mathrm{K}_{\mathrm{up}} \frac{1}{2 \rho_{\mathrm{a} 3}}\left(\frac{\mathrm{m}_{\mathrm{a}}}{\mathrm{A}_{\mathrm{e}}}\right)^{2}+\mathrm{K}_{\mathrm{do}} \frac{1}{2 \rho_{\mathrm{a} 3}}\left(\frac{\mathrm{m}_{\mathrm{a}}}{\mathrm{A}_{\mathrm{e}}}\right)^{2} \\
& \left.+\mathrm{K}_{\theta \mathrm{t}} \frac{1}{2 \rho_{\mathrm{a} 56}}\left(\frac{\mathrm{m}_{\mathrm{a}}}{\mathrm{n}_{\mathrm{b}} \mathrm{A}_{\mathrm{fr}}}\right)^{2}\right]
\end{aligned}
$$


$\mathrm{K}_{\theta \mathrm{t}}$ is the total loss coefficient across the heat exchanger bundles and includes the kinetic energy losses at the outlet of the A-frame. For isothermal flow $\mathrm{K}_{\theta t}$ is given by

$$
\mathrm{K}_{\theta \mathrm{t}}=\mathrm{K}_{\mathrm{he}}+\left(\frac{1}{\sin \theta_{\mathrm{m}}}-1\right)\left[\left(\frac{1}{\sin \theta_{\mathrm{m}}}-1\right)+2 \mathrm{~K}_{\mathrm{ci}}^{0.5}\right]+\mathrm{K}_{\mathrm{dj}}+\mathrm{K}_{\mathrm{o}}
$$

where $\theta_{\mathrm{m}}$ is the actual mean flow incidence angle and is given as a function of the semi-apex angle in the following empirical equation

$\theta_{\mathrm{m}}=0.0019 \theta^{2}+0.9133 \theta-3.1558$

The heat exchanger loss coefficient for normal isothermal flow, $K_{\text {he, is }}$ given by equation (A.3). $\mathrm{K}_{\mathrm{ci}}$ is the entrance contraction loss coefficient for normal flow and is based on the normal approach free stream velocity.

$$
\mathrm{K}_{\mathrm{ci}}=\left[\frac{1-1 / \sigma_{\mathrm{c}}}{\sigma}\right]^{2}
$$

where $\sigma_{\mathrm{c}}$ is a function of $\sigma_{21}$, is given by the following empirical equation

$$
\begin{aligned}
\sigma_{\mathrm{c}}= & 0.6155417+0.04566493 \sigma_{21}-0.336651 \sigma_{21}^{2}+0.4082743 \sigma_{21}^{3}+2.672041 \sigma_{21}^{4} \\
& -5.963169 \sigma_{21}^{5}+3.558944 \sigma_{21}^{6}
\end{aligned}
$$

The jetting loss coefficient is expressed by the following correlation

$$
\begin{aligned}
\mathrm{K}_{\mathrm{dj}}= & {\left[\left\{-2.89188\left(\frac{\mathrm{L}_{\mathrm{w}}}{\mathrm{L}_{\mathrm{t}}}\right)+2.93291\left(\frac{\mathrm{L}_{\mathrm{w}}}{\mathrm{L}_{\mathrm{t}}}\right)^{2}\right\}\left(\frac{\mathrm{L}_{\mathrm{t}}}{\mathrm{L}_{\mathrm{s}}}\right)\left(\frac{\mathrm{L}_{\mathrm{b}}}{\mathrm{L}_{\mathrm{s}}}\right)\left(\frac{28}{\theta}\right)^{0.4}\right.} \\
& \left.+\left\{\left(\frac{\mathrm{L}_{\mathrm{s}}}{\mathrm{L}_{\mathrm{b}}}\right) \exp \left(2.36987+5.8601 \times 10^{-2} \theta-3.3797 \times 10^{-3} \theta^{2}\right)\right\}\left(\frac{\mathrm{L}_{\mathrm{t}}}{\mathrm{L}_{\mathrm{r}}}\right)\right]^{2}
\end{aligned}
$$

where $\theta$ is in degrees. Refer to figure A.1 for the length dimensions denoted by L and an appropriate subscript. 
The outlet loss coefficient is given by

$$
\begin{aligned}
\mathrm{K}_{\mathrm{o}}= & {\left[\left\{-2.89188\left(\frac{\mathrm{L}_{\mathrm{w}}}{\mathrm{L}_{\mathrm{t}}}\right)+2.93291\left(\frac{\mathrm{L}_{\mathrm{w}}}{\mathrm{L}_{\mathrm{t}}}\right)^{2}\right\}\left(\frac{\mathrm{L}_{\mathrm{s}}}{\mathrm{L}_{\mathrm{b}}}\right)^{3}+1.9874-3.02783\left(\frac{\mathrm{d}_{\mathrm{s}}}{2 \mathrm{~L}_{\mathrm{b}}}\right)\right.} \\
& \left.+2.0187\left(\frac{\mathrm{d}_{\mathrm{s}}}{2 \mathrm{~L}_{\mathrm{b}}}\right)^{2}\right]\left(\frac{\mathrm{L}_{\mathrm{t}}}{\mathrm{L}_{\mathrm{s}}}\right)^{2}
\end{aligned}
$$

(A.12)

Loss coefficients resulting from upstream and downstream obstacles, $\mathrm{K}_{\mathrm{up}}$ and $\mathrm{K}_{\mathrm{do}}$, are based on the mean velocity through the fan. These coefficients are given by Kröger [04KR1] in empirical relations as a function the projected area of the obstacle and the distance from the fan. The upstream obstacles that are of importance are the inlet screen and the screen support beam. Important downstream obstacles are the fan drive system support beam and walkway (refer to figure A.1). The pressure drop resulting from the platform supports is taken into account by the loss coefficient $\mathrm{K}_{\mathrm{ts}}$.

\section{A.4.2. Evaluation of loss coefficients}

The loss coefficient are evaluated for the air properties given in section A.1.2.

$\mathrm{K}_{\mathrm{he}}$ is evaluated according to equation (A.3)

$$
\begin{aligned}
\mathrm{K}_{\mathrm{he}} & =4464.831 \mathrm{Ry}^{-0.43927}=4464.831\left(\frac{\mathrm{m}_{\mathrm{a}}}{\mu_{\mathrm{a}} \mathrm{n}_{\mathrm{b}} \mathrm{A}_{\mathrm{fr}}}\right)^{-0.43927}=4464.831\left(\frac{\mathrm{m}_{\mathrm{a}}}{1.849 \times 10^{-5} \cdot 8 \cdot 27.434}\right)^{-0.43927} \\
& =397.3837 \mathrm{~m}_{\mathrm{a}}^{-0.43927}
\end{aligned}
$$

$\theta_{\mathrm{m}}$ is given by equation (A.8)

$\theta_{m}=0.0019 \theta^{2}+0.9133 \theta-3.1558=0.0019 \cdot 28^{2}+0.9133 \cdot 28-3.1558=23.91^{\circ}$

where, according to equation (A.10), $\sigma_{\mathrm{c}}$ is

$$
\begin{aligned}
\sigma_{c}= & 0.6155417+0.04566493 \cdot 0.86-0.336651 \cdot 0.86^{2}+0.4082743 \cdot 0.86^{3}+2.672041 \cdot 0.86^{4} \\
& -5.963169 \cdot 0.86^{5}+3.558944 \cdot 0.86^{6}=0.761
\end{aligned}
$$


so that contraction loss coefficient given by equation (A.9) is

$$
\mathrm{K}_{\mathrm{ci}}=\left[\frac{1-1 / 0.761}{0.41}\right]^{2}=0.587
$$

The jetting loss coefficient is calculated according to equation (A.11)

$$
\begin{aligned}
\mathrm{K}_{\mathrm{dj}} & =\left[\left\{-2.89188\left(\frac{0.397}{9.55}\right)+2.93291\left(\frac{0.397}{9.55}\right)^{2}\right\}\left(\frac{9.55}{4.102}\right)\left(\frac{4.924}{4.102}\right)\left(\frac{28}{28}\right)^{0.4}\right. \\
& \left.+\left\{\left(\frac{4.102}{4.924}\right) \exp \left(2.36987+5.8601 \times 10^{-2} \cdot 28-3.3797 \times 10^{-3} \cdot 28^{2}\right)\right\}^{0.5}\left(\frac{9.55}{10.6}\right)\right]^{2} \\
& =1.696
\end{aligned}
$$

According to equation (A.12) the outlet loss coefficient is given as

$$
\begin{aligned}
\mathrm{K}_{\mathrm{o}}= & {\left[\left\{-2.89188\left(\frac{0.397}{9.55}\right)+2.93291\left(\frac{0.397}{9.55}\right)^{2}\right\}\left(\frac{4.102}{4.924}\right)^{3}+1.9874\right.} \\
& \left.-3.02783\left(\frac{2.34}{2 \cdot 4.924}\right)+2.0187\left(\frac{2.34}{2 \cdot 4.924}\right)^{2}\right]\left(\frac{9.55}{4.102}\right)^{2} \\
= & 7.129
\end{aligned}
$$

The total loss coefficient across the heat exchanger bundles can now be calculated in terms of $\mathrm{m}_{\mathrm{a}}$.

$$
\begin{aligned}
& \mathrm{K}_{\theta \mathrm{t}}=\mathrm{K}_{\mathrm{he}}+\left(\frac{1}{\sin \theta_{\mathrm{m}}}-1\right)\left[\left(\frac{1}{\sin \theta_{\mathrm{m}}}-1\right)+2 \mathrm{~K}_{\mathrm{ci}}^{0.5}\right]+\mathrm{K}_{\mathrm{dj}}+\mathrm{K}_{\mathrm{o}} \\
& =397.3837 \mathrm{~m}_{\mathrm{a}}^{-0.43927}+\left(\frac{1}{\sin 23.906}-1\right)\left[\left(\frac{1}{\sin 23.906}-1\right)+2 \cdot 0.587^{0.5}\right]+1.696+7.129 \\
& =397.3837 \mathrm{~m}_{\mathrm{a}}^{-0.43927}+13.232
\end{aligned}
$$


The upstream and downstream loss coefficients, according to Kröger [04KR1], are given in table A.1.

Table A.1: Upstream and downstream loss coefficients

\begin{tabular}{lllll}
\hline Upstream or downstream & Obstacle & $\mathrm{x}_{\mathrm{ob}} / \mathrm{d}_{\mathrm{c}}$ & $\mathrm{A}_{\mathrm{ob}} / \mathrm{A}_{\mathrm{c}}$ & Loss coefficient \\
\hline Upstream & Screen & 0.140 & 0.109 & 0.11 \\
Upstream & Support Beam & 0.145 & 0.154 & 0.17 \\
Downstream & Support Beam & 0.058 & 0.0523 & 0.16 \\
Downstream & Walkway & 0.108 & 0.0912 & 0.19 \\
\hline
\end{tabular}

Based on table A.1 the upstream and down stream loss coefficients are $\mathrm{K}_{\mathrm{up}}=0.28$ and $\mathrm{K}_{\mathrm{do}}=0.35$, respectively. Equation (A.6) can now be written in terms of mass flow rate

$$
\begin{aligned}
\Delta \mathrm{p}_{\mathrm{e}} & =-\left\{\frac{1.6033}{2 \cdot 1.085(8 \cdot 27.434)^{2}} \mathrm{~m}_{\mathrm{a}}^{2}+\frac{0.28}{2 \cdot 1.085\left[\pi / 4\left(9.216^{2}-1.4^{2}\right)\right]^{2}} \mathrm{~m}_{\mathrm{a}}^{2}\right. \\
& \left.+\frac{0.35}{2 \cdot 1.085\left[\pi / 4\left(9.216^{2}-1.4^{2}\right)\right]^{2}} \mathrm{~m}_{\mathrm{a}}^{2}+\frac{\left(397.3847 \mathrm{~m}_{\mathrm{a}}^{-0.43927}+13.232\right)}{2 \cdot 1.085(8 \cdot 27.434)^{2}} \mathrm{~m}_{\mathrm{a}}^{2}\right\} \\
& =-\left(2.1029 \times 10^{-4} \mathrm{~m}_{\mathrm{a}}^{2}+3.8018 \times 10^{-3} \mathrm{~m}_{\mathrm{a}}^{1.56073}\right), \mathrm{Pa}
\end{aligned}
$$

or in terms of the volume flow rate $\mathrm{V}_{\mathrm{a}}$

$$
\Delta \mathrm{p}_{\mathrm{e}}=-\left(2.4756 \times 10^{-4} \mathrm{~V}_{\mathrm{a}}^{2}+4.31807 \times 10^{-3} \mathrm{~V}_{\mathrm{a}}^{1.56073}\right), \mathrm{Pa}
$$




\section{Appendix B - Fan installation specifications}

\section{B.1. Fan installation dimensions}

As mentioned in section 1.3, the performance of two types of axial fans are numerically investigated in this study. Fan blade geometry and performance characteristics, for the A-fan and B-fan are given in section B.2 and section B.3 respectively. Dimensions and specifications of the fan system in a typical fan unit in the ACSC under consideration are given below



Figure B.1: Fan system dimensions

Fan diameter

Hub-tip-ratio of A-fan

Hub-tip-ratio of B-fan

Ratio of hub thickness to fan diameter of A-fan

Ratio of hub thickness to fan diameter of B-fan

Height of bellmouth fan inlet from fan platform

Bellmouth inlet radius

Number of fan blades

Rotational speed
$\mathrm{d}_{\mathrm{F}}=9.145 \mathrm{~m}$

$\mathrm{d}_{\mathrm{h}} / \mathrm{d}_{\mathrm{F}}=0.153$

$\mathrm{d}_{\mathrm{h}} / \mathrm{d}_{\mathrm{F}}=0.4$

$\mathrm{H}_{\mathrm{h}} / \mathrm{d}_{\mathrm{h}}=0.02$

$\mathrm{H}_{\mathrm{h}} / \mathrm{d}_{\mathrm{h}}=0.1$

$\mathrm{H}_{\mathrm{b}}=1.92 \mathrm{~m}$

$\mathrm{r}_{\mathrm{b}}=1.16 \mathrm{~m}$

$\mathrm{n}_{\mathrm{bl}}=8$

$\mathrm{N}=125 \mathrm{rpm}$ 


\section{B.2. A-fan specifications}

The A-fan is an actual mass-produced commercial cooling fan. Information regarding its blade geometry was unavailable and therefore had to be determined by measurement. The performance characteristics given in section B.2.2 were obtained from the manufacturer. A single fan blade of the A-fan is shown in figure B.2.

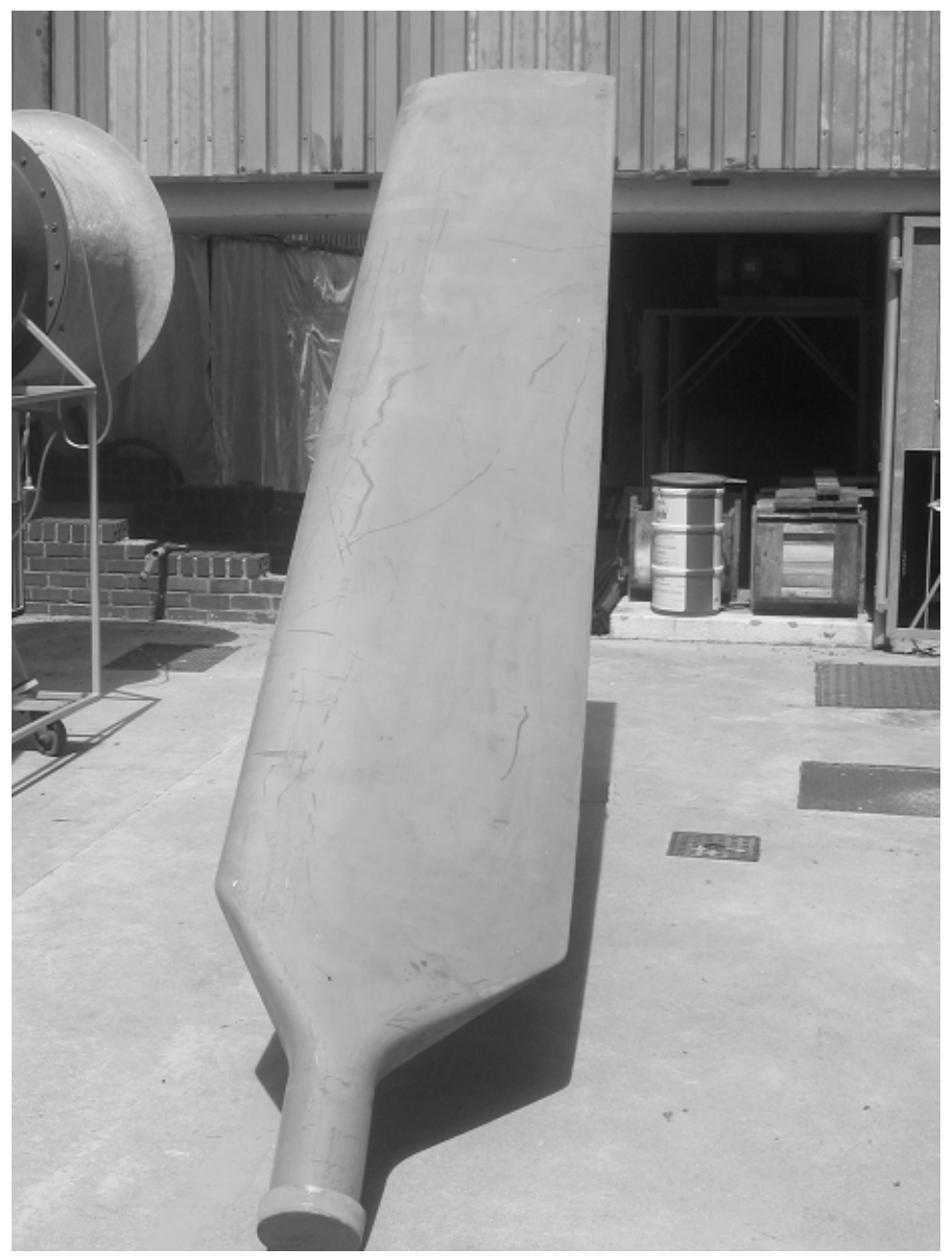

Figure B.2: Photographic image of a single fan blade of the A-fan 


\section{B.2.1. Blade geometry of the A-fan}

Figure B. 3 shows the main dimensions of the A-fan blade.

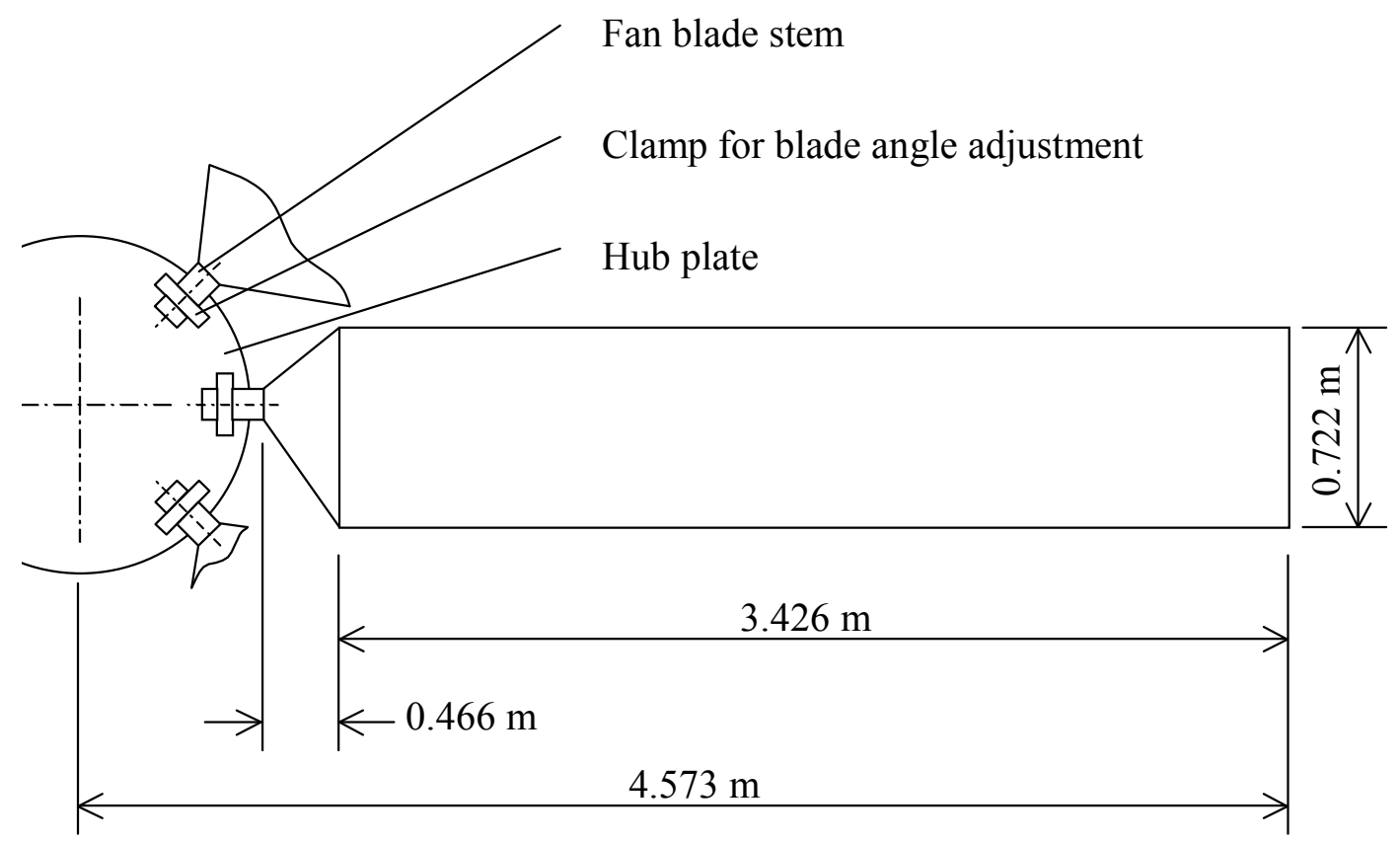

Figure B.3: A-fan blade dimensions

The A-fan employs a blade profile shown in figure B.4.

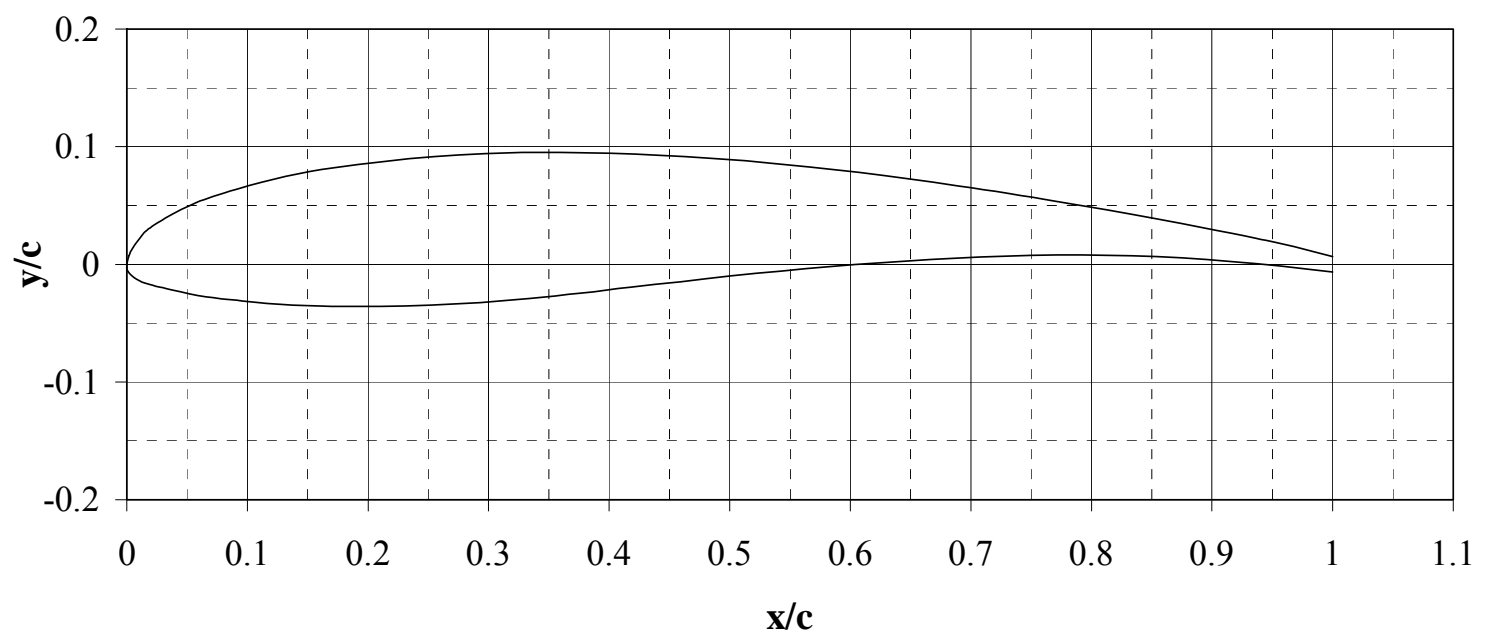

Figure B.4: A-fan blade profile 
The blade angle distribution at a blade angle setting of, $\gamma_{\mathrm{pt}}=16^{\circ}$, is given in figure B.5.

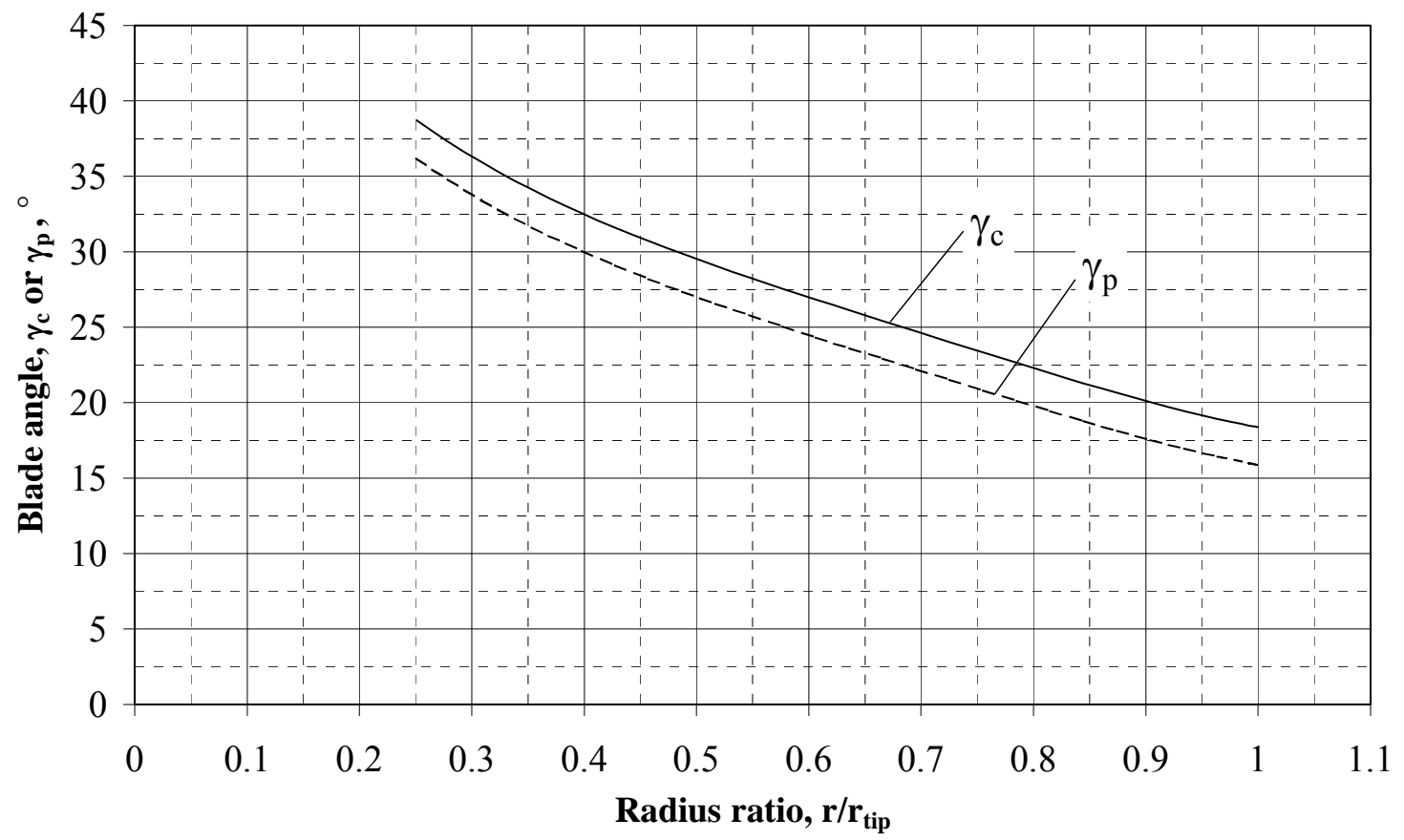

Figure B.5: Blade angle distribution at $\gamma_{\mathrm{pt}}=16^{\circ}$

\section{B.2.2. Performance characteristics of the A-fan}

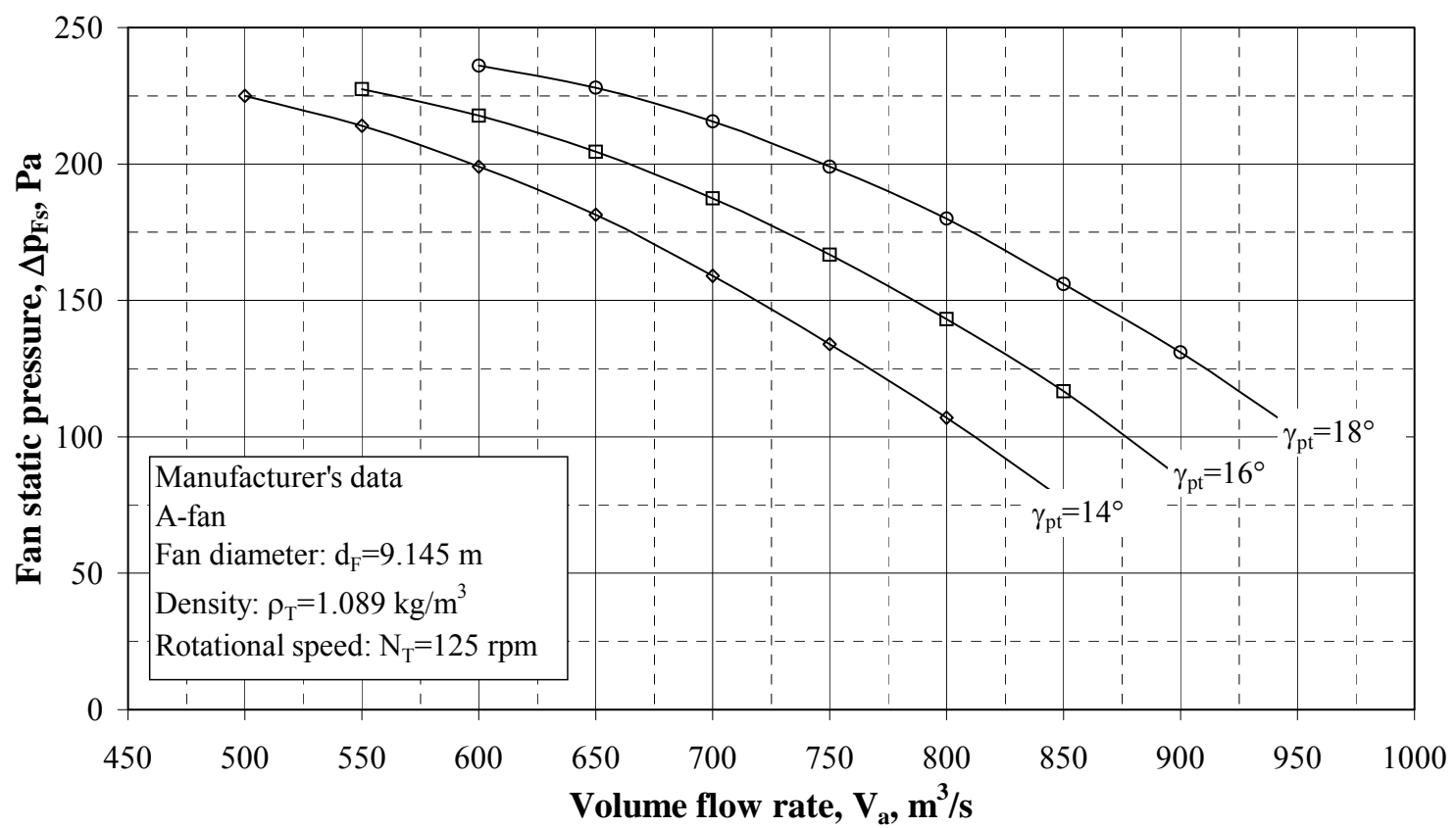

Figure B.6: Fan static pressure characteristic of the A-fan 


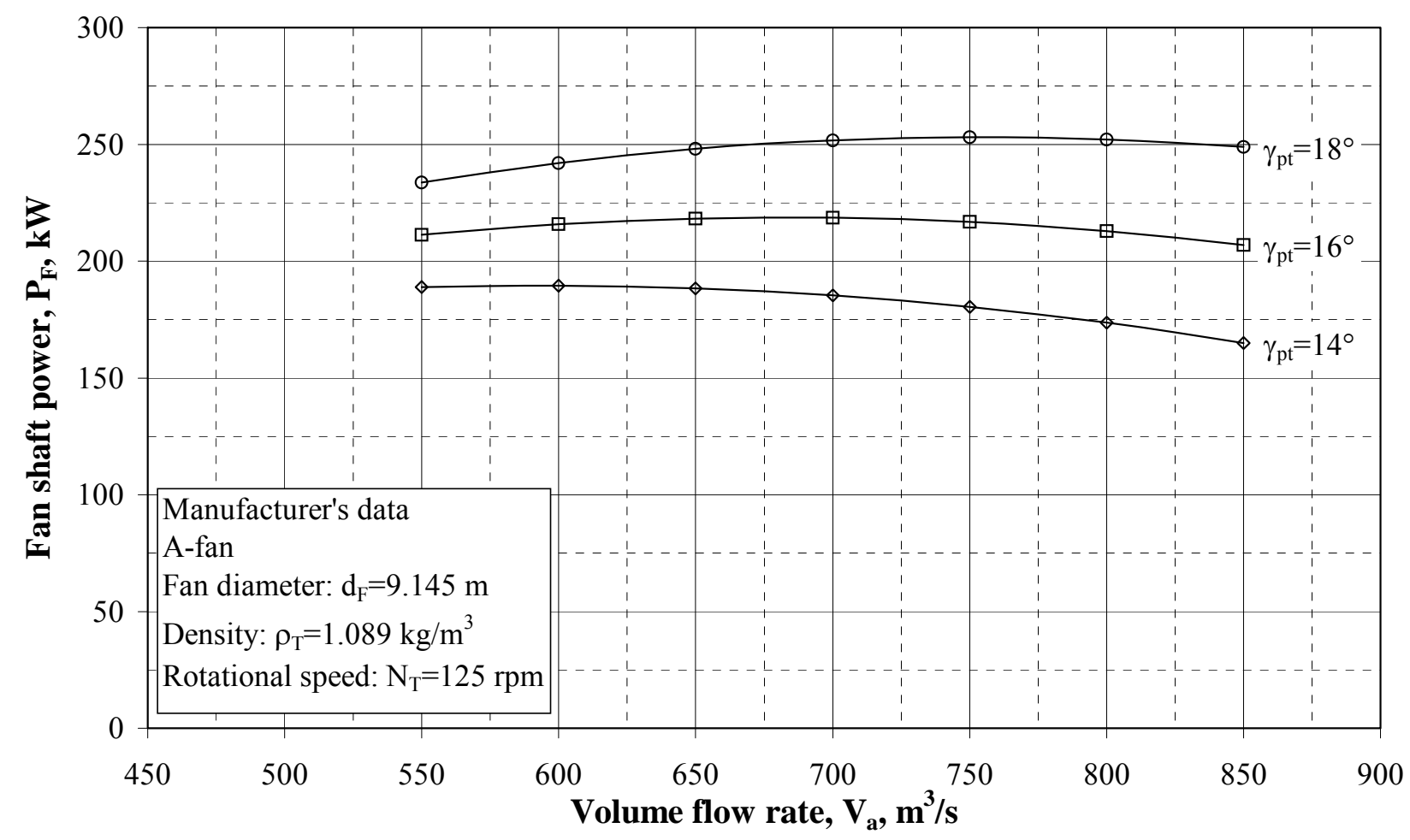

Figure B.7: Fan shaft power characteristic of the A-fan

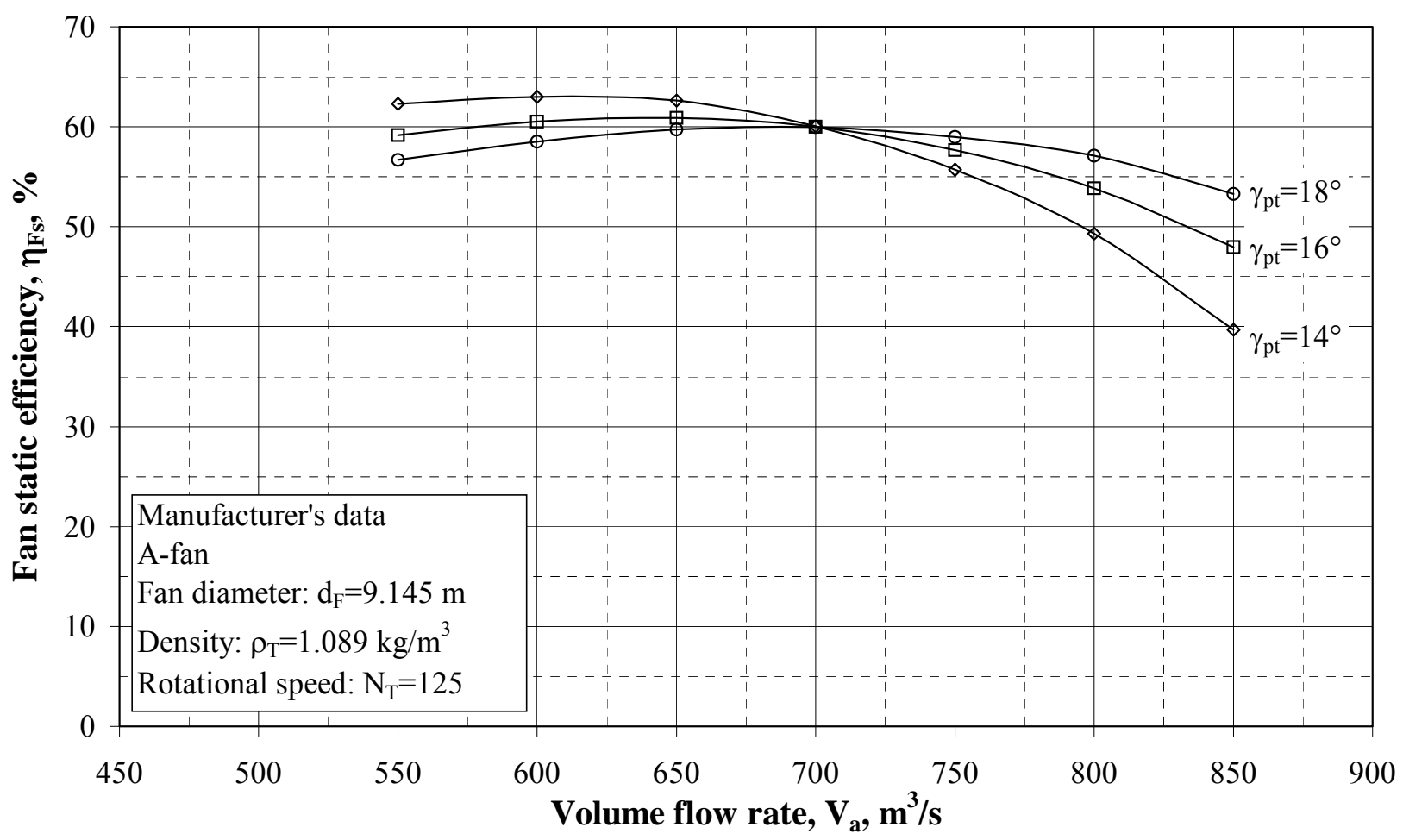

Figure B.8: Fan static efficiency of the A-fan 


\section{B.3. B-fan specifications}

The B-fan is a prototype fan designed by Bruneau [94BR1] for application in an actual ACSC. A scale model with a diameter of $\mathrm{d}_{\mathrm{F}}=1.542 \mathrm{~m}$ was built and tested at the Department of Mechanical Engineering, University of Stellenbosch. The characteristics of the model fan determined according to BS848 [97BS1] for a type A configuration, are given in section B.3.2. Figure B.9 shows the model B-fan from inside the settling chamber of the fan test facility.

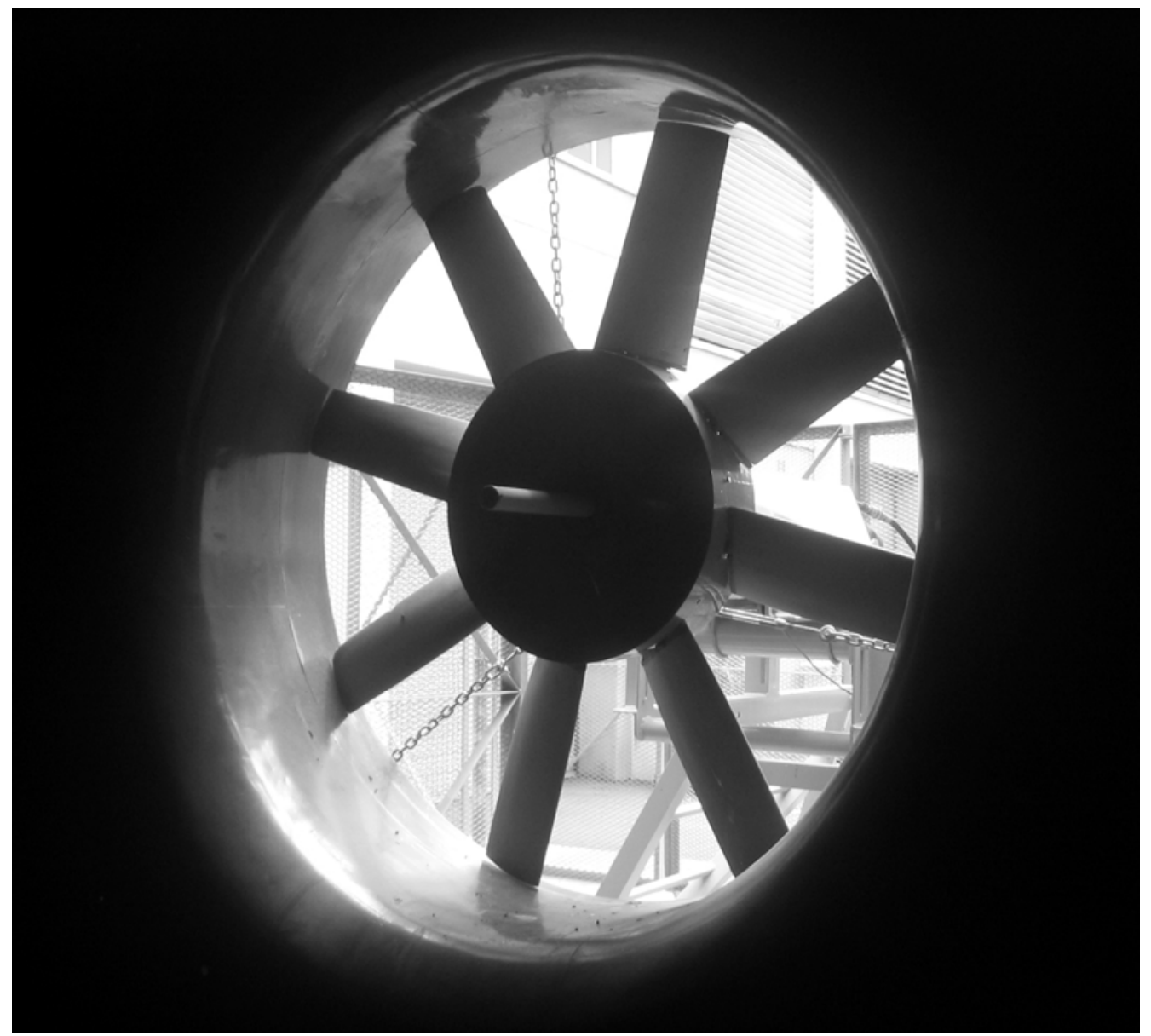

Figure B.9: Photographic image of the model B-fan 


\section{B.3.1. Blade geometry of the B-fan}

The B-fan employs an NASA GA(W)-2 airfoil, the characteristics of which were determined by $\mathrm{McGhee}$ et al [77MC1].

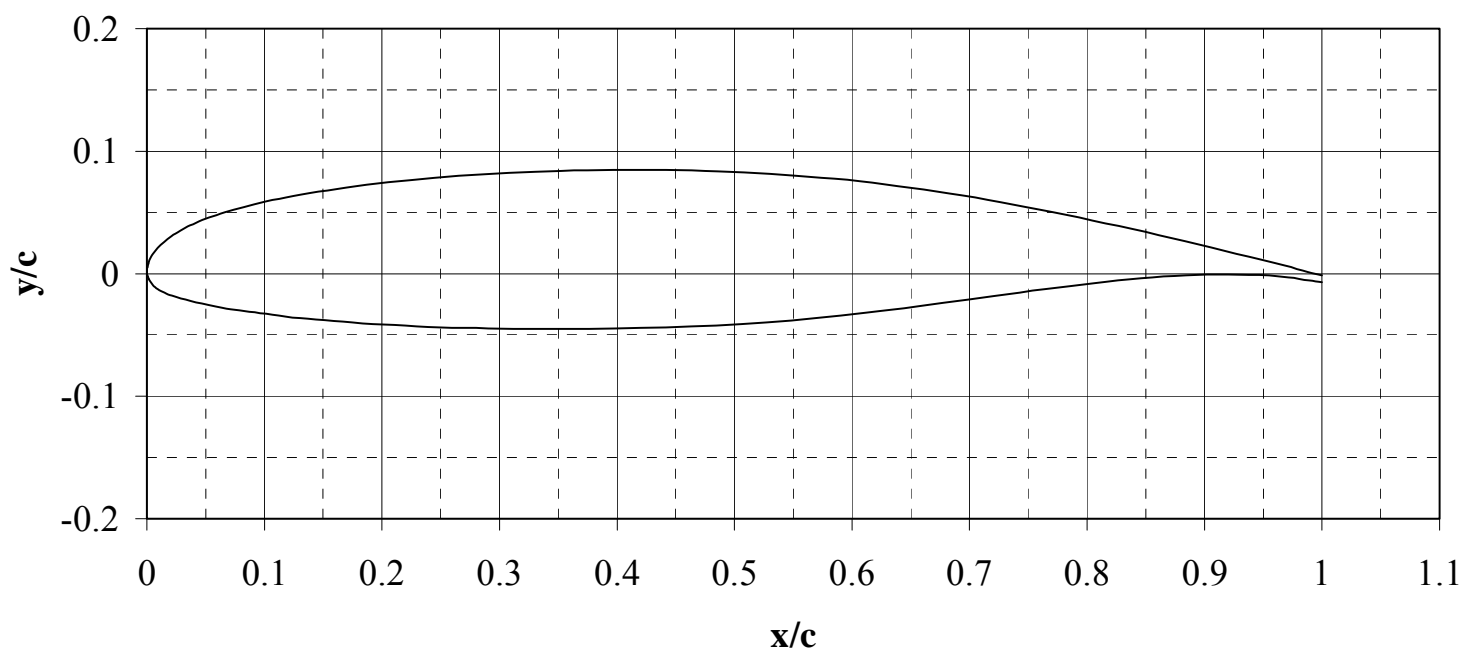

Figure B.10: B-fan blade profile, NASA GA(W)-2, McGhee et al [77MC1]

The variation in blade angle referenced to the chord line, $\gamma_{\mathrm{c}}$, and chord length, $\mathrm{c}$, for $\mathrm{d}_{\mathrm{F}}=1.542 \mathrm{~m}$ and $\gamma_{\mathrm{cr}}=30^{\circ}$ is given in figure B. 11 as a function of radius ratio.

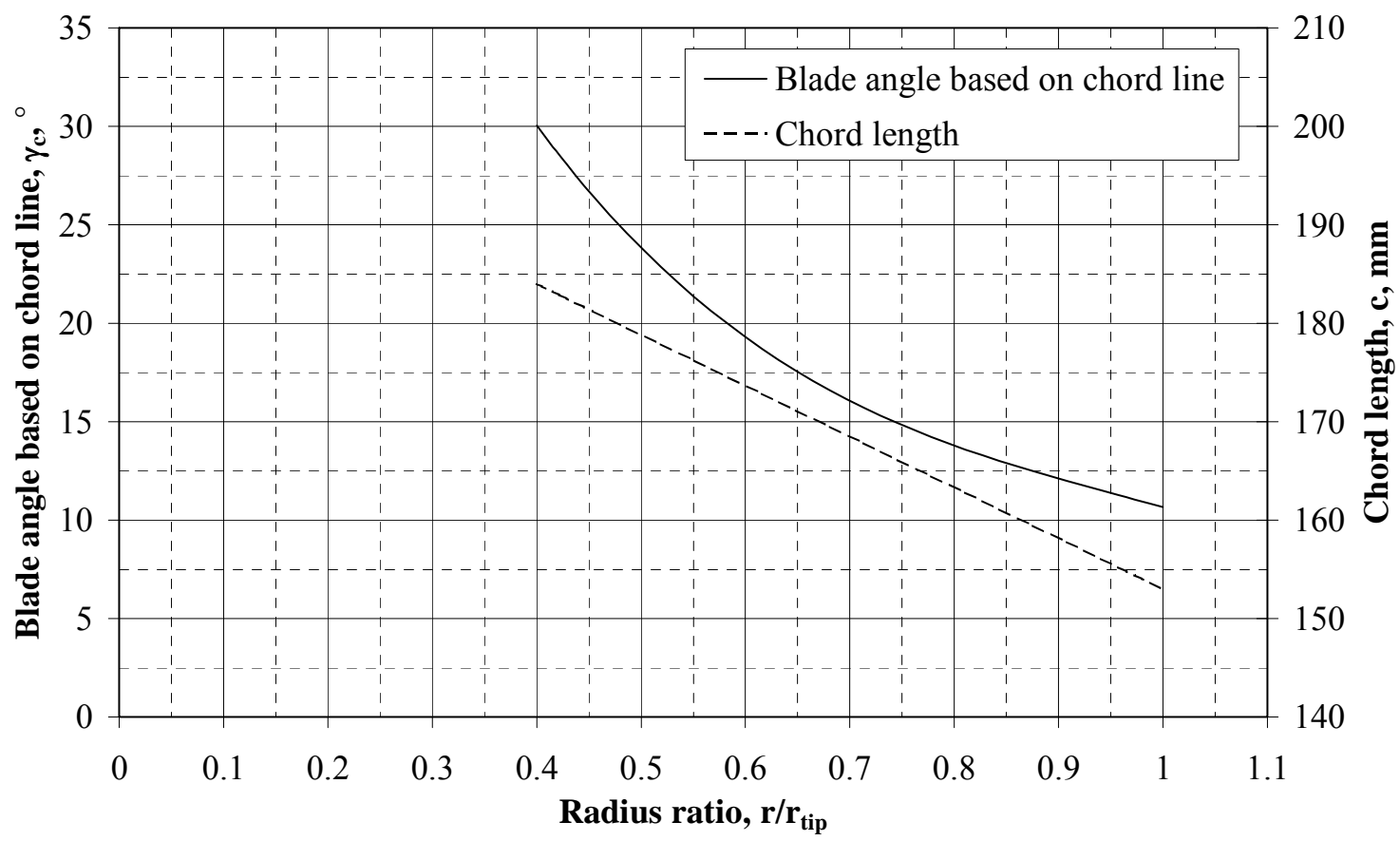

Figure B.11: Blade angle at $\gamma_{\mathrm{cr}}=30^{\circ}$ and chord length as a function of $r / \mathrm{r}_{\text {tip }}$ 


\section{B.3.2. Performance characteristics of the B-fan model}

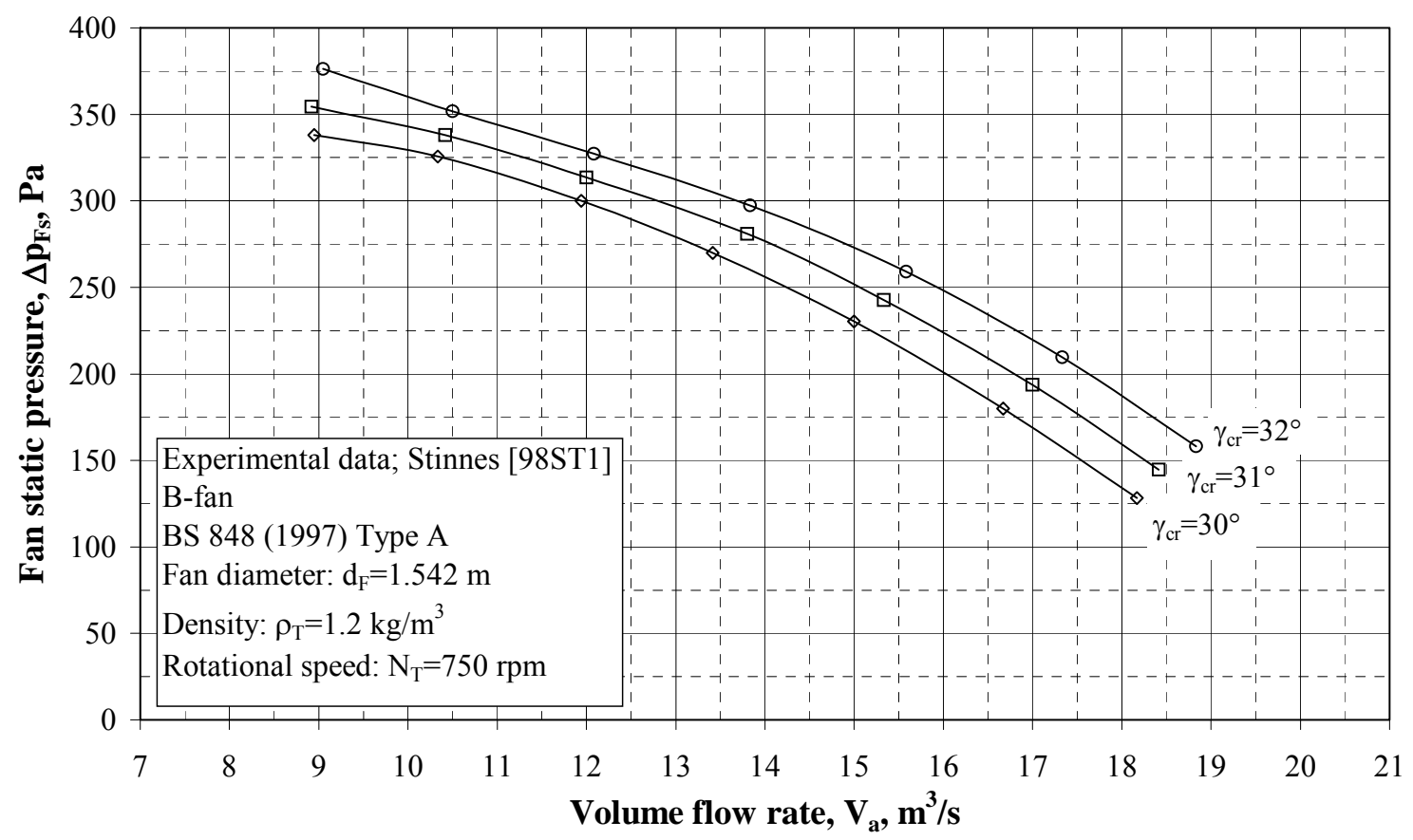

Figure B.12: Fan static pressure characteristic of the B-fan

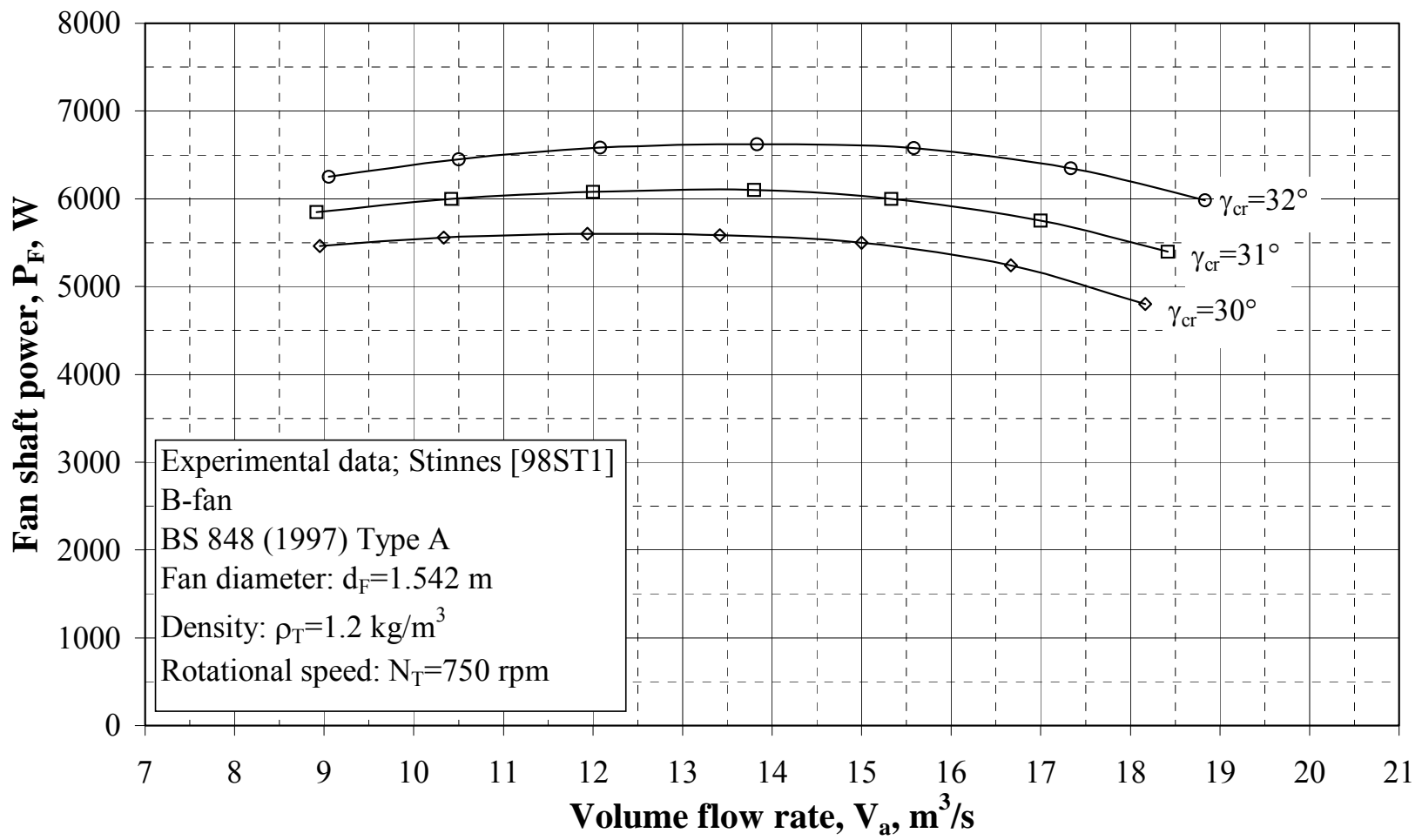

Figure B.13: Fan shaft power characteristic of the B-fan 


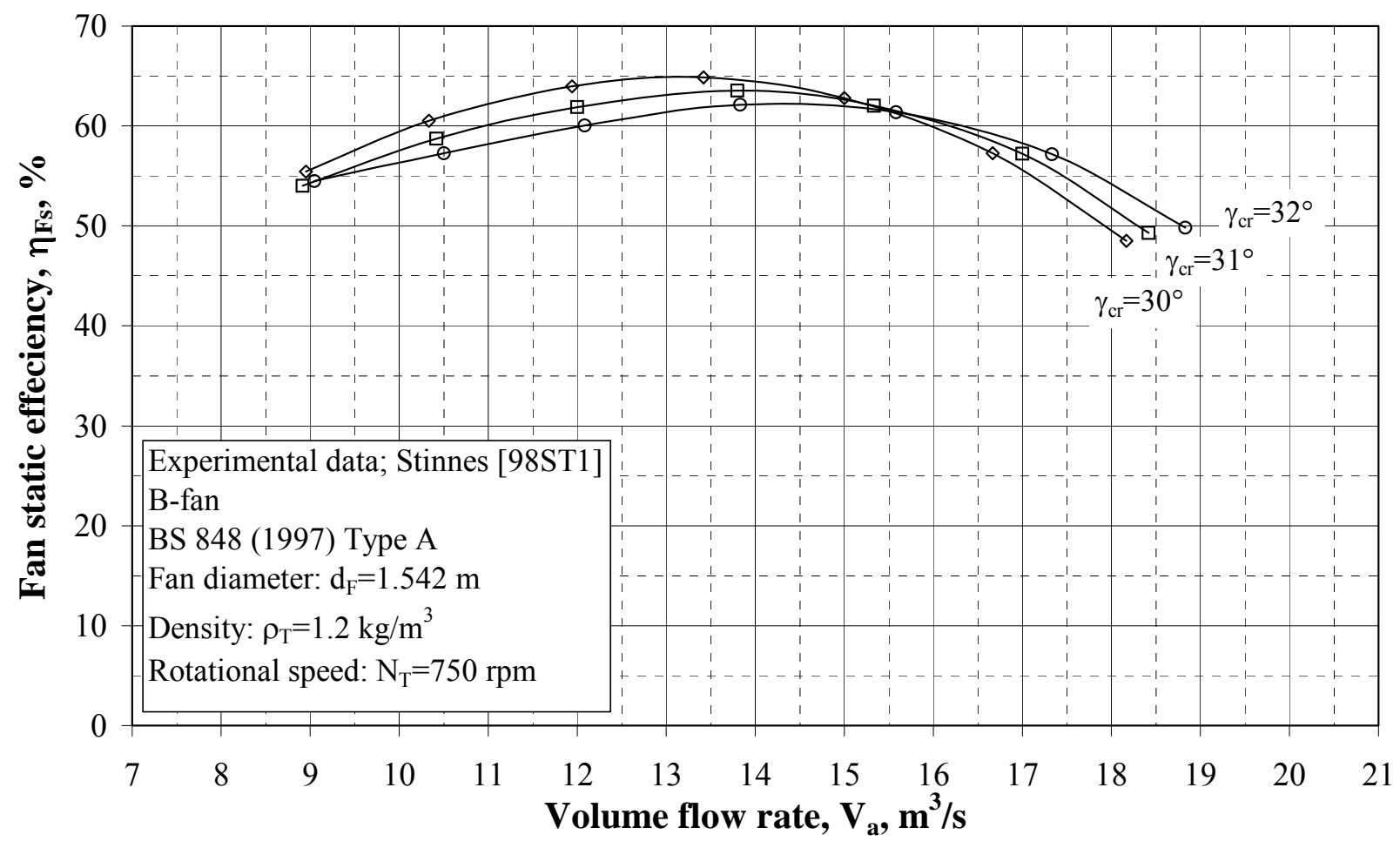

Figure B.14: Fan static efficiency of the B-fan 


\section{Appendix C - Calculation of source terms in the numerical heat exchanger model}

\section{C.1. Momentum sink terms}

The numerical modelling of a flow resistance, or pressure drop, in a region of a flow domain, require the addition of a momentum sink terms to the relevant momentum equations. In this section, the calculation of the momentum sink terms for the numerical heat exchanger model, shown in figure C.1, is discussed.



Figure C.1: Numerical heat exchanger model

Equation (A.13) can be approximated by a second order polynomial

$$
\begin{aligned}
\Delta \mathrm{p}_{\mathrm{e}} & =-\left(2.4756 \times 10^{-4} \mathrm{~V}_{\mathrm{a}}^{2}+4.31807 \times 10^{-3} \mathrm{~V}_{\mathrm{a}}^{1.56073}\right) \\
& \approx-\left(4.132315 \mathrm{E} \times 10^{-4} \mathrm{~V}_{\mathrm{a}}^{2}+5.629484 \times 10^{-2} \mathrm{~V}_{\mathrm{a}}\right), \mathrm{Pa}
\end{aligned}
$$

The volume flow rate can be written in terms of the average velocity in the z-direction

$$
\mathrm{V}_{\mathrm{a}}=|\mathrm{w}|\left(\mathrm{L}_{\mathrm{x}} \times \mathrm{L}_{\mathrm{y}}\right)
$$


so that equation (C.1) written in terms of $\mathrm{w}$, becomes

$$
\begin{aligned}
\Delta \mathrm{p}_{\mathrm{e}} & =-\left(4.132315 \mathrm{E} \times 10^{-4} \mathrm{~V}_{\mathrm{a}}^{2}+5.629484 \times 10^{-2} \mathrm{~V}_{\mathrm{a}}\right) \\
& =4.132315 \times 10^{-4}\left(\mathrm{~L}_{\mathrm{x}} \times \mathrm{L}_{\mathrm{y}}\right)^{2}|\mathrm{w}| \mathrm{w}+5.629484 \times 10^{-2}\left(\mathrm{~L}_{\mathrm{x}} \times \mathrm{L}_{\mathrm{y}}\right) \mathrm{W} \\
& =6.4163|\mathrm{w}| \mathrm{w}+7.1048 \mathrm{w} \quad, \mathrm{Pa}
\end{aligned}
$$

The body forces acting in the z-direction in each cell of the numerical heat exchanger model, shown in figure C.1, is given by

$$
\mathrm{F}_{\mathrm{z}}=\frac{\Delta \mathrm{p}_{\mathrm{e}}}{\mathrm{L}_{\mathrm{z}}}=32.082|\mathrm{w}| \mathrm{w}+35.074 \mathrm{w} \quad, \mathrm{N} / \mathrm{m}^{3}
$$

Due to the fact that flow is restricted in the $\mathrm{x}$ and $\mathrm{y}$-directions, $|\mathbf{v}| \approx|\mathrm{w}|$, so that the body force in the z-direction given in table 3.4 becomes

$$
\mathrm{F}_{\mathrm{z}}=\left(\mathrm{C}_{\mathrm{z}} \frac{1}{2} \rho|\mathrm{w}| \mathrm{w}+\frac{\mu}{\alpha_{\mathrm{z}}} \mathrm{w}\right)
$$

By comparing equations (C.4) and equation (C.5), the viscous and inertial loss coefficients, $1 / \alpha_{z}$ and $C_{z}$, can now be calculated

$$
\begin{aligned}
& C_{z} \frac{1}{2} \rho=32.082 \\
& C_{z}=59.1364
\end{aligned}
$$

and

$$
\begin{aligned}
& \frac{\mu}{\alpha_{z}}=35.074 \\
& \frac{1}{\alpha_{z}}=1.897 \times 10^{6}
\end{aligned}
$$




\section{C.2. Heat source terms}

An UDF (refer so section 3.2) was written to model heat transfer to the air. In the UDF the mass flow rate, $\mathrm{m}_{\mathrm{a}}$, and the average inlet temperature, $\mathrm{T}_{\mathrm{ai}}$, are read from the solver. These values are then used in order to calculate the heat source terms in the heat exchanger model at each iteration. The calculation procedure and equations used in this code are given below.

The characteristic flow parameter given by equation (A.5), for the first tube row, is adapted so as to account for the reduction in effective frontal area due to a fewer number of tubes

$$
\mathrm{Ry}_{1}=\frac{\mathrm{m}_{\mathrm{a}}}{\mu \mathrm{n}_{\mathrm{b}} \mathrm{A}_{\mathrm{fr}} \frac{\mathrm{n}_{\mathrm{tb} 1}}{\mathrm{n}_{\mathrm{tb} 2}}}
$$

The effective air-side heat transfer coefficient is calculated according to equation (A.4)

$$
\mathrm{hA}_{1}=\mathrm{k}_{\mathrm{a}} \operatorname{Pr}^{0.333} \mathrm{n}_{\mathrm{b}} \mathrm{A}_{\mathrm{fr}} \mathrm{Ny}_{1} \frac{\mathrm{n}_{\mathrm{bt} 1}}{\mathrm{n}_{\mathrm{bt} 2}}
$$

where $\mathrm{Ny}_{1}$ is the characteristic heat transfer parameter given by equation (A.1). The heat transfer rate for the first tube row, is calculated according to equation (2.7)

$\mathrm{Q}_{1}=\mathrm{m}_{\mathrm{a}} \mathrm{c}_{\mathrm{pa}}\left(\mathrm{T}_{\mathrm{aol}}-\mathrm{T}_{\mathrm{ail}}\right)=\mathrm{e}_{1} \mathrm{~m}_{\mathrm{a}} \mathrm{c}_{\mathrm{pa}}\left(\mathrm{T}_{\mathrm{s}}-\mathrm{T}_{\mathrm{ail}}\right)$

By rearranging equation (C.8), a relation for the air outlet temperature is obtained

$$
\mathrm{T}_{\mathrm{ao} 1}=\mathrm{e}_{1} \mathrm{~T}_{\mathrm{s}}+\left(1-\mathrm{e}_{1}\right) \mathrm{T}_{\mathrm{ai} 1}
$$

where $\mathrm{e}_{1}$ is the effectiveness of the first tube row calculated according to equation (2.8).

$$
\mathrm{e}_{1}=1-\exp \left(\frac{-\mathrm{UA}_{1}}{\mathrm{~m}_{\mathrm{a}} \mathrm{c}_{\mathrm{pa}}}\right)
$$


In the above equation the thermal resistance of the condensate film, typically in the order of $2 \%$ of the total thermal resistance, is neglected, so that the $\mathrm{UA}_{1}=\mathrm{hA} \mathrm{A}_{1}$. With the outlet temperature of the first tube row, $T_{a o l}$, equal to the inlet temperature of the second tube row, $\mathrm{T}_{\mathrm{ai} 2}$, the heat transfer rate from the second tube row, $\mathrm{Q}_{2}$, can be calculated using a similar procedure described above. The outlet temperature of the second row is thus given by

$\mathrm{T}_{\mathrm{ao} 2}=\mathrm{e}_{2} \mathrm{~T}_{\mathrm{s}}+\left(1-\mathrm{e}_{2}\right) \mathrm{T}_{\mathrm{ai} 2}=\mathrm{e}_{2} \mathrm{~T}_{\mathrm{s}}+\left(1-\mathrm{e}_{2}\right)\left[\mathrm{e}_{1} \mathrm{~T}_{\mathrm{s}}+\left(1-\mathrm{e}_{1}\right) \mathrm{T}_{\mathrm{ai} 1}\right]$

The total heat transfer rate per fan unit is then

$\mathrm{Q}_{\text {tot }}=\mathrm{Q}_{1}+\mathrm{Q}_{2}=\mathrm{m}_{\mathrm{a}} \mathrm{c}_{\mathrm{pa}}\left(\mathrm{T}_{\mathrm{ao} 2}-\mathrm{T}_{\mathrm{ai} 1}\right)$

Numerically the heat transfer to the air is modelled by adding heat source terms the relevant energy equations. The heat source terms, $\mathrm{F}_{\mathrm{E}}$, are calculated such that it would result in a uniform outlet temperature distribution.

$\mathrm{F}_{\mathrm{E}}=\frac{\delta \mathrm{Q}}{\delta \mathrm{V}}=\frac{\delta \mathrm{m}_{\mathrm{a}} \mathrm{c}_{\mathrm{pa}}}{\delta \mathrm{V}}\left(\mathrm{T}_{\mathrm{a} 22}-\mathrm{T}_{\mathrm{a} 11}\right)=\frac{\rho|\mathrm{w}| \mathrm{c}_{\mathrm{pa}}}{\mathrm{L}_{\mathrm{z}}}\left(\mathrm{T}_{\mathrm{a} 22}-\mathrm{T}_{\mathrm{ai1}}\right), \mathrm{W} / \mathrm{m}^{3}$

where $\delta \mathrm{m}_{\mathrm{a}}$ and $\delta \mathrm{V}$ are the mass flow rate through a cell and the volume of a cell, respectively. 


\section{Appendix D - Fan blade profile lift and drag characteristics}

The actuator disc model discussed in section 3.2.2, requires isolated blade profile lift and drag coefficients, as a function of angle of attack $(\alpha)$.

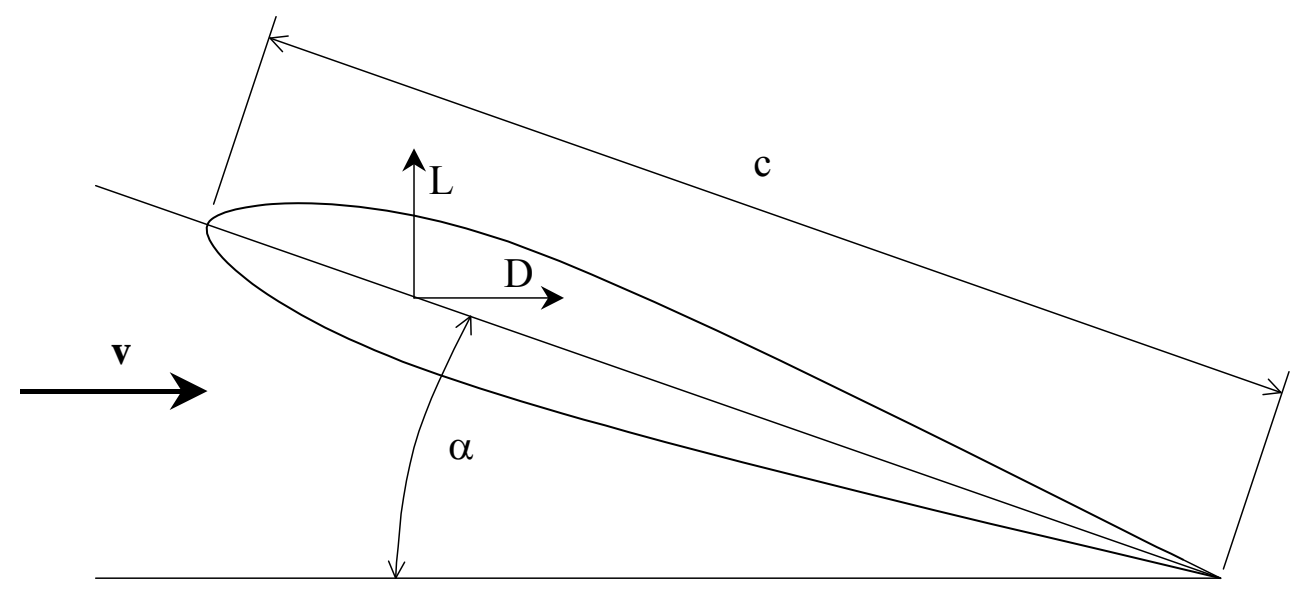

Figure D.1: Lift and drag forces on an isolated blade profile

The lift coefficient and drag coefficient per unit length of span are defined by equation (D.1) and equation (D.2), respectively.

$$
\mathrm{C}_{\mathrm{L}}=\frac{\mathrm{L}}{\frac{1}{2} \rho|\mathbf{v}|^{2} \mathrm{c}}
$$

and

$$
C_{D}=\frac{D}{\frac{1}{2} \rho|\mathbf{v}|^{2} c}
$$

where L, D and $\mathbf{v}$ is the lift force, drag force and free stream velocity magnitude, respectively, as shown in figure D.1. Distorted flow patterns near the fan inlet, and back flow near the hub, may result in a wide range of angles of attack $(\alpha)$. Depending on the severity of these factors, angles of attack, ranging between $-90^{\circ}<\alpha<90^{\circ}$ can be expected. 
The lift and drag characteristics of a blade profile (or airfoil) are a function of geometry, Reynolds number, and angle of attack, and can be determined by one of the following methods:

a) Analytically. By applying classical potential flow and boundary layer theory, [60SC1], [82HO1], [91WH1], the pressure and skin friction distribution along the airfoil can be determined for a specified flow condition. By integrating these parameters along the surface or perimeter of the airfoil, the aerodynamic forces can be calculated. This method can only be applied for a limited range (below stall) of angle of attack.

b) Empirically. Hoerner [65HO1] and Hoerner and Borst [75HO1] provide empirical correlations for the lift and drag coefficients of airfoils, that are functions of camber ratio, thickness ratio, Reynolds number and angle of attack. These correlations are also limited to angles of attack below stall. Thiart and von Backström [93TH1], discuss the implementation of these correlations in an actuator disc model, and recommend the use of flat plate data beyond stall.

c) Numerically. CFD-based methods [99VA1] can be used to analyse the flow field around an airfoil using a two-dimensional or three-dimensional computational grid. It is typically found that the lift force, which is mainly dependent on pressure force, can be predicted with fair accuracy for attached flow conditions. The prediction of drag coefficient at low angles of attack however, is often less accurate. This is due to inaccuracies in predicting the viscous wall shear stresses. Insufficient grid resolution and the fact that transition in the boundary layer is neglected (the flow is assumed to be either fully laminar or turbulent), are some of the factors that might cause these inaccuracies. Despite these facts, RANS (Reynolds Averaged Navier Stokes) methods can effectively be used to predict the aerodynamic characteristics of airfoils for a wide range of flow conditions.

d) Experimentally. The use of experimentally determined wind tunnel data is ideal. Experimental data is however not always available, as in the case of the A-fan blade profile. Furthermore, readily available experimental data is usually limited to the attached flow conditions, and do not include data beyond stall. 
In this study, numerically determined data was used if experimental data was unavailable. The purpose of this appendix is to discuss and validate this numerical procedure. Furthermore, the lift and drag coefficients for the A-fan and B-fan blade profiles are given.

\section{D.1. Numerically determined lift and drag coefficients}

By modelling the flow field around a particular fan blade profile (or airfoil), at a prescribed angle of attack and Reynolds number, the resulting pressure and viscous forces acting on its surface, can be calculated. In this section, such a method is evaluated by comparing numerically predicted lift and drag coefficients to experimental data, for the NASA GA(W)-2 airfoil tested by $\mathrm{McGhee}$ et al. [77MC1].

\section{D.1.1. Computational aspects}

A two-dimensional computational grid was used to resolve the flow field around the fan blade profile. The circular flow domain has a radius of thirty chord lengths and consists of 28800 rectangular elements, as shown in figure D.2.



Figure D.2: Computational grid for the NASA GA(W)-2 airfoil

Details of the mesh near the surface are shown in figure D.3. The height of the wall-adjacent cells corresponds to $\mathrm{y}^{+} \approx 30$. This condition ensures the effective implementation of the loglaw wall function, discussed in section 2.1 . 


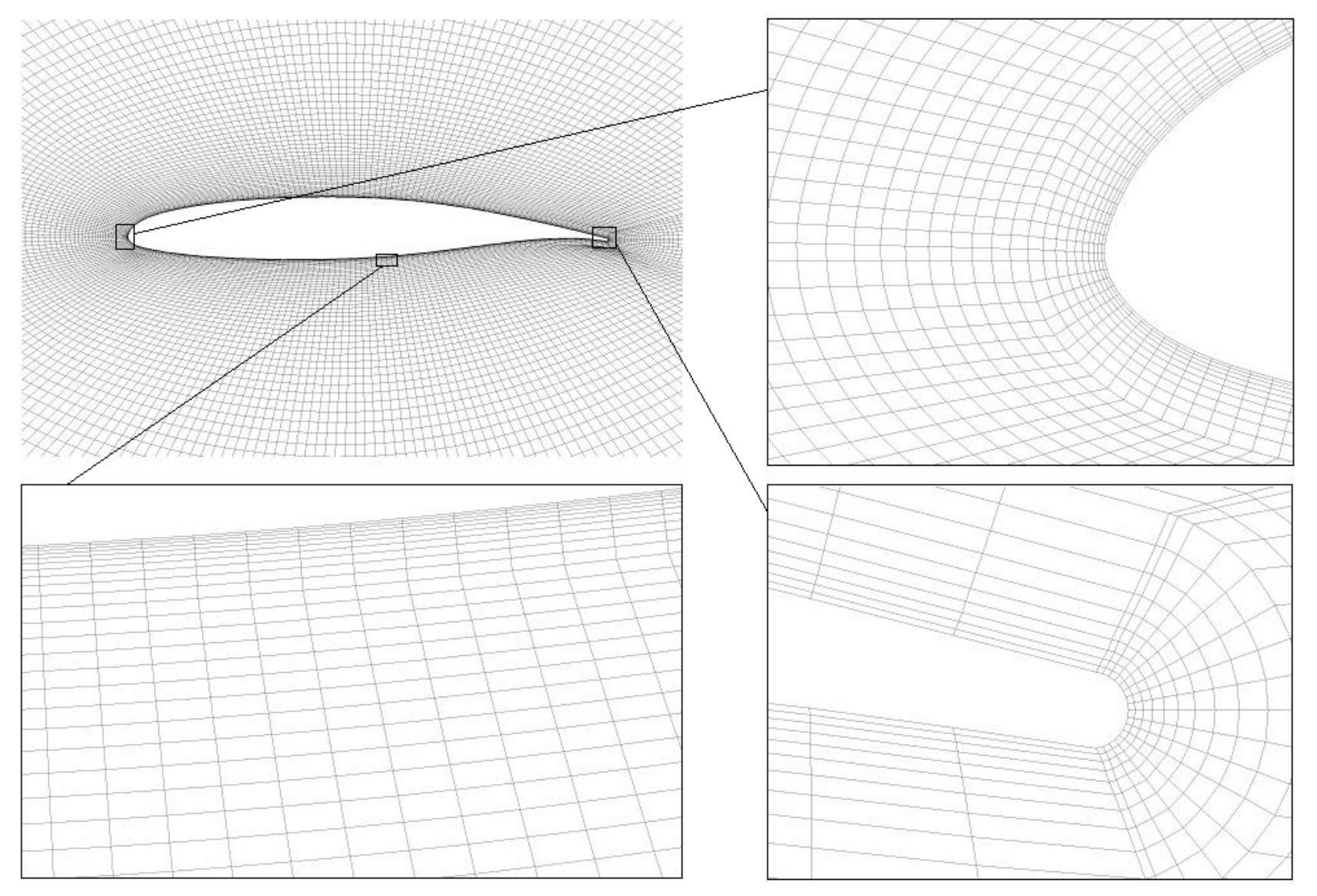

Figure D.3: Computational grid near the surface of the NASA GA(W)-2 airfoil

The flow was assumed to be incompressible and time independent (steady state).

Numerical results obtained employing two different turbulence models, namely the k- $\varepsilon$ model of Launder and Spalding [74SP1], and the k- $\omega$ shear stress transport (SST) model of Menter [94ME1], were compared.

A velocity inlet boundary condition was specified at the periphery of the domain. The angle of attack was thus determined by prescribing the appropriate velocity vector at this boundary. The surface of the airfoil was modelled as a zero-slip wall.

For angles of attack below stall, the second order upwind discritization scheme was employed for the convective terms in the momentum equations. Beyond stall the flow was found to be highly unstable (or transient), characterised by periodic vortex shedding. Under such conditions first order upwind discritization was used in order to improve convergence. 


\section{D.1.2. Results and discussion}

The numerically determined lift and drag coefficients, using both the k- $\varepsilon$ turbulence and the k- $\omega$ SST turbulence model, are compared to experimental data in figure D.4 and figure D.5, respectively.

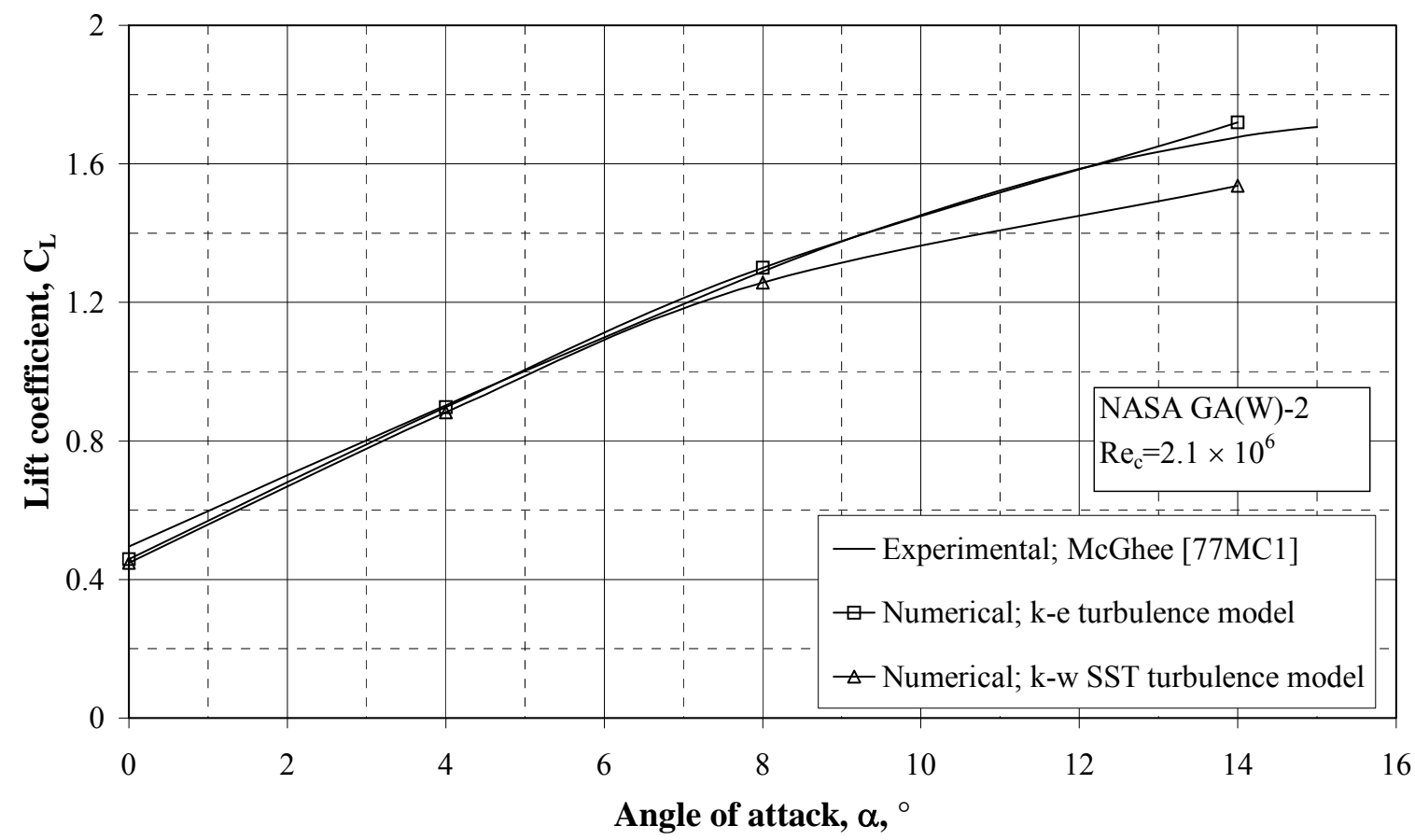

Figure D.4: Numerically determined lift coefficient of the NASA GA(W)-2 airfoil



Figure D.5: Numerically determined drag coefficient of the NASA GA(W)-2 airfoil 
The average percentage error between the numerically predicted lift coefficient and experimental data, using the k- $\varepsilon$ turbulence model and the k- $\omega$ SST turbulence model, are $2.5 \%$ and $5.8 \%$, respectively.

It can be seen in figure D.4 that the prediction of the drag coefficient is less accurate, particularly at low angles of attack where viscous forces are dominant. The best results are again obtained using the k- $\varepsilon$ model, which predicts the drag coefficient within an average error of $25 \%$, compared to $57 \%$ using the $\mathrm{k}-\omega$ SST model.

It was found that the actuator disc model was more dependent on (or sensitive to) lift coefficient data, than on drag coefficient data, at low angles of attack. A possible reason for this is the relatively high lift-drag-ratio, $C_{L} / C_{D} \approx 100$, that occurs for $0^{\circ}<\alpha<4^{\circ}$. For this particular application, the numerical prediction of the drag coefficient using the $\mathrm{k}-\varepsilon$ model was therefore sufficiently accurate, and produced acceptable results.

For angles of attack beyond stall separated flow conditions were observed as shown in figure D.6 for $\alpha=24^{\circ}$.



Figure D.6: Streamline plot for the NASA GA(W)-2 airfoil at $\alpha=24^{\circ}$ 
Due to the periodic nature of the flow, the lift and drag coefficients were averaged, as shown in figure D.7.

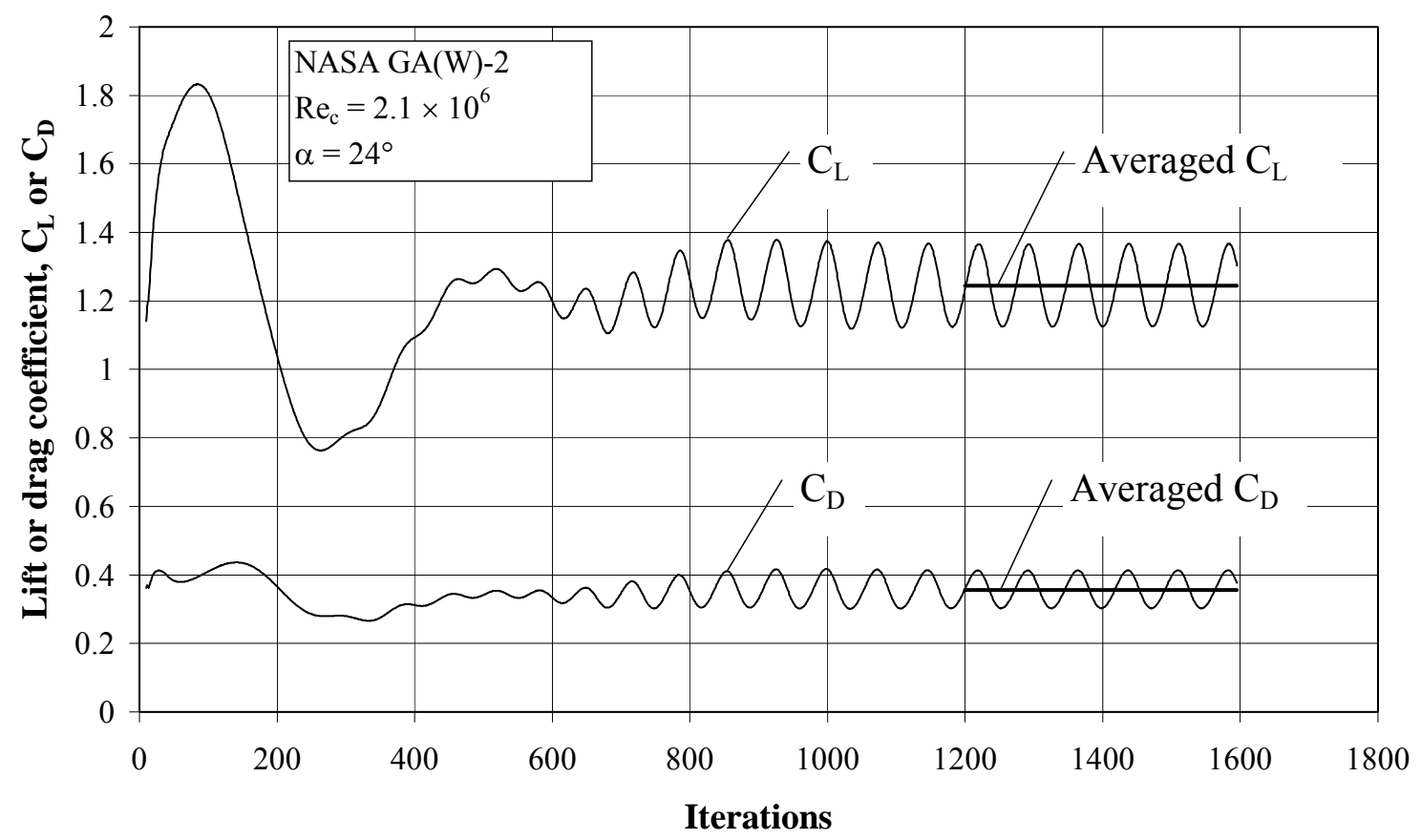

Figure D.7: Numerically determined lift and drag coefficients for the NASA GA(W)-2 airfoil at $\alpha=24^{\circ}$

The accuracy of the lift and drag coefficients beyond stall could not be determined. It should therefore be emphasised that the numerical procedure discussed above serves as a method to approximate the time averaged forces on a particular airfoil section under prescribed flow conditions.

\section{D.2. A-fan blade profile lift and drag characteristics}

Owing to the unavailability of experimental data, the lift and drag characteristics of the A-fan blade profile was determined numerically, using the same resolution grid as discussed in the previous section. For the A-fan with a diameter of $\mathrm{d}_{\mathrm{F}}=9.145 \mathrm{~m}$ operating under normal conditions, the Reynolds number based on the chord length of the fan blade, may range between $4 \times 10^{5}<\operatorname{Re}_{c}<2.6 \times 10^{6}$. The variation of lift and drag coefficients within this range of Reynolds numbers were however found to be negligible. Numerical simulations were therefore conducted at an average Reynolds number of $1.5 \times 10^{6}$. The numerically predicted 
lift and drag coefficients for the A-fan blade profile are given in figure D.8. For use in the actuator disc model, the numerical data was represented by a series of polynomial curve fits.

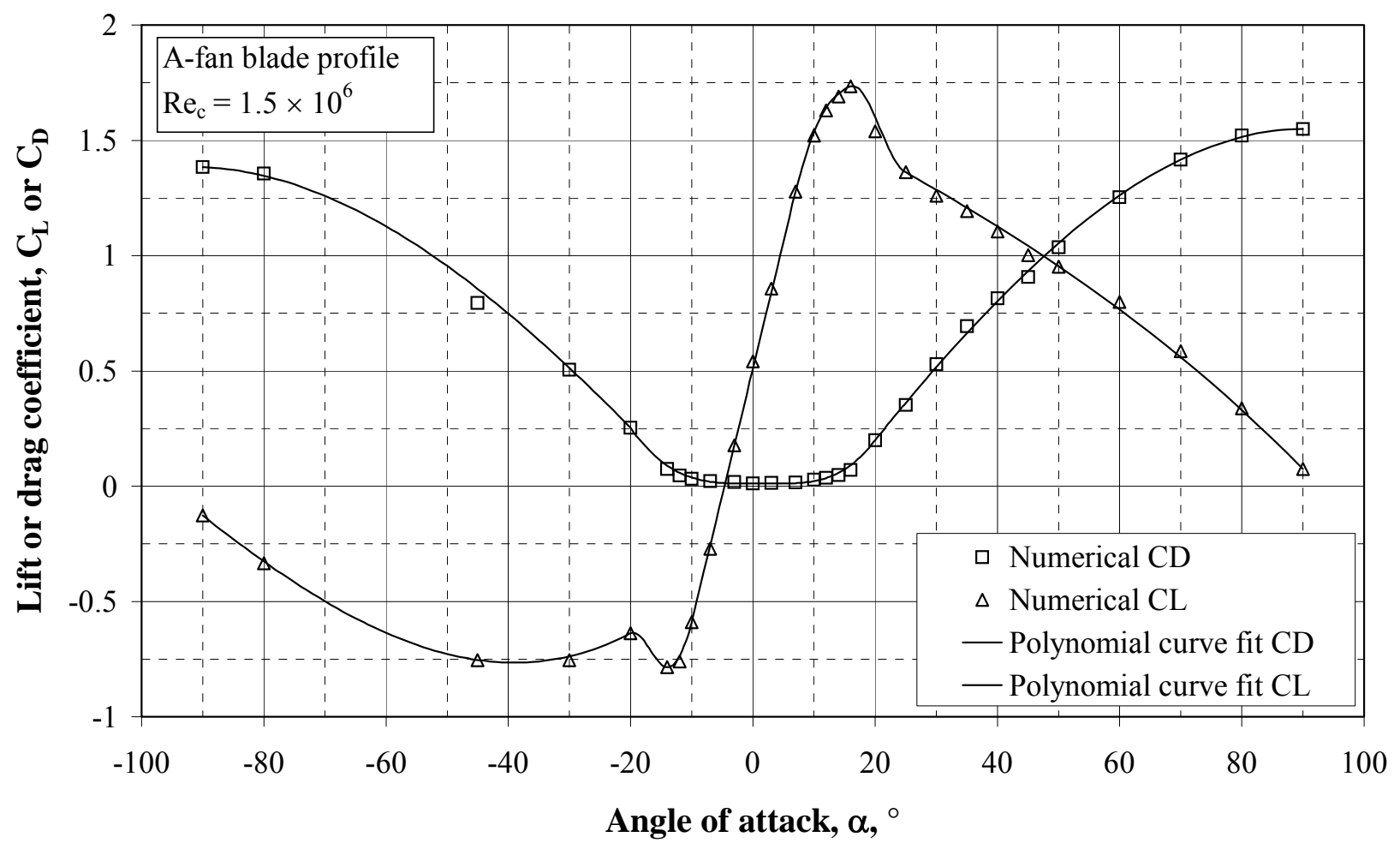

Figure D.8: Lift and drag coefficients of the A-fan blade profile for $-90^{\circ}<\alpha<90^{\circ}$

\section{D.3. B-fan blade profile lift and drag characteristics}

Experimental lift and drag coefficient data of the NASA GA(W)-2 airfoil used in the design of the B-fan is given in Bruneau [94BR1] (it is assumed that the experimental data corresponds to Reynolds number of approximately $1.9 \times 10^{6}$ ). For angles of attack falling outside the range of experimental data, the coefficients were determined numerically at the same Reynolds number. The experimental and numerical data was again represented by a set of polynomial curve fits, as shown in figure D.9. As in the case of the A-fan, the Reynolds number effects are neglected. 


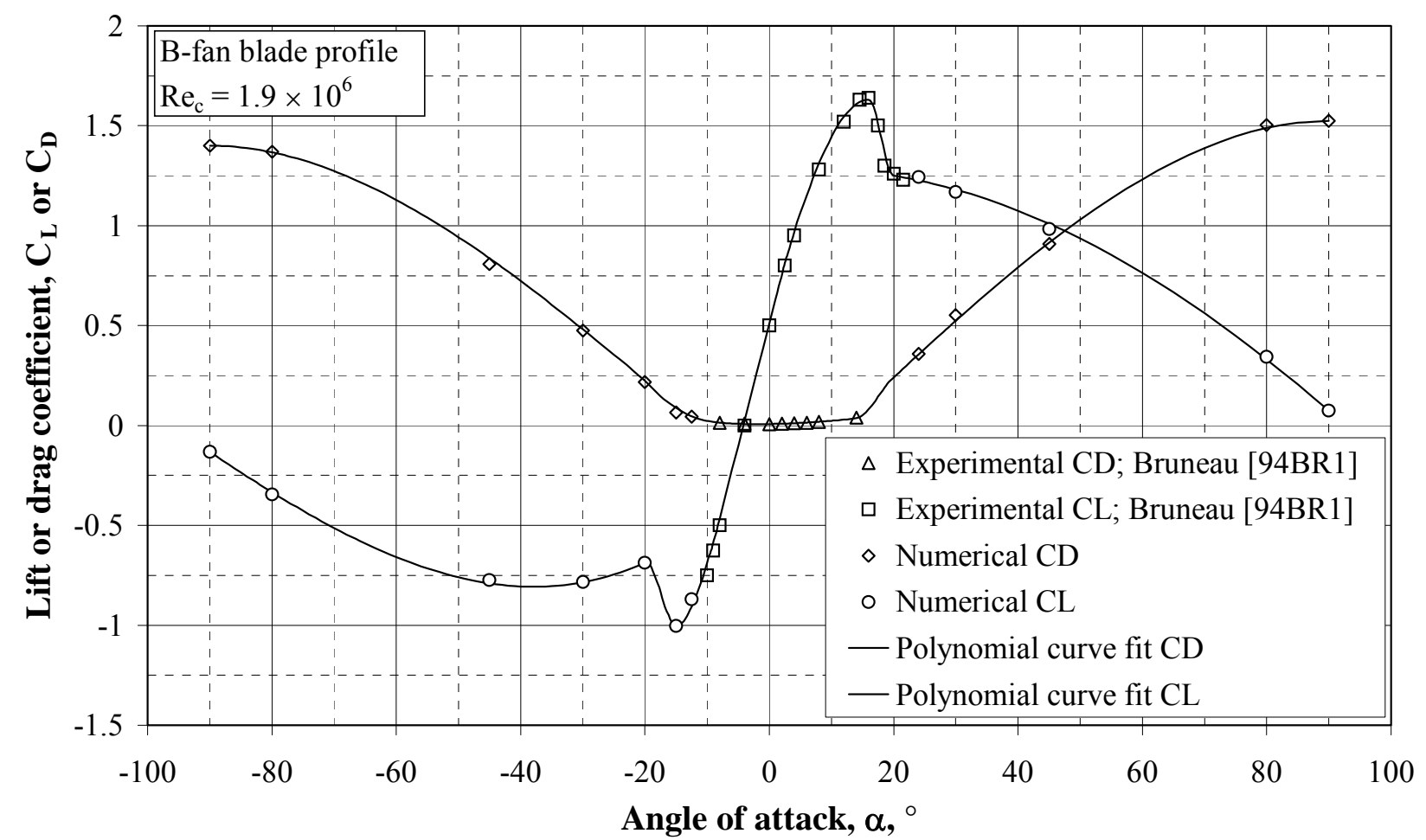

Figure D.9: Lift and drag coefficients of the B-fan blade profile for $-90^{\circ}<\alpha<90^{\circ}$ 


\section{Appendix E - Numerical fan performance results for a section of the ACSC under windless conditions}

E.1. Fan performance of the A-fan at a platform height of $\mathrm{H}_{\mathrm{i}}=26 \mathrm{~m}$



Figure E.1: Volumetric effectiveness for the A-fan $\left(\mathrm{d}_{\mathrm{F}}=9.145 \mathrm{~m}, \gamma_{\mathrm{pt}}=16^{\circ}\right)$ at $\mathrm{H}_{\mathrm{i}}=26 \mathrm{~m}$

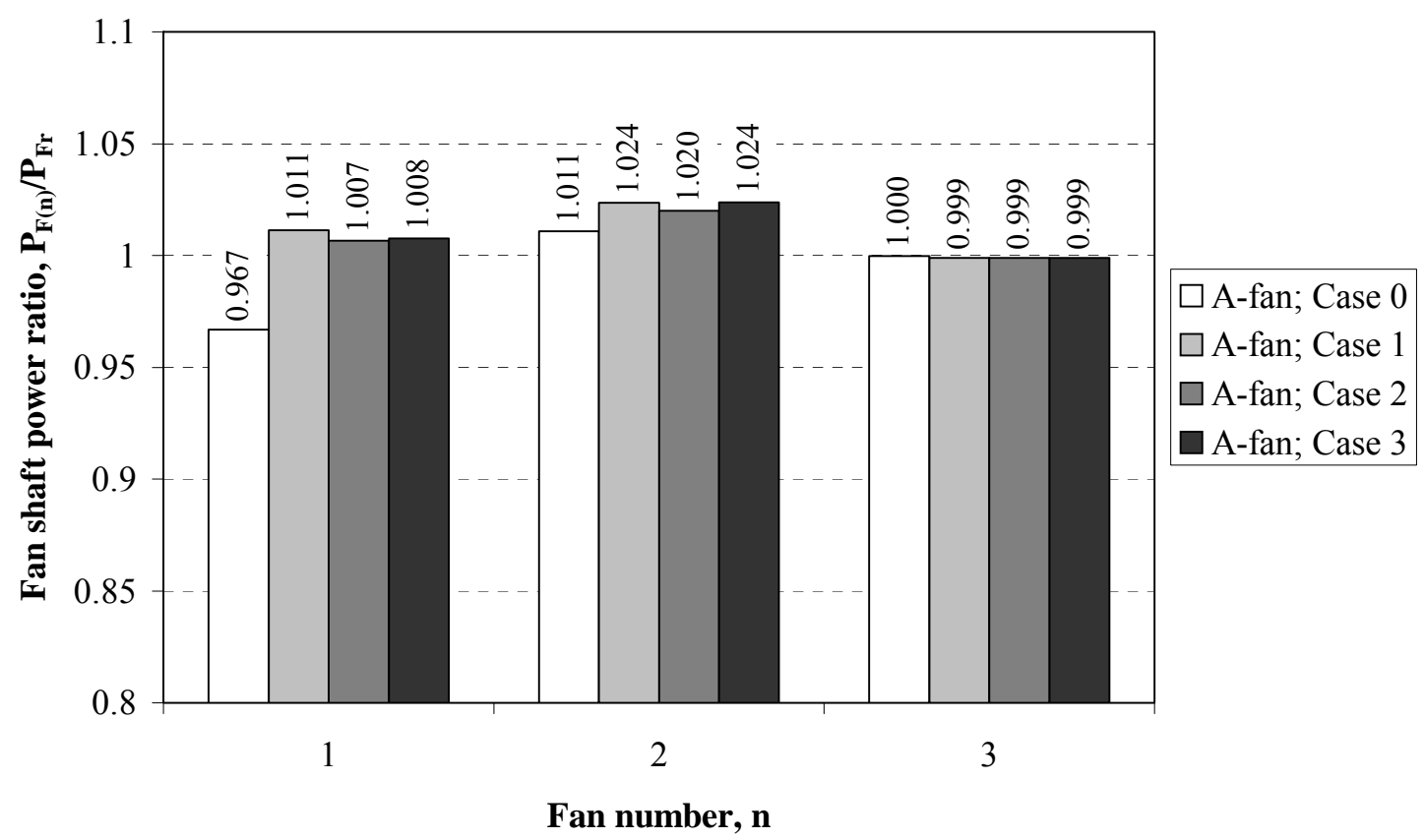

Figure E.2: Fan shaft power ratio for the A-fan $\left(\mathrm{d}_{\mathrm{F}}=9.145 \mathrm{~m}, \gamma_{\mathrm{pt}}=16^{\circ}\right)$ at $\mathrm{H}_{\mathrm{i}}=26 \mathrm{~m}$ 


\section{E.2. Fan performance of the B-fan at a platform height of $\mathrm{H}_{\mathrm{i}}=26 \mathrm{~m}$}

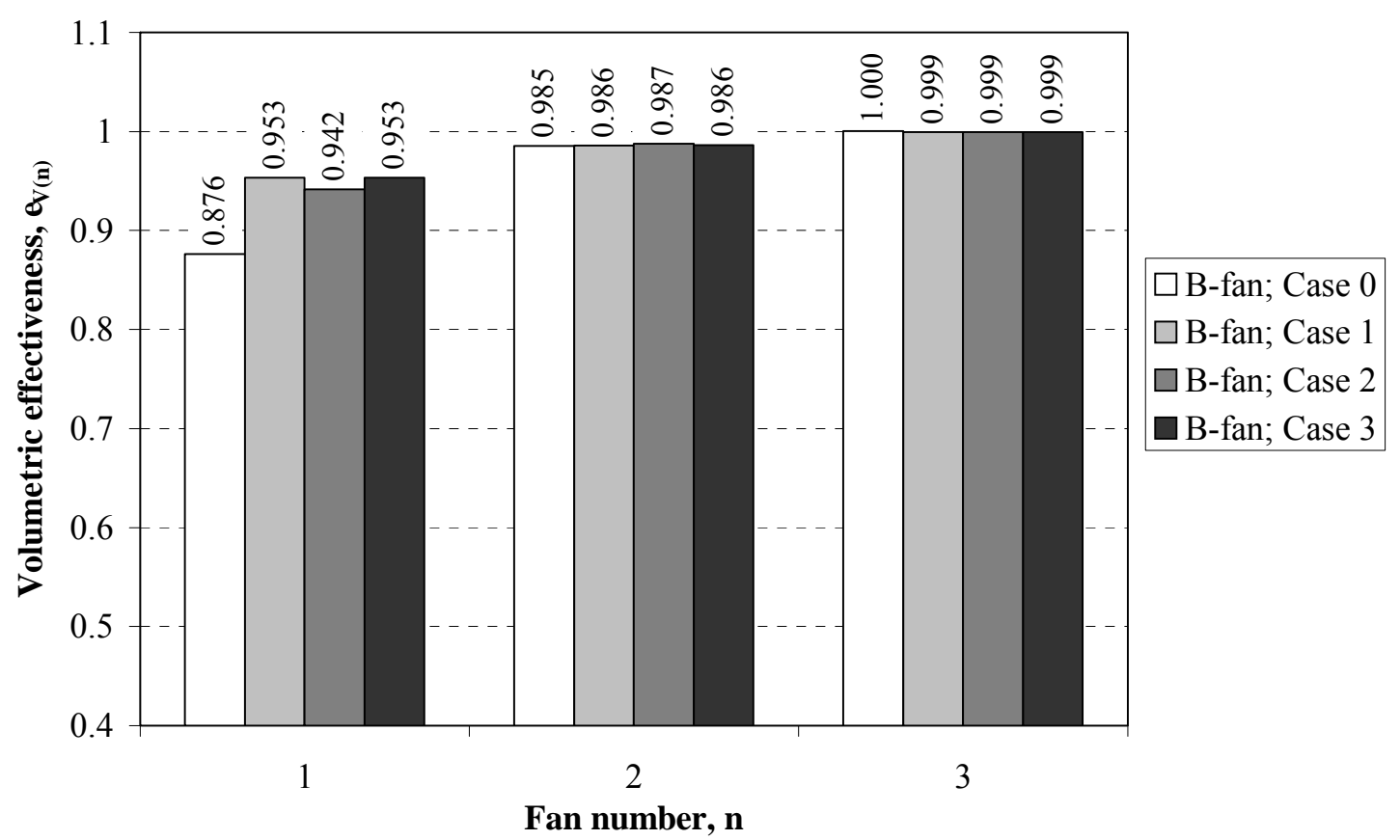

Figure E.3: Volumetric effectiveness for the B-fan $\left(d_{\mathrm{F}}=9.145 \mathrm{~m}, \gamma_{\mathrm{cr}}=34.5^{\circ}\right)$ at $\mathrm{H}_{\mathrm{i}}=26 \mathrm{~m}$



Figure E.4: Fan shaft power ratio for the B-fan $\left(\mathrm{d}_{\mathrm{F}}=9.145 \mathrm{~m}, \gamma_{\mathrm{cr}}=34.5^{\circ}\right)$ at $\mathrm{H}_{\mathrm{i}}=26 \mathrm{~m}$ 


\section{E.3. Fan performance of the A-fan at a platform height of $\mathrm{H}_{\mathrm{i}}=22 \mathrm{~m}$}



Figure E.5: Volumetric effectiveness for the A-fan $\left(\mathrm{d}_{\mathrm{F}}=9.145 \mathrm{~m}, \gamma_{\mathrm{pt}}=16^{\circ}\right)$ at $\mathrm{H}_{\mathrm{i}}=22 \mathrm{~m}$

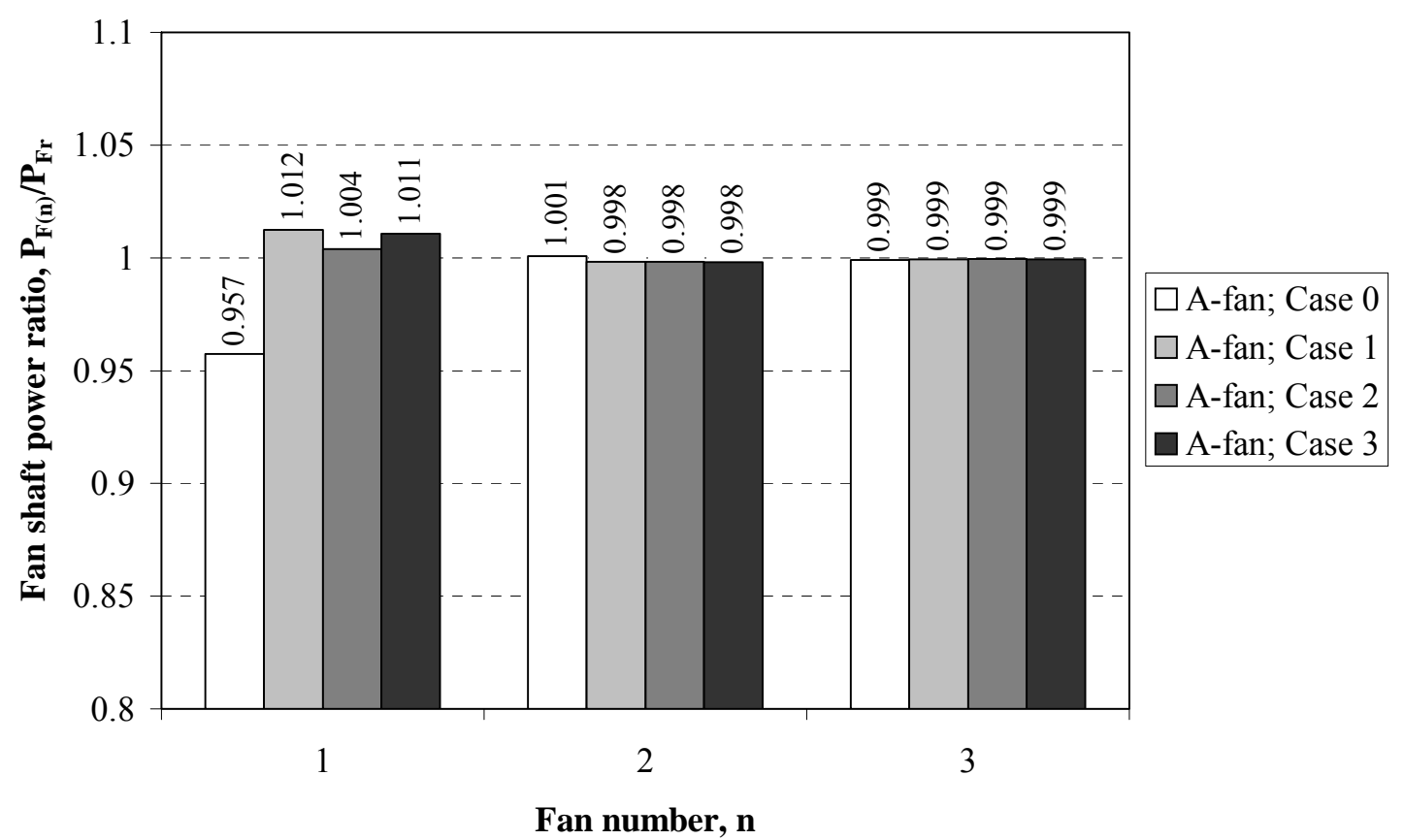

Figure E.6: Fan shaft power ratio for the A-fan $\left(\mathrm{d}_{\mathrm{F}}=9.145 \mathrm{~m}, \gamma_{\mathrm{pt}}=16^{\circ}\right)$ at $\mathrm{H}_{\mathrm{i}}=22 \mathrm{~m}$ 


\section{E.4. Fan performance of the B-fan at a platform height of $\mathrm{H}_{\mathrm{i}}=22 \mathrm{~m}$}

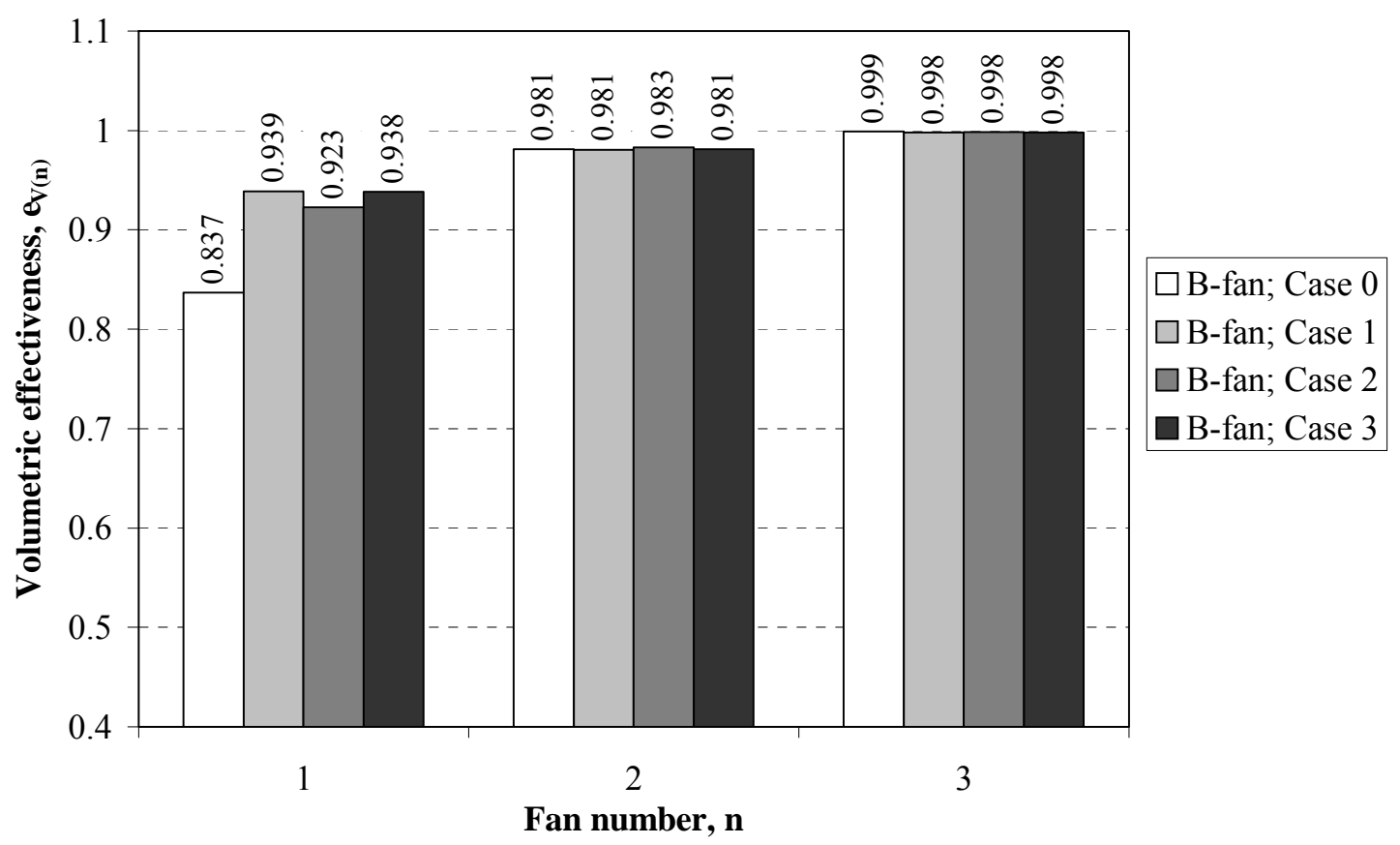

Figure E.7: Volumetric effectiveness for the B-fan $\left(\mathrm{d}_{\mathrm{F}}=9.145 \mathrm{~m}, \gamma_{\mathrm{cr}}=34.5^{\circ}\right)$ at $\mathrm{H}_{\mathrm{i}}=22 \mathrm{~m}$

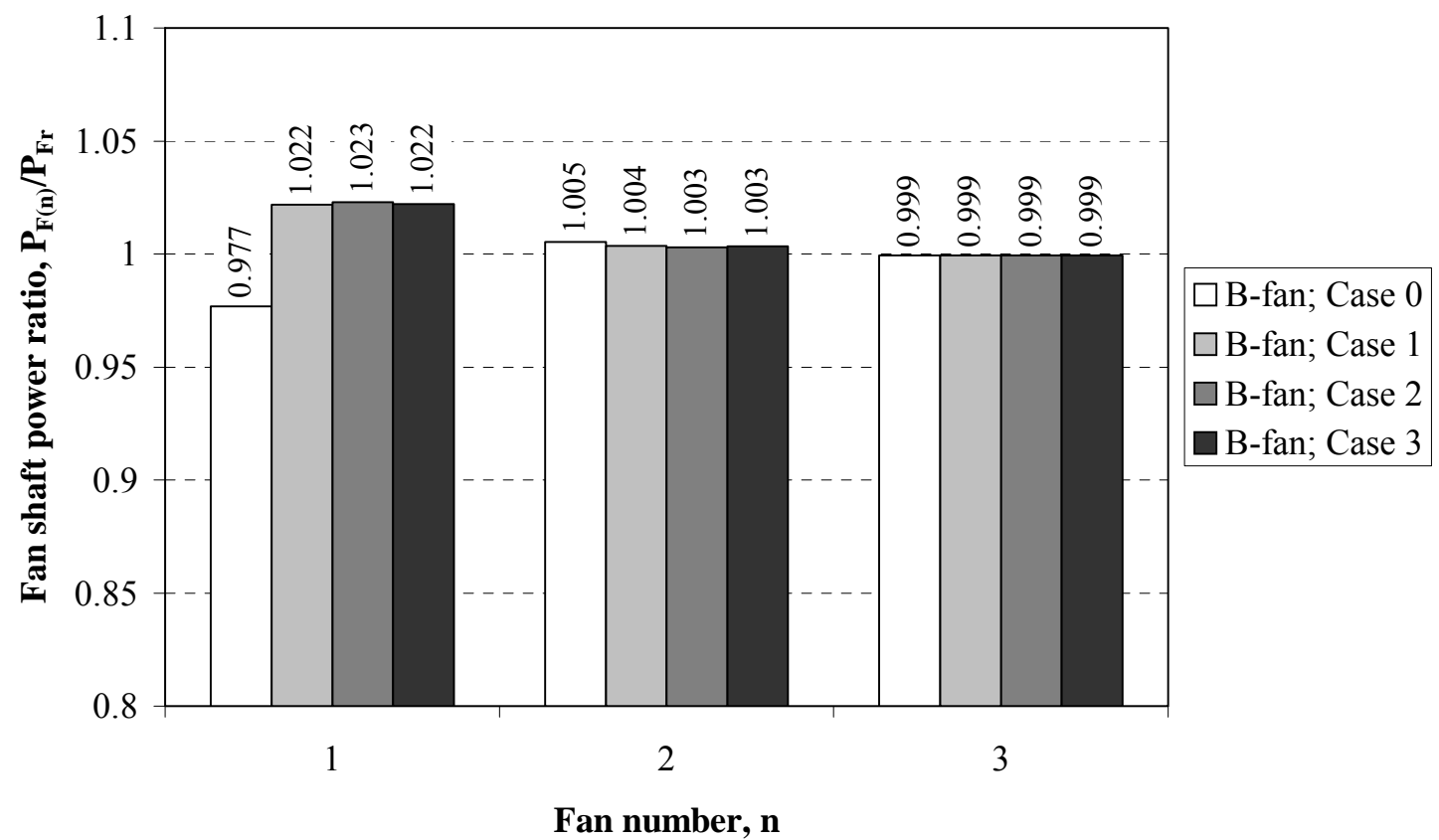

Figure E.8: Fan shaft power ratio for the $\mathrm{B}-\mathrm{fan}\left(\mathrm{d}_{\mathrm{F}}=9.145 \mathrm{~m}, \gamma_{\mathrm{cr}}=34.5^{\circ}\right)$ at $\mathrm{H}_{\mathrm{i}}=22 \mathrm{~m}$ 


\section{E.4. Fan performance of the A-fan at a platform height of $\mathrm{H}_{\mathrm{i}}=18 \mathrm{~m}$}

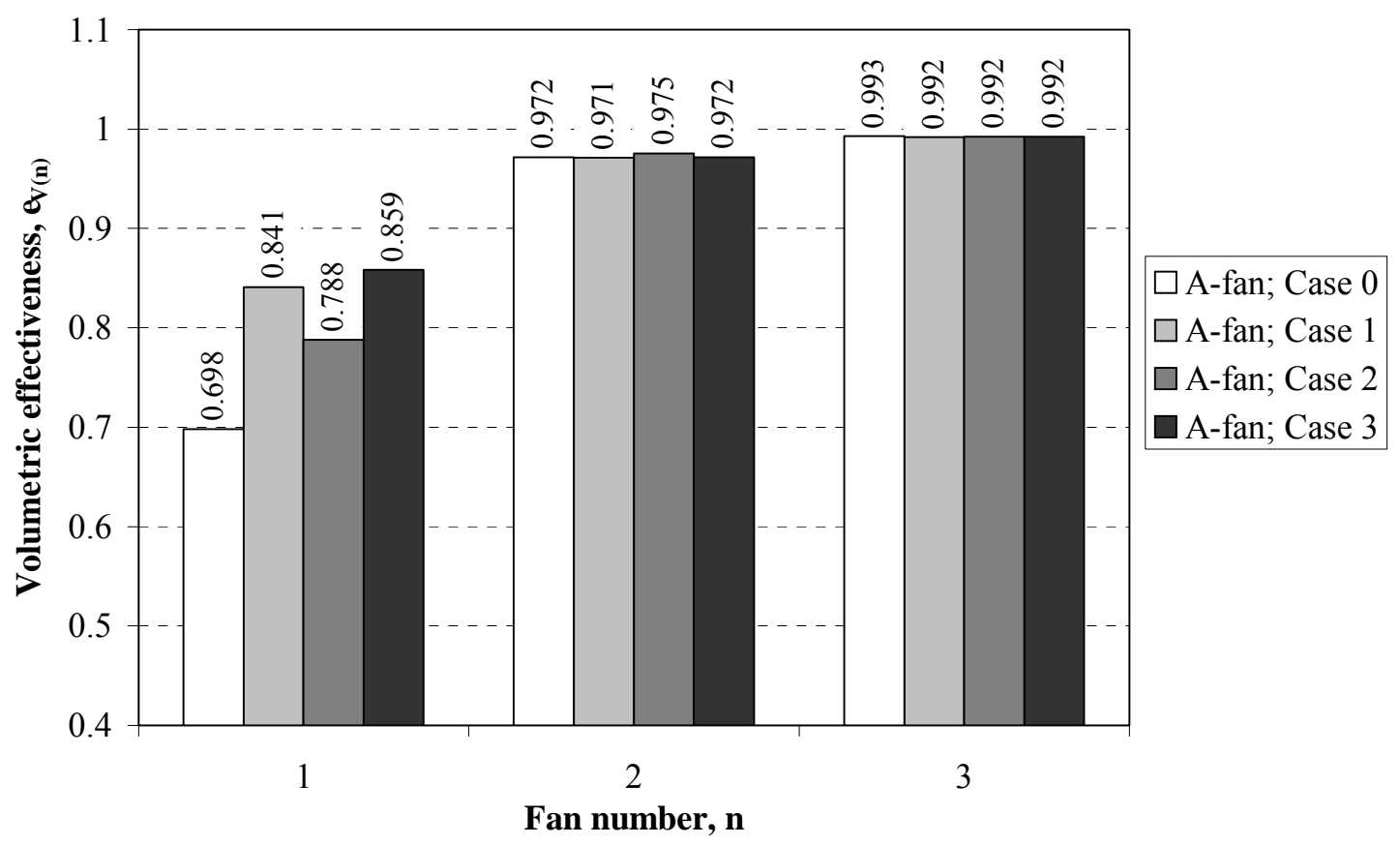

Figure E.9: Fan shaft power ratio for the A-fan $\left(\mathrm{d}_{\mathrm{F}}=9.145 \mathrm{~m}, \gamma_{\mathrm{pt}}=16^{\circ}\right)$ at $\mathrm{H}_{\mathrm{i}}=18 \mathrm{~m}$

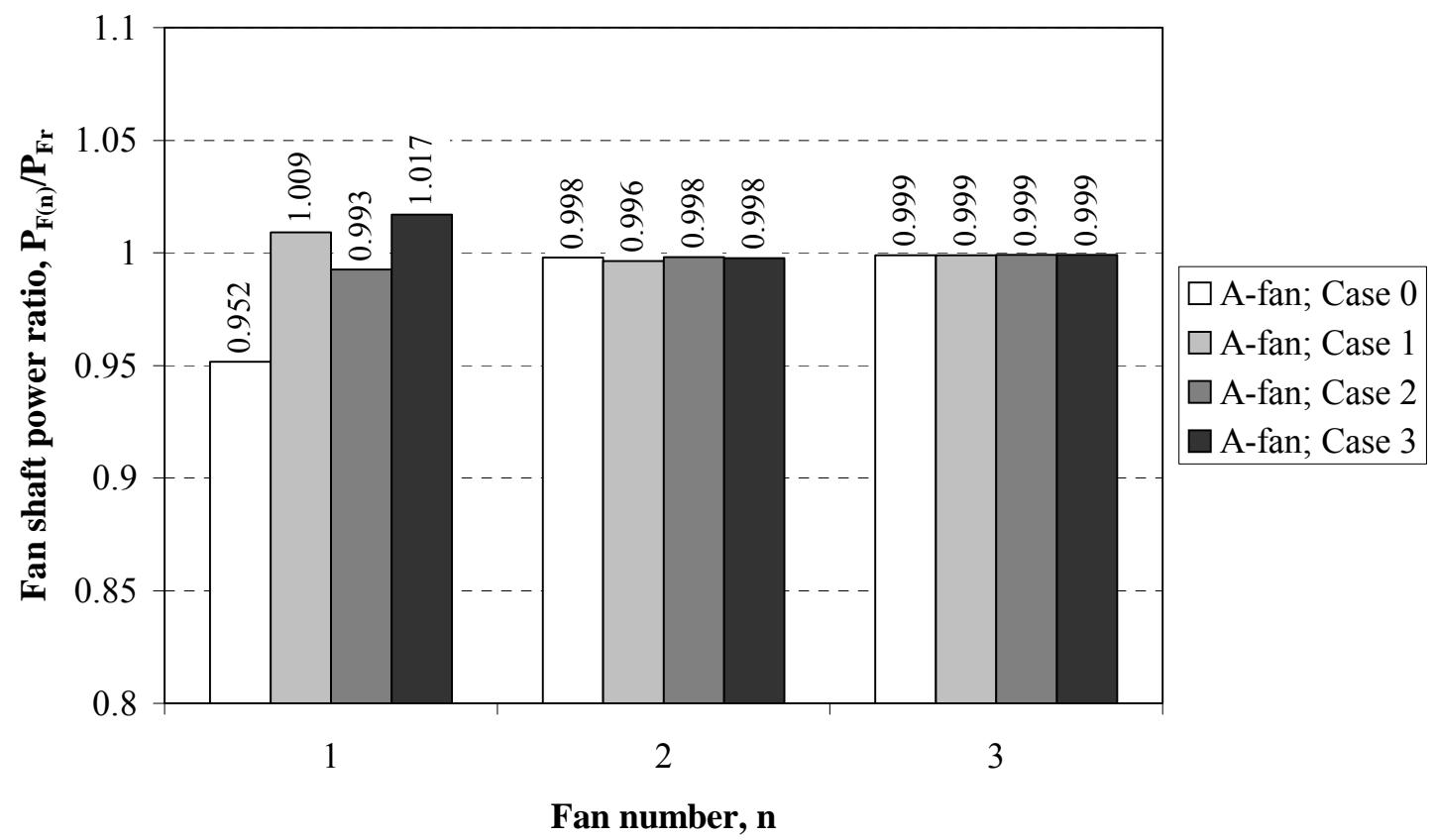

Figure E.10: Fan shaft power ratio for the A-fan $\left(\mathrm{d}_{\mathrm{F}}=9.145 \mathrm{~m}, \gamma_{\mathrm{pt}}=16^{\circ}\right)$ at $\mathrm{H}_{\mathrm{i}}=18 \mathrm{~m}$ 


\section{E.5. Fan performance of the B-fan at a platform height of $\mathrm{H}_{\mathrm{i}}=18 \mathrm{~m}$}

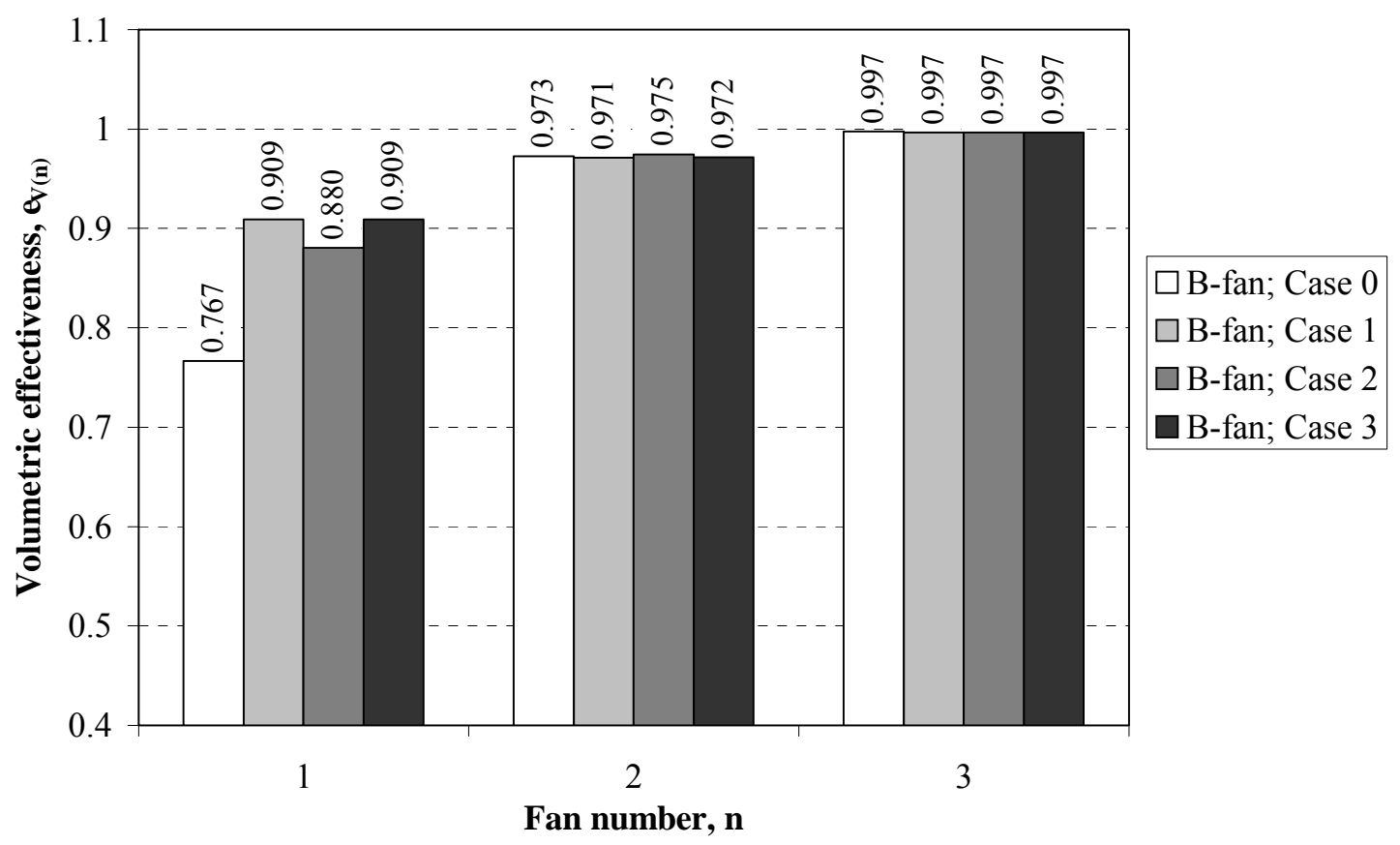

Figure E.11: Volumetric effectiveness for the B-fan $\left(\mathrm{d}_{\mathrm{F}}=9.145 \mathrm{~m}, \gamma_{\mathrm{cr}}=34.5^{\circ}\right)$ at $\mathrm{H}_{\mathrm{i}}=18 \mathrm{~m}$

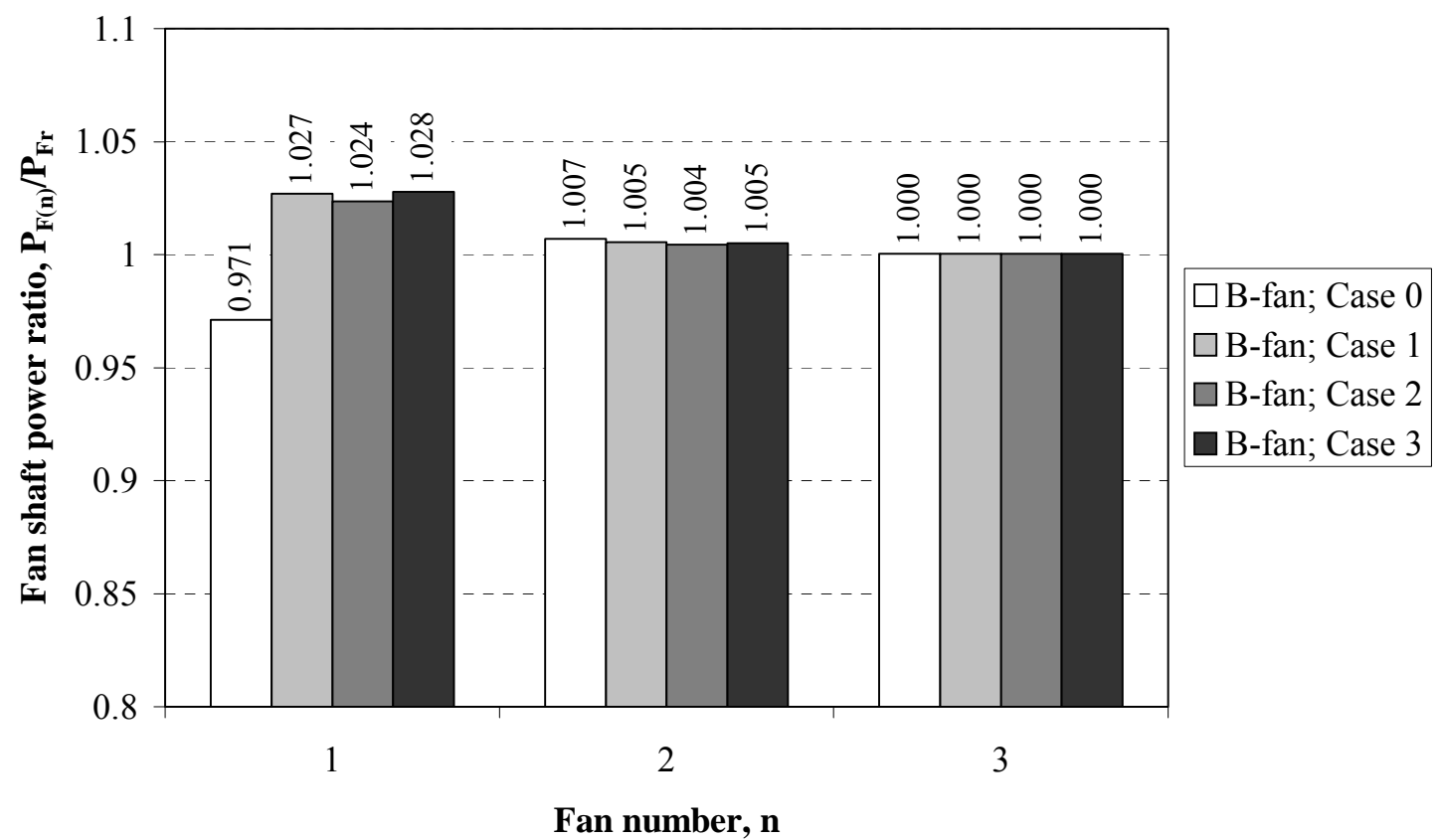

Figure E.12: Fan shaft power ratio for the $B-f a n\left(d_{F}=9.145 \mathrm{~m}, \gamma_{c r}=34.5^{\circ}\right)$ at $H_{i}=18 \mathrm{~m}$ 


\section{E.7. Fan performance of the A-fan at a platform height of $\mathrm{H}_{\mathrm{i}}=14 \mathrm{~m}$}

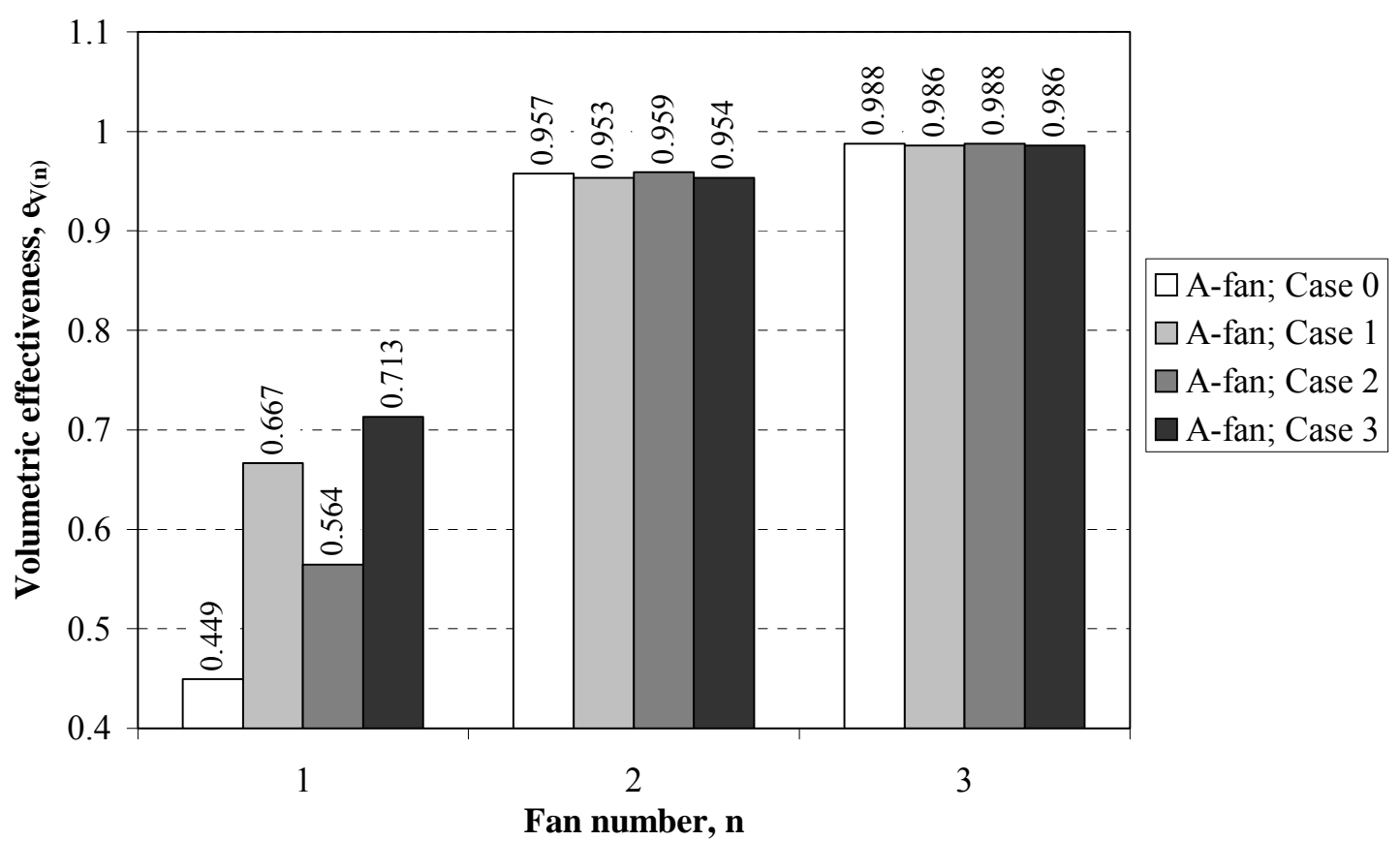

Figure E.13: Fan shaft power ratio for the A-fan $\left(d_{F}=9.145 \mathrm{~m}, \gamma_{\mathrm{pt}}=16^{\circ}\right)$ at $\mathrm{H}_{\mathrm{i}}=14 \mathrm{~m}$

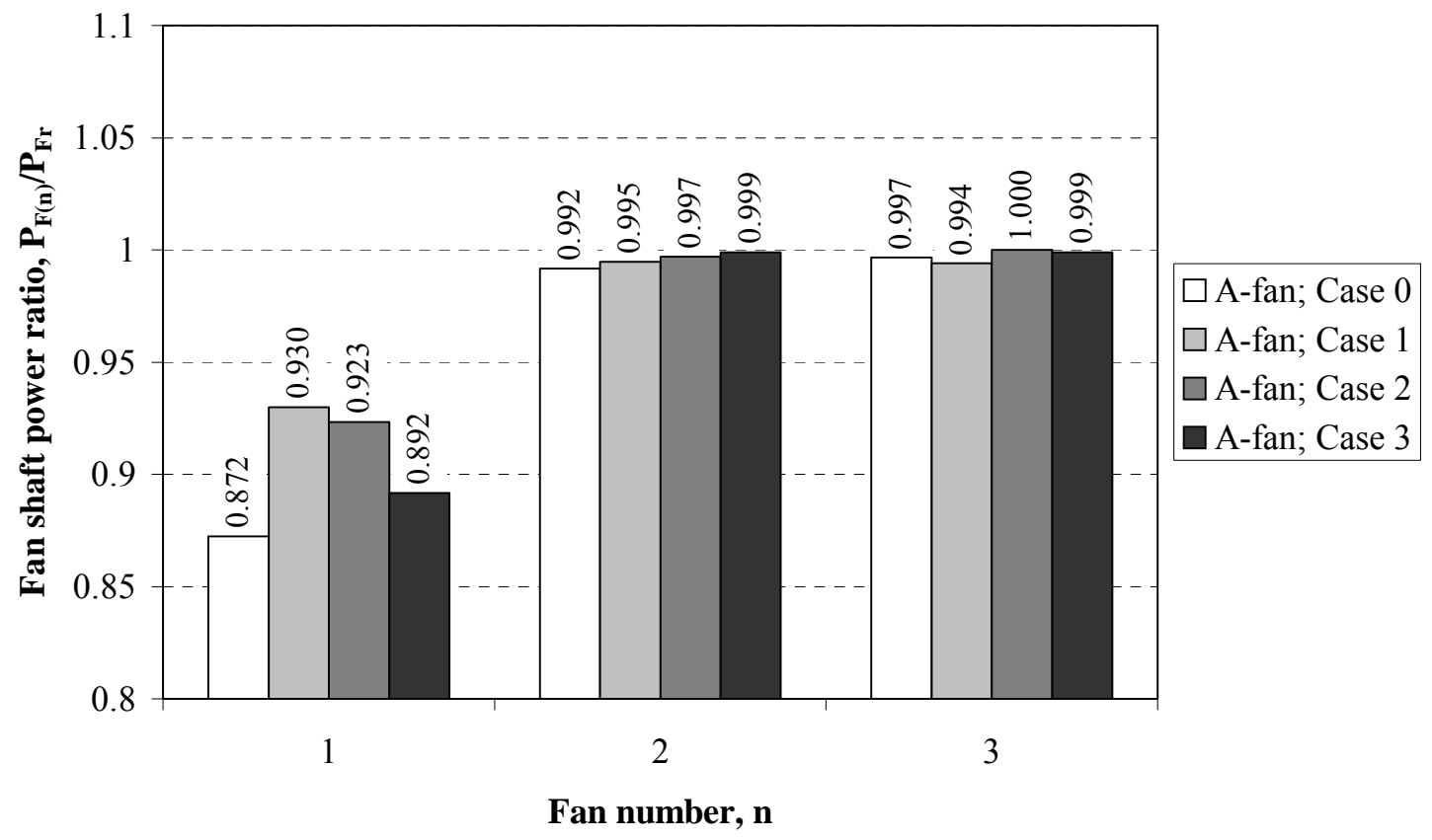

Figure E.14: Fan shaft power ratio for the A-fan $\left(\mathrm{d}_{\mathrm{F}}=9.145 \mathrm{~m}, \gamma_{\mathrm{pt}}=16^{\circ}\right)$ at $\mathrm{H}_{\mathrm{i}}=14 \mathrm{~m}$ 


\section{E.8. Fan performance of the B-fan at a platform height of $\mathrm{H}_{\mathrm{i}}=14 \mathrm{~m}$}

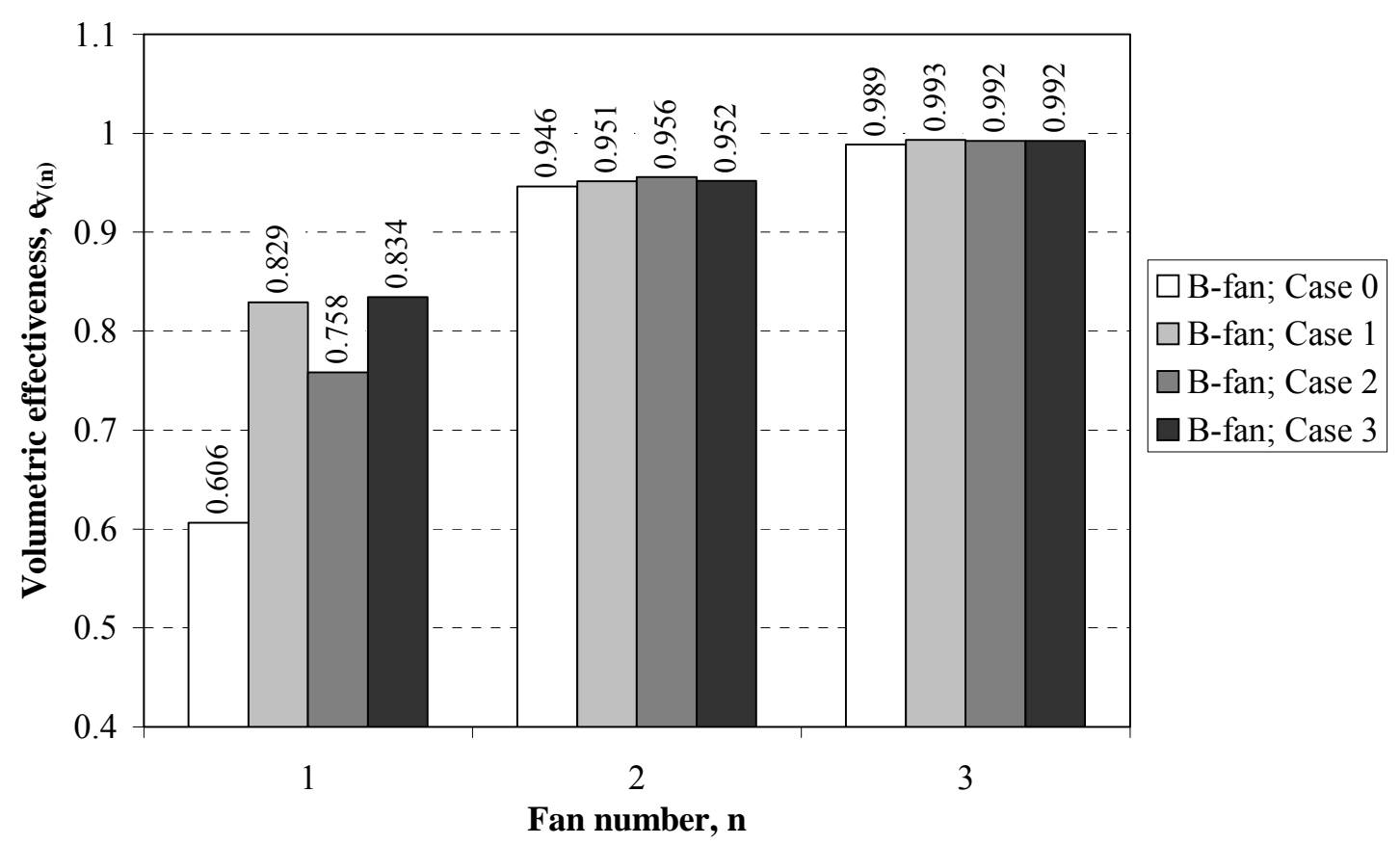

Figure E.15: Volumetric effectiveness for the B-fan $\left(\mathrm{d}_{\mathrm{F}}=9.145 \mathrm{~m}, \gamma_{\mathrm{cr}}=34.5^{\circ}\right)$ at $\mathrm{H}_{\mathrm{i}}=14 \mathrm{~m}$

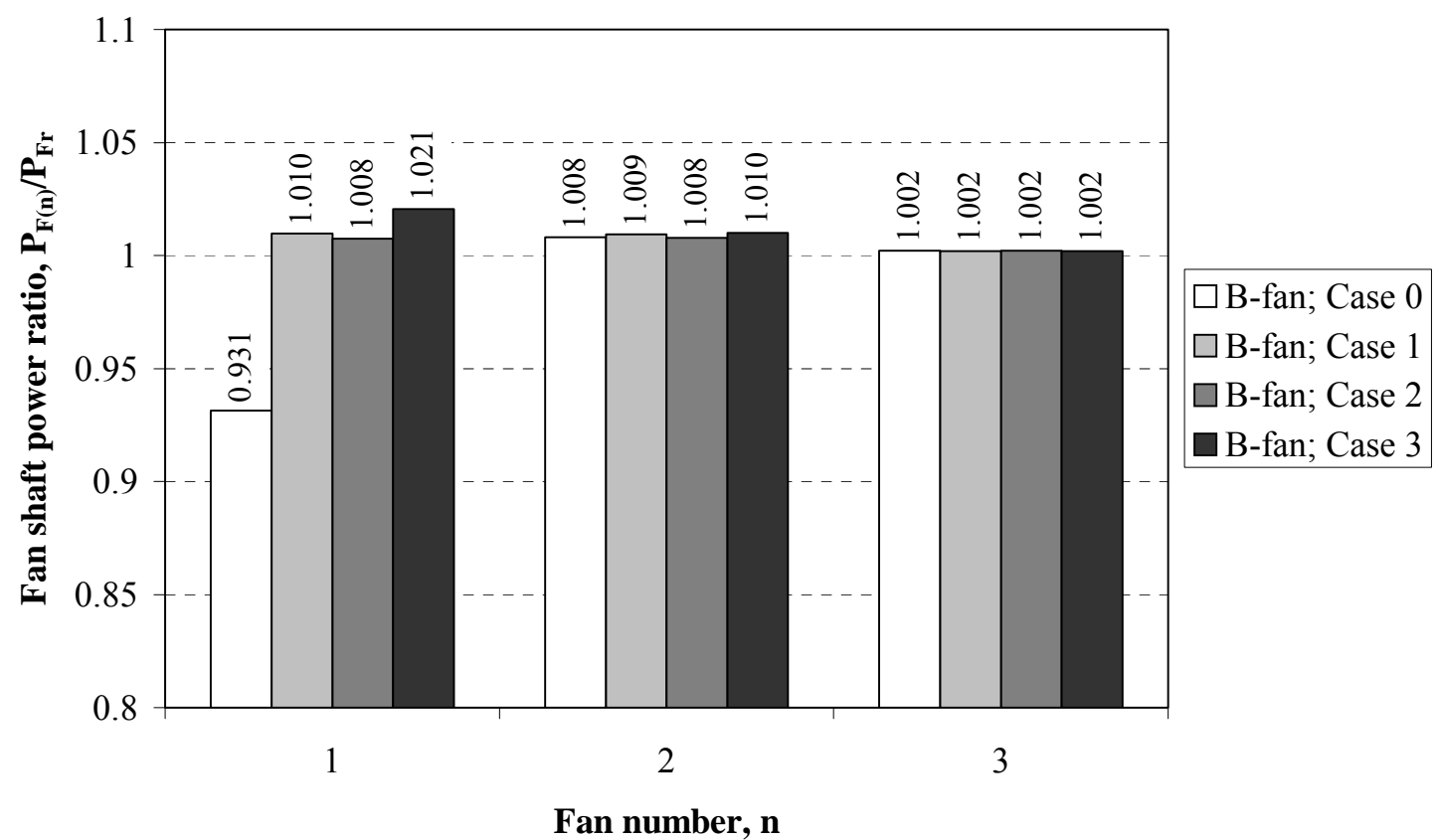

Figure E.16: Fan shaft power ratio for the B-fan $\left(\mathrm{d}_{\mathrm{F}}=9.145 \mathrm{~m}, \gamma_{\mathrm{cr}}=34.5^{\circ}\right)$ at $\mathrm{H}_{\mathrm{i}}=14 \mathrm{~m}$ 
